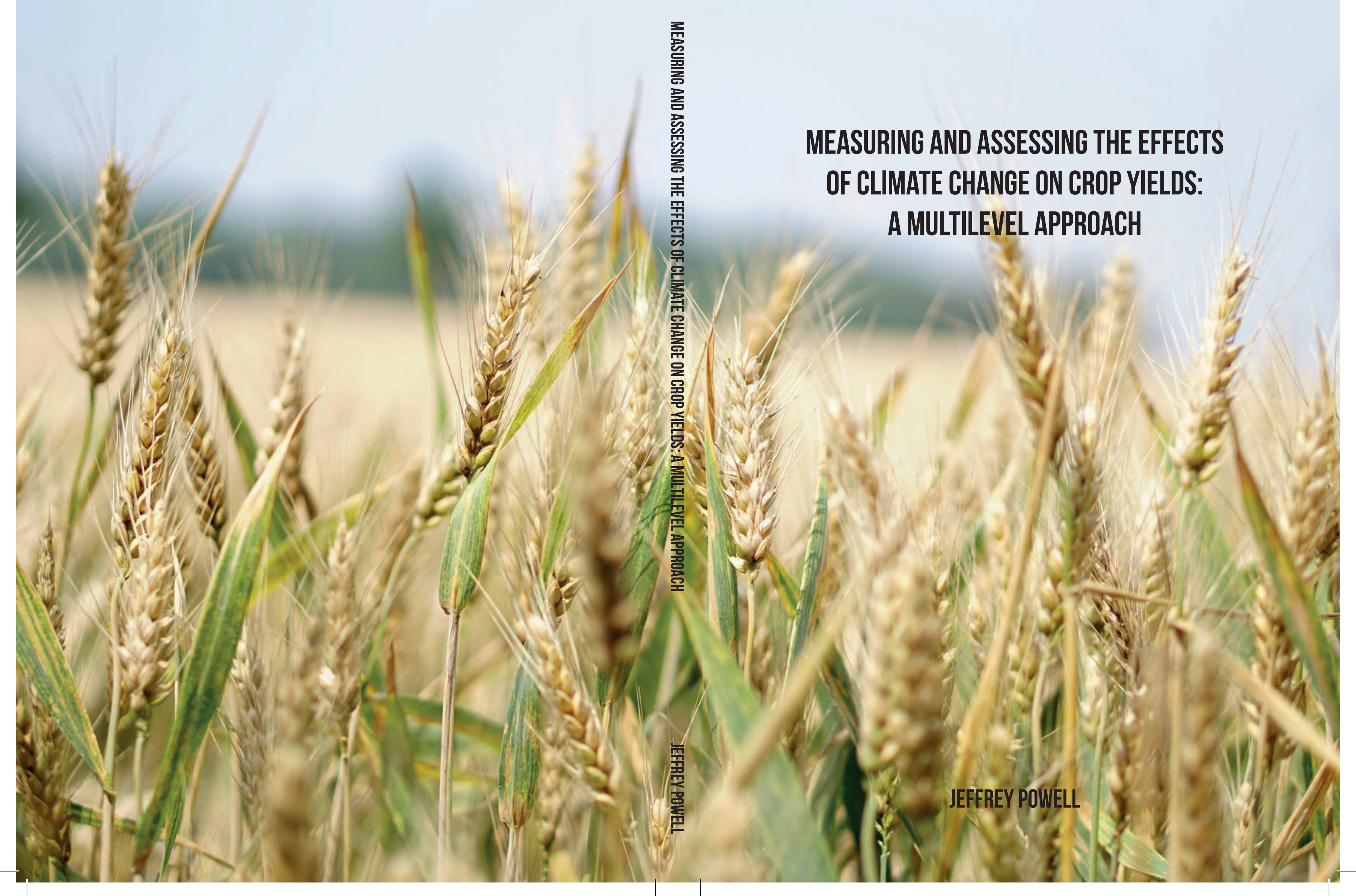


1. Macroeconomic questions have to be answered using both macroeconomic and microeconomic tools.

(this thesis)

2. Measuring the effects of climate change on crop yields requires multilevel analysis. (this thesis)

3. Aggregation is a necessary sin in economic research.

4. Recent increases in the amount of data and computer capacity, and the development of machine learning algorithms diminish the relevance of statistically based approaches.

5. In the long run, pure self-interest is just as self-defeating as pure altruism.

6. Reading allows you to experience multiple lives.

Propositions belonging to the thesis, entitled

Measuring and assessing the effects of climate change on crop yields a multi-level approach

Jeffrey Parker Powell

Wageningen, 12 January 2021 

Measuring and Assessing the Effects of Climate Change on Crop Yields: A Multilevel Approach

Jeffrey P. Powell 


\section{Thesis committee}

\section{Promotor}

Prof. Dr J.C.M. (Hans) van Meijl

Special Professor, Macroeconomic assessment of the circular and bioeconomy,

Wageningen University \& Research

\section{Co-promotor}

Dr J.H.M. (Jack) Peerlings

Senior Lecturer, Agricultural Economics and Rural Policy

Wageningen University \& Research

\section{Other members}

Prof. Dr M.A.H. Banse, Johann Heinrich von Thünen-Institut, Braunschweig, Germany Prof. Dr E.H. Bulte, Wageningen University \& Research

Prof. Dr M.K. van Ittersum, Wageningen University \& Research

Dr Z. Smeets-Kristkova, Wageningen University \& Research

This research was conducted at Wageningen Economic Research under the auspices of the Department of Social Sciences: Agricultural Economics and Policy 


\title{
Measuring and Assessing the Effects of Climate Change on Crop Yields: A Multilevel Approach
}

\author{
Jeffrey P. Powell
}

\section{Thesis}

submitted in fulfillment of the requirements for the degree of doctor at Wageningen University

by the authority of the Rector Magnificus,

Prof. Dr A.P.J. Mol,

in the presence of the

Thesis Committee appointed by the Academic Board

to be defended in public

on Tuesday 12 January 2021 at 13:30

at 4 p.m. in the Aula. 
Jeffrey P. Powell

Measuring and Assessing the Effects of Climate Change on Crop Yields: A Multilevel Approach

PhD thesis, Wageningen University, Wageningen, the Netherlands (2021)

With references, with summary in English

ISBN 978-94-6395-664-2

DOI https://doi.org/10.18174/537761 




\section{Table of contents}

$\begin{array}{lll}\text { Chapter } 1 & \text { Introduction }\end{array}$

Chapter 2 Global Scale Climate-Crop Yield Relationships: a Response to 33 Lobell and Field

Chapter $3 \quad$ Convergence of European Wheat Yields 53

Chapter $4 \quad$ Effects of Changing Weather Patterns on the Trade of 97 Major Food Crops

Chapter $5 \quad$ Measuring the Effects of Extreme Weather Events on Yields

Chapter 6 Forecasting Food Crop Yields and Assessing their Credibility

Chapter 7 Conclusions and Discussion 
CHAPTER 1 


\section{Introduction}




\subsection{Background}

Yields of crops, the amount of production per area, is an important measure for topics ranging from food security to sustainable energy. Recent increases in productivity, mainly through increased yields, has reduced stress on agricultural markets and led the OECD/ FAO (2020) to predict that stable prices will continue in the medium future as productivity outpaces increases in demand. Demand for agricultural products, mainly triggered by population growth and increases in the demand for meat and biofuels by developing countries, are expected to led to increases in the demand for agricultural products (Kuiper, 2018; Hovhannisyan and Grigoryan, 2016; Madvar, 2019, Cardoso, 2019). While the supply of agricultural products is under increasing pressure from both climate changes and efforts to mitigate the effects of climate changes. Climate changes are expected to decrease the production of important food crops and lead to higher global food prices (von Lampe, et al., 2014, Wiebe, et al., 2015) all else equal. One consequence of The Paris Agreement was the wide-scale adoption of a framework for global action to address climate change (UNFCCC, 2015). Hasegawa et al., (2018), argues that stringent climate mitigation policy would have a greater negative impact on global food security than the impacts of climate change itself. Higher yield could mitigate these negative food security impacts; Doelman et al. (2019) showed that $9 \%$ crop productivity growth is needed to mitigate the food security effect of the climate mitigation options. Therefore, measuring and forecasting crop yields, the amount of production of a crop per area, has become an increasingly relevant topic for the topic of food security and agricultural prices.

Yields are also an important topic for assessing the economic and social viability of a bioeconomy, particularly in regards to first generation biomass products. Yield and yield gap are intensively studied from an agronomic perspective (Ittersum, et al., 2013, Schils et al. 2018, Van Dijk et al. 2020). These studies stress the large heterogeneity of the agricultural landscape, characterized by large differences in yields, intensities and farm structures combined with substantial differences in environmental conditions, inducing large differences in inputs and eventually outputs. A bioeconomy has been defined as an economy in which the basic economic building blocks, such as energy, material and chemical, are derived from renewable biological resources (McCormick and Kautto, 2013). It encompasses the production of renewable biological resources and the conversion of these resources, residues, by-products and side streams, into value added products, such as food, feed, biobased products, services and bioenergy (EU, 2018). A European bioeconomy will have wide and deep implications for sustainability, the environment, and society as a whole both within and beyond the continent (European Commission, 2012, 2018a, 2018b; OECD, 2018). First generation biomass products, the topic at hand, use crops that can alternatively be used for human consumption either directly or indirectly and their adoption might have profound implications for feeding the world (Farrell et al., 
2006; Sims et al., 2008; Mouël and Forslund, 2017, van Meijl et al., 2018, Philippidis et al., 2019).

Crop yields are therefore a central element in discussions of food security and the consequences of climate change, and they are an important determinant of the feasibility of a bioeconomy. Regarding the latter, they are an important indicator of the economic potential of biobased products for several reasons. First, crops represent a significant proportion of the costs of producing biobased products. For example, estimated crop share costs for biofuels is about $70 \%$ of total production costs for corn-based ethanol and $85-90 \%$ for biodiesel (Carriquiry et al., 2014). Therefore, all else equal, higher costs for crops will reduce the economic attractiveness of biobased products, while an increase in crop yields may lead to a reduction in costs. Second, the use of crops for the production of biobased products is controversial to the degree that it reduces the amount of crops available for human consumption either directly or indirectly. Higher yields would help to mitigate that potential dilemma. Third, the crops involved are important economic resources which are traded and consumed globally, and so their use in one area has broad implications for consumption across the planet. In addition to their importance as a determinant of the viability of a bioeconomy, crop yields are important in determining whether the world can meet expected increases in demands for food and feed. Increasing population and purchasing power will increase the demand for food and feed in the coming decades (e.g. FAO, 2012; Lampe et al., 2014; van Meijl et al., 2020a, 2020b).

All of the research questions addressed in this manuscript concern yields at various levels of aggregation ranging from groups of countries to countries to farms within a specific country. Why study yields, and specifically, why not study crop production? Crop production is an explicit measure of the amount of a crop available for use, however, it is subject to the vagaries of the moment. Yield, in contrast, is a more robust measure of the potential production of a crop through time because it measures production per area, and thereby includes a measure of technical development and, in combination with the land price, it is closely related to the competitiveness of countries and the determination of international trade flows. A figure showing yields through time shows how production changes holding area stable, in short, it shows how technology, broadly defined, has been applied to alter production. If we can discern and measure a consistent pattern of change through time and can assume that the pattern will extend into the forecasted future, we can estimate future yields and production. Expected relative yield developments can be used to predict expected international trade developments (von Lampe et al., 2014). An exclusive focus on yields can be deceptive, for example, the intensive use of high yield varieties, chemical fertilizers, irrigation and weed and pest control on a small plot of land will give rise to high yields for that plot, but may not be sustainable, generally applicable to other plots or environmentally sustainable or, I would add, economically viable at greater 
scales of production (Fan, et al., 2012; Grinsven et al, 2014). However, yields, based on farms producing for major, economically efficient and competitive markets taken through time, provide a good approximation of expected production.

Variations in crop yields through time can be estimated reasonably well with a few weather features such as minimum and maximum temperatures and precipitation, along with a trend term to pick-up technological progress where technology is widely defined to include improvements such as farmer education, seeds, infrastructure, soil improvements and machinery and other inputs (Lobell et al., 2007). Polynomial and interaction terms for the weather features can increase accuracy given that there are enough years of data and enough degrees of freedom, and a polynomial trend term can be used to model decreasing or increasing rates of technological change. For large countries, the data to do these types of calculations is readily available, for instance, the USDA has high quality county and state yield data for major crops dating back over a 100 years which can easily be merged with weather data from The National Oceanic and Atmospheric Administration (USDA, 2020; National Oceanic and Atmospheric Administration, 2020; National Agricultural Statistic Service,2020 ). Similarly, at a global level, yield data from Food and Agriculture Organization (FAO) and weather data from the Hadley Centre/Climatic Research Unit Temperature can be combined to run time series analyses of yields (FAO, 2020; HadCRU, 2020) . These data sources form the foundations for estimating yields in Chapters 2, 3, 4, and 6 of this manuscript.

Several methods have been applied to assess the impact of temperatures and other weather features on crop yields (Zhao, 2017). Process-based crop models take data and assumptions about soils, solar radiation, management practices and projected daily rainfall and temperatures, and feed these through process-based mathematical models of plant growth and seed formation (Roberts, 2017). These models are used to run simulations using historical and projected future weather (e.g., Rosenzweig et al 1994). A second approach uses statistical regression models to link historical yield outcomes to historical weather aggregates and extrapolates from observed associations to make predictions about yields under simulated or forecasted climate conditions (Schlenker and Roberts 2009). A third runs simulations based on the combinations of models of various types (Rosenzweig, 2014, Assen, 2015). Finally, a fourth method artificially warms crops under near-natural field conditions to directly measure the impact of increased temperatures (Ottman, 2012).

The models discussed in this manuscript are examples of the second approach in that they use historical data to estimate regression models which are then used to forecast future yields. In several papers in the manuscript, forecasted yields are used as input into a general equilibrium model in order to assess the impact of crop yields on production, 
prices, value added and international trade flows, within a larger economic context (Nelson, et al., 2013; Robinson et al., 2014, van Meijl et al., 2018b). The econometric models employed make the assumption that patterns in the past will continue throughout the forecasted period. In many cases, this means that yields are projected to continue to increase into the future at approximately the same rate, although linear models can also pick-up decreasing and increasing rates of growth as well.

The assumption that historical patterns can be estimated and will continue into the medium future can be wrong. Developments that might adversely disrupt yield forecasts include increases in extreme weather events (Beillouin et al., 2020, Tigchelaar et al., 2018, Mehrabi and Ramankutty, 2019). Chapter 5 in this manuscript estimates the number of extreme events that are expected to occur in the Netherlands and then attempts to estimate the effects of those events on wheat yields.

An important factor to consider when forecasting crop yields is climate change at various levels of geographic aggregation. The effects of climate change on yields have been previously investigated (Greenstone and Deschenes, 2006; Licker et al., 2010; Lobell et al., 2011; Schlenker and Roberts, 2009). For instance, statistically significant results of the effects of temperatures and precipitation on yields of major food crops have been studied, with Lobell and Field providing one of the first papers with results applicable on a global scale (Lobell and Field, 2007). In addition, a series of articles using computable general equilibrium models (CGE) models examined the effects of climate changes on global production and consumption (Nelson et al., 2013a,b; Valin et al., 2014, Wiebe et al., 2015, van Meijl et al., 2018b). Other studies have examined the effects of climate changes at lower levels of aggregation, for instance at regional and country levels of analysis (Erda et al., 2005; Prato et al., 2010). Finally, literature on the adaptation of farms to climate changes has addressed farm level adaptation to changing weather patterns (Bradshaw et al., 2004; Gebrehiwot and Veen, 2013; Luers et al., 2002; Pandey et al., 2007; van Wijk et al., 2012, Mitter et al., 2019).

Despite this work multiple levels of analysis, many issues concerning the forecasting of crop yields and the consequences for production require additional research. In the next section I address four additions to the previous research which will form the basis of the topics addressed in this manuscript. 


\subsection{Research questions}

Will climate change have significant country and crop specific effects on crop production? While climate changes will continue to affect crop yields, those effects will vary across space and type of crop. This variation in effect has not always been treated properly. For example, in an important, early, paper investigating the effects of climate change on crop yields, Lobell and Field (2007) use an econometric technique that aggregates away country specific differences and thereby they effectively assume that the consequences of global changes in maximum and minimum temperatures and precipitation will affect all crops and all countries in the same manner. However, it is to be expected that impacts will vary across crops and countries (Kukal and Suat, 2018).

Are crops yields in Europe converging and if so, what will be the effects on the supply of crops used in the production of biomass products?

Climate changes affecting yields do not occur in a vacuum. Other factors, including economic drivers, may work to mitigate or exacerbate those changes. In many places throughout the world potential yields are assumed to be higher than actual yields. These yield gaps can have several causes including the inefficient use of production inputs (see Ittersum and Cassmann, 2013, Schils et al., 2018). An important region where these yield gaps appear to be present is in the newer member states of the EU. It could therefore be argued that better use of inputs could raise yields and output despite climate changes or increases in consumption due to an expanding bioeconomy. The issue of convergence in this context is important because some advocates of an increasingly biobased economy argue that because crop yields from the newer states of the EU are far below those of more established states, we can expect that, as those yields in those countries increase and converge towards their more productive neighbors, the negative effects on human consumption of using more crops to produce biomass products or any negative effects on yields caused by climate change will be reduced (e.g. Edwards et al., 2010; de Wit et al., 2011). A closely associated issue is whether agricultural land use will change as yields change. For these arguments to work it is important to first establish whether crops yields in the EU are converging and if they are converging, whether convergence necessarily leads to increases in crops used in the biomass economy.

How will changing weather patterns due to climate changes affect the global trade of major food crops? What will be the effects on less developed countries?

If we accept that the effects of changing weather patterns caused by climate changes will have diverse effects on yields globally, then global trade patterns are likely to change as well (Josling et al., 2010 and Tamiotti et al., 2009, Wiebe et al., 2015). In fact, it has been argued that the economic effects of changing weather patterns on food consumption will depend as much on its role in trade as on it does on crop production directly (Reilly et 
al., 1994; Sonka, 1991). Research in this area requires both the forecast of weather effects on yields and a modeling framework that is able to estimate the resulting effects on production and trade globally and at a country level. Effects on less developed countries are especially important given that they are likely to be more vulnerable to the negative consequences of changing weather patterns.

What will be the implications of extreme weather events on yields?

The effects of changing weather patterns will likely have local as well as regional effects. This is especially true for extreme weather events when compared to the average effects of climate change over time (Bozzola, 2018). Extreme weather events are expected to increase worldwide, therefore, anticipating and calculating their effects on crop yields is important for topics ranging from food security to the economic viability of biomass products. The Intergovernmental Panel on Climate Change, confirming previous findings, attaches high confidence to the probability that extreme weather events will reduce food production (Pachauri and Reisinger, 2007, 2008; Field et al., 2012; Porter et al., 2014). Extreme events are expected to affect the volatility of yields and are seen as the principle immediate threat to global crop production (Meehl et al., 2000; Rosenzweig et al., 2001; Olesen et al., 2007; Urban et al., 2012; Min et al., 2011; Lobell et al., 2013, Rosenzweig, et al., 2014, Müller et al., 2017). A natural question that arises is how to precisely measure the effects of extreme weather on crop yields. The measurement requires analysis at a low level of spatial aggregation and ideally one that measures changes through time (Konrad et al., 2018; Holden and Quiggin, 2017). In addition, detailed farm level input data is required to isolate the effects of weather events on a crop.

How do the various econometric techniques used to forecast yields affect predictions of country level yields?

An accurate forecast of crop yields is a critical piece of information used by policy makers to make informed decisions on topics ranging from food security to the economics of biomass products. An accessible and transparent framework is needed to allow them to assess the tradeoffs involved when forecasting yields and to assess the accuracy of those forecasts.

\subsection{Modeling}

It is common to use linear trend models to forecast crop yields, e.g. Tilman et al., (2011) and Grassini et al., (2013), use this approach. Tilman et al., (2011), as a part of their effort to forecast global food demand, include a time trend variable along with several other variables in their model. Specifically, they: "...used past yield relationships and trends to estimate yields that might be achievable by 2050 ". They use aggregated yield data 
composed of just nine time points, specifically mean yields for 1965, 1970, 1975, etc., combined with economic and biophysical data to forecast yields using a linear trend model. Grassini et al., (2013), claim that the mathematical form of the historical yield trend can be linear, exponential, parabolic, linear plateau or flat for the 36 countries and regions in their study. They claim that linear models, with or without a discontinuous break point, adequately describe all yield trends in their study. However, the standard use of simple linear trend models when more sophisticated more are readily available raises questions about the accuracy of resulting crop yield forecasts (Harri et al., 2009; Shen et al., 2018).

Forecasting crop yields in isolation is of limited value. Crop production does not exist in an economic vacuum, farmers have to compete for resources with other producers and choose amongst the many crops they can sow. Given that crops are an important input in the production of biomass products and that there are global markets for these crops, a global analysis is a natural starting point for an economic analysis of crop yield changes. Crop markets are interconnected and there are strong economic links between those sectors and the other sectors in the economy. Therefore, a global multi-sector model is essential to analyze the total economic impacts of changes in crop yields. The obvious candidate for these types of analyses are computable general equilibrium (CGE) models with a focus on the agri-food sectors and bioeconomy. MAGNET, developed by Wageningen University and Research Centre in the Netherlands, is such a model with a strong focus on land use and the bioeconomy as it includes explicit land markets and many agricultural food processing, biofuel, bioenergy and biomateral sectors (Woltjer et al., 2014; van Meijl et al., 2006; van Meijl et al., 2018a).

MAGNET (Modular Applied General Equilibrium Toolbox), has been used extensively to study the impact of policy changes on international trade, production, and consumption in agricultural and food products (van Meijl et al., 2006, van Meijl et al., 2020a). It is an extension and significant reorganization of the GTAP model (e.g. Hertel, 1997), a widely used tool for global trade analyzes. Given that MAGNET is extensively used in this manuscript to analyze the economic effects of changes in crop yield, I provide here a brief description of the MAGNET model including the database which forms the foundation of the model, as well the method of modeling actor behavior and markets.

The data used in the forthcoming analyses was based primarily on versions 7 and 8 of the database collected and processed by GTAP at Purdue University. Version 7 uses 2004 as a base year while version 8 uses 2007. The databases contain balanced economic data for regions and economic sectors, where balance means that, for instance, the value of a country's reported export of a sector are forced to equal the value of imports recorded for that country by the receiving country. The regions (of which there are 129 in version 8 ) and sectors (57 in version 8 ) are aggregated in accordance with specific research 
questions addressed in the manuscript. Note that regions can be individual countries or collections of countries. For the purpose of this manuscript, the regional aggregation used in the analyses consisted of all primary crop producing countries and regions. The sectoral aggregation consisted of the primary agricultural sectors available in MAGNET, namely, paddy rice, wheat, grains, and oils. The agricultural sectors are well represented in the 57 sectors representing the entire global economy. The remaining sectors were aggregated into a general manufacturing sector and a service sector. A consequence of using MAGNET is that yield shocks due to changes in weather have to be estimated for all sectors and regions in the model. Accordingly, econometric analyses need to be run for all crop sectors, not only those sectors producing biomass inputs, and for all regions conceivably affected by the estimated changes even if the data appeared to be of poor quality. This due to the fact that MAGNET instantiates changes based on the interactions of across all sectors and regions so that leaving out significant crops or sectors would result in a misspecification error.

The model used in the analyses retained the standard GTAP/MAGNET specification of five factors of production, specifically skilled and unskilled labor, capital, land, and natural resources. Aggregation in the model allows less important sectors to be bundled together and allows us to focus analyses on the specific regions and sectors under investigation. Aggregation also has the practical effect of reducing the negative impacts of missing, suspect or sparse data. For instance, large regions of Africa are often aggregated together in CGE analyses to circumvent the issue of poor or missing data. For instance, often during the balancing procedures used to develop a database a country's reported exports do not match imports and "adjustments" to transform the data so that the exports balance with imports. Results of such adjustments can potentially be mitigated by aggregating countries and sectors not directly relevant to a given research question. That said, the GTAP database has widely been accepted as the best representation of the global economy and numerous articles based on that model have been published in top scientific journals and served as the basis of policy recommendations for governments around the world (Taheripour et al., 2010; Suttles et al., 2014; Frank et al., 2019; Leclere et al., 2020).

MAGNET captures the behavior of three types of agents: households, firms and governments, for each region represented in the model. Household behavior is captured via a representative regional household that is assumed to maximize its utility, collect all income that is generated in the economy, and allocate that income over private households, government expenditures, and savings for investment goods. Income is derived from payments by firms to the regional household for the use of endowments of skilled and unskilled labor, land, capital, and natural resources. The regional household also receives income from taxes paid by the private household, firms, and the government expenditures. Firms, profit maximizers, produce commodities by employing the aforementioned 
endowments and intermediate inputs from other firms based on constant returns to scale production technology and sell them to private households, the government, and other producers. Domestically produced goods can be either sold on the domestic market or exported. Similarly, intermediate, private household, and government demand for goods can be satisfied by domestic production or by imports.

Demand for and supply of commodities and endowments are traded in markets which are modeled as perfectly competitive and which clear via price adjustments. Because all markets are in equilibrium, firms earn zero economic profits, households are on their budget constraints, and global savings must equal global investments. Since the CGE model can only determine relative prices, the GDP deflator is set as the numéraire of the model against which all other prices are benchmarked. Changes in prices resulting from model simulations therefore constitute real price changes.

For the analyses carried out in this manuscript, econometrically derived forecasts were used to "shock" the MAGNET model from the starting equilibrium of 2007, the most recent GTAP database when the analyses were run, to a year in the future, say 2025, at which point a new equilibrium can be meaningfully calculated and used to assess any changes in comparison to the data in 2007. Projections into the future are obtained by allowing the exogenous endowments of capital, land, natural resources, and labor, and the productivity of these factors, most notably crop yields, to grow according to standard forecast growth paths which are based on readily available economic data. Any additional changes to the model were caused by the yield shocks we implemented.

In order to use MAGNET for dynamic analyses, model data needed to be updated from 2007 (the most recent year for which GTAP data was available) to 2010, the most recent year then available in the FAO database, using readily available, macroeconomic data. This process of "priming" MAGNET with the most recent data allows CGE researchers to formulate a baseline upon which to compare the effects of shocks. The MAGNET model is used to project outcomes to a desired year in the future while incorporating the alternative crop productivity shocks based on our econometric forecasts. MAGNET output is used to determine the effects of changes in crop yields on the quantity of crops produced, real market prices for wheat, and the amount of land used to grow wheat and other crops, holding all else in the model constant. The shocks are implemented in two scenarios, namely, a low yield and high yield scenario, those results were then compared to a baseline or business as usual scenario.

In CGE models like MAGNET, crop yield changes are typically modelled either as a linear trend or compound annual rates of yield increase without taking into account that yields, while generally increasing, are increasing at a decreasing rate. Next to the exogenous trend 
the yield in MAGNET depends endogenously on the substitution possibilities between land and other production factors. If lands get relatively more expensive than land will be substituted with more labor and or capital (van Meijl et al., 2006). In a recent study , Zeist et al., (2020) discussed projections of crop yields by global agricultural land-use and integrated assessment models. The study evaluated crop yield projections "by comparing them to empirical data on attainable yields by employing a linear and plateauing continuation of observed attainable yield trends". The studies concluded that global projected yields by 2050 remain below the attainable yields, on average for all cereals on the global level. van Zeist et al. (2020) find that "this is also true for future pathways with high technological progress and mitigation efforts, indicating that projected yield increases are not overly optimistic, even under systemic transformations".

\subsection{Research objective and questions}

\section{Research objective}

Whether an economy based on first generation biomass products will be successful is largely dependent on the yields of crops used in their production. Crop yields also play an important role in future food security concerns. The objective of the research in this manuscript is to examine significant economic and climate factors influencing yields across several levels of aggregation. By using various levels of aggregation, research questions and tools of analysis are able to address issues specific to the scale and time under investigation.

\section{Research questions}

In order to address the overall research objectives, five research questions have been formulated that will be addressed in the manuscript:

1. Will climate change have significant country and crop specific effects on crop production?

2. Are crops yields in Europe converging and if so, what will be the effects on the supply of crops used in the production of biomass products?

3. How will changing weather patterns due to climate change affect the global trade of major food crops? What will be the effects on less developed countries?

4. What will be the implications of extreme weather events on yields?

5. How do the various econometric models used to forecast yields affect predictions of country level yields? 


\subsection{Methodology}

This section discusses the methodologies that will be used to answer the research questions outlined above.

Will climate change have significant country and crop specific effects on crop production? This research question is motivated by the desire to extend an original paper by Lobell and Field (2007). It is argued that Lobell and Field missed an important chance to measure country and crop differences in their analysis of the effects of climate change on crop yields. We retain the same data sources and use the same methods to prepare the data, only adding an additional year of newly available data. The main technical difference with the original paper is the econometric method used in the regressions. While the original paper essentially aggregated away country and crop differences, thereby effectively assuming that the consequences of global changes in maximum and minimum temperatures and precipitation affect all crops and all countries in the same manner, I will apply a panel method that can account for country and crop specific differences. In addition, their underlying statistical assumptions are critiqued.

This research will bring together analyzes of global weather variables and crop yields. Following Lobell and Field, the basis for the crop data used in the research is derived from the FAO (FAOSTAT). The FAO website contains data for major producers for over sixty years although specific data were occasionally missing or suspiciously large or small. Gridded time series climate data from such as the CRU TS 2.1 (CRU TS) and later the Berkeley Earth (Berkeley Earth) datasets will be used to forecast weather variables. Gridded data here means that important weather indicators are calculated per grid (say 1-degree latitude and 1-degree longitude for $360 * 720$ grids partitioning the globe). Global spatial datasets such SAGE and Earthstat (EarthStat) will then be used to calculate the percentage of a grid dedicated to growing a crop (Leff, 2004).

We, my coauthor and I, will develop and test several panel models with data aggregated at the country level across years for which we have data (generally 1961-2006), i.e., for each country and year we will collected data which we then regress using various panel techniques including "pooled", "within" and "between" (see e.g. Baltagi, 2008; Frees, 2004; Hsiao, 2003). For model specification and diagnostics we will follow methods outlined in, i.e., Lütkepohl and Krätzig (2004).

Are crops yields in Europe converging and if so, what will be the effects on the supply of crops used in the production of biomass products?

The second research question will be answered in two steps. First, European yields of crops that are used for biofuel production are forecasted using the econometric tools outlined 
above. Yearly FAO data measuring yields from 1961 to 2010 will be used to econometrically estimate and forecast changes in yields across Europe. From the outcomes we will then estimate whether yields converge. To estimate convergence and dynamic panel models will be used (Phillips and Donggyu, 2007 and 2009, Baltagi, 2008; Frees, 2004; Hsiao, 2003). Transitions in land use will be modeled using the approach described in van Meijl et al., (2006).

The second step in the analysis is to measure the economic consequences of changing crop yields. Scenarios will be run using estimated yields described above as input into MAGNET. The outcomes of the scenarios will provide insights into the overall economic consequences of convergence. MAGNET results, like all CGE models, provide a narrative framework through which the total economic impact of changes in yields can be analyzed. Together, the complementary approaches of econometrics and general equilibrium model will allow a more complete economic analysis of the consequences of yield changes and a more nuanced analysis of the potential impacts on crops of use to the bioeconomy.

How will changing weather patterns due to climate changes affect the global trade of major food crops? What will be the effects on less developed countries?

This research will examine the economic effects of expected changes in temperatures and precipitation on the trade of ten major food crops. It will essentially bring together the estimation of the effects of climate change on crop yields and the MAGNET model. The relative effects on trade for developing versus developed countries will be emphasized.

More specifically, in order to determine the effects of changes in precipitation and temperature on trade two methodologies will be applied, namely, econometric methods to forecast changes in yields resulting from changes in the weather variables, thereafter, the forecasts are used to simulate the effects of the altered yields on the exports and imports of food crops using MAGNET. A series of econometric models using panel data (see e.g. Baltagi, 2008; Frees, 2004; Hsiao, 2003) and autoregressive integrated moving average models (Hamilton, 1994), will be used to estimate and forecast relationships between yields and weather data, the results of which will be used as input into MAGNET to determine the effects on trade.

What will be the implications of extreme weather events on yields?

To investigate the effects of extreme weather events on yields we will take the case of winter wheat yields in the Netherlands grown over a twelve year period. In contrast to the country level aggregations of the previous research questions, this research allows us to examine the effects of one consequence of climate change at a local, farm and crop level. 
Answering this research question requires answering two sub-questions. The first is the need to establish what defines an extreme weather event. The answer to this question will vary across regions and time. Once we have established what an extreme event is, then we can estimate the effects that those events might have on crops controlling for the other significant inputs which affect yields on a particular farm. In short, we will need to ask what are the effects of extreme weather events after having removed the effects of other factors affecting yields through time.

Data will be collected on historical weather patterns in the Netherlands dating back over a hundred years in the case of average, minimum and maximum temperatures, and certain regions such as the weather station De Bilt in the center of the country. This relatively long-term weather data will be used to establish a pattern of the number of extreme events which have occurred and thereby could be expected to occur in the future. Next panel data, which included production inputs and weather data over the period 20022013, will be used to estimate the effects of extreme weather events such as rainfall and high temperatures on winter wheat over that period. In this manner, we will be able to predict the effect of extreme weather events on yields in the future.

How do the various econometric models used to forecast yields affect predictions of country level yields? How far into the future should you trust forecasts?

The standard use of linear trend models to forecast crop yields appear to be overly simplistic. To the degree that these forecasts are used as input into CGE models, they might significantly affect predictions of the amount of crops available in the future. We will examine the effects of various time series forecasting techniques and measure their effects on county level crop yields. Yields of ten important global food crops will be forecasted for ten years and their accuracy reported. A comparison is made between the results of the standard linear models used to forecast yields, and auto-regressive, integrated, moving average (ARIMA) forecasts. We will outline the decisions needed to develop an ARIMA model and compare the accuracy of resulting forecasts to those of the standard linear model. Moreover, we will try to answer the question of whether it is meaningful to forecast decades into the future, as is common practice in CGE models, given the uncertainty involved in forecasting (Zeist et al., 2020).

\section{Manuscript overview}

The next five chapters of the manuscript will consist of further introducing and answering each of the research questions in the order discussed above. The final chapter will present the conclusions and provide critical reflection of the research. Finally, it will present some policy and research recommendations. 


\section{References}

Asseng, S., Ewert, F., Martre, P., Rötter, R. P., Lobell, D. B., Cammarano, D., Kimball, B. A., Ottman, M. J., Wall, G. W., White, J. W., Reynolds, M. P., Alderman, P. D., Prasad, P. V. V., Aggarwal, P. K., Anothai, J., Basso, B., Biernath, C., Challinor, A. J., De Sanctis, G., Doltra, J., Fereres, E., Garcia-Vila, M., Gayler, S., Hoogenboom, G., Hunt, L. A., Izaurralde, R. C., Jabloun, M., Jones, C. D., Kersebaum, K. C., Koehler, A-K., Müller, C., Naresh Kumar, S., Nendel, C., O'Leary, G., Olesen, J. E., Palosuo, T., Priesack, E., Eyshi Rezaei, E., Ruane, A. C., Semenov, M. A., Shcherbak, I., Stöckle, C., Stratonovitch, P., Streck, T., Supit, I., Tao, F., Thorburn, P. J., Waha, K., Wang, E., Wallach, D., Wolf, J., Zhao, Z., Zhu, Y (2017). Rising temperatures reduce global wheat production. Nature Climate Change 143-147 52

Baltagi, B.H. (2008). Econometric Analysis of Panel Data, fourth edition, John Wiley \& Sons, Ltd.

Beillouin Damien, Schauberger Bernhard, Bastos Ana, Ciais Phillipe and Makowski David (2020). Impact of extreme weather conditions on European crop production in 2018. Phil. Trans. R. Soc.

Bozzola, M., Massetti, E., Mendelsohn, R. and Fabian Capitanio (2018). A Ricardian analysis of the impact of climate change on Italian agriculture. European Review of Agricultural Economics Vol 45 (1): 57-79

Bradshaw, B., Dolan, H. and Smit, B. (2004). Farm-level adaptation to climatic variability and change: crop diversification in the Canadian prairies. Climatic Change 67: 119-141.

Carriquiry, M.A., Xiaodong D., and Timilsina, G.R. (2014). Production Costs of Biofuels, Chapter 3 in The Impacts of Biofuels on the Economy, Environment, and Poverty: A Global Perspective. Govinda R. Timilsina and David Zilberman Editors. Springer, New York, Heidelber, Dordrecht, London.

Cardoso , L.C.B., Bittencourt, M.V.L., Litt, H. W., Irwin, E.G. (2019). Biofuels policies and fuel demand elasticities in Brazil, Energy Policy, Vol 128, Pages 296-305.

Dijk, M. van, Morley, T., Loon, M. van, Reidsma, P., Tesfaye, K., Ittersum, M.K. van, (2020). Reducing the maize yield gap in Ethiopia: Decomposition and policy simulation, Agricultural Systems, Vol $183,102828$.

Leclere D, Obersteiner M, Barrett M, Butchart SHM, Chaudhary A, De Palma A, DeClerck FAJ, Di Marco $M$ (2020). Bending the curve of terrestrial biodiversity needs an integrated strategy. Nature DOI: 10.1038/s41586-020-2705-y

Doelman , Jonathan, Stehfest, Elke, Tabeau , Andrzej, Meijl van, Hans (2019). Making the Paris agreement climate targets consistent with Food Security objectives, Global Food Security, Volume 23, December 2019, Pages 93-103. https://doi.org/10.1016/j.gfs.2019.04.003

Edwards, R., Declan, M., Comparison, M.L. (2010). Models and results for marginal biofuels production from different feedstock. Publications Office of the European Union, Copyright European Union JREC-IE, European Commission, EUR 24485 EN.

Erda, L., Wei, X., Hui, J., Yinlong, X., Yue, L., Liping, B., and Luyong, X. (2005). Climate Change Impacts on Crop Yield and Quality with CO2 Fertilization in China. Philosophical Transactions of The Royal Society, Biological Sciences, 360(1463):2149-54. 
European Commission (2012). Innovating for Sustainable Growth: A Bioeconomy for Europe. Available online https://publications.europa.eu/nl/publication-detail/-/publication/1f0d85158dc0-4435-ba53-9570e47dbd51, accessed 1.3.2020.

European Commission (2018a). A Sustainable Bioeconomy for Europe:Strengthening the Connection between Economy, Society and the Environment. Updated Bioeconomy Strategy. Available online https://ec.europa.eu/research/bioeconomy/pdf/ec_bioeconomy_strategy_2018.pdf, accessed 1.3.2020.

European Commission (2018b). Bioeconomy: the European way to use our natural resources. Action plan 2018. Available online https://publications.europa.eu/en/publication-detail/-/publication/ cb9a00d6-d289-11e8-9424-01 aa75ed71a1, accessed 1.3.2020.

European Union, (2018). Biobased economy. http://www.biobasedeconomy.eu/. Accessed on 127-2018.

Fan, Mingsheng, Shen, Jianbo, Yuan, Lixing, Jiang, Rongfeng, Chen Xinping, Davies, William J., Zhang , Fusuo (2012). Improving crop productivity and resource use efficiency to ensure food security and environmental quality in China. Journal of Experimental Botany, Volume 63, Issue 1: 13-24.

FAO, (2012). World Agriculture Towards 2030/2050. The 2012 Revision. ESA Working Paper No. 12-03 http://www.fao.org/docrep/016/ap106e/ap106e.pdf

FAO, http://www.fao.org/faostat/en/\#data/QC, Accessed 2020.

Farrell, A.E., Plevin, R.J., Turner, B.T., Jones, A.D., O'Hare, M., and Kammen, D.M. (2006) . Ethanol Can Contribute to Energy and Environmental Goals. Science 311 (5760) (January 27): 506-508. doi:10.1126/science.1121416.

Field, C.B., Barros, V., Stocker, T.F., Qin, D., Dokken, D.J., Ebi, K.L., Mastrandrea, M.D., Mach, K.J., Plattner, G.K., Allen, S.K., Tignor, M., and Midgley, P.M. (Eds.), (2012). Managing the Risks of Extreme Events and Disasters to Advance Climate Change Adaptation. A Special Report of Working Groups I and II of the Intergovernmental Panel on Climate Change, Cambridge University Press, Cambridge, UK, and New York, USA

Frank, S., Havlík, P., Stehfest, E., van Meijl, H., Witzke, P., Perez-Dominguez, I., Doelman, J. C., Fellmann, T., Levin-Koopman, J., Tabeau, A., Valin, H. (2019). Agriculture mitigation wedges for a 1.5 degree world: a multi-model assessment. Nature Climate Change. 9, p.: 66-72.

Frees, E. W., (2004). Longitudinal and Panel Data: Analysis and Applications in the Social Sciences. Cambridge University Press

Gebrehiwot, T. and van der Veen, A., (2013). Farm level adaptation to climate change: The case of farmer's in the Ethiopian Highlands. Environmental Management, 52:29-44.

Grassini, P., Eskridge, K.M., and Cassman, K.G., (2013). Distinguishing between yield advances and yield plateaus in historical crop production trends. Nature Communications December, 4(2918):2918.

Greenstone, M. and Deschenes, O., (2006). The economic impacts of climate change: Evidence from agricultural profits and random fluctuations in weather. FEEM Working Paper No. 6. 
Grinsven van, H., Spiertz, J., Westhoek, H., Bouwman, A., Erisman, J. (2014). Nitrogen use and food production in European regions from a global perspective. The Journal of Agricultural Science, 152(S1), 9-19.

HadCru, University of East Anglia Climatic Research Unit (CRU) https://sites.uea.ac.uk/cru/data Harri, A., Erdem, C., Coble, K. H. and Knight, T. O., (2009). Crop yield distributions: a reconciliation of previous research and statistical tests for normality. Applied Economic Perspectives and Policy 31(1): 163-182.

Hasegawa , Tomoko, Fujimori , Shinichiro, Havlik, Petr, Valin , Hugo, Bodirsky , Benjamin, Doelman , Jonathan, Fellmann , Thomas, Kyle , Page, Levin-Koopman , Jason, Lotze-Campen, Hermann, Mason-D'Croz , Daniel, Ochi, Yuki, Perez-Dominguez , Ignacio, Stehfest , Elke, Sulser B., Timothy B., Tabeau , Andrzej, Takahashi , Kiyoshi, Takakura , Jun'ya, Meijl van, Hans, Zeist van , Willem-Jan, Wiebe D., Keith D., Witzke , Peter (2018). Risk of increased food insecurity under stringent global climate change mitigation policy, Nature Climate Change, volume 8, pages 699-703.

Hertel Thomas W, editor (1997). Global trade analysis: modeling and applications. Cambridge University Press.

Holden, S.T. and Quiggin, J., (2018). Climate risk and state-contingent technology adoption: shocks, drought tolerance and preferences. European Review of Agricultural Economics Vol 44 (2): 285:308.

Hovhannisyan, S.V., Grigoryan, K.A. (2016). The main problems and features of the global and local meat production, Annals of Agrarian Science, Volume 14, Issue 4, 2016, Pages 315-318.

Hsiao, C., (2003). Analysis of Panel Data. Cambridge University Press, New York, second edition.

Ittersum, M.K. van and Cassmamn, K.G., (2013). Yield gap analysis - rationale, methods and applications, introduction to the special issue. Field crops research: 143: 1-3.

Josling, T., Anderson, K., Schmitz, A., and Tangermann, S., (2010). Agricultural products: One hundred years of contributions by agricultural economists. American Journal of Agricultural Economics, 92(2):424-446.

Konrad, M.T., Levin, G. and Mette Termansen, (2018). Landowners' motivation for adopting perennial energy crops: drivers, barriers and neighbourhood effects. European Review of Agricultural Economics Vol 45 (5) pp. 809-829.

Kuiper, M., Shutes, L., Verma, M., Tabeau, A., van Meijl, H. (2018). Exploring the impact of alternative population projections on prices, growth and poverty developments. Background paper to the UNCTAD-FAO Commodities and Development Report 2017, Commodity markets, economic growth and development. Available at http://www.fao.org/documents/card/en/ c/98191c26-5684- 4a91-8366-a63f31345a7f/.

Kukal, Meetpal S. and Irmak, Suat, (2018). Climate-Driven Crop Yield and Yield Variability and Climate Change Impacts on the U.S. Great Plains Agricultural Production. Scientific Reports volume 8, Article number: 3450.

Lampe von, M, D. Willenbockel, H. Ahammad, E. Blanc, Y. Cai, K. Calvin, S. Fujimori, T. Hasegawa, P. Havlik, E. Heyhoe, P. Kyle, H. Lotze-Campen, D. Mason d'Croz, G. Nelson, R.D. Sands, C. Schmitz, A.A. Tabeau, H. Valin, D. van der Mensbrugghe, J.C.M. van Meijl (2014). Why do global long- 
term scenarios for agriculture differ? An overview of the AgMIP Global Economic Model Intercomparison. Agricultural Economics 2014, 45(1): 3-20.

Le Mouël, C. and A. Forslund, (2017). European Review of Agricultural Economics, Vol 44 (4): pp. $541-$ 591.

Leff, B., Ramankutty, N., and Foley, J.A., (2004). Geographic distribution of major crops across the world Global Biogeochemical cycles Vol. 18.

Licker, R., Johnston, M., Foley, J. A., Barford, C., Kucharik, C. J., Monfreda, C., and Ramankutty, N., (2010). Mind the gap: how do climate and agricultural management explain the 'yield gap' of cropland around the world? Global Ecology and Biogeography, 19(6):769-782.

Lobell, D. B., Schlenker, W., and Costa-Roberts, J., (2011). Climate trends and global crop production since 1980. Science, 333(6042):616-620.

Lobell, D.B., Hammer, G.L., McLean, G., Messina, C., Roberts, M.J., Schlenker, W.,

(2013). The critical role of extreme heat for maize production in the United

States. Nat. Clim. Chang. 3, 497-501

Lobell, D. B. and Field, C.B., (2007). Global scale climate-crop yield relationships and the impacts of recent warming Environ. Res. Lett. 2

Lobell, D.B., Cahill, K.N., Field, C.B. (2007). Historical effects of temperature and precipitation on California crop yields Climatic Change 81, 187-203.

Luers, A. L., Lobell, D.B., Sklar, L. S., Addams, C.R., and Matson, P.A., (2002). A method for quantifying vulnerability, applied to the agricultural system of the Yaqui Valley, Mexico. Global Environmental Change, 13(4):255-267.

Lütkepohl, H., \& Krätzig, M. (Eds.) (2004). Applied Time Series Econometrics (Themes in Modern Econometrics). Cambridge: Cambridge University Press. doi:10.1017/CBO9780511606885

Madvar, M.D., Aslani, A., Ahmadi, M.H., Sadat, N., Ghomi, K. (2019), Current status and future forecasting of biofuels technology development. Energy Research. Vol. 43 (3), 1142-1160.

McCormick, K., Kautto, N., (2013). The Bioeconomy in Europe: An Overview. Sustainability, 5, 25892608.

Meehl, G.A., Zwiers, F., Evans, J., Knutson, T., Mearns, L., Whetton, P., (2000). Trends in

extreme weather and climate events: issues related to modeling extremes in

projections of future climate change. Bull. Am. Meteorol. Soc. 81 (3)

Mehrabi Z, Ramankutty N. (2019). Synchronized failure of global crop production. Nat. Ecol. Evol. 3, 780-786

Meijl van, H., Havlik, P., Lotze-Campen, H., Stehfest, E., Witzke, P., Pérez-Domínguez, I., Bodirsky, B., van Dijk, M., Doelman, J. C., Fellmann, T., Humpenoeder, F., Levin-Koopman, J., Mueller, C., Popp, A., Tabeau, A., Valin, H., van Zeist, W.-J. (2018). Comparing impacts of climate change and mitigation on global agriculture by 2050. Environ. Res. Lett. 13064021.

Meijl van, H, Rheenen van, T., Tabeau, A., and Eickhout, B., (2006). The impact of different policy environments on agricultural land use in Europe. Agriculture, Ecosystems \& Environment. Vol 114, Issue 1, pp 21-38. 
Meijl, van, H., Shutes, L., Valin, H., Stehfest , E., Dijk van, M, Kuiper, M, Tabeau , A, Zeist van, W., Hasegawa , T., Havlik , P., (2020b). Modelling alternative futures of global food security: Insights from FOODSECURE, Global Food Security, 25, 100358.

Meijl van, H., Tabeau, A., Stehfest, E., Doelman, J., Lucas, P., (2020a). How Food Secure are the Green, Rocky and Middle Roads: Food Security Effects in different world development paths, Environmental Research Communication, https://doi.org/10.1088/2515-7620/ab7aba.

Meijl van, H., Tsiropoulos, Y., Barteling , H., R., Hoefnagels, Smeets , E., Tabeau , A., Faaij , A, (2018) On the macro-economic impact of bioenergy and biochemicals - Introducing advanced bioeconomy sectors into an economic modelling framework with a case study for the Netherlands, Biomass and Bioenergy, 108 . - p. 381 - 397

Min, S., Zhang, X., Zwiers, F., Hegerl, G., (2011). Human contribution to more-intense

precipitation extremes. Nature 470, 378-381.

Mitter, H., Larcher, M., Schönhart, M., Stöttinger, M, Schmid, E. (2019). Exploring Farmers' Climate Change Perceptions and Adaptation Intentions: Empirical Evidence from Austria. Environmental Management 63, 804-821.

Müller, Christoph, Elliott, Joshua, Chryssanthacopoulos, James, Arneth, Almut, Balkovic, Juraj, Ciais, Philippe, Deryng, Delphine, (2017). "Global gridded crop model evaluation: benchmarking, skills, deficiencies and implications." Geoscientific Model Development (Copernicus GmbH) 10: 1403-1422.

National Agricultural Statistics Service (NASS). https://www.nass.usda.gov/Statistics_by_Subject/, accessed 2020.

Nelson, G., Ahammad, H., Deryng, D., Elliott, J., Fujimori, S., Havlik, P., Heyhoe, E., Kyle, P., Lampe von, M., Lotze-Campen, H., d'Croz M.D., Meijl van, H., Mensbrugghe van der, D., Müller, C., Robertson, R., Sands, R.D., Schmid, E., Schmitz, C., Tabeau, A., Valin, H., Willenbockel, D. (2013), Assessing uncertainty along the climate-crop-economy modeling chain, Proceedings of the National Academy of Sciences U.S.A. 111(9): 3274-3279.

Nelson, G. C., Valin, H., Sands, R. D., Havlik, P., Derying, D., Elliot, J., Fujimori, S., Hasegawa, T., Heyhoe, E., Kyle, P., von Lampe, M., Lotze-Campen, H., Mason d'Croz, D., van Meijl, H., van der Mensbrugghe, D., Müller, C., Popp, A., Robertson, R., Robinson, S., Schmid, E., Schmitz, C., Tabeau, A., and Willenbockel, D. (2013a). Climate change effects on agriculture: Economic responses to biophysical shocks. PNAS. Epub ahead of printing.

Nelson, G. C., van der Mensbrugghe, D., Blanc, E., Calvin, K., Hasegawa, T., Havlik, P., Kyle, P., LotzeCampen, H., von Lampe, M., Mason d'Croz, D., van Meijl, H., Müller, C., Reilly, J., Robertson, R., Sands, R. D., Schmitz, C., Tabeau, A., Takahashi, K., and Valin, H. (2013b). Agriculture and climate change in global scenarios: why don't the models agree. Agricultural Economics, 45(1):85-101.

National Oceanic and Atmospheric Administration (NOAA), https://www.ncdc.noaa.gov/dataaccess/satellite-data/satellite-data-access-datasets, accessed 2020.

OECD - Organisation for Economic Co-operation and Development (2018). Meeting Policy Challenges for a Sustainable Bioeconomy. Paris: OECD Publishing. 
OECD/FAO (2020), OECD-FAO Agricultural Outlook 2020-2029, FAO, Rome/OECD Publishing, Paris, https://doi.org/10.1787/1112c23b-en.

Olesen, J.E., Carter, T.R., Díaz-Ambrona,C. H., Fronzek, S., Heidmann, T., Hickler, T. , Holt, T. , Minguez, M. I.,Morales, P.,Palutikof, J. P., Quemada, M. , Ruiz-Ramos, M., Rubæk, G. H. , Sau, F., Smith, B. \& Sykes, M. T., (2007). Uncertainties in projected impacts of climate

change on European agriculture and terrestrial ecosystems based on scenarios

from regional climate models. Climate Change, 81, 123-143.

Ottman, M. J., Kimball, B. A., White, J. W., Wall, G. W. (2012). Wheat Growth Response to Increased Temperature from Varied Planting Dates and Supplemental Infrared Heating. Agronomy Journal, 104, 7-16

Pachauri, R. K., and Reisinger, A., (2008). "Climate change 2007. Synthesis report. Contribution of Working Groups I, II and III to the fourth assessment report." Cambridge University Press, Cambridge.

Pachauri, Rajendra K., Reisinger, A., (2007). "IPCC fourth assessment report." IPCC, Geneva 2007.

Pandey, S., Bhandari, H., and Hardy, B., (2007). Economic costs of drought and rice farmers' coping mechanisms: a cross- country comparative analysis. Technical report, IRRI (International Rice Research Institute).

Peter, P.C.B., Sul, D., (2007). Transition modeling and econometric convergence tests. Econometrica;75(6):1771-855

Peter, P.C.B., Sul D., (2009). Economic transition and growth. Journal of Applied Economics; 24:1153-85.

Philippidis, G., H. Bartelings, J. Helming, R. M'Barek, E. Smeets, H. van Meijl (2019). Levelling the playing field for EU biomass usage. Economic Systems Research, p. 1-20.

Porter, J.R., Xie, L. (2014). Climate change 2014: impacts, adaptation, and vulnerability. Working Group II contribution to the IPCC Fifth Assessment Report.

Prato, T., Zeyuan, Q., Pederson, G., Fagre, D., Bengston, L. E., and Williams, J. R., (2010). Potential economic benefits of adapting agricultural production systems to future climate change. Environmental Management, 45(1):577-89.

Reilly, J., Hohmann, N., and Kane, S., (1994). Climate change and agricultural trade: Who benefits, who loses? Global Environmental Change, 4(1):24-36.

Roberts, J, Michael, Braun, Noah O., Sinclair, Thomas R., Lobell, David B., Wolfram Schlenker (2017). Comparing and combining process-based crop models and statistical models with some implications for climate change. Environmental Research Letters 129095010.

Robinson, S., Meijl van, H., Willenbockel, D., Valin, H., Fujimori, S., Masui, T., Sands, R., Wise, M., Calvin, K., Havlik, P., Mason d'Croz, D., Tabeau, A., Kavallari, A., Schmitz, C., Dietrich, J. P. and von Lampe, M. (2014), Comparing supply-side specifications in models of global agriculture and the food system. Agricultural Economics, 45: 21-35.

Rosenzweig, Cynthia, Elliott, Joshua, Deryng, Delphine, Ruane, C. Alex, Müller, Christoph, Arneth, Almut, Boote, J. Kenneth, Folberth, Christian, Glotter, Michael, Khabarov, Nikolay, Neumann, Kathleen, Piontek, Franziska, Pugh, A. M. Thomas, Schmid, Erwin, Stehfest, Elke, Yang, Hong, 
Jones , W. James (2014). Global multi-model crop-climate impact assessment. Proceedings of the National Academy of Sciences, 111 (9): 3268-3273.

Rosenzweig, C., Iglesias, A., Yang, X.B., Epstein, P.R., Chivian, E., (2001). Climate change and extreme weather events - implications for food production, plant diseases, and pests. Glob. Chang. Human Health 2 (2), 90-104.

Schils, R., Olesen, J., Kersebaum, K., Rijk, B., Oberforster, M., Kalyada, V., Khitrykau, M., Gobin, A., Kirchev, H., Manolova, V., Manolov, I., Trnka, M., Hlavinka, P., Paluoso, T., Peltonen-Sainio, P., Pirjo, Jauhiainen, L., Lorgeou, J., Marrou, H., Danalatos, N., Ittersum, M. (2018). Cereal yield gaps across Europe. European Journal of Agronomy. 101. 109-120.

Schlenker, W. and Roberts, M. J., (2009). Nonlinear temperature effects indicate severe damages to U.S. crop yields under climate change. Proceedings of the National Academy of Sciences of the United States of America (PNAS), 106(37):15594- 15598.

Shen, Z., Odening, M. and Okhrin, O., (2018). Adaptive local parametric estimation of crop yields: implications for crop insurance rate making. European Review of Agricultural Economics 45 (2): 173-203

Sims, R., Taylor, M., Saddler, J., Mabee, W., (2008). From $1^{\text {st }}$ to $2^{\text {nd }}$ generation Biofuel Technologies Full Report: An Overview of Current Industry and RD\&D Activities. IEA.

Sonka, S., (1991). Methodological guidelines for assessing the socio-economic impacts of climate change on agriculture. In Climate Change: Evaluating the Socio-Economic Impacts:21-45. $O E C D$, Paris.

Suttles, S.A., Tyner, W.E., Shively, G., Sands, R.D. and Sohngen, B., (2014). Economic effects of bioenergy policy in the United States and Europe: A general equilibrium approach focusing on forest biomass. Renewable Energy, Volume 69: 428-436.

Taheripour, F., Hertel, T., Tyner, W.E., Beckman, J.F. and Birur, D., (2010). Biofuels and their by-products: Global economic and environmental implications. Biomass and Bioenergy, 34(3): 278-289.

Tamiotti, L., Teh, R., Kulaç glu, V., Olhoff, A., Simmons, B., and Abaza, H., (2009). Trade and climate change. A report by the United Nations Environment Programme and the World Trade Organization.

Tigchelaar M, Battisti DS, Naylor RL, Ray DK (2018). Future warming increases probability of globally synchronized maize production shocks. Proc. Natl Acad. Sci. USA 115

Tilman, D., Balzer, C., Hill, J., and Befort, B.L., (2011). Global food demand and the sustainable intensification of agriculture. PNAS 108, 50, 20260-20264.

UNFCCC. United Nations Framework Convention on Climate Change, Adoption of the Paris Agreement (2015). Proposal by the President (1/CP21) [cited 2016 02, Feb.] Available from: http://unfccc.int/resource/docs/2015/cop21/eng/10a01.pdf.

Urban, D., Roberts, M.J., Schlenker, W., Lobell, D.B., (2012). Projected temperature changes indicate significant increase in inter-annual variability of U.S. maize yields. Clim. Chang. 112 (2), 525-533.

USDA, https://www.fas.usda.gov/data, accessed 2020. 
Valin, H., Sands, R. D., van der Mensbrugghe, D., Nelson, G. C., Ahammad, H., Blanc, E., Bodirsky, B., Fujimori, S., Hasegawa, T., Havlik, P., Heyhoe, E., and Kyle, K., (2014). The future of food demand: Understanding differences in global economic models. Agricultural Economics, 41(1):51-67.

Wiebe, Keith, Hermann Lotze-Campen, Ronald Sands, Andrzej Tabeau, Dominique van der Mensbrugghe, Anne Biewald, Benjamin Bodirsky, Shahnila Islam, Aikaterini Kavallari, Daniel Mason-D'Croz, Christoph Mueller, Christoph, Alexander Popp, Richard Robertson, Sherman Robinson, Hans van Meijl, Dirk Willenbockel (2015), Climate change impacts on agriculture in 2050 under a range of plausible socioeconomic and emissions scenarios, Environmental Research Letters, ERL-100988, Vol. 10, Nr. 8, pp. 85010-85024.

Wijk, M.T. van, Rufino, M.C., Enahoro, D., Parsons, D., Silvestri, S., Valdivia, R.O., Herrero, M., (2012). A review on farm household modelling with a focus on climate change adaptation and mitigation. Working Paper No. 20. CGIAR Research Program on Climate Change, Agriculture and Food Security (CCAFS). Copenhagen, Denmark. Available online at: www.ccafs.cgiar.org

Wit, M. de, Londo, M., Andre, F., (2011). Productivity developments in European agriculture: relations to and opportunities for biomass production. Renewable and Sustainable Energy Reviews; 15:2397-412

Woltjer, G. B. (2011). Meat consumption, production and land use: model implementation and scenarios. WOT-werkdocument 269, Wageningen

Woltjer, G.B. and Kuiper, M.H., (2014). The MAGNET Model: Module description. Wageningen, LEI Wageningen UR (University \& Research centre), LEI Report 14-057. 146 pp.; 18 fig.; 45 tab.; 39 ref.

Zeist, W.J., Stehfest, Elke, Doelman, Jonathan, Valin, Hugo, Calvin, Katherine, Fujimori, Shinichiro, Hasegawa, Tomoko, Havlik, Petr, Humpenöder, Florian, Kyle, Page, Lotze-Campen, Hermann, Mason-D'Croz, Daniel, Meijl van, Hans, Popp, Alexander, Sulser B., Timothy, Tabeau, Andrzej, Verhagen, Willem, Wiebe, Keith, (2020), Are scenario projections overly optimistic about future yield progress? Global Environmental Change, Volume 64, September 2020, 102120.

Zhao, Chuang, Liu , Bing, Piao, Shilong, Wang , Xuhui, Lobell B., David, Huang, Yao, Huang , Mengtian, Yao, Yitong, Bassu, Ciais P., Simona, Durand , Jean-Louis, Elliott , Joshua, Ewert , Frank, Janssens A., Ivan, Li, Tao, Lin, Erda, Liu, Qiang, Martre, Pierre, Müller, Christoph, Peng, Shushi, Peñuelas, Josep, Ruane C., Alex, Wallach, Daniel, Wang, Tao, Wu, Donghai,

Liu, Zhuo, Zhu, Yan, Zhu, Zaichun, Asseng, Senthold (2017). Temperature increase reduces global yields. Proceedings of the National Academy of Sciences, 114 (35): 9326-9331. 
Introduction | $\mathbf{3 1}$ 
CHAPTER 2 


\section{Global scale climate-crop yield relationships: a response to Lobell and Field}

JP Powell and Karl Shutes

LEl (Agricultural Economics Research Institute), P.O. Box 29703, 2502 LS Den Haag, The Netherlands. 
Correct model specification and data aggregation are critical for properly assessing and predicting the implications of climate change. The data and analyses used in Lobell and Field (2007) are reexamined and alternative model specifications and approaches are considered. In contrast to a single, generic model, a more comprehensive use of standard econometric techniques suggests that models should be crop and country specific. We show that a deeper issue concerns the high level of aggregation employed in their paper. Lobell and Field's decision to aggregate yields at the global rather than country level discards important information about the effects of climate change on yields and exaggerates the relationships they report. Country specific and panel data models using less aggregated data are introduced and the results are compared to those of Lobell and Field. Results show that the relationship between changes in yields and changes in climate variables are much weaker than those reported by Lobell and Field.

Keywords: Climate change, crop yields, panel data 


\section{Introduction}

This paper critically reexamines the data and analyses used in Lobell and Field (2007), and suggests an alternative approach. Using an updated version of the same database and following the same data preparation and econometric techniques we were largely able to reproduce Lobell and Field's results. However, we find some potential problems with their model specification which affect their conclusions. In contrast to a single generic model for all crops and all countries, a more comprehensive use of standard econometric techniques suggests that models should be crop and country specific. Results are presented of the adjusted models and compared to those of Lobell and Field. In addition, we show that a more fundamental issue concerns the high level of aggregation used in their paper. Lobell and Field's decision to aggregate yields at the global level discards important information about the effects of climate change on yields and greatly inflates the explanatory power of their model. A panel data analysis with less aggregated data is introduced and the resulting benefits explored. Results show that the relationship between changes in yields and changes in climate variables are much weaker than those reported by Lobell and Field.

In general, we confirm Lobell and Field's claim that global temperatures have been increasing in the major crop growing regions over the forty-six years of available data. Figures clearly show that yields for most crops have increased, although barley yields appear to have stabilized or even fallen in recent decades (Figure 1). Average temperatures appear to be slightly increasing, while it is difficult to discern a dominant pattern for precipitation.
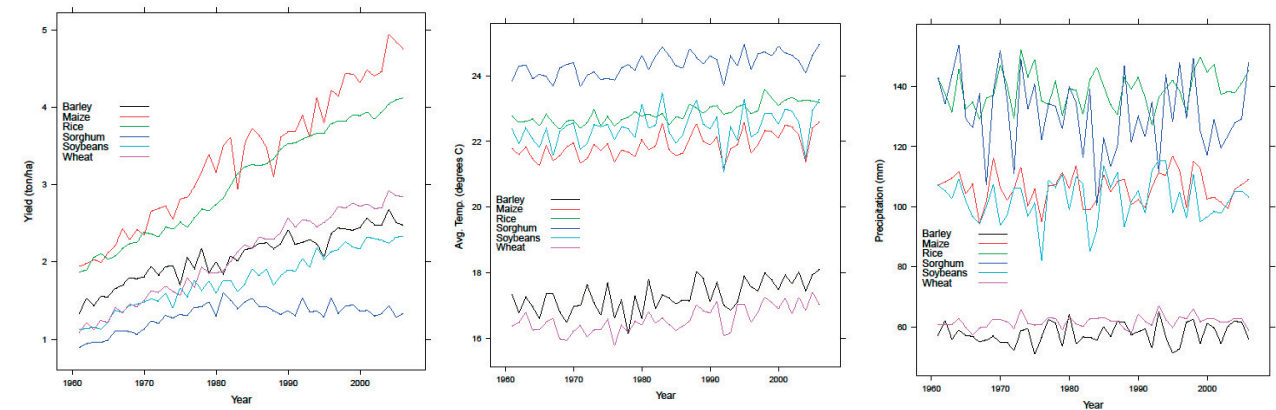

Figure 1. Average yearly crop yields and yearly averages of climate data in grids which grow said crops. Climate data is weighted according to the area of a grid devoted to the production of a crop (figures updated from Lobell and Field, 2007).

Regressions of the climate variables on time confirm the observed trends (Table 1). Coefficients for all crop yields are increasing and significant. Minimum temperatures for all crops are increasing, and they too have significant t-values. Similarly, maximum daily 
temperatures are increasing with the exception of soybeans, in which case the coefficient is not significant. A lack of significance means that it is not statistically meaningful to draw conclusions about the coefficient in question; a point to which we will later return. Regression results for precipitation reflect the ambiguity seen in the precipitation figure above; all coefficients are insignificant except for wheat growing regions, in which case the significance of the coefficient is only borderline significant.

Table 1. Trend regressions for yields, minimum, and maximum temperatures and precipitation for years 1961-2006.

\begin{tabular}{lllll} 
& $\begin{array}{l}\text { Yields } \\
\text { (hectogram/hectare) }\end{array}$ & $\begin{array}{l}\text { Minimum Temp. } \\
\left(\mathbf{C}^{\circ}\right)\end{array}$ & $\begin{array}{l}\text { Maximum Temp. } \\
\left(\mathbf{C}^{\circ}\right)\end{array}$ & $\begin{array}{l}\text { Precipitation } \\
(\mathbf{m m})\end{array}$ \\
\hline Wheat: & $411.9^{* * *}$ & $0.2123^{* * * *}$ & $0.1767^{* * *}$ & 0.3721. \\
\hline Rice: & $527.4^{* * *}$ & $0.2137^{* * *}$ & $0.1248^{* * *}$ & 0.7674 \\
\hline Maize: & $632.3^{* * *}$ & $0.2063^{* * *}$ & $0.1005^{*}$ & 0.0923 \\
\hline Soybean: & $263.7^{* * *}$ & $0.2021^{* * *}$ & 0.04279 & 0.2318 \\
\hline Barley: & $234.9^{* * *}$ & $0.2079^{* *}$ & $0.2080^{* * *}$ & 0.4687 \\
\hline Sorghum: & $84.43^{* * *}$ & $0.1643^{* * *}$ & $0.1578^{* * *}$ & -1.628 \\
\hline
\end{tabular}

Significance codes: $0^{\prime * * * \prime} 0.001^{* * * \prime} 0.01^{\prime * \prime} 0.05^{\prime \prime} 0.1^{\prime \prime \prime} 1$

\section{Methods}

For reasons of comparison, we initially follow Lobell and Field's procedures for preparing and analyzing the data. Their basic methodology is outlined below, along with explanations of potential problems and descriptions of how our methodology differs to theirs.

Lobell and Field wish to explain how global yields for six major crops as reported by the FAO have been affected by changes in temperatures and precipitation. We initially use the same data, but add the four additional years of reliable climate data which has become available since the original article was published. The FAO data we use spans a period from 1961 to 2006 and measures hectograms of a crop per hectare (FAOSTAT). Lobell and Field chose to use global yield levels, in other words, for each year in their study, one global yield data point is used rather than yields per country per year. That choice, country level data is available from the same FAO source, turns out to have important implications for their results, and is a point which we will explore in some detail below.

Lobell and Field use three independent variables to estimate changes in yields, namely, precipitation, minimum and maximum temperatures. Precipitation is the monthly average precipitation in a grid while the minimum and maximum temperatures are monthly average low and high temperatures in grids growing the six crops under consideration. Temperature and precipitation data was obtained from the East Anglia Climate Research 
Unit (CRUTS) 2.1 database. The globe is divided into $720 * 360$ equally sized grids according to a grid's latitude and longitude. Temperatures and precipitation are reported for each grid. We use the updated East Anglia CRU TS 3.0 database, however, differences between the two databases appear to be minimal particularly at the aggregation level used. In any case, figures derived from the two sources are nearly identical for common years (Figure 1), suggesting that differences in results are not due to differences in the data used. Spatially weighted averages of the CRU data were computed for each crop, with weights defined by the spatial distribution of crop area based on Leff et al. (2004). The greater the percentage of a grid devoted to a particular crop, the greater the weight of any changes in climate the grid undergoes. Furthermore, we followed Lobell and Field's method of defining global growing seasons for each crop. Their method allows the selection of months particularly important to the growth of a crop. For instance, the months from May to October are important months for the production of wheat, so only climate data from those months was selected and used in the analysis. Finally, both yield and climate data are analyzed after taking first differences. This means that yearly changes in yields, temperatures and precipitation are analyzed. First differencing minimizes the influences of slowly changing factors and removes individual effects (Baltagi, 2008). The result is a crop-specific monthly time series of selected global temperatures and precipitation for the years 1961-2006.

The approach we apply differs to that of Lobell and Field in two important ways. While we initially use the same aggregation, weighting, and differencing procedures they used, we are more systematic in regards to reporting how we arrive at the model we ultimately use for each of the crops. This will allow other researchers the opportunity to challenge our results. The section immediately below explains how we derive our individual crop models based on the initial, general, model presented by Lobell and Field. The section thereafter presents two alternative approaches which are country and crop specific. The data and methodology we use in that section closely parallels that of Lobell and Field, but are collected and analyzed at a country as opposed to global level, allowing us to incorporate important country level variation into the models. The stated goal of Lobell and Field is to draw general, global, conclusions about climate change, we do the same using a more disaggregated level of data and draw very different conclusions about the impact of climate change on yields.

\section{Results}

\subsection{Lobell and Field's Approach}

The unadjusted R-squareds we calculated, with the exception of sorghum, appear to be comparable to those reported in Lobell and Field (Table 2). Lobell and Field are presumably reporting unadjusted R-squareds, although it is more common to reported 
adjusted R-squareds. Most of the differences in the R-squareds we find and those of Lobell and Field can perhaps be attributed to the four additional years of data we use. Given a lack of reported information in the original article, we cannot account for the difference in the results for sorghum, and will have to let the matter stand as it is.

In addition, Lobell and Field did not report the significance of the variables they used as is common when reporting econometric results. Their Figure 3 does report temperature coefficients and significance, but it also raises several points. First, it reports results for only one of the temperature variables or an average of the temperature values. However, contrary to Lobell and Field, our results, presented in detail below, show that precipitation is significant for some of the crops and particularly rice. Second, because the values are reported by decade, it appears that they were estimated using only ten years of data. Third, the figure seems to show that for many decades temperature did not significantly influence yields and we are told that precipitation had only minor impacts on yields. If both these observations are true, it becomes difficult to understand the high R-squareds reported in their paper. The regressions we ran using their data show that many of the variables are insignificant, but that significance varies per crop and along with the other variables present in a regression. In general, a high R-squared in an equation with few or no significant t-statistics, such as in the results we found in Lobell and Field's regressions, is an indication of multicollinearity among variables. The very high correlation between changes in maximum and minimum temperatures is presented in the last column of Table 2. This high degree of collinearity is an indication that one of the two variables can probably be dropped from the regression or that other regression techniques should be applied.

Table 2. Comparison of our results with those of Lobell and Field.

\begin{tabular}{lllll} 
Crop & R-Squared & Adjusted R-squared & $\begin{array}{l}\text { Lobell and Field } \\
\text { R-squareds }\end{array}$ & $\begin{array}{l}\text { Correlations Max. } \\
\text { and Min. }\end{array}$ \\
\hline Wheat: & 0.39 & 0.34 & 0.41 & 0.88 \\
\hline Rice: & 0.27 & 0.21 & 0.29 & 0.75 \\
\hline Maize: & 0.47 & 0.43 & 0.47 & 0.88 \\
\hline Soybean: & 0.48 & 0.45 & 0.52 & 0.86 \\
\hline Barley: & 0.65 & 0.62 & 0.65 & 0.93 \\
\hline Sorghum: & 0.40 & 0.36 & 0.29 & 0.71 \\
\hline
\end{tabular}

Table 3 shows the results of, presumably, the same regressions as those run by Lobell and Field, but with standard measures of significance for each coefficient ( $t$-values) and the regression as a whole. The high F-statistics, all of which are significant, indicate that the models fit the data well. However, only in the case of wheat are all of the coefficients significant, while in the case of barley, none of the coefficients is significant. The results 
raise some questions about the effects, if any, of many of the climate change variables on yield changes.

Table 3. General regression model as alluded to in Lobell and Field.

\begin{tabular}{lllll} 
Change in Yield & $\begin{array}{l}\text { Change in } \\
\text { Precipitation }\end{array}$ & Change in Minimum & Change in Maximum & F-statistic \\
\hline Wheat: & $17.933^{* *}$ & $-443.146^{* * *}$ & $254.877^{* *}$ & 8.614 \\
\hline Rice: & 2.941 & 41.050 & -85.198 & 4.933 \\
\hline Maize: & 5.451 & 4.356 & $-346.651^{*}$ & 12.17 \\
\hline Soybean: & $5.518^{*}$ & 54.334 & -62.438 & 12.78 \\
\hline Barley: & 5.326 & -125.937 & -62.478 & 25.33 \\
\hline Sorghum: & 0.1861 & -38.9504 & $-117.9836^{*}$ & 9.259 \\
\hline
\end{tabular}

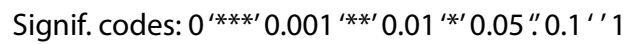

Despite the results reported by Lobell and Field, it is statistically impossible to draw any general conclusions about the implications of climate changes from the results presented in Table 3. For example, although all of the precipitation coefficients are positive, only those of wheat and soybeans are significant. The effect of minimum temperatures on yields is mixed; an increase in minimum temperatures in wheat growing regions lowers yields and, if a t-value of 0.1 is accepted, raises yields in the rice growing areas. The exercise of removing either minimum or maximum temperatures, as would be suggested by the correlations reported in Table 2, produces more interesting results. For instance, once the maximum temperature variable is removed, increases in minimum temperatures reduce yields for wheat, maize, barley and sorghum and precipitation becomes significant for most crops (Table 4).

Table 4. Dropping maximum temperature from the model.

\begin{tabular}{lllll} 
Change in Yield & $\begin{array}{l}\text { Change in } \\
\text { Precipitation }\end{array}$ & Change in Minimum & F-statistic & Adjusted R2 \\
\hline Wheat: & 7.351 & $-135.603^{* * *}$ & 7.782 & 0.2356 \\
\hline Rice: & $4.186^{* *}$ & -33.459 & 6.77 & 0.2078 \\
\hline Maize: & $13.12^{* *}$ & $-379.179^{* * *}$ & 14.49 & 0.3802 \\
\hline Soybean: & $7.503^{* * *}$ & -7.942 & 18.35 & 0.4409 \\
\hline Barley: & $8.147^{* *}$ & $-200.597^{* * *}$ & 38.55 & 0.6306 \\
\hline Sorghum: & $1.5091^{*}$ & $-154.9032^{* * *}$ & 9.943 & 0.289 \\
\hline
\end{tabular}

Signif. codes: $0^{\prime * * * \prime} 0.001^{* * * \prime} 0.01^{* * \prime} 0.05 " 0.1^{\prime \prime \prime} 1$

In the case of wheat, dropping maximum temperature implies that precipitation is no longer significant; and, although the minimum temperature remains significant, its impact on yield changes is diminished and the overall goodness of fit of the model falls. 
Precipitation, for all crops except wheat, becomes significant, and dropping maximum temperature makes one of the two remaining variables significant for all crops. It is not entirely clear from the results presented in Tables 4, and a similar exercise that drops maximum temperature, which of the two temperatures should be dropped, however, it is apparent that one of the two should be dropped. Furthermore, the results indicate that it is inappropriate to use a single, generic model for all crops, different crops react differently to climate change variables.

Picking a model is not only a matter of choosing the model with the highest R-squared. A parsimonious model may be preferred to a model with a higher R-squared. Unfortunately, Lobell and Field did not indicate whether they considered alternative models, for instance, whether they considered including order terms in their models. It is particularly important to consider the order of a model when analyzing time series data because the value of a time series variable is often highly dependent on its previous value. There are numerous, standard, tests which can help to specify and diagnose a model, some of which will be discussed below.

\subsection{Model Specification and Diagnostics}

Model specification involves decisions about which variables to include in a model and their order. It also includes the introduction of possible deterministic terms and distributional assumptions. The following section presents standard procedures for model specification and diagnostics (Lütkepohl and Krätzig, 2004). Using these criteria, a model for each crop is specified.

Given the climate variables used by Lobell and Field, all reasonable models, including those with interaction effects were considered. In particular, model permutations including various combinations of the variables were modeled. Models for each crop without order terms were compared using AIC (Hirotugu, 1974), BIC (Schwarz, 1978), and HQ (Hannen \& Quinn (1979) criteria. In essence, these types of criteria penalize models based on the number of variables included in a model; all else equal, a model with fewer variables is preferred to one with more.

The first question to answer is whether there is evidence of autocorrelation in the models. Autocorrelation functions (ACF) and partial autocorrelation functions (PACF) plots for each of the crops, before first differencing, indicate that autocorrelation is likely present in the basic, zero order, models (Figure 2). The figures for maize are nearly textbook examples of an autoregressive series of one lag $A R(1)$, which can potentially be corrected with the firstdifferencing procedures followed by Lobell and Field and adopted in our analysis. 

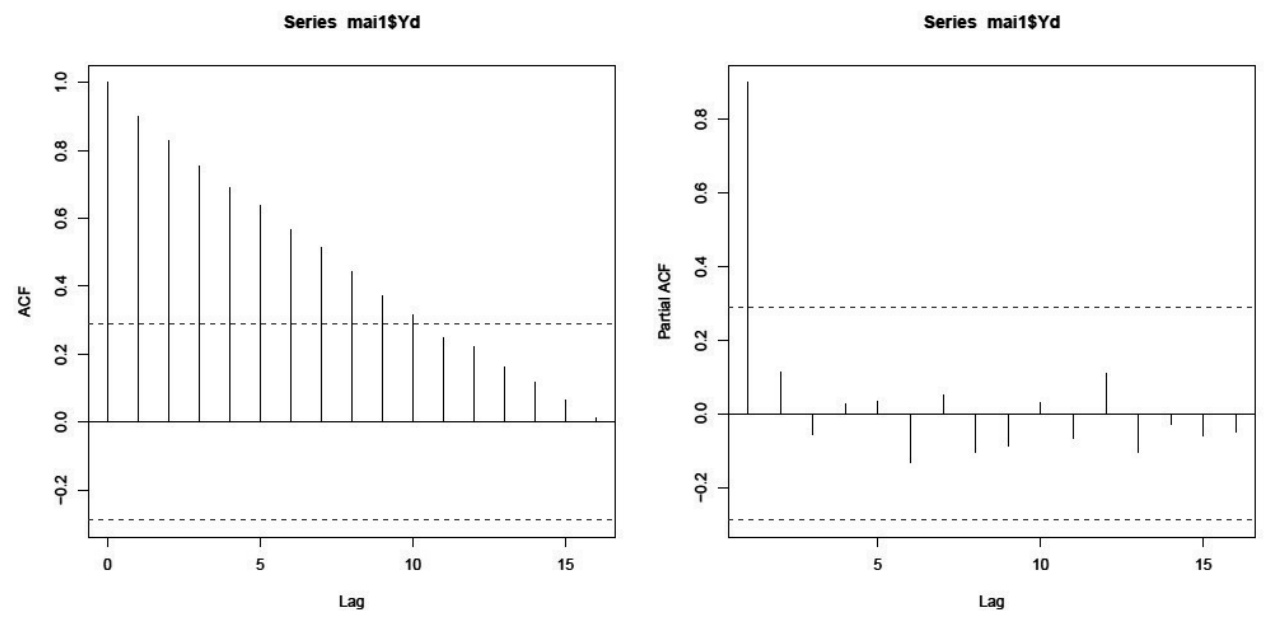

Figure 2. ACF and PACF for Maize.

Therefore, the next step was to specify more general models, those including autoregression (AR) and moving average (MA) terms. Using generalized least squares, ARMA models were systematically run with different $A R$ and MA order terms. Matrices containing the resulting AIC and BIC criterion for each model were created for each crop. The matrices provided a systematic means to compare the criteria. Models with higher order, for instance the sorghum ARMA $(1,3)$ model did not solve, probably as a result of the small number of observations relative to the number of variables included in higher order ARMA models. The following table of sorghum is representative of the matrices produced:

Table 5. AICs for ARMA sorghum models.

\begin{tabular}{lllll} 
& MA 0 & MA 1 & MA 2 & MA 3 \\
\hline AR0 & 735.63 & 728.91 & 727.39 & 727.06 \\
\hline AR1 & 729.41 & 729.85 & 732.00 & \\
\hline AR2 & 728.06 & 729.28 & 729.50 & \\
\hline AR3 & 727.94 & & & \\
\hline
\end{tabular}

Note that differences between models are often small, for sorghum the difference between $\operatorname{ARIMA}(0,2), \operatorname{ARMA}(0,3)$ and $\operatorname{ARMA}(3,0)$ are negligible, implying that a case could be made for any of these models. However, the criteria do indicate that higher order models out-perform the models reported in Lobell and Field ARMA $(0,0)$. Based on the criteria, the following models should be considered:

1. Maize: difference in yields with differences in precipitation and differences in maximum temperature with order $\operatorname{ARMA}(0,1)$.

2. Wheat: differences in yields with differences in differences in precipitation and differences in minimum and maximum temperatures with order $\operatorname{ARMA}(0,1)$. 
3. Soy: differences in yields with differences in differences in precipitation only with order $\operatorname{ARMA}(1,2)$.

4. Rice: differences in yields with differences in precipitation only and order $\operatorname{ARMA}(0,0)$.

5. Barley: differences in yields with differences in differences in precipitation and minimum temperature and order $\operatorname{ARMA}(0,3)$.

6. Sorghum: differences in yields with differences in differences in maximum temperature only. For sorghum and order $\operatorname{ARMA}(0,3)$.

Table 6. Choosing the "best" model.

\begin{tabular}{lllll} 
Change in Yield & $\begin{array}{l}\text { Change in } \\
\text { Precipitation }\end{array}$ & $\begin{array}{l}\text { Change in } \\
\text { Minimum Temp. }\end{array}$ & $\begin{array}{l}\text { Change in } \\
\text { Maximum Temp. }\end{array}$ & $\begin{array}{l}\text { Adjusted } \\
\text { R-squared }\end{array}$ \\
\hline Wheat: & $17.933^{* *}$ & $-443.146^{* * *}$ & $254.877^{* *}$ & 0.3417 \\
\hline Rice: & $3.557^{* * *}$ & -- & - & 0.2115 \\
\hline Maize: & 5.541 & -- & $-342.243^{* * *}$ & 0.4459 \\
\hline Soybean: & $7.543^{* * *}$ & -- & -- & 0.4518 \\
\hline Barley: & $8.147^{* *}$ & $-200.597^{* * *}$ & -- & 0.6346 \\
\hline Sorghum: & -- & -- & $-141.71^{* * *}$ & 0.3834 \\
\hline
\end{tabular}

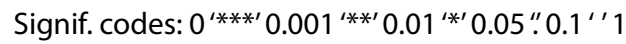

Once a model is specified, it needs to be tested to determine whether basic econometric assumptions apply. The next few paragraphs present results from the standard forms of the Portmanteau, Breusch-Godfrey, Jarque-Bera, ARCH-LM and RESET tests. Using the basic specified model for each crop, i.e., models without order terms, we conducted a Portmanteau test to test whether there may be correlation in the residuals. No order terms were included in order to remain close to the original model of Lobell and Field. The results below were produced using the Box-Pierce (1970) version of the test statistic. Other versions of the Portmanteau tests were run, for instance with greater lags than the two reported below and the Ljung-Box (1978) test, and they all generally confirmed the results below. Recall that the null hypothesis of no residual autocorrelation is rejected for large values of the statistic. For crops except wheat and rice, autocorrelation, despite first differencing, appears to be present in the models, confirming the AIC, BIC and HQ tests presented above. 
Table 7. Statistics and associated $p$-values in parentheses

\begin{tabular}{llllll} 
& Portmanteau & Breusch-Godfrey & Jarque-Bera & ARCH-LM & RESET \\
\hline Wheat: & $1.855(\mathbf{0 . 1 7 3})$ & $2.003(\mathbf{0 . 1 5 7})$ & $2.875(0.238)$ & $0.203(0.904)$ & $0.291(0.593)$ \\
\hline Rice: & $0.053(\mathbf{0 . 8 1 9})$ & $0.054(\mathbf{0 . 8 1 6})$ & $2.232(0.328)$ & $0.911(0.634)$ & $3.639(\mathbf{0 . 0 6 3})$ \\
\hline Maize: & $8.419(0.004)$ & $8.840(0.003)$ & $1.295(0.523)$ & $1.043(0.594)$ & $0.008(0.930)$ \\
\hline Soybean: & $8.173(0.004)$ & $8.914(0.003)$ & $1.874(0.392)$ & $3.879(0.144)$ & $0.317(0.576)$ \\
\hline Barley: & $4.158(0.042)$ & $4.162(0.041)$ & $1.879(0.391)$ & $2.897(0.235)$ & $0.238(0.629)$ \\
\hline Sorghum: & $6.048(0.014)$ & $6.305(0.012)$ & $1.272(0.530)$ & $0.234(0.890)$ & $0.605(0.441)$ \\
\hline
\end{tabular}

LM tests, such as the Breusch-Godfrey (Breusch, 1979), are another means to test for autocorrelation in AR models. The hypothesis is that an auxiliary regression which contains lagged error terms from the original regression will explain very little (i.e., that there is no autocorrelation). Once again, a null is commonly rejected if the p-value of the Breusch-Godfrey statistic is less than 0.05 . In the case of rice and wheat, the null of no autocorrelation cannot be rejected. The Jarque-Bera (or Lomnicki-Jarque-Bera (LJB)) is a test for non-normality based on the third and fourth moments (Lomnicki (1961) and Jarque and Bera (1978)). The test statistic has a chi-squared distribution if the null is correct, and the null hypothesis is rejected if the LJB is large. If the null is rejected, the normal distribution is rejected. The test, along with other tests of non-normality, indicates that the data appear to have the same first four moments as the normal distribution. The ARCHLM tests for neglected conditional heteroskedasticity and is based on fitting an ARCH(q) model to the estimation residuals. It has an asymptotic chi-squared distribution if the null hypothesis of no conditional heteroskedasticity holds (Engle, 1982). Large values of the test statistic indicate that the null is false and, hence, there may be $\mathrm{ARCH}$ in the residuals. The low values indicate that it is not worthwhile to fit ARCH or ARCH-type models to the residuals. Finally, the regression specification error test (RESET) was proposed by Ramsey (1969). It is used to test a given model against general unspecified alternative models. A null hypothesis of no misspecification is rejected if the test value is large. It appears that we cannot reject the null, i.e., the models do not appear to be misspecified although the case of rice is borderline and would be rejected at the $95 \%$ significance level.

One lesson to be drawn from the previous tests is that the effects of changes in climate on crop yields need to be considered on a crop specific basis. Regressing all of the variables leads to multicollinearity and inefficient models. In addition, ARMA structured models should be considered.

\subsection{Aggregation}

It is usually possible to correct for multicollinearity and serial correlation, but the level of aggregation in Lobell and Field presents a more fundamental issue. Recall that the aggregation procedures used by the authors weight 0.5 degree by 0.5 degree grids 
according to the fixed percentage of land devoted to a crop under consideration, i.e., grids for each crop are weighted based on the percentage of land in a grid devoted to that specific crop in the year 2004 (Leff, 2004). As a consequence, climate variables for grids with a greater percentage of a crop receive more weight. For instance, climate changes a effecting grids in Kansas, where great swaths of land are used to grow maize, will count for more in terms of the climate changes they experience than less densely planted grids. Lobell and Field also use yearly, global, yields of crops. The procedure implies, effectively, that land in all grids around the world is treated identically in regards to changes in yield. The result is that climate variables are, in a sense, forced through 41 years of yield data. Differences in productivity across grids or even countries, for which data is available, is not taken into account, in particular, variation in the effects of climate change variables in a particular country on yields in that country are not included in the analysis. A great deal of variation, important for econometric analysis, is thereby lost.
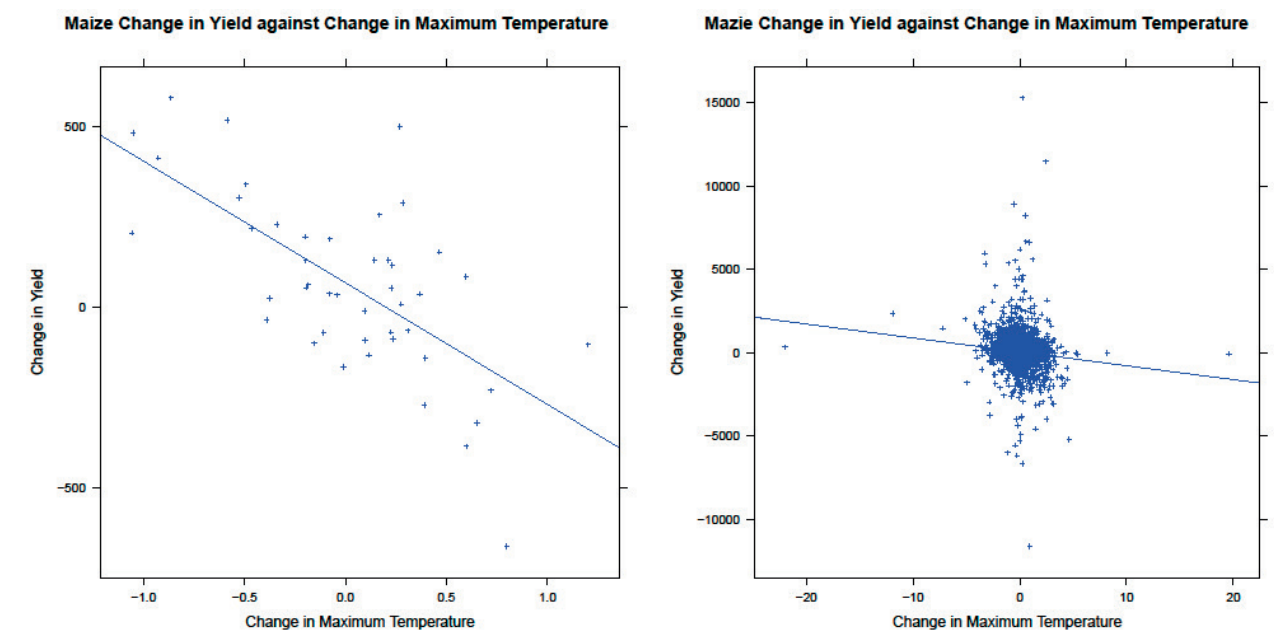

Figures $\mathbf{3} \mathbf{a}$ and $\mathbf{3} \mathbf{b}$. Regressions of change in yields and maximum temperatures at different levels of aggregation. The first figure aggregates at the global level while the second aggregates at the country level.

There are several figures which emphasize the importance of these issues. Figure $3 a$ is similar to that found on page 3 of the article by Lobell and Field. It clearly shows a negative trend in the change of yields given a change in the maximum temperature for maize (the figure has been scaled as in the original article). The relationship is, fortunately, apparent in the robustness of the coefficient and significance of maximum temperature in all of the regressions in the above tables. However, given an aggregation at the country level (figure $3 b)$, that relationship becomes tenuous. Similar figures for each crop show virtually the same relationships. 
In creating figure $3 \mathrm{~b}$, the same weighting procedures were used as those previously described, but instead of weighting at a global level, we weighted each crop at a country level and used country FAO yield data. Each point in the figure is the yield in a particular country and the corresponding average temperature in grids growing a particular crop in that country in a given year. Grids within countries are weighted in terms of the percentage of the grid's production in a country's total production. The greater the percentage of area devoted to a crop, the greater its climate changes count for the country as a whole. The blue line is a fitted line between change in yield and change in maximum temperature, it too is decreasing as in Figure 4a. But the relationship is precarious; small changes in values may cause large changes in slope. In fact, the figure shows that there is very little relationship between changes in yield and changes in temperature, in that the data are in a nearly circular pattern. All of the figures for all of the crops and variables have similar forms. Country level panel data analyses confirm the tenuous nature of the global relationship between yields and climate.

Critically, we are not claiming that climate changes have no impact on changes in yields. What we are claiming is that different countries and crops will face different climate change challenges, this is even apparent in the adjusted, highly aggregated, regressions run by Lobell and Field and analyzed in the preceding sections.

Table 8 below further emphasizes the information that can be gleaned from disaggregating the data. Using only those countries for which there are complete datasets, i.e., those for which 45 years of data are available, we regressed changes in yields against changes of each of the climate variables taken individually. The results give only a rough indication of the relationships between climate variables and yields and are intended to demonstrate another possibility for calculating the effects of climate change by starting the analysis at a country level. Testing the regressions for each country and each possible model is manageable given modern software packages. However, interpreting the results and adjusting models for so many countries requires expertise and time. For instance, the null hypothesis of no residual correlation was not rejected for a large majority of the countries for each crop and each variable. However, in a few cases, less than 10 for all crops and all countries, it was rejected. Results for the RESET and Jarque-Bera tests were similar; they generally indicated normal, well-specified models, however, they occasionally pointed to poor specification which could probably be corrected by including a squared term and non-normality which could be corrected by the removal of one or two questionable outliers. An advantage of examining each country individually and the reason we have included it in this comment is to emphasize the apparent diversity of the effects of climate change across countries and crops.

The column in Table 8 entitled "Total No. of Countries", reports the number of countries in each crop analysis. The analysis of wheat, for example, consists of 57 countries each 
with 45 years of data. Given the qualifications listed in the previous paragraph, we found that of those 57 countries, only 10 had statistically significant results for changes in yield against changes in precipitation, 9 countries had significant results for changes in yield against changes in minimum temperature, and 11 had significant changes in yield against changes in maximum temperature. By statistically significant we mean that the coefficient has a significant $t$-value. Of the 10 wheat growing countries, 4 showed a positive relationship between changes in precipitation and changes in yields and 6 showed a negative relationship for the same regression. In other words, some countries will experience decreases in yields while others will experience increases as a result of increases in precipitation. The point of the table is to show the diversity of responses to climate changes. For instance, a majority of rice and maize growing countries have benefited from changes in precipitation. However, in general, a majority of countries will suffer from an increase in temperature, and to the degree that these crops are grown for local consumption, this is an important outcome.

Table 8. Country level effects of climate change variables on changes in yield.

\begin{tabular}{cccccccccccc} 
& \multicolumn{4}{c}{} & \multicolumn{2}{c}{ Precipitation } & \multicolumn{2}{c}{ Minimum Temperature } & \multicolumn{2}{c}{ Maximum Temperature } \\
\hline & $\begin{array}{c}\text { Total No. } \\
\text { Countries }\end{array}$ & $\begin{array}{c}\text { Signf. } \\
\text { Results }\end{array}$ & Positive & Negative & $\begin{array}{c}\text { Signf. } \\
\text { Results }\end{array}$ & Positive & Negative & $\begin{array}{c}\text { Signf. } \\
\text { Results }\end{array}$ & Positive & Negative \\
\hline Wheat: & 57 & $\mathbf{1 0}$ & 4 & 6 & $\mathbf{9}$ & 0 & 9 & $\mathbf{1 1}$ & 0 & 11 \\
\hline Rice: & 66 & $\mathbf{1 8}$ & 13 & 5 & $\mathbf{6}$ & 5 & 1 & $\mathbf{1 3}$ & 10 & 3 \\
\hline Maize: & 67 & $\mathbf{1 9}$ & 17 & 2 & $\mathbf{8}$ & 2 & 6 & $\mathbf{1 4}$ & 2 & 12 \\
\hline Soybean: & 18 & $\mathbf{1 0}$ & 5 & 5 & $\mathbf{5}$ & 2 & 3 & $\mathbf{7}$ & 2 & 5 \\
\hline Barley: & 50 & $\mathbf{1 4}$ & 7 & 7 & $\mathbf{1 8}$ & 2 & 16 & $\mathbf{1 9}$ & 1 & 18 \\
\hline Sorghum: & 26 & $\mathbf{3}$ & 3 & 0 & $\mathbf{5}$ & 0 & 5 & $\mathbf{5}$ & 0 & 5 \\
\hline
\end{tabular}

Another alternative to aggregation, and one that directly addresses the question posed by Lobell and Field, is to use a panel data model. A series of panel data analyses were run using only those countries for which there are complete data sets. In the interest of parsimony, we chose to compare the pooled panel data analyses for each crop to the findings of Lobell and Field. Recall that a pooled panel ignores the panel structure of the data and reflects the assumption that all countries have the same intercepts and slopes. A complete panel study would involve running a nonstationary panel model to account for the long time element, but given the low explanatory power of the model, and all of the models we tested, the basic conclusions of the pooled model remain. A comparison of the results from pooled panel data analyses with the "best" models presented in Table 6 yields striking results (Table 9 ). 
Table 9. Panel Models, pooled models reported.

\begin{tabular}{lllll} 
& $\begin{array}{l}\text { Change in } \\
\text { Precipitation }\end{array}$ & $\begin{array}{l}\text { Change in } \\
\text { Minimum Temp. }\end{array}$ & $\begin{array}{l}\text { Change in } \\
\text { Maximum Temp. }\end{array}$ & Adjusted R-squared \\
\hline Wheat: & $-1.073^{*}$ & -31.100 & $-75.098^{* * *}$ & 0.0232 \\
\hline Rice: & -0.00378 & -- & -- & 0.0000 \\
\hline Maize: & $0.741^{* * *}$ & -- & $-68.065^{* * *}$ & 0.0342 \\
\hline Soybean: & 0.3121 & -- & -- & 0.002 \\
\hline Barley: & $-0.7296^{*}$ & $-120.157^{* * *}$ & -- & 0.0427 \\
\hline Sorghum: & -- & -- & $-25.1226^{* *}$ & 0.0025 \\
\hline
\end{tabular}

Signif. codes: $0^{\prime * * * \prime} 0.001^{1 * * \prime} 0.01^{* * \prime} 0.05{ }^{\prime \prime} 0.1^{\prime \prime \prime}$

For wheat, precipitation has gone from significant to only marginally significant, while the minimum temperature has become insignificant. Maximum temperature remains significant, although it only has a quarter of the impact that it had in the highly aggregated model. The high correlation between minimum and maximum temperatures is still an issue. For instance, dropping minimum temperature makes precipitation significant although the explanatory power of the model remains low and homogeneity cannot be rejected.

In comparison to the aggregated model for rice, precipitation in the disaggregated model becomes insignificant; however, running the pooled regression with either maximum or minimum temperatures (without precipitation) yields significant results. In the case of maize, both precipitation and maximum temperatures are significant in the pooled model. The results for soybeans closely parallels those of rice, precipitation is now insignificant but including only maximum temperature makes that variable significant. For barley, both precipitation and minimum temperature remain significant, but their impact on yields is greatly diminished. Finally, the effect of a change in the maximum temperature on sorghum yields is also much smaller in the pooled panel data model than it was in the aggregated model.

One of the general messages that can be drawn from these results is that only one temperature is needed in the model and precipitation can have either positive or negative effects for some crops. Another conclusion is that increases in temperatures have negative effects for all crops in the pooled model. However, the most striking result is the small R-squareds in the pooled model when compared to the highly aggregated model of Lobell and Field. Tests for unobserved effects (Wooldridge, 2002) indicate that there is evidence of unobserved effects in the residuals. In other words, changes in yields are only partially explained by the regressed climate change variables. For example, whereas Lobell and Frank found an R-squared of 0.6346 for barley, our model yields an R-squared of 0.0427 . 
Although many permutations of the pooled models remain statistically significant, they all explain much less of changes in yields than the aggregated models.

\section{Conclusions}

Lobell and Field provide a very general model purporting to show that a large amount of changes in crop yields can be largely explained by changes in three climate variables. We show that such a general model, although parsimonious, cannot adequately account for the diversity of changes in yields that occur across different crops and countries. In addition, issues of collinearity and autocorrelation are clearly a problem in their reported model and should have been addressed by the authors. At a minimum, basic statistical tests should have been conducted and reported. We suspect that many of these tests were conducted by Lobell and Field, but reproducibility requires that they be reported as well. Other works by the authors indicate that they are aware of many of the issues we have noted. For instance, in Lobell (2007), a number of issues highlighted in this comment are considered. Models used in that paper are based on country-crop pairings, thereby allowing for country specific relationships, rather than global relationships. In Schlenker \& Lobell (2010), the authors consider a panel based model for Sub-Saharan Africa with a quadratic trend and no differencing. They do suggest that the measurement error might be increased by using this approach and hence use two different datasets for the weather, though they suggest that the fixed effects used in such an analysis will capture the biases introduced by omitted variables. However, the point remains that in the paper under consideration Lobell and Fields claim to have found a model that shows that climate changes have significantly reduced crop yields, but that model appears to be suspect.

We demonstrate that the high explanatory power of their model is questionable. We have presented a case that their basic model is misspecified and includes highly correlated and insignificant variables. The aggregation level used by authors also raises important questions. Global aggregation effectively means that observed global changes in yields are applied equally across all grids based on the fixed weight each grid has in regards to its contribution to the total global yield. In short, all grids growing a specific crop are treated equally in regards to their contributions to changes in yields, regardless of their location. The methodology means that Lobell and Field regress 41 years of yield data (42 less one year used for differencing) on 41 years of climate change data. By using only one global yield point per year, important variation is lost. In contrast, we use country level yield data so that yield variations reflect changes in climate variables at a country rather than global level. The approach increases the number of observations into the thousands and, accordingly, increases the observed variation. 
As direct result of their methodology, we believe that Lobell and Field (2007) are able to report very high R-squared relationships between changes in yields of six major crops and changes in minimum and maximum temperatures and precipitation. In other words, Lobell and Field's study seems to indicate that a large proportion of changes in yields can be explained by climate change variables. If true, and the effects of climate changes are indeed negative as the authors claim, policies aimed at mitigating climate changes at the world level would be strongly reinforced. Using updated versions of the same data sets we were essentially able to reproduce the reported results, including the high R-squareds. However, by employing a basic panel data model we arrive at very different conclusions about the effects of climate change on changes in yields. By disaggregating the data we show that climate changes by themselves explain only a very small part of changes in yields. Although yields of some crops in some countries have been adversely affected by increases in temperatures and change in precipitation, some crops in some countries have benefited. In short, models should be crop and country specific. 


\section{References}

Akaike, Hirotugu 1974 A new look at the statistical model identification IEEE Transactions on Automatic Control 19 (6): 716-723

Baltagi, Badi H 2008 Econometric Analysis of Panel Data, fourth edition, John Wiley \& Sons, Ltd.

Box, G. E. P. and Pierce, D. A. 1970 Distribution of the Autocorrelations in Autoregressive Moving Average Time Series Models Journal of the American Statistical Association 65: 1509-1526

Breusch, T.S. 1979 Testing for Autocorrelation in Dynamic Linear Models Australian Economic Papers 17 334-355

CRU dataset. University of East Anglia Climate Research Unit (CRU). Phil Jones, lan Harris. CRU Time Series (TS) high resolution gridded datasets. NCAS British Atmospheric Data Centre, 2008, Accessed December, 2010.

Engle, Robert F. 1982 Autoregressive Conditional Heteroscedasticity with Estimates of Variance of United Kingdom Inflation Econometrica 50:987-1008

FAOSTAT: http://faostat.fao.org/site/567/default.aspx\#ancor, accessed December, 2010.

Hannan, E. J., and B. G. Quinn 1979 The Determination of the Order of an Autoregression

Journal of the Royal Statistical Society B 41 190-195

Jarque, Carlos M. and Bera, Anil K. 1980 Efficient tests for normality, homoscedasticity and serial independence of regression residuals Economics Letters 6 (3): 255-259

Leff, B., N. Ramankutty, and J. A. Foley 2004 Geographic distribution of major crops across the world Global Biogeochemical cycles Vol. 18

Ljung, G. M. and Box, G. E. P 1978 On a measure of lack of fit in time series model Biometrika 65 1978: 297-303

Lobell, David B. 2007 Changes in diurnal temperature range and national cereal yields Agricultural and Forest Meteorology 145, no. 3-4: 229 - 238

Lobell, David B. and Christopher B. Field 2007 Global scale climate-crop yield relationships and the impacts of recent warming Environ. Res. Lett. 2

Ramsey, J.B. 1969 Tests for Specification Errors in Classical Linear Least Squares Regression Analysis J. Roy. Statist. Soc. B., 31(2), 350-371

Schlenker, Wolfram, and David B Lobell. 2010 Robust negative impacts of climate change on African agriculture Environmental Research Letters 5, no. 1 (January)

Schwarz, Gideon E. 1978 Estimating the dimension of a model Annals of Statistics 6 (2): 461-464

Wooldridge, J 2002 Econometric Analysis of Cross-Section and Panel Data MIT press 
Global scale climate-crop yield relationships: a response to Lobell and Field ｜ 51 
CHAPTER 3 


\title{
Convergence of European wheat yields
}

\author{
J.P. Powell, M. Rutten
}


The paper makes several contributions to the study of wheat yield changes in Europe and the resulting economic consequences in the near to medium term future. In particular, it addresses the issue of the effects of yield changes on land use. The transition and growth of yields are estimated using a combination of convergence, time series and dynamic panel models. Scenarios are then run using estimated yields as input into a computable general equilibrium (CGE) model. The CGE model provides a narrative framework through which the total economic impact of changes in yields can be analyzed. Together, the complementary approaches of econometrics and general equilibrium models allow a more complete economic analysis of the consequences of yield changes for this important biofuels crop to emerge. Although there is no evidence of a common rate of yield convergence across Europe, there is evidence of absolute convergence. Standard time series and panel forecasting methods indicate the potential for only very modest yearly yield increases across most of Europe given optimistic assumptions; although potential yearly increases in newer European states could, in some cases, be substantially higher. However, the total amount of land released as a result of potential yield increases in the wheat sector is only modest because of an increase in demand for land by sectors other than wheat. The overall question of whether significant yield increases will necessarily lead to large increases in land available to produce bioenergy crops is rejected. Land freed by wheat yield increases will go to the production of a wide range of agricultural products that value it as an input. The same reasoning which links yields and land use applies to all agricultural products when there are well functioning markets. 


\section{Introduction}

\subsection{Issue}

The paper addresses the effects of forecasted yield increases on land use in the European agricultural sector. The argument linking yields and land use is that technological advances which lead to increased yields will provide a means to circumvent the difficult tradeoffs required to meet the various demands for biomass products $[13,53,55]$. The claim is that an increase in yields will mean that less land will have to be used to produce the same amount of crops, thereby avoiding or at least mitigating a part of the land use effects incurred when converting agricultural and nonagricultural lands into bioenergy crop production. Furthermore, given that a large component of the total costs of producing bioenergy products is the cost of the crop used, technological improvements that increase yields are expected to have positive economic consequences for bioenergy products in terms of prices and quantities produced [22]. This follows because crops are the principle cost of producing first generation biofuels; estimated biofuel share costs in Europe are approximately $70 \%$ for sugar beet, $75 \%$ for wheat, rye and maize, and $80 \%$ for rapeseed oil [37].

A review by de Wit et al. (2011) summarizes the findings of four reports that calculated the amount of additional land made available from yield increases [55]. The main argument in those reports is that yield increases will release land which is currently being used to grow crops to grow bioenergy crops and, particularly, crops to produce biofuels $[14,16,17,19]$. The calculated amount of land released for the production of biofuels in those studies is the hypothetical maximum in that each of the studies assumes that any land that is freed (in the case of the REFUEL study, 60 million hectares) will go to bioenergy production rather than the production of food, feed or fiber. Furthermore, it has been argued that a large potential source of production gains might come from expected yield increases in the newer states of Europe. Current yields for those countries are far below the European mean, suggesting that yields there are due for an increase. It follows that the question of whether yields in Central and Eastern Europe will converge to those in Western Europe will largely determine whether yields in Europe as a whole will increase.

It is self-evident that yield increases reduce the amount of land required to grow crops, all else equal, but how the freed land will be used depends on wider economic and social considerations. The argument underlying the conclusions of the studies mentioned rests on two assumptions. The first is that the land made available from increased yields will go to produce bioenergy crops rather than for some other use. Secondly, and more fundamentally, it assumes that there will be a demand, at a competitive price, for products which use bioenergy crops. Demand for such products is a necessary condition, but by no means a sufficient condition for increasing the production of bioenergy crops. This paper 
addresses the first issue, in short, it asks what will be produced on freed land resulting from yield increases. The answer to the second issue, not addressed here, is largely dependent on government policies and the prices of petroleum and other bioenergy crop substitutes [49].

Land use has been an important consideration in assessing the economic viability and environmental impacts of biofuels and other biomass products since Searchinger et al. 's [44] paper first raised the issue. Searchinger et al.'s paper and many others which followed, have put land use on the political agenda as well, indeed, mitigating the negative effects of land used to produce biofuels is an important part of the European Biofuels Directive (2009/28/EC) [15]. While other researchers have used computable general equilibrium (CGE) models to address the issue of the effects of bioenergy crops on land use $[25,26,41,33]$, our modeling framework differs to previous studies by introducing explicit econometric models to forecast yields as opposed to using standard yield assumptions of CGE models which are often difficult to reconstruct and reproduce. In addition, land use in MAGNET, the CGE model we use, has a sophisticated land supply module allowing us to better model the effects of yield changes on land use. It is the combination of econometric forecasting methods and the improved CGE framework which distinguishes our work and allows us to more fully address the research question.

The structure of the remainder of the paper follows directly from the main research question. In order to answer that question, we first need to determine the extent to which yields will increase in the future. We briefly discuss the data used in the analyses and then apply various techniques to understand the trajectory in which wheat yields have been following. We then build an econometric model in order to forecast yields. The forecasted yields are then used as input into MAGNET in order to assess their impact on land use.

\section{Data and methodology}

\subsection{Data}

\subsubsection{FAO data}

The study consists of two main parts. The first attempts to forecast European crop yields and the second calculates the economic consequences of those increases. All of the data used in the econometric analyses are publicly available and an effort has been made to be as explicit as is practicable about the techniques used with the aim to ensure reproducibility. The FAO data spans a period from 1961 to 2010 and measures hectograms of wheat produced per hectare [18]. In some instances, particularly in the panel econometric analyses, only the years between 2001 and 2009 are used. The year 2001 was chosen because it appears to be the first stable year for yields following the 
economic changes resulting from political events in Central and Eastern Europe which form the bulk of the newer countries in the study. The year 2009 was chosen because it is the latest year for which Penn World Trade data is available. Whenever possible, country level data is used, in other words, FAO yields per country are used in the analyses rather than, say, aggregated group data. Aggregated data have well documented limits when used in econometric analyses [4].

\subsubsection{Penn world trade data}

GDP data from the Penn World Trade version 7.0 is used in the analyses [28]. In particular, the variable constant price GDP per capita and expenditure shares is used as an exogenous variable to explain changes in yields. The GDP data is meant to provide a rough estimate of the wealth and technological development of a country. The assumption is that rather than a particular legislative policy such as in de Wit et al. (2011), a good general variable associated with yields is a country's GDP per person. This variable has been widely used throughout the convergence literature as a measure of economic development at least since the Solow Swan and Ramsey economic growth models [46,42]. Whereas those models use macro-variables such as capital, labor, and technology to explain differences in real GDP rates across countries, we use real GDP per person as a proxy for those other variables. In short, we are not trying to explain the causes of yield increases, such an exercise would involve using data that does not exist at the macro level or is of poor quality for many of the newer European countries (it does exist for established European countries). Rather, we are using real GDP per person to test whether changes in that variable result in econometrically significant changes in yields. Other explanatory variables such as land supply, labor, and fertilizer use were considered as exogenous variables, but their availability and quality, particularly for Central and Eastern European countries, led us to the conclusion that more countries could be included in the analyses by using real GDP per person as a catchall for economic development and as a measure of the capabilities of countries to increase their yields. We are not the first to observe the strong correlation between real per person GDP and yields (for example, see Hafner [23]). Finally, in a few cases, less than $1 \%$ of the total number of data points used, a year of yield or GDP data was missing from the FAO or Penn World Trade databases. This is particularly true in the first years of the analysis of the newer European countries. If a country was missing data, then a simple linear prediction method was used to estimate the missing year. Essentially, a linear regression was run and the resulting relationship was used to estimate the missing point.

\subsubsection{MAGNET data and behavior}

The global economic simulation model used in the analysis is the Modular Applied GeNeral Equilibrium Toolbox (MAGNET), a CGE model developed at LEl which is a part of Wageningen University and Research Centre in the Netherlands [52]. MAGNET has been 
extensively used to study the impact of policy changes on international trade, production, consumption, prices and the use of production factors such as land, capital and labor $[47,50,51]$. It is an extension and significant reorganization of the Global Trade Analysis Project (GTAP) model, a widely used tool for global trade analyses [27]. Extensions include more refined production and consumption structures, and, of particular importance to the current study, MAGNET has a more sophisticated land market module which makes it particularly suitable for land use analyses. Below follows an intuitive description of the model, including the database which forms the heart of the model, the modeling of actor behavior and markets, and a description of the land supply module.

The data used in the analysis is based primarily on version 8 of the database collected and processed by Global Trade Analysis Project (GTAP). Version 8 uses 2007 as its base year and contains balanced economic data for 129 regions and 57 economic sectors. For the purpose of this analysis, the 129 regions and 57 sectors have been aggregated into more meaningful categories. In a CGE model, the data for all regions and sectors must be included in the analysis in one form or another. Aggregation allows less important data to be bundled together and the focus to be directed on specific regions and sectors. $A$ practical reason for aggregating is that it allows a model to solve in a reasonable period of time. The regional aggregation used in the analysis consists of twelve large European wheat producing countries as reported by the FAO in 2010. All other regions in the world have been aggregated into a category labeled 'Rest of World' (ROW). The sectoral aggregation consists of 12 primary agricultural sectors, including wheat, available in MAGNET. The remaining sectors have been aggregated into a manufacturing and a service sector. The model retains the standard MAGNET specification of five factors of production, including skilled and unskilled labor, capital, land and natural resources. The land use data used in MAGNET were obtained from data compiled by GTAP in a two step process [21]. First, SAGE (Center for Sustainability and the Global Environment) land cover data for 2004 are corrected for the percentage change over 2004- 2007 as reported by FAO [48]. In a second step, the data are distributed over crops in proportion to harvested area using data from SAGE/FAO, and over livestock sectors using data on value add of land in those sectors.

MAGNET captures the behavior of three types of agents: households, firms, and government, for each of the regions in the model. Household behavior is captured via a representative regional household which aims to maximize its utility, collects all income that is generated in the economy, and allocates that income over private households, government expenditures, and savings for investment goods. Income is derived from payments by firms to the regional household for the use of endowments of skilled and unskilled labor, land, capital and natural resources. The regional household also receives income from taxes paid by the private household, firms, and government expenditures. Firms, profit maximizers, produce commodities by employing the aforementioned 
endowments and intermediate inputs from other firms using constant returns to scale production technology and sell them to private households, the government, and other producers. Domestically produced goods can be either sold on the domestic market or exported. Similarly, intermediate, private household, and government demand for goods can be satisfied by domestic production or by imports.

Demand for and supply of commodities and endowments are traded in markets which are perfectly competitive and clear via price adjustments. Because all markets are in equilibrium, firms earn zero economic profit, households are on their budget constraints, and global savings must equal global investments. Since the CGE model can only determine relative prices, the GDP deflator is set as the numéraire of the model against which all other prices are benchmarked. Changes in prices resulting from the model simulations therefore constitute real price changes. For the current study, we are using the model to carry out dynamic analyses over time, specifically for 2007 (the base year) until 2020. Projections into the future are obtained by allowing the exogenous endowments of capital, land, natural resources, and labor, and the productivity of these factors, most notably yields, to grow according to specified growth paths which are based on readily available economic data.

\subsubsection{MAGNET's land supply curve}

Land supply is modeled in MAGNET using a land supply curve which specifies the relationship between land supply and a land rental rate [29]. The general idea underlying the land supply curve specification is that the most productive land is the first to be put into production. However, the potential land available for use in agriculture production is limited. If there is a relatively large amount of land available to meet an increase in land demand, then rental rate increases will be modest (see Fig. 1). That situation is depicted by points situated on the left, flat, part of the land supply curve. However, when agricultural land is scarce, an increase in demand for agricultural land will lead to large increases of land rental rates as the available land supply approaches the asymptote in Fig. 1.

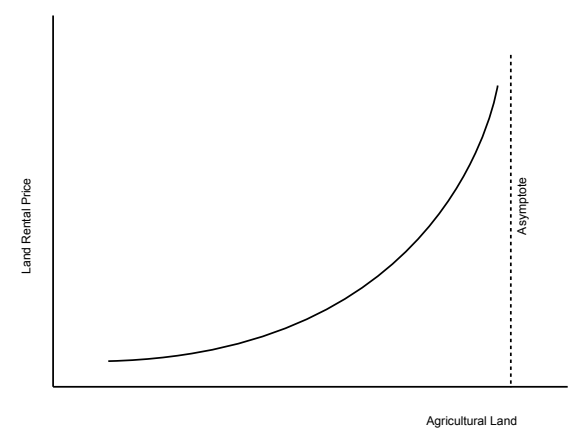

Fig. 1. Land supply curve. 


\subsection{Econometric methodology}

An important first step to test our main research question is to forecast yield increases in Europe. Several complementary methodological approaches are employed to conduct this step of the analysis. In the first step, the current state of wheat yield increases is presented and analyzed using univariate and standard time series econometric techniques. Analyses are, whenever possible, presented via figures. The objective of this step is to determine the general shape of the data and to identify differences across Europe and between Europe and the world. Thereafter, a model of convergence is presented in order to test whether yields in Europe are converging to a common level, and, if so, at what rate. If the yields of European countries are converging, then forecasting future yields is a relatively simple matter as yields in newer European states can be expected to be more or less similar to those in established Europe at some calculable point in the future.

Once this first step has given us an overview of yield trends, we can begin the process of specifying a model to forecast yields. Two approaches are considered, a country level, time series approach and models based on panel data. There are clear trade-offs between the two approaches. The time series approach uses well established methods to forecast yields per country. This approach benefits from long data series, unfortunately, several Central and Eastern European have only very short series. The panel approach can be used with shorter series because it, essentially, combines data across countries so that many short series amount to one long series. The problem is that panel models are only helpful if the underlying data generating mechanisms of countries are reasonably comparable. The matter of choosing between the two econometric methods or combining their results occupies an important part of the discussion to follow. Once a decision has been made, the chosen forecasting method will be used to provide input into MAGNET in order to assess the effects of yield changes on land use and other economic indicators.

\subsection{MAGNET methodology}

In order to use MAGNET for dynamic analyses the model must be updated from 2007 (the most recent year for which GTAP data is available) to 2010, using readily available economic data. The model projects forward until 2020 while incorporating alternative wheat productivity shocks based on econometric forecasts. MAGNET results show the effects of changes in wheat yields on the quantity of wheat produced, real market prices for wheat, and land used to grow wheat and other crops, holding all else in the model constant. The shocks are implemented in two scenarios, namely, a low yield and high yield scenario, and results are compared to a baseline or business as usual scenario. Development of the business as usual scenario is the starting point of a dynamic CGE analysis. In a sense, it forms the backdrop to which other scenarios are compared. The baseline models a future in which socioeconomic drivers continue to follow current trends assuming that no policy changes. For the current study, the mean of projected yields is 
incorporated into the baseline and forms the point of comparison for the low and high yield scenarios. Data for running the baseline, low, and high scenarios are taken primarily from the last three columns of Table 5. For reasons which will be explained, some of the data used in the MAGNET scenarios are adjusted to reflect additional econometric results.

\section{Results and discussion}

\subsection{Current state of European yields}

Crop yields in Europe are expected to increase, however, they are expected to do so at a decreasing rate $[32,34,45]$. The intent of the analysis in this section is to present the broad path that yields have followed over the last 50 years in order to identify general trends and to compare world and European yield rates. If yields in Europe are increasing at a decreasing rate, then the argument that less land will be needed to grow the same amount of wheat diminishes in importance accordingly. Finally, note that yields are rates, they measure an amount of output per area and are not the amount of wheat produced. The difference is fundamental, for instance, several smaller countries, such as the Netherlands, have very high yields but are not large producers. Therefore, an increase in yields in the Netherlands has less of an impact on land use than an increase in, say, the Ukraine.

\subsubsection{European trends}

Fig. $2 \mathrm{a}$ and $\mathrm{b}$ presents yields through time for the 43 European countries for which data is available. The Whittaker-Hodrick-Prescott (WHP) smoothing filter was used to derive a smooth curve representation of yields which is more sensitive to longer term fluctuations [30]. There are several trends to note in Fig. 2a. The figure clearly shows a general leveling of yield rates beginning in the 1990s and continuing unabated until the present. The trend is particularly evident in the higher yield countries; econometric analyses to follow confirm that trend. Another outstanding feature is the sharp drop and then recovering of yields for many countries beginning in the mid-1990s, these are Central and Eastern European countries undergoing market rationalization in which less efficient farmers and techniques were forced out of the market to the benefit of more efficient farming techniques [36]. How yields in these newer countries develop is really at the core of the matter, if their yields eventually reach the same levels as those in Western Europe, then wheat output can be significantly expanded without using more land. Finally, there appears to be greater variance or volatility in yields of many of the newer countries. Yields for high yield countries such as the Netherlands, Germany and France appear to be relatively immune to major fluctuations, while those countries with lower yields have experienced large fluctuations. Large fluctuations and short time series make forecasting difficult as will become apparent in later discussions. 


\subsubsection{Histogram world}

A histogram of changes in world wheat yields is presented as a point of contrast to European yield changes. In effect, the next two sections are meant to give an impression of historical yield increases. 3a and b show logged wheat yields in 1961 and 2010 for both world and European aggregations for countries with data in both 1961 and 2010. In both figures, the darker histogram represents yield data in 1961 and the lighter 2010, while the gray area in the middle represents the intersection of the two periods. Fig. 3a shows that the world's entire distribution has shifted to the right and the mean of the data has increased from 13,439 to 30,881 . However, in 2010 , there was still a group of countries with low yields including Venezuela, Honduras, Burundi, Libya and Ecuador. The average growth rate over the entire period was $1.7 \%$ and the standard deviation increased from 8940 in 1961 to 20,030 in 2010. Table 1 shows that developed countries continue to dominate the top yield positions. Most importantly for the current analysis, European countries are well represented in the list of the world's most productive wheat producers. This, along with the results in Fig. 2b, suggest that non-European countries might view European yields as a benchmark with the proviso that once the benchmark has been achieved, increases in yields slow.
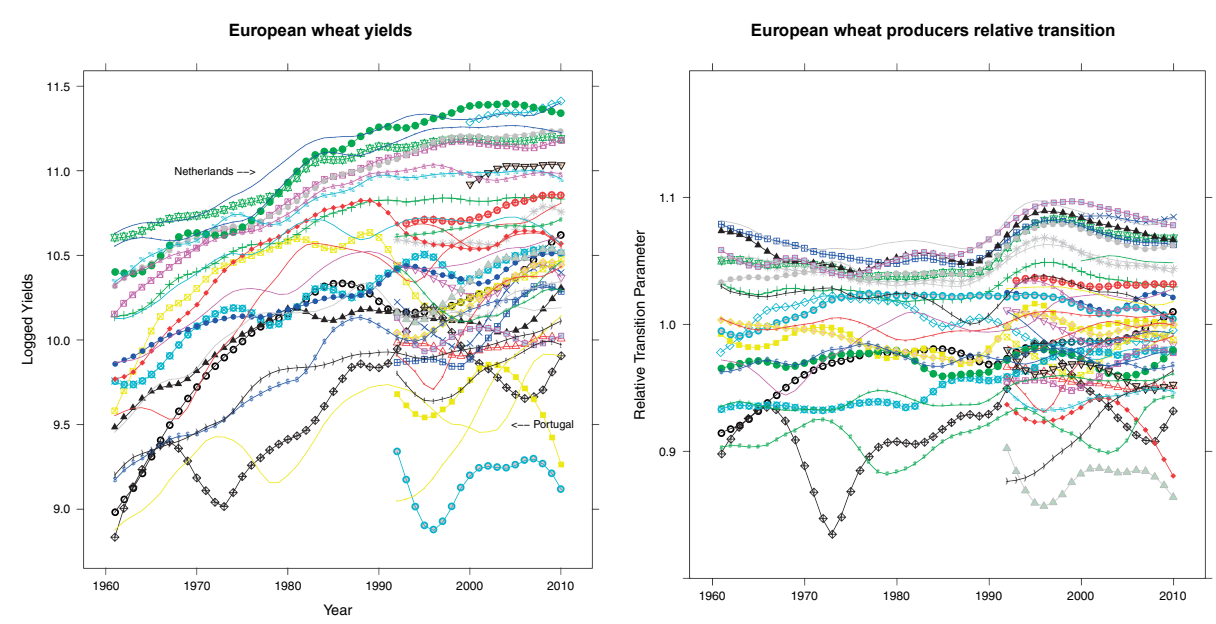

Fig 2. European wheat yields, European wheat producers relative transition 

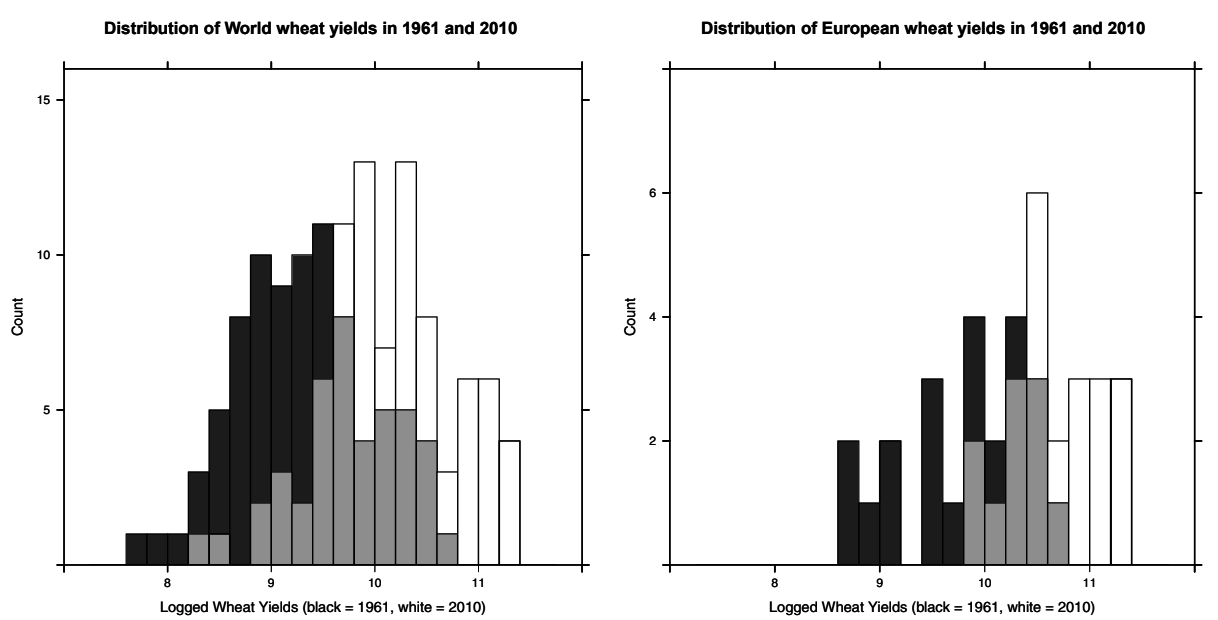

Fig. 3. Wheat yields. (a) World wheat yields and (b) European wheat yields.

Table 1. World top 20 wheat yields in 1961 and 2010.

\begin{tabular}{llll} 
Country $^{\text {a }}$ & Yield (1961) & Country & Yield (2010) \\
\hline DNK & 41,205 & NLD & 89,092 \\
\hline NLD & 39,251 & IRL & 85,990 \\
\hline GBR & 35,372 & NZL & 81,241 \\
\hline IRL & 33,676 & GBR & 76,810 \\
\hline NZL & 33,517 & DEU & 73,102 \\
\hline SWE & 32,627 & FRA & 70,415 \\
\hline DEU & 28,607 & DNK & 66,264 \\
\hline NOR & 28,300 & NAM & 65,789 \\
\hline JPN & 27,455 & SAU & 65,000 \\
\hline CHE & 27,134 & ZMB & 63,118 \\
\hline AUT & 25,802 & CHL & 57,658 \\
\hline NCL & 25,000 & CHE & 57,377 \\
\hline EGY & 24,697 & EGY & 55,741 \\
\hline FRA & 23,950 & MEX & 54,185 \\
\hline KOR & 22,657 & SWE & 54,029 \\
\hline POL & 19,929 & AUT & 50,117 \\
\hline FIN & 19,436 & MLT & 48,519 \\
\hline ITA & 19,103 & CHN & 47,485 \\
\hline HUN & 19,095 & NOR & 40,648 \\
\hline NGA & 17,778 & ALB & 39,905
\end{tabular}

a Complete list of ISO 3 country codes used in this paper: Albania (ALB), Armenia (ARM), Austria (AUT), Belarus (BLR), Belgium (BEL), Bulgaria (BGR), Chile (CHL), China (CHN), Croatia (HRV), Cyprus (CYP), Czech Republic (CZE), Denmark (DNK), Egypt (EGY), Estonia (EST), Finland (FIN), France (FRA), Georgia (GEO), Germany (DEU), Great Britain (GBR), Greece (GRC), Hungary (HUN), Ireland (IRE), Italy (ITA), Japan (JPN), Kazakhstan (KAZ), Korea (KOR), Kyrgyzstan (KGZ), Lithuania (LTU), Luxembourg (LUX), Macedonia (MKD), Malta (MLT), Namibia (NAM), Netherlands (NLD), New Caledonia (NCL), New Zealand (NZL), Nigeria (NGA), Norway (NOR), Poland (POL), Portugal (PRT), Romanian (ROU), Saudi Arabia (SAU), Slovakia (SVK), Slovenia (SVN), Spain (ESP), Sweden (SWE), Switzerland (CHE), Tajikistan (TJK), Turkey (TUR), Turkmenistan (TKM), Ukraine (UKR), Zambia (ZMB). 
Table 2. European wheat yields in 1961 and 2010.

\begin{tabular}{llll} 
Country & Yield (1961) & Country & Yield (2010) \\
\hline DNK & 41,205 & NLD & 89,092 \\
\hline NLD & 39,251 & IRL & 85,990 \\
\hline GBR & 35,372 & GBR & 76,810 \\
\hline IRL & 33,676 & DEU & 73,102 \\
\hline SWE & 32,627 & FRA & 70,415 \\
\hline DEU & 28,607 & DNK & 66,264 \\
\hline NOR & 28,300 & CHE & 57,377 \\
\hline CHE & 27,134 & SWE & 54,029 \\
\hline AUT & 25,802 & AUT & 50,117 \\
\hline FRA & 23,950 & MLT & 48,519 \\
\hline POL & 19,929 & NOR & 40,648 \\
\hline FIN & 19,436 & ALB & 39,905 \\
\hline ITA & 19,103 & POL & 39,432 \\
\hline HUN & 19,095 & HUN & 37,221 \\
\hline BGR & 15,416 & ITA & 36,997 \\
\hline MLT & 13,746 & BGR & 36,032 \\
\hline ROU & 13,438 & FIN & 34,299 \\
\hline GRC & GRC & 31,373 \\
\hline TUR & 13,026 & ESP & 29,417 \\
\hline ESP & 9093 & ROU & 27,000 \\
\hline ALB & 8837 & TUR & 24,411 \\
\hline PRT & 7731 & CYP & 19,956 \\
\hline CYP & 6515 & PRT & 18,493 \\
\hline & 5793 & & \\
\hline & & & \\
\hline
\end{tabular}

\subsubsection{Histogram Europe}

Data for Fig. 3b was constructed using only those European countries for which data was available in 1961 and 2010. As a result, there are 23 countries represented in the figure. The mean in 1961 was 21,178 and 47,256 in 2010, both are around one-and-a-half times greater than their world average equivalents. The average growth rate over the entire period was $1.6 \%$ compared to a world average of 1.7. The data for 2010 appears to be less widely distributed, but this is due to the log scale, in fact, the standard deviation has increased from 10,757 in 1961 to 20,869 in 2010. In 1961, Denmark, the country with the highest country with the lowest yield. While in 2010, the Netherlands, the country with the highest yield in that year, had a yield of 89,092 compared to Portugal with a yield of 18,493 . The significance of which is that in 1961 the highest yield was 7.11 times greater than the lowest yield, while that number was 4.81 in 2010. Great deviations in yields, even among the 23 established European countries, persist, but differences between top and bottom producers appear to be diminishing. This topic will be revisited below using two models of convergence. Table 2 confirms the observation that countries with top yields tend to stay on top. Denmark, the Netherlands, the United Kingdom and Ireland have the top spots in both years; while Cyprus, Portugal, Spain and Turkey occupy the bottom of 
the table in both years. The relative positions remain fairly stable, suggesting that general technological improvements affect country yields more or less equally. The histograms show that yields in Europe are high relative to the rest of the world, but the decreasing rate of European increases suggests that there are limits to the rate at which yields can economically increase. However, they also suggest that there are potential increases available both globally and within Europe. The next section asks if there is any evidence that European yields are converging to common levels. In short, we can presume from the figures that increases in yields are possible, but is there any evidence that those potential increases can be realized?

\subsubsection{Growth rates}

Table 3 provides a breakdown of yield growth rates for 5, 10-year periods for several aggregations. The table is meant to show how yield growth rates vary among regions and across time. The methodology used to construct the table was, for each aggregation, to split the data by decade and calculate the corresponding average. Percentage increases were then calculated using the standard methodology. Again, only countries with complete data sets were used in the study.

Yield growth rates appear consistently strong for the first three decades in each aggregation. Values range from around $1.5 \%$ to over $3 \%$ over these three decades. The difference between 1.5 and 3.0 is enormous; a growth rate of 1.5 implies a doubling of yields every 47 years while a rate of 3.0 implies a doubling every 23 years. All regions experienced slower growth in the 1991-2000 decade. While the yields of major wheat producers (second column) continued to top the other aggregations at a rate of $1.3 \%$, that rate was well below the average for the same aggregation in the previous three decades. The contraction in yield rates for European countries with low yields can be seen in the obvious dip that occurs in this period, see Figs. 2a and b. However, yields in all regions were relatively anemic in that decade. The last decade in the analysis, 2001-2010, saw a slight recovery in the growth of yields for the world, the OECD, and Europe as a whole, where Europe's growth was primarily due to the recovery of the yields of countries in the lower half of the European yield table. Europe's top wheat producing countries are at the bottom of the table with a growth rate of just $0.32 \%$, corresponding to a doubling of yields every 217 years!

\subsection{Convergence and relative transition}

Previous sections have given an overview of yield changes across various aggregations. In this section the focus is on whether the yields of individual countries are converging; in other words, whether yields are approaching some common rate. If the countries in Europe are approaching a common rate, then we can conclude that, all else equal, the yields of Central and Eastern European countries will eventually reach Western European 
rates. Two types of convergence are discussed. The underlying assumption of first type, known as log $t$ convergence, is that if there is a common source of sustained yield increase, then with the diffusion of technology and learning across countries, learning through formal education, and on the job learning, it can reasonably be supposed that all countries ultimately come to share in the growth of yields [35]. Note that log $t$ does not test whether countries are approaching a common, absolute, yield level, only whether countries share a common rate of increase. In contrast, the second type of convergence, absolute convergence, tests whether countries are approaching a common yield level.

\subsubsection{Transition coefficients}

The first step towards understanding the concept of log $t$ is the calculation of the relative transition coefficient. The basic concept behind the procedure to calculate log $t$ is to eliminate the common growth component among countries in the analysis by scaling the data $[38,39]$. The transformation eases comparison of the relative changes in yields across countries. Changes in yields for each country are then measured relative to the average growth rate of the entire cross-section. This simple comparative method allows a wide range of time paths and heterogeneity to be modeled while maintaining the commonality of the panel. Furthermore, it allows convergence to be analyzed over different time periods and over different geographic areas. In our specific case, the transition path is measured by considering the relative share of wheat yields of country $i$ in total wheat yields in a specific year, where log $y t$ denotes the cross-section average of yields in the entire panel or a subset thereof (see Eq. (1)). The quantity $h_{i t}$ eliminates the common growth component and provides a measure of each country's share in common growth and technological progress. Because $h_{i t}$ is time dependent, it describes how a country's share evolves over time. In effect, $h_{i t}$ is a time parameter that traces a transition curve for a country, indicating that country's share of total yields in period t:

$h_{i t}=\log y_{i, t} \overline{\log y_{t}}$

\subsubsection{Transition figures}

Fig. 2a, at the beginning of the paper, traces individual European country trajectories relative to their cross-section average. The data has once again been filtered using the WHP method to reduce short-term fluctuations and then logged for convenience. If there was convergence, then the figure would have a funnel-like shape with the stem of the funnel on the right hand side of the figure (see [38,39] for an example). However, in Fig. 2a the spread remains relatively stable. In short, there is no visual evidence of either convergence or divergence for yields across Europe.

Fig. $4 \mathrm{a}$ and $\mathrm{b}$ shows transition paths for yields of the top world and European wheat producers. In Fig. 4a Germany and France lead the pack, far outpacing other world wheat 
producers. In addition to the initial drop and subsequent recovery of yields as seen in the European figure as well, the outstanding feature in Fig. 4a is the steady progression of China to the extent that it has moved onto a higher trajectory surpassing major producers such as the United States, Canada and Pakistan. It is also possible to discern what appears to be convergence among countries other than China, Germany and France. For instance, the spread between the US, Canada, Turkey, Pakistan, Iran, and perhaps Ukraine and the Russian Federation appears to be less in 2010 than it was in 1960, an indication of convergence. Australia fell out of the group in the late 1990s, but may be bouncing back in recent years so perhaps it will rejoin the others. Fig. $4 \mathrm{~b}$ shows what again appears to be a remarkable degree of convergence among top European producers. Germany and France joined with the United Kingdom and Denmark to form a tightly knit group, while Spain joined Italy, Poland and Romania to form another group. Trends among the newer members of the top European producers vary, Uzbekistan has seen remarkable increases in yields relative to the others, while yields in the Czech Republic, Ukraine and the Russian Federation have stabilized since early 2000.

The essential conclusion of these figures is that with few exceptions, there is little visual evidence that the yields of wheat producing countries in Europe or the rest of the world are converging to one common growth rate. No evidence, in short, that the yields of Central and Eastern European countries will converge to a common source of sustained yield increase. The log $t$ regression test provides a more systematic test of these findings.

Table 3. Yield growth rates in five periods.

\begin{tabular}{llllllll} 
Period & $\begin{array}{l}\text { World } \\
(\mathbf{8 5})\end{array}$ & $\begin{array}{l}\text { Major } \\
\text { world } \\
\text { producers } \\
\mathbf{( 1 0 )}\end{array}$ & $\begin{array}{l}\text { OECD } \\
\mathbf{( 2 6 )}\end{array}$ & $\begin{array}{l}\text { Europe } \\
\mathbf{( 2 3 )}\end{array}$ & $\begin{array}{l}\text { Top Europe } \\
\mathbf{( 1 7 )}\end{array}$ & $\begin{array}{l}\text { Bottom } \\
\text { Europe (6) }\end{array}$ & $\begin{array}{l}\text { Europe's } \\
\text { top } \\
\text { producers } \\
(\mathbf{8})\end{array}$ \\
\hline $1961-1970$ & 1.70 & 3.41 & 1.71 & 2.08 & 1.83 & 3.20 & 1.91 \\
\hline $1971-1980$ & 1.83 & 1.45 & 1.54 & 1.91 & 1.74 & 2.50 & 1.53 \\
\hline $1981-1990$ & 2.12 & 2.33 & 2.28 & 2.18 & 2.25 & 1.93 & 2.57 \\
\hline $1991-2000$ & 0.36 & 1.30 & 0.39 & 0.17 & 0.47 & 1.20 & 0.40 \\
\hline $2001-2010$ & 0.87 & 0.80 & 0.48 & 0.50 & 0.42 & 0.84 & 0.32 \\
\hline
\end{tabular}

Note: The numbers in brackets are the number of observations, only those countries with complete datasets over the entire period are included in the analysis. Top producing countries are distinguished from countries with high yields. Top and bottom Europe are those countries in the top half and lower half of an ordered European yield table. 

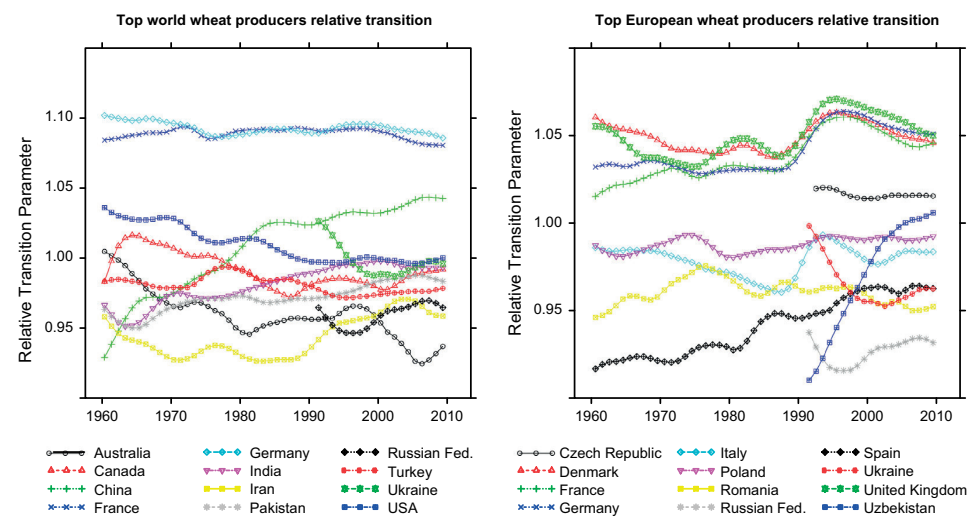

Fig. 4. Wheat yields. (a) Yields of major world wheat producers and (b) yields of major European wheat producers.

\subsubsection{Log tregression test}

The corresponding regression test of convergence is called the log $t$ test because it is based on a time series linear regression of a cross section variance ratio of the transition parameter on log $t$ (time). Simply put, the test asks whether sample countries are converging to a common source of sustained yield increase.

Formally, the 'log $t$ ' regression model is defined as

$\left(\log H_{1} / H_{t}\right)-2 \log (\log t)=\alpha+\gamma \log t+u_{t} \quad$ for $t=T_{0}, \ldots, T$

where $H_{t}=N^{-1} \sum_{i=1}^{N}\left(h_{i t}-1\right)^{2}$ and $h_{i t}=\log y_{i t} / N^{-1} \sum_{i=1}^{N} \log y_{i t}$ as before.

The convergence test for top world wheat producers from 1961 to 2010 gives a point estimate of 0.74 with a standard error of 0.19 , where standard errors are calculated using an automated heteroskedasticity autocorrelation consistent (HAC) procedure, and is therefore highly significant. A significant negative number such as this implies divergence of yields. In other words, there is a strong statistical evidence that yield rates among the top world producers are diverging from one another. Similarly, tests of top European wheat producers return an estimate of 0.90 and a standard error of 0.27 . For all European wheat producers the estimate is 0.84 with a standard error of 0.15 . In both cases then, despite hints to the contrary in the figures, there is a strong evidence of divergence among these countries. Results for subsets consisting of only, for instance, Denmark, the United Kingdom, Germany and France were not significant. The results confirm the impression that there is no evidence of a convergence of yield rates within Europe, a result which implies that yield rates will vary across Europe. 


\subsubsection{Absolute convergence}

Absolute convergence is the more obvious type of convergence, it tells us whether yields are converging towards a common level [7]. Fig. 5a and b illustrates this type of convergence. The figures show growth rates versus initial yield levels. There are 85 countries represented in the world figure and 23 in the European figure. The working hypothesis is that countries with lower initial yield rates will increase their yields at a faster rate than countries with higher initial rates. The reasoning behind absolute convergence is that countries with lower initial rates will be readily able to adapt and implement extant technologies. The hypothesis is supported by the data, Fig. 5a shows a downward trend which is statistically significant. In other words, lower initial yield rates are correlated with higher growth rates over the period 1961-2010. Data for Europe also show a highly significant negative trend. The importance of this finding for the current study is that we can expect, on average, that new European countries with lower initial yields will increase their yields at higher rates than established European countries. In short, although there is not a common yield rate among countries, we can expect, on an average, that countries with lower yields will catch up to world and European averages.

\subsection{Real per person GDP}

Results of previous sections have been mixed. We have seen that, on an average, European yield growth rates have slowed over the last decades, but that they continue to increase. Although we have to reject a common source of convergence among European countries, we can expect, on an average, that countries with lower yields will increase their yields at a faster rate than countries with higher yields. In this section we begin the process of developing a model to forecast yields. The argument, as outlined in Section 2.1.2, is that as Central and Eastern European countries develop economically, driven by increases in increases in the productivity of capital, labor and land, so will their yields. Yields, after all, are a measure of partial productivity, namely, the productivity of land. Land is only one input in the agricultural production process, labor is of course another important input. At this point we may be accused of including an endogenous variable on the right hand side of the equation since GDP per person is driven in part by yields. However, agricultural production, as has just been argued, is only partially driven by yields, and given that agricultural production makes up only a small percentage of GDP for European countries, we argue that yields have only a small impact on the real GDP per person of most European countries [9]. For instance, the agricultural sector represents only $1.8 \%$ of the GDP of countries in the European Union, although it constitutes a larger percent of Eastern European countries such as Kazakhstan (5.2\%), Turkmenistan (7.6\%), and Macedonia (9.6\%), and especially Uzbekistan (18.5\%), Kyrgyzstan (20.2\%) and Tajikistan (23.3\%). However, if the general argument is accepted for the 43 countries in the following analyses, then it follows that real GDP per person can be used as an exogenous variable to explain yields. 
a

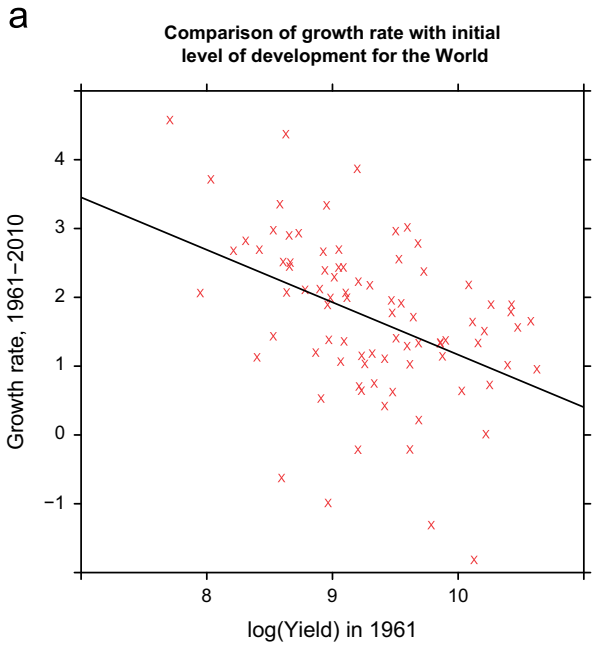

b

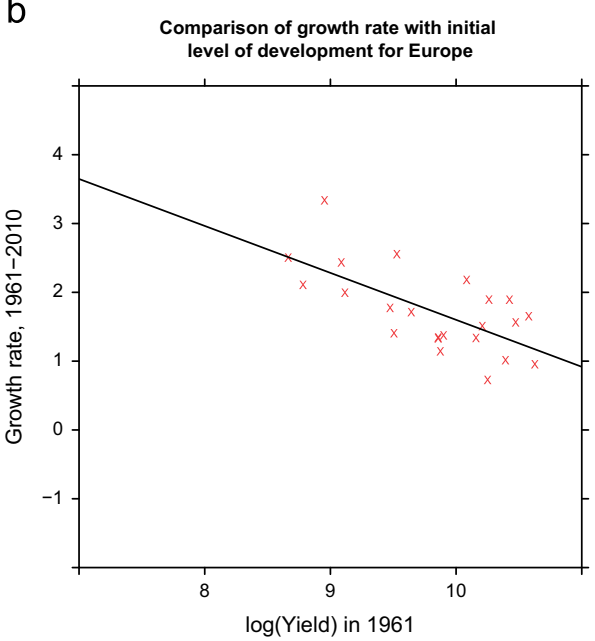

Fig. 5. Yield convergence. (a) Convergence world and, (b) Convergence Europe

\subsubsection{LOESS regression}

In the following sections we begin to examine the relationship between yields and real GDP per person. Locally weighted or LOESS regressions are a method of regression which use a smoothing procedure to average independent variables in a moving fashion [1012]. Rather than giving all points equal weight in determining the shape of the fitted line as with linear regression, the weights of points close in time receive greater weight than points further away. In a sense, the figures give insight into local relationships within a wider time frame. Fig. $6 a$ and $b$ plot logged yields against logged real GDP per person. The data set consists of 64 countries for which there is yield and GDP data for years common to the two data sets in the period from 1961 to 2009. The data for each country is then split across six periods. In other words, there are 64 country observations for 1961, 64 for 1971 , and so on.

The striking feature of Fig. 6 is that the relationship between yields and GDP is flat until logged GDP per person reaches a level of between around 3000 and 8000 dollars per person, after which yields rise steadily with the GDP variable. The implications for the current study are that steady yield increases can be expected for countries which reach that threshold. Fig. $6 \mathrm{~b}$ implies an even more striking relationship between yields and GDP. The data is split as in the previous analysis and consists of 17 European countries. The European case appears to be similar to the world case, yields seem fairly stable in relation to real GDP per person and then rise after a GDP threshold is met. However, after a given GDP level is reached, yields fall again. The figure confirms that yields for each decade have increased, although the increase from 2001 to 2009 is small as previously observed in Fig. 4b. Furthermore, it is also possible to see increases in real GDP per person over the 
decades as the curves shift to the right. In most years, for a given real GDP per person, yields have increased. However, those European countries with the highest yields continue to achieve higher yields and GDP in every decade, but higher yields across that group are negatively correlated with GDP in any given decade. The odd relationship pictured is almost entirely due to Switzerland and Norway, both of whom have high real per person GDPs and high yields, but their very high GDP in a sense 'outweighs' their high yields. Removing these two countries reestablishes the positive correlation between yields and GDP. The implication is that there are countries with characteristics which exclude them from the general correlation relationship, data for these exceptional countries should be considered for removal or modification from econometric analyses intended to detect common relationships between yields and GDP. As a consequence, the econometric models to follow were run both with and without Switzerland and Norway included in the models. However, removing either or both countries did not significantly alter the statistical significance of the basic underlying relationships.
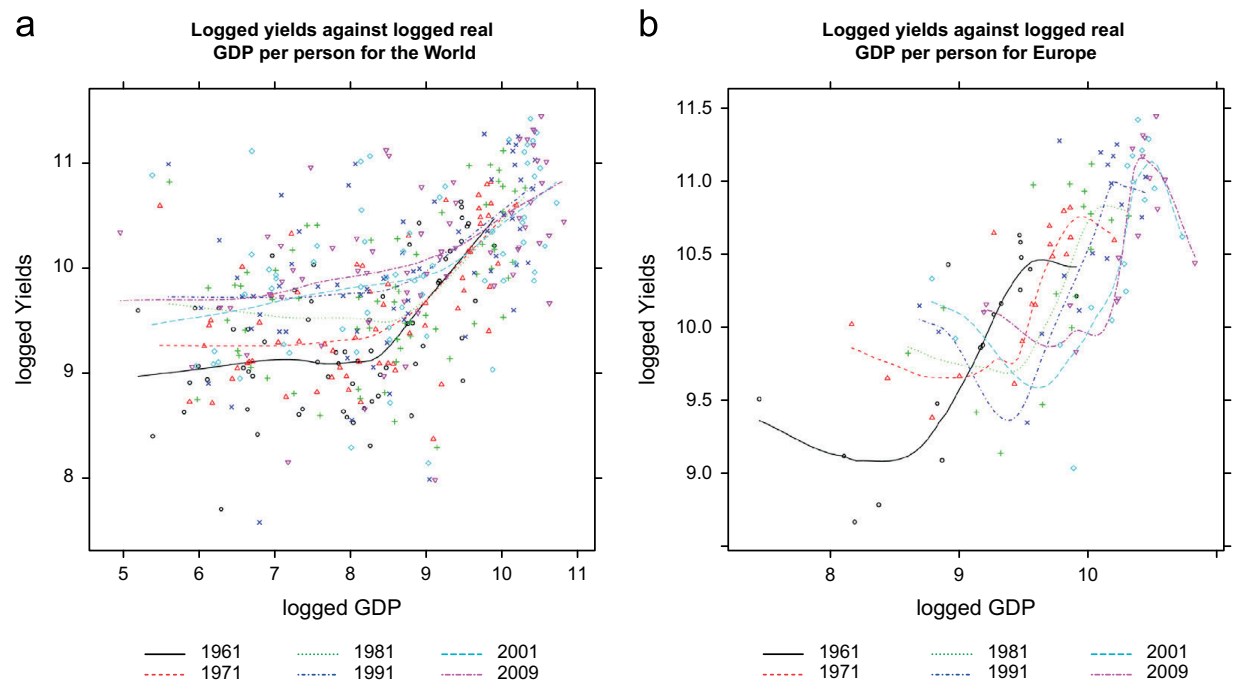

Fig. 6. Wheat YieldsversusGDP.(a)WorldyieldsversusGDPand(b)EuropeanyieldversusGDP. Figures 6 and 7

\subsubsection{GDP transition}

Fig. 7a and $b$ is important for further establishing and reinforcing the apparent relationship between yields and GDP. Fig. 7a shows the relative transition of real GDP per person for all European countries in the study. Once again, there is significant statistical support for divergence among these economies due to the large divergence that occurred in the 1990s as Central and Eastern European economies joined Europe. Just as for yields, the convergence tests for the PWT data show strong evidence of divergence with an estimate 
of 1.27 and a HAC standard error of 0.27 . Subsets of the data, for instance using only data for countries with 60 years or more of data, also show divergence. There does not appear to be a common source of European economic GDP per person growth, and it is therefore difficult to presume that all European countries will ultimately come to share in equal economic development rates. However, the strong correlation between yields and real GDP per person implies a causal relationship in the sense that increases in real GDP are highly correlated with positive changes in yields - a relationship explored in greater detail below. Incidentally, the divergence of Europe's real GDP per person result contrasts sharply with results reported by Sul and Phillips for US states [39]. There does not appear to be a common source of sustained real GDP per person growth in Europe as there is across US states.

a

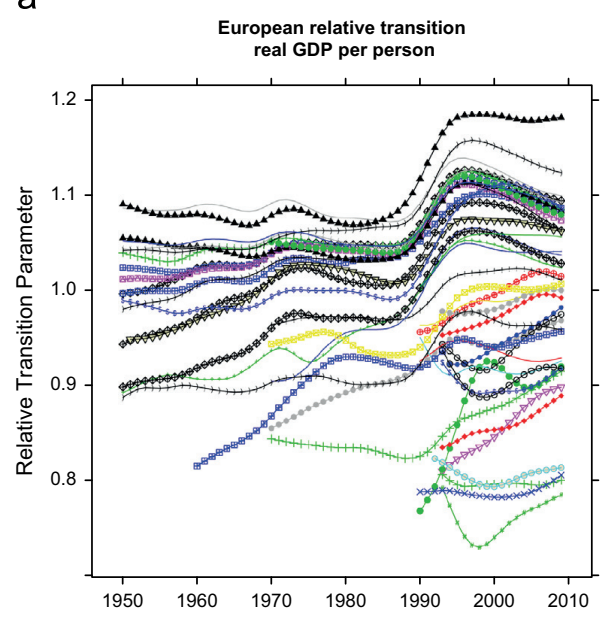

b

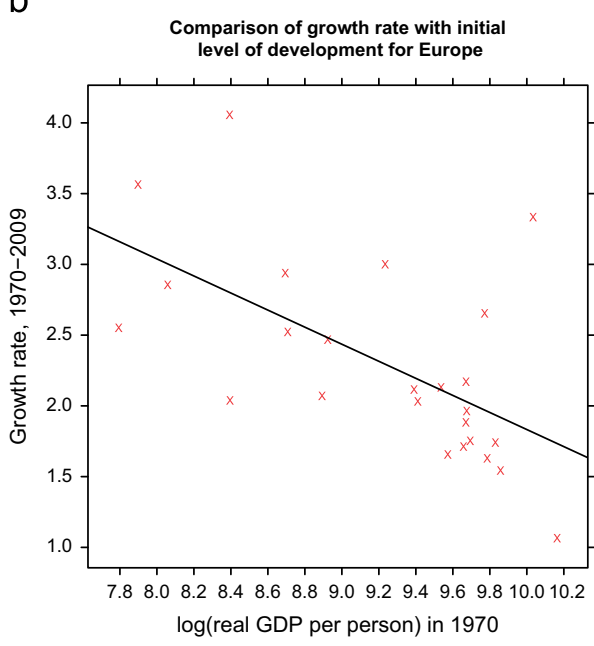

Fig. 7. European convergence of real GDP per person. (a) Real GDP per person European transition parameters and (b) real GDP per person convergence Europe.

\subsubsection{GDP absolute convergence}

Fig. $7 \mathrm{~b}$ illustrates the idea of absolute economic convergence for 25 European countries for the period from 1970 to 2009 . Along the $x$-axis is logged real GDP per person for each country in 1970. Along the $y$-axis is the average growth rate for each country in the study over the entire period. Just as with yields, there appears to be absolute convergence in Europe in that countries with lower initial levels of real GDP per person, on an average, have higher growth rates than countries with higher initial GDP per person levels. Fig. 8 shows the distribution of real GDP per person for 43 countries in Europe. If the argument made in relationship to Fig. $6 a$ and $b$ is accepted, then the countries at the bottom of the distribution such as Tajikistan, Kyrgyzstan, Georgia, Armenia, and Ukraine can expect, on an average, large increases in yields as their economies grow beyond the log GDP per 
person 'activation' rate. While the yields of more established counties will continue to grow at rates similar to those they have experienced in the recent past.

\subsection{Econometric model}

In previous sections we have examined yield and real GDP per person developments through time and sought relationships between those two variables. In this section we use econometric models to attempt to quantify the influence of real GDP per person on yields. If that relationship is statistically significant, it can then be used to forecast future yields. The data used in the analysis has a panel format, meaning that it is composed of sets of countries observed over consecutive years. The panels used in the study were complete in that data was available for all countries in all periods. The panel structure allows economic effects that cannot be distinguished with the use of either cross-section or time series data alone to be identified, in short, it allows patterns across time and observations to be discerned and untangled $[5,40,56]$.

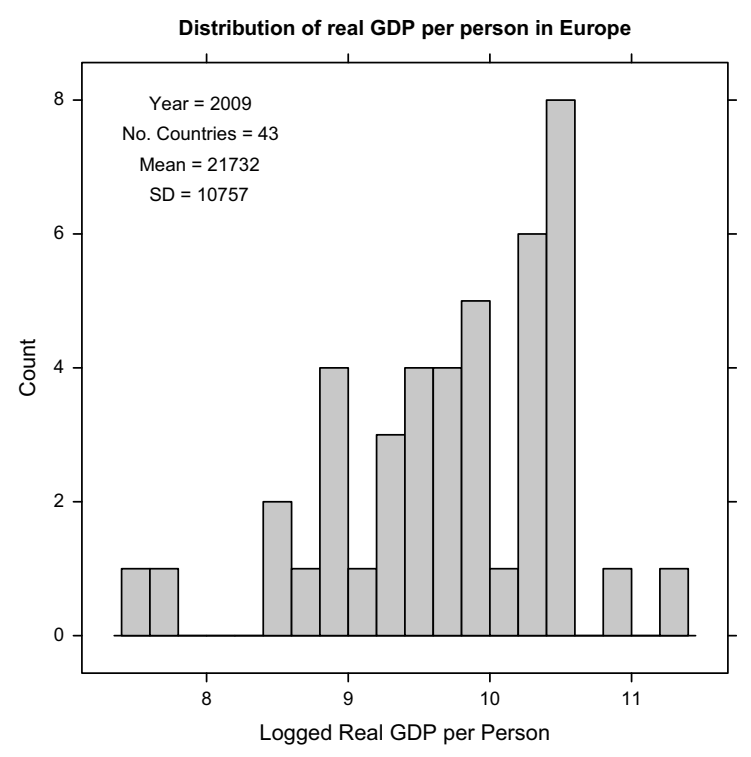

Fig. 8. Real GDP per person, Europe.

Panel data is commonly used to estimate dynamic econometric models because of its many advantages over other forms of data [8]. For example, even in cases when the coefficient on the lagged dependent variable is not of direct interest, including that it may be crucial for recovering consistent estimates of the exogenous variables. Improvements in agricultural yields are a dynamic process, and one of the advantages of panel data is that it allows insight into the dynamics of adjustment, in other words, it shows how yields have changed through time. Finally, at a practical level, the use of stochastic dynamic models 
is an appropriate econometric technique for the case at hand given the small number of years and the large number of countries available in the study. These estimation methods do not require the time dimension to become large in order to obtain consistent estimates. This advantage allows us to make estimates despite the small number of observations available for Central and Eastern Europe.

\subsubsection{Dynamic panel model}

This section outlines the rationale underlying our choice of which dynamic panel model to use. Only the essential features of the chosen model are described, the interested reader is directed to accompanying references for details. Dynamic relationships are characterized by the introduction of a lagged dependent variable among the regressors, i.e.:

$y_{i t}=\alpha y_{i, t-1}+x^{\prime}{ }_{i t} \beta+\left(\eta_{i}+v_{i t}\right), \quad|\alpha|<1, \quad i=1,2, \ldots, N, \quad t=2,3 \ldots T$

where, in the case at hand, $y_{i, t}$ is the yield for country $i$ in year $t$, and $y_{i, t-1}$ is a yield observation for the same country in the previous year, $\eta_{i}$ is an unobserved country specific time invariant effect that allows for heterogeneity in the means of the $y_{i t}$ series across individuals, and $v_{i t}$ is a disturbance term. Individual effects $\eta_{i}$ are treated as stochastic, which implies that they are necessarily correlated with the lagged dependent variable $y_{i, t-1}$ unless the distribution of the $\eta_{i}$ is degenerate. The disturbances $v_{i t}$ are initially assumed to be serially uncorrelated. These assumptions jointly imply that the Ordinary Least Squares (OLS) estimator of $\alpha$ in Eq. (4) is inconsistent since the explanatory variable $y_{i, t-1}$ is positively correlated with the error term $\eta_{i}+v_{i t}$ due to the presence of individual effects (see [8] for details).

In short, the presence of the $y_{i, t-1}$ term on the right hand side of the equation means that there is an endogeneity problem, in essence, we are trying to explain yield changes with a highly correlated version of the same variable! The techniques outlined below are simply a means to overcome the endogeneity issue. The basic first differenced Two Stage Least Squares (2SLS) estimator for the $A R 1$ panel model was proposed by Anderson and Hsiao $[1,2]$ to address the problem. The data is first differenced in order to remove $\eta_{i}$ from the error term and any other time invariant characteristics of the data [8]:

$\Delta y_{i t}=\alpha \Delta y_{i, t-1}+\beta^{\prime} \Delta x_{i t}+\Delta v_{i t}, \quad|\alpha|<1, \quad i=1,2, \ldots, N, \quad t=2,3 \ldots T$

where $\Delta y_{i t}=y_{i t}-y_{i, t-1}$. The dependence of $\Delta v_{i t}$ on $v_{i, t-1}$ implies that OLS estimates of $\alpha$ in the first differenced model are inconsistent. However, consistent estimates of $\alpha$ can be obtained using 2 SLS with instrumental variables that are both correlated with with $\Delta y_{i t-1}$ 
and orthogonal to $\Delta \mathrm{v}_{i, t^{*}}$ The resulting 2SLS estimator is consistent in large N, fixed T panels, and identifies the autoregressive parameter a provided that at least three time series observations are available [8]. Additional instruments are available when the panel has more than three time series observations. Hansen [24] provides a convenient framework for obtaining asymptotically efficient estimators when T>3, while first-differenced GMM estimators for the AR(1) panel model were developed by Holtz-Eain et al. [31] and Arellano and Bond [3].

Rather than the level values, lagged values of $y$ can be used. In this way the endogeneity issue is addressed by noting that all values of $y_{i, t-k^{\prime}}$ with $k>1$ can be used as instruments for $\Delta y_{i, t-k}$. In the language of general method of moments (GMM), an orthogonality condition. In turn, auto-correlation is addressed by noting that if $\Delta v_{i t}$ is white noise, then the covariance matrix of the vector whose typical element is $\Delta \mathrm{v}_{i t}$ is proportional to matrix $\mathrm{Hthat}$ has 2 on the main diagonal, 1 on the first sub-diagonals, and 0 elsewhere.

In practice, the one-step GMM estimation of equation amounts to computing

$$
\hat{\gamma}=\left[\left(\sum_{i=1}^{N} W^{\prime}{ }_{i} Z_{i}\right)\left(\sum_{i=1}^{N} Z^{\prime}{ }_{i} H Z_{i}\right)^{-1}\left(\sum_{i=1}^{N} Z^{\prime}{ }_{i} W_{i}\right)\right]^{-1} \times\left(\sum_{i=1}^{N} W^{\prime}{ }_{i} Z_{i}\right)\left(\sum_{i=1}^{N} Z^{\prime}{ }_{i} H Z_{i}\right)^{-1}\left(\sum_{i=1}^{N} Z^{\prime}{ }_{i} \Delta y_{i}\right)
$$

where

$$
\Delta y_{i}=\left[\Delta y_{i 3} \cdots \Delta y_{i T}\right]^{\prime}
$$

and $Z_{i}$ is defined as in [5]. In essence, the additional differenced exogenous variables are available as instruments. Once the one step estimator is computed, the sample covariance matrix of the estimated residuals can be used instead of $H$ to obtain two step estimates which are both consistent and asymptotically efficient. Standard GMM theory applies, except that Windmeijer [54] has computed finite sample corrections to the asymptotic covariance matrix of the parameters.

\subsubsection{Panel results}

The results in Table 4 are calculated using the one and two step Arellano Bover version of the GMM model [5] described above. Three aggregations are shown in the table, Europe as a whole, and the partition of that data into rich and poor Europe. Rich and poor sets were obtained by ordering all European countries by real GDP per person and then splitting the result into two more or less equal groups. The Europe data consists of 43 countries, with rich and poor consisting of 22 and 21 countries respectively. Results confirm the story presented so far. In both models and in all aggregations estimates on lagged yields are significant at the $5 \%$ level. This confirms the observation in Fig. $2 \mathrm{~b}$ that, on an average and after accounting for the effects of real GDP per person, increases in yields are declining 
for rich Europe. Additionally, and perhaps surprisingly, results also suggest that yields in Central and Eastern Europe are declining at approximately the same amount.

Results for the effects of changes in real GDP per person are mixed across the different aggregations. For rich Europe, increases in real GDP per person are positive but insignificant, meaning that no statistical relationship can be drawn between the two variables at generally accepted levels of significance. This result confirms what can be observed in Fig. 6b, recalling that data used in the regressions only runs from 2001 to 2009. The richer countries are at the relatively flat section of the relationship near the top of the figures. In contrast to rich Europe, for poor Europe there is a significant positive relationship between increases in real GDP per person and yields. This too can be observed in Fig. 6b, where the generally poorer Central and Eastern European countries are at the beginning of the positive effects of GDP on yields. Each one U.S. Dollar increase in real GDP per person leads to an increase of $2.03 \mathrm{hg}$ of wheat produced per hectare (or 0.203 $\mathrm{kg}$ per hectare). The European aggregation as a whole appears to be primarily driven by the relationship in poorer Europe. Observations in those countries mean that higher real GDP per country for European countries taken as a whole are positive and significant, although, unsurprisingly, the effect of an increase in GDP is smaller for Europe (0.611) then it is for exclusively poor countries. The implication for the analysis in its entirety is that real GDP per person can be used as a positive predictor of future yields for poor European countries and as a roughly positive indicator for the entire European aggregation.

\subsection{Forecasting}

\subsubsection{Time series forecasting}

Previous sections have used historical data to define relationships between yields, lagged yields, and real GDP per person. We now turn to the issue of forecasting yields based on those historical relationships.

Table 4. Dynamic estimates of European wheat yield data for 2001-2009.

\begin{tabular}{l|ll|ll|ll} 
Model & \multicolumn{2}{l}{ Europe } & \multicolumn{3}{l}{ Rich Europe } & \multicolumn{2}{l}{ Poor Europe } \\
\hline & Estimate & $\begin{array}{l}\text { Std. } \\
\text { error }\end{array}$ & Estimate & $\begin{array}{l}\text { Std. } \\
\text { error }\end{array}$ & Estimate & Std. error \\
\hline Arellano-Bover & & & & & & \\
\hline Yield & -0.1426 & $0.0596^{*}$ & -0.1685 & $0.0847^{*}$ & -0.1892 & $0.0763^{*}$ \\
\hline GDP per person & 0.6516 & $0.2926^{*}$ & 0.2167 & 0.1909 & 2.0653 & $0.3809^{* *}$ \\
\hline & & & & & & \\
\hline Dynamic two-stage & & & & & & \\
\hline Yield & -0.1654 & $0.0673^{*}$ & -0.1680 & $0.0855^{*}$ & -0.1837 & $0.0789^{*}$ \\
\hline GDP per person & 0.6112 & $0.3006^{*}$ & 0.1897 & 0.1810 & 2.0310 & $0.4141^{* *}$ \\
\hline
\end{tabular}

Note: Estimators for wheat yields across several aggregations.

* Significance at the $5 \%$ level.

${ }^{* *}$ Significance at the $1 \%$ level. 
Forecasting yields for individual countries, as opposed to aggregations of countries, is a straightforward process using standard time series techniques. Given that the data that we are using is reported on a yearly basis, there is no need to correct forecasts for seasonality, although there is clearly a trend which recommends against simple exponential smoothing. As in the aggregate European, poor, and rich country models described directly above (see Eq. (3), the model used to forecast individual country yields is based on an autoregressive model (a lagged value of yields is included on the right hand side of the equation) and includes real GDP per person. Standard tests confirm the use of an $A R(1)$ specification. The technique used to forecast yields was to use historical relationships to formulate a model and then project that relationship into the future. In general, the further one forecasts into the future, the less one is sure that the relationship holds. The amount of uncertainty is generally measured by the standard error of the residuals which is calculated in the following equation:

$$
s_{e}=\sqrt{1+\frac{1}{N-2}+\sum_{i=1}^{N} e_{i}^{2}}
$$

A forecast interval indicates uncertainty through time. It is calculated using the following equation:

$$
\hat{y} \pm 1.96 s_{e} \sqrt{1+\frac{1}{N}+\frac{(x-\bar{x})^{2}}{(N-1) s_{x}^{2}}}
$$

where $N$ is the total number of observations, $x$ is the mean of the observed $x$ values, $s_{x}$ is the standard deviation of the observed $x$ values and $s_{e}$ is calculated as in Eq. (7).

For those countries in the sample with a complete data set, $N$ is equal to 50. However, for newer countries, data is generally only available from the 1990 s onwards. Some other exceptions include Germany, for which PWT data begins in 1970, and Belgium for which the FAO began keeping separate records only in 2000. For Central and Eastern European countries in particular, large variations in yields in the initial decade of their independence make time series forecasting problematic. The large standard error of the residuals, see Eq. (7), means that forecast intervals (8) are at times too broad to make meaningful forecasts far into the future. For this reason, we kept the forecast period to a relatively short 10 year period. Fig. 9 shows time series forecasts for Germany and Poland. The large gray areas represent the amount of uncertainty associated with the forecasts. For Germany the standard error is, relative to that of Poland, small, so that the size of the gray area remains fairly stable though time, while that of Poland increases to reflect the increase in uncertainty through time. 
Table 5 contains forecasts for each country within Europe using the methodology described above. An $80 \%$ interval is presented in the table meaning, loosely, that we can be $80 \%$ confident that the true yield value will lie within the interval. The $80 \%$ interval can be constructed by simply replacing 1.96 with 1.282 in Eq. (8). The values in Table 5 are used to calculate the likelihood that yields will reach a particular level in the future from which a rate can then be calculated. The first column in the table is realized yields in 2009; the second contains the predicted mean in 2020 . The smallest and greatest $80 \%$ columns in the tables are the smallest and greatest yields that can be expected within the $80 \%$ interval. The last three columns of the table show how much yields, in percentage terms, would have to improve yearly in order to achieve the mean, smallest and greatest levels of the interval in 2020 using the starting, realized, values in 2009. The negative numbers in the last column for Belgium, Bosnia and Herzegovina, and Kyrgyzstan are a result of the high standard errors for these countries which make forecasting values for those countries dubious. For the remaining countries in that column, the values range from less than $1 \%$ for Luxembourg to over 7\% for Georgia.

Given the average of around $2.79 \%$ for countries with nonnegative values is at the upper end of the historical values as shown in Table 3, the implication is that a such a large increase over a sustained period is optimistic for the group as a whole, but possible. The large increases required of countries such as Belarus, Turkmenistan, Bulgaria and Georgia would imply particularly impressive, sustained, yield increases.

\subsubsection{Panel forecasting using the best linear unbiased predictor}

As shown above, the large standard errors caused by the small number of observations for some countries in the data set make time series forecasting for those countries difficult. Fortunately, panel forecasting methods allow forecasts to be estimated for the individual members of a panel data set (see [5] for complete argument). The advantage of this approach is that a panel data set can be used to estimate a single, general, model based on a relatively small number of observations and the results can then be applied to the disaggregated members of the set. The disadvantage is that a panel model estimates one model for all countries. Therefore, if there is a great deal of heterogeneity within the data, in the sense that underlying relationships vary greatly across countries, then a panel model will be less appropriate.

The methodology used to forecast panel models is intuitive. Suppose that we want to predict $S$ periods ahead for the $i$ th individual of a panel. For the generalized least squares (GLS) model, when the variance-covariance structure of the disturbances is known, Goldberger [43] showed that the best linear unbiased predictor (BLUP) of $y_{i} T+S$ is

$$
\hat{y}_{i, T+S}=Z_{i, T+S}^{\prime} \hat{\delta}_{G L S}+w^{\prime} \Omega^{-1} \hat{u}_{G L S} \text { for } s \geq 1
$$


where $\hat{u}_{G L S}=y-Z \hat{\delta}_{G L S}$ and $w=E\left(u_{i, T+s} u\right)$. Note that for period $T+S$

$u_{i, T+S}=\mu_{i}+v_{i, T+S}$

and where $l_{i}$ is the $i$ th column of $I_{N^{\prime}}$ In this case:

$w^{\prime} \Omega^{-1}=\sigma_{\mu}^{2}\left(l_{i}^{\prime} \otimes l_{T}^{\prime}\right)\left[\frac{1}{\sigma_{1}^{2}} P+\frac{1}{\sigma_{v}^{2}} Q\right]=\frac{\sigma_{\mu}^{2}}{\sigma_{1}^{2}}\left(l_{i}^{\prime} \otimes l_{T}^{\prime}\right)$

A typical element of $w^{\prime} \Omega^{-1} \hat{u}_{G L S}$ becomes $\left(\left(T \sigma_{\mu}^{2} / \sigma_{1}^{2}\right) \overline{\hat{u}}_{i, G I S}\right)$, where $\overline{\hat{u}}_{i, G L S}=\sum_{t=1}^{T} \hat{u}_{i t, G L S} / T$.Therefore, the BLUP for $y_{i, T+S}$ corrects the GLS prediction by a fraction of the mean of the GLS residuals corresponding to that ith individual. In practice, the optimal variance components are replaced with their estimated values.

The best quadratic unbiased (BQU) estimators of the variance components arise from the spectral decomposition of $\Omega$ [6]. The estimated variance terms can be calculated using the following equations:

$$
\begin{aligned}
& \hat{\sigma}_{1}^{2}=\frac{u^{\prime} P u}{\operatorname{tr}(P)}=T \sum_{i=1}^{N} \bar{u}_{i .}^{2} / N \\
& \hat{\sigma}_{v}^{2}=\frac{u^{\prime} Q u}{\operatorname{tr}(Q)}=\frac{\sum_{i=1}^{N} \sum_{t=1}^{T}\left(u_{i t}-\bar{u}_{i .}\right)^{2}}{N(T-1)}
\end{aligned}
$$

where the sigmas are calculated in the usual manner from the Within and Random effects models.
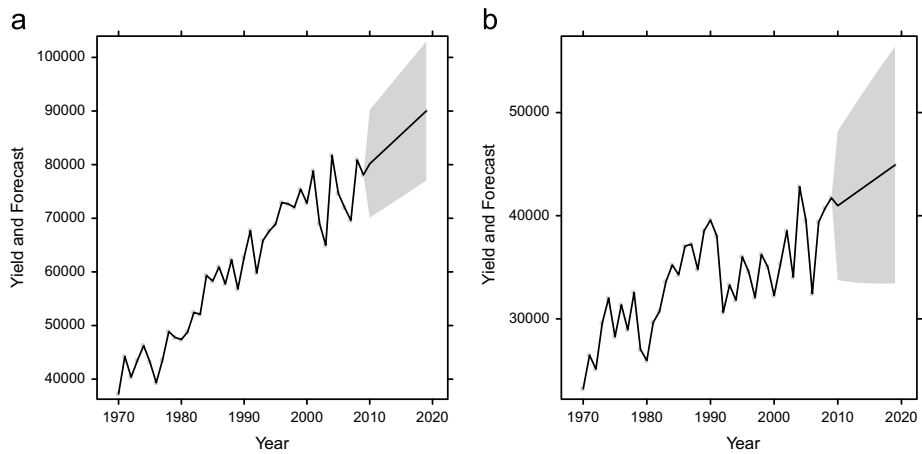

Fig. 9. Yield time series forecasts for Germany and Poland (95\% confidence interval). (a) German time series and (b) Polish time series. 


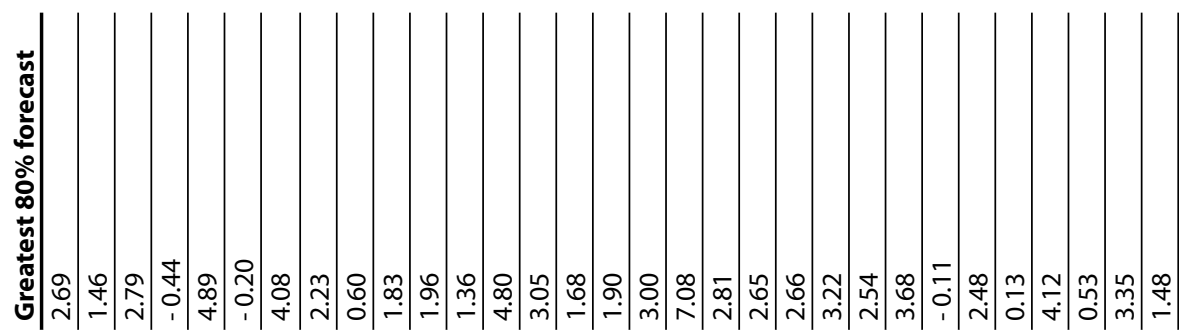

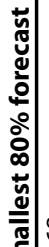

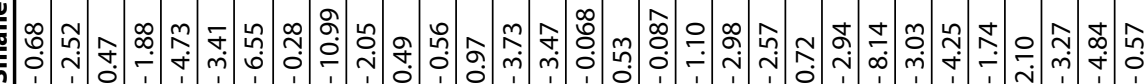

ปั

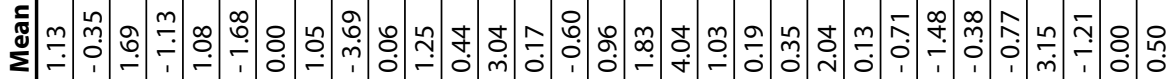

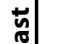

ఫे

:े

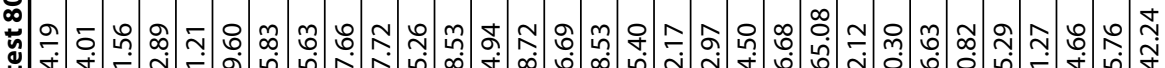

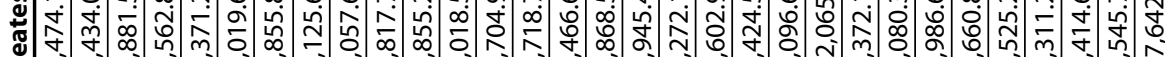

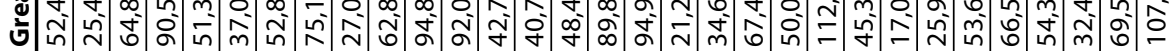

ํํำ

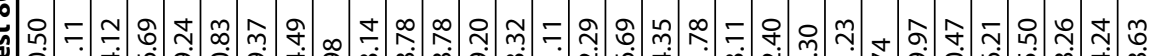
产

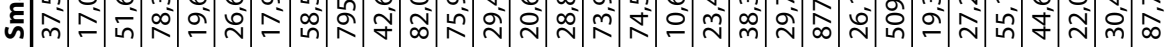

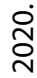

ํำ

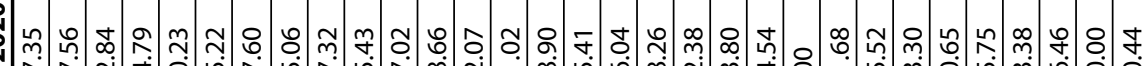
言

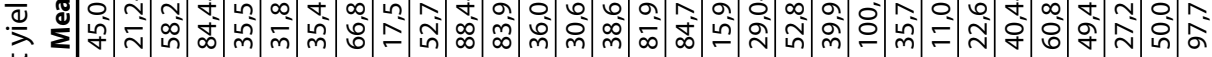
范

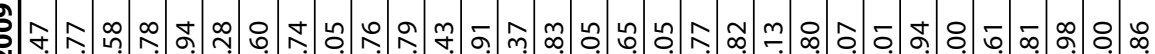

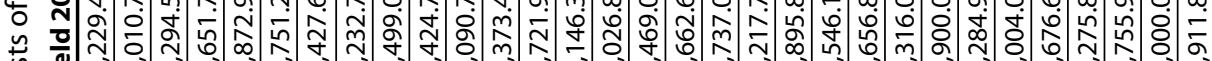

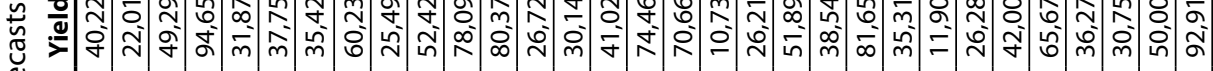
힌

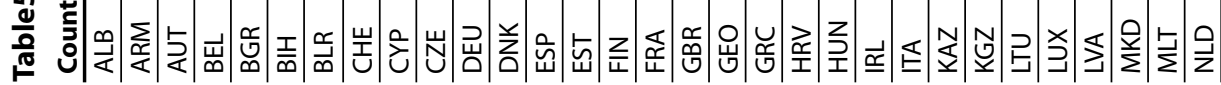




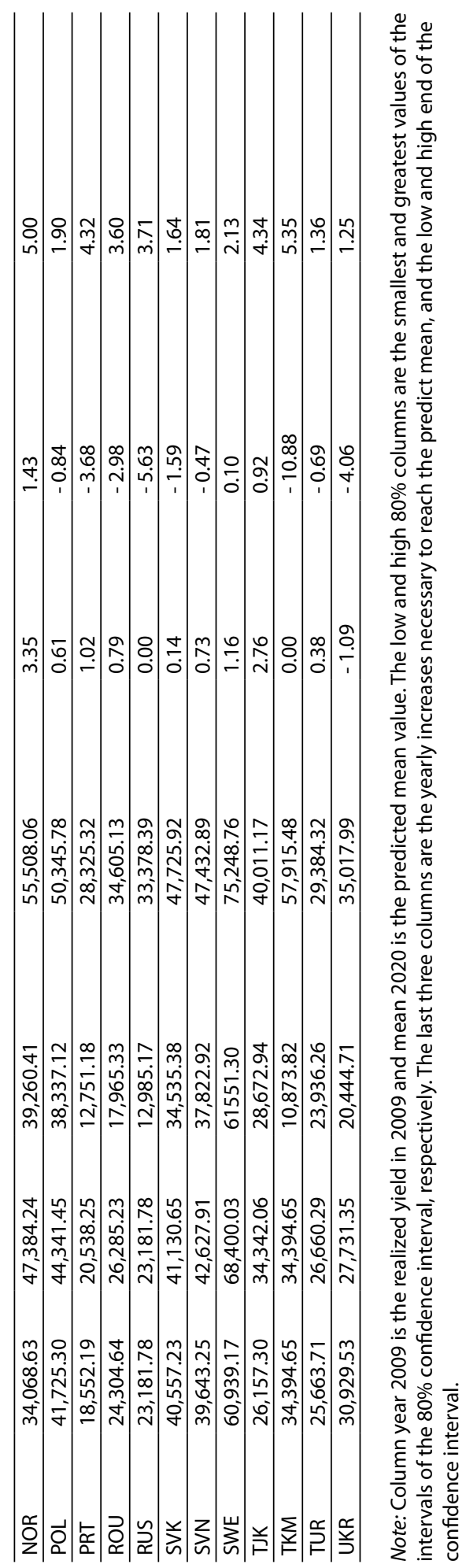


Fig. 10 presents realized yields versus predicted yields per country. All 43 countries are represented in the figure. Each symbol represents the realized and predicted values of wheat yields for a country in a particular year (2001-2009), so there should be nine symbols for each country. The intention of the figure is not to identify specific points, the figure contains far too much data to do that, rather, it is intended to show general patterns for countries. In general it appears that countries consistently out or underperform their predicted values. For instance, Germany, Denmark, France, the Netherlands, the United Kingdom and Ireland, countries above the bisector, consistently outperform expectations. In other words, their realized wheat yields out perform what the panel model forecasts they should be. While Spain, Finland, Greece, Italy, Norway and Portugal, those countries below the bisector, consistently underperform expectations. This suggests that there may be country specific structural effects at work which determine how wheat yields correlate with real GDP per person.

Table 5 presents similar data to that used immediately in Fig. 10. In particular, it shows realized 2009 yields versus predicted yields for the same year. In other words, panel results using lagged yields and real GDP per person are used to forecast 2009 yields which are then compared to realized yields. For instance, Albania, the first country in the table, is performing well above what the model predicts for that year, while Austria, the second country in the table, is performing well under expectation.

Results of the panel forecasting model are disappointing. Unsurprisingly perhaps given the great diversity among countries within the panel under consideration. The Western, Central, and Eastern European countries are on very different economic trajectories. In fact, standard F-statistics soundly reject the null hypothesis that the countries have one common intercept, in other words, when forecasting, a single aggregated model based on data from the entire panel should be rejected in favor of country specific models. Therefore, we shall use forecasts from our time series models Section 3.5.1, as input into MAGNET. 


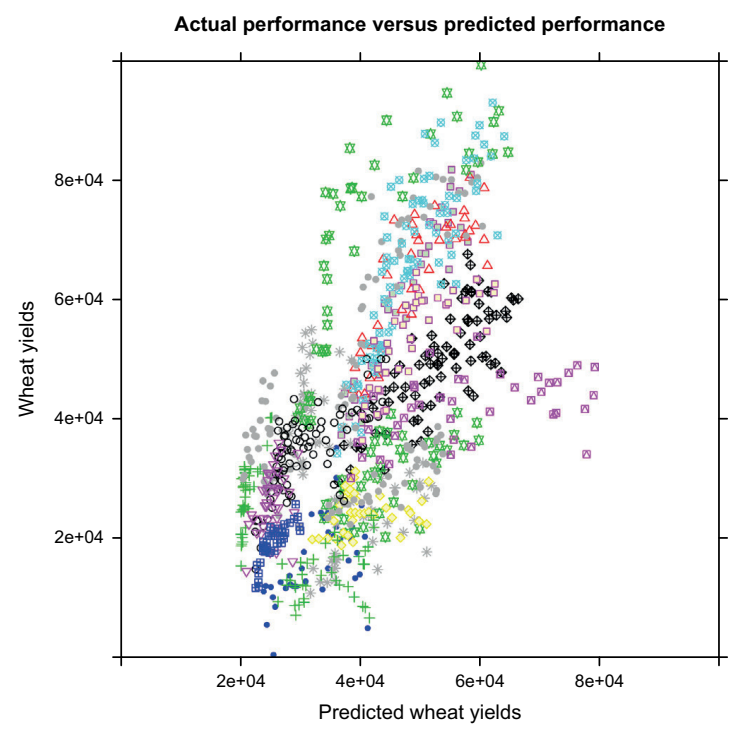

Fig. 10. Relative yield performance.

\subsubsection{MAGNET results}

As is true for any CGE analysis, the results presented here should not be used to make precise predictions about economic events. Rather, CGEs are uniquely suited as a means to guide us through the significant effects of a shock to an economy. In the case at hand, MAGNET results give an indication of the economic impacts of changes in yields as they ripple through the European and world economies. In addition, MAGNET, and other CGE models, are deterministic models which show that the changes needed to move from one equilibrium to another [20]. With these qualifications in mind, the MAGNET model can help us to understand the economic implications of yield changes on the amount and price of wheat and land use.

Recall that three MAGNET scenarios were run using top wheat producing regions in Europe. The scenarios consisted of a base scenario which uses the mean of predicted yields, and low and high yield scenarios, all of which were based initially on data found in the last three columns of Table 5 . Results from Table 5 were only used when they could be accurately calculated. In some cases, given the small number of observations available, standard errors were too large to make meaningful predictions using standard time series methods. In such cases, yield predictions were made in consideration of the figures, tables and panel forecasts described in the previous sections. 
The mean, low and high scenarios for all countries were formulated with regard to the additional information based on the above described analyses. Twelve top producing European countries, with an equal number of established and newer countries, were chosen for the analysis. Expected yields across all countries show a great deal of variation, from possible negative changes in yields to very positive changes. The main point of running the analyses is to show how changes in yields may affect important economic variables including land use. In the case of the yearly mean shocks, most values appear reasonable in the given data. For established European countries they range from around a tenth of a percent growth in yields for Italy to 3\% for Spain. For newer European countries, the range of values is large and never above $1 \%$. In the case of Ukraine, the mean yield change is negative $1 \%$. However, that number is suspect for previously stated reasons so that value was changed to zero in the base or mean scenario. Admittedly, this is a somewhat arbitrary change, another value could have been chosen, but a growth rate of $0 \%$ over a 10 year period is conservative given historical trends. For the lower yield scenarios, values for established Europe range from negative three for Italy to positive $1 \%$ for Spain. Given the length of the time series available for these countries, a negative growth rate is probabilistically possible so these numbers were used in the analysis. In the case of newer European countries, the negative numbers were again set to zero. Again, the small number of historical values available makes precise forecasts impossible and zero seems a conservative value. The high forecast values for established Europe range from just about one and half percent for Denmark to nearly $5 \%$ for Spain. Values for new Europe range from around $1 \%$ for Ukraine to nearly $4 \%$ for Romania and the Russian Federation. Sustained growth rates of $3 \%$ and higher have not been experienced since the 1960s, but recall that the high yield scenario is intended to measure effects of yield increases which are high, but probabilistically possible. which are probabilistically unlikely to occur and so these values are used in the analysis. In short, the scenarios are designed to provide pessimistic and optimistic extremes. It is most likely that actual values will occur somewhere between these two extremes - with the mean forecast being the most likely. The scenarios offer an experiment that tests yield ranges from negative to very positive percentage changes in yields (Table 6).

MAGNET scenario results, given that the model assumes perfect competition, should not deviate significantly from what standard economic theory tells us should happen in the event of a shock. The basic idea of a shock is to run an experiment in which one or a few aspects of an economy are changed and then to examine how the rest of the economy adjusts to the shock once the economy has reached a new equilibrium. Standard theory can best be described using a simple supply and demand diagram. For example, in the event of an improvement in the technology used to produce wheat, we would expect the supply curve to shift out from S1 to S2 in Fig. 11. The initial increase in the quantity of wheat produced is the distance $E C$. However, at that price supply exceeds demand so 
firms will reduce their supply while demand will increase as buyers switch from wheat substitutes to the now cheaper wheat $F$. At the new equilibrium equation (2), standard theory says that prices should be lower and the quantity of wheat sold higher than it was in the original equilibrium. In the case of a reduction in the technology used to produce wheat, theory says that wheat prices will rise and the quantity produced will fall.

MAGNET results largely conform to theory as can be seen in Table 7. The first two columns show production quantity and production price for wheat production in Europe and the rest of the world (ROW). In the low yield improvement case, wheat production is less efficient than in the base, mean case and, as a consequence, the quantity produced in European countries falls except the Czech Republic, the Russian Federation and Ukraine, all of whom experience slight increases in production quantity. However, in all three cases, yields in both the mean and the low yield scenarios were set to zero. In other words, there was no change in wheat yields for these countries. In fact, they are relatively more efficient in the production of wheat given that other countries in the scenarios have seen reductions in their ability to produce wheat; therefore, they will produce more wheat for consumption and export. The other countries all experience a reduction in their ability to produce wheat relative to the base case, and in all cases the quantity produced falls. Since the rest of the world received no shock it is relatively more efficient than Europe in the production of wheat following the low yield shock, and therefore produces more for their own consumption and export to Europe. The price of production in the low yield scenario increases for all countries in the world. This is because the production of wheat has become less efficient so that it is more expensive to meet wheat demand.

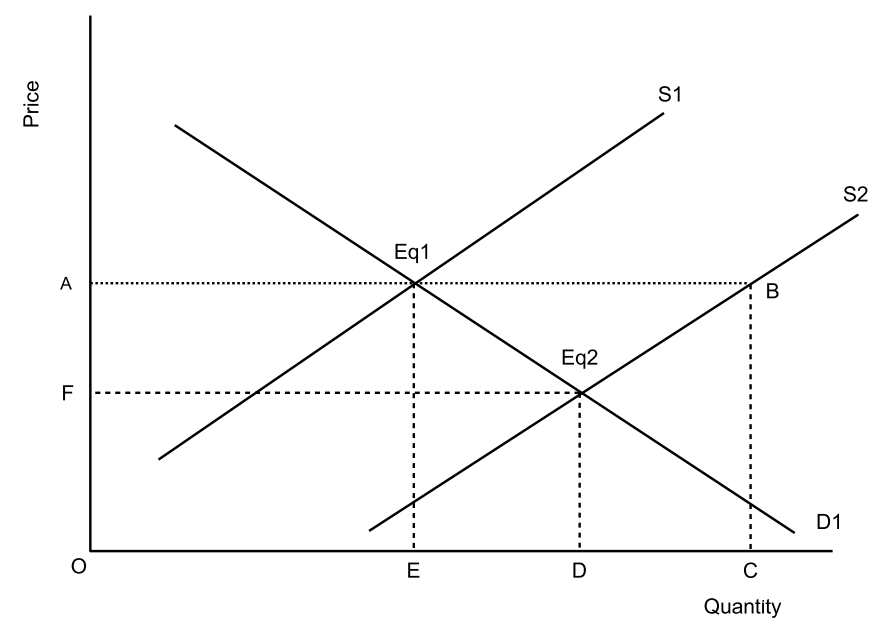

Fig. 11. Supply and demand in the case of technological improvement. 
Table 6. Forecast of wheat yields in 2020.

\begin{tabular}{llllllll} 
Country & GDP2009 & $\begin{array}{l}\text { Realized } \\
\text { yields }\end{array}$ & $\begin{array}{l}\text { Predicted } \\
\text { yields }\end{array}$ & Country & GDP 2009 & $\begin{array}{l}\text { Realized } \\
\text { yields }\end{array}$ & $\begin{array}{l}\text { Predicted } \\
\text { yields }\end{array}$ \\
\hline ALB & 6641.8 & 40,229 & 27,626 & ITA & 27,710 & 35,316 & 46,875 \\
\hline ARM & 5375.1 & 22,011 & 26,468 & KAZ & 11,734 & 11,900 & 32,279 \\
\hline AUT & 37,415 & 49,295 & 55,743 & KGZ & 2300 & 26,285 & 23,659 \\
\hline BEL & 34,630 & 94,652 & 53,198 & LTU & 14,187 & 42,004 & 34,520 \\
\hline BGR & 10,923 & 31,873 & 31,537 & LUX & 84,585 & 65,677 & 98,842 \\
\hline BIH & 7116,2 & 37,751 & 28,059 & LVA & 12,776 & 36,276 & 33,231 \\
\hline BLR & 12,782 & 35,428 & 33,236 & MKD & 7681.5 & 30,756 & 28,576 \\
\hline CHE & 39,634 & 60,233 & 57,770 & MLT & 21,666 & 50,000 & 41,353 \\
\hline CYP & 18,997 & 25,499 & 38,915 & NLD & 37,052 & 92,912 & 55,411 \\
\hline CZE & 21,972 & 52,425 & 41,633 & NOR & 49,980 & 34,069 & 67,223 \\
\hline DEU & 32,494 & 78,091 & 51,246 & POL & 16,376 & 41,725 & 36,520 \\
\hline DNK & 33,932 & 80,373 & 52,560 & PRT & 19,904 & 18,552 & 39,743 \\
\hline ESP & 27,649 & 26,722 & 46,820 & ROU & 9741,4 & 24,305 & 30,458 \\
\hline EST & 16,295 & 30,146 & 36,445 & RUS & 14,645 & 23,182 & 34,938 \\
\hline FIN & 32,187 & 41,027 & 50,966 & SVK & 19,145 & 40,557 & 39,050 \\
\hline FRA & 30,837 & 74,469 & 49,733 & SVN & 24,958 & 39,643 & 44,361 \\
\hline GBR & 33,407 & 70,663 & 52,081 & SWE & 35,246 & 60,939 & 53,761 \\
\hline GEO & 5062.6 & 10,737 & 26,183 & TJK & 1872.9 & 26,157 & 53,761 \\
\hline GRC & 27,304 & 26,218 & 46,505 & TKM & 6934.9 & 34,395 & 27,894 \\
\hline HRV & 15,085 & 51,896 & 35,340 & TUR & 9919.4 & 25,664 & 30,621 \\
\hline HUN & 16,521 & 38,546 & 36,653 & UKR & 6413.9 & 30,930 & 27,418 \\
\hline RL & 33,406 & 81,657 & 52,080 & & & & \\
\hline & & & & & & & \\
\hline
\end{tabular}

Table 7. MAGNET wheat results land demand, production quantity, production price, and land price.

\begin{tabular}{lllllllll}
\multirow{2}{*}{ Country } & \multicolumn{2}{l}{ Prod. quantity } & \multicolumn{2}{l}{ Prod.price } & \multicolumn{2}{l}{ Land use } & \multicolumn{2}{c}{ Land price } \\
\cline { 2 - 10 } & Low & High & Low & High & Low & High & Low & High \\
\hline ROW & 0.50 & -3.36 & 0.05 & -0.34 & 0.42 & -2.83 & 0.04 & -0.17 \\
\hline DNK & -0.48 & -0.78 & 0.89 & -0.73 & 7.38 & -7.23 & 2.96 & -2.61 \\
\hline FRA & -1.21 & -1.25 & 0.87 & -0.74 & 6.81 & -7.59 & 4.81 & -4.69 \\
\hline DEU & -0.61 & -1.76 & 0.74 & -0.71 & 4.99 & -6.20 & 1.16 & -1.21 \\
\hline ITA & -9.52 & 2.92 & 4.33 & -2.32 & 16.11 & -14.39 & 6.04 & -4.56 \\
\hline ESP & -3.37 & 0.10 & 1.65 & -1.05 & 11.68 & -10.29 & 4.33 & -3.30 \\
\hline GBR & -0.82 & -0.79 & 0.82 & -0.59 & 8.11 & -7.66 & 5.03 & -4.23 \\
\hline CZE & 0.87 & 8.94 & 0.45 & -4.41 & 1.27 & -6.89 & 0.80 & -3.64 \\
\hline POL & -1.80 & 2.88 & 1.80 & -3.35 & 3.66 & -7.92 & 1.45 & -2.95 \\
\hline ROU & -4.18 & 14.73 & 2.61 & -7.27 & 2.59 & -9.4 & 1.25 & -4.05 \\
\hline RUS & 0.35 & 27.25 & 0.08 & -7.89 & 0.33 & -6.88 & 0.01 & -0.02 \\
\hline UKR & 0.24 & 3.31 & 0.03 & -2.95 & 0.22 & -7.28 & 0.07 & -2.96 \\
\hline XSU & -0.09 & 19.20 & 0.10 & -10.76 & -0.06 & -14.11 & 0.78 & -5.49 \\
\hline
\end{tabular}

Note: XSU is an aggregated region which includes Uzbekistan. 
For the high yield case, in which wheat yields improve, the quantity of wheat produced increases for Italy, Poland, Ukraine and slightly for Spain, but is especially high for the Czech Republic, Romania, Uzbekistan (XSU) and the Russian Federation. The last four countries are driving what is happening in this scenario. The large yield increase they experience, especially when compared to the relatively anemic increases in the rest of Europe, means that their production increases dramatically and it becomes more efficient for many other European and countries in the rest of the world to import wheat from those four countries. The result is a decrease in production quantity for most other countries and a decrease in the price of production for all countries.

\subsubsection{Land use}

We are now in a position to ask what happens to land use in relationship to exogenous changes in yields. The basic economic mechanisms are the same as those in the previous analysis. However, instead of a shift in the supply curve of wheat, now the demand curve for land shifts as more or less land is needed to grow the same amount of wheat. For example, a technological improvement in the production of wheat shifts the demand curve for land to the left reducing the demand for land and lowering its price at the new equilibrium. This shift is directly modeled in both the low and high scenarios. The low yield scenario models the case that land is less efficient than the predicted mean and, as a result, land use increases in all countries except Uzbekistan, which realizes a slight decrease as a result of the narrow difference between the mean and low scenarios for that country. The high yield scenario leads to a reduction in land used to grow wheat for all countries. Again, the high yield case means that the same amount of land can be used to grow more wheat so less land is needed to meet the demand for wheat. Changes in the price of land follow along the same reasoning; less efficient land used to grow wheat means that more land is needed to grow the same amount of wheat. The additional land must be bought in the perfectly functioning land market, thereby raising the price of land. In the case of more efficient production, the price of land falls because less land is needed to grow the same amount of wheat so the excess land is sold in the market thereby lowering the price of land.

The land 'freed' by the increase in wheat yields is not exclusively available for the production of wheat. Other crops, and any other MAGNET sector using land, compete with wheat for land as an input and market prices for intermediate and final products will determine to which use the freed land is eventually allocated. Indeed, MAGNET results show that land use for non-wheat crops and other sectors using land decreases as a result of reduced wheat yields while wheat yields improve. These other sectors are harmed by or benefit from decreases or increases in wheat yields. Therefore, the argument that yield creases release land which is currently being used to grow wheat or other crops to grow bioenergy crops should be tempered by the fact that other crops and sectors using 
land, besides bioenergy crops, compete in the marketplace for the same land. The market value of intermediate and final products will determine to which sector the freed land is allocated.

\section{Conclusions}

Two complementary methodologies have been used in the foregoing analysis, the first to estimate and forecast yields, and the second to calculate the resulting effects on land use. A wide variety of tools were used to analyze the historical and possible future growth patterns of wheat yields.

We found that yields for the world and Europe have significantly increased in the period from 1961 to 2010. For instance, yields for European countries with the highest yields have more than doubled in that period, while those with the lowest yields have more than tripled in some cases. However, there is strong evidence of a general leveling of yields since the 1990s, a trend which is particularly evident for countries with higher yields, but also extending to Central and Eastern European countries as well. Fig. $2 \mathrm{~b}$ reaffirms previous observations that growth rates have been decreasing across most of Europe as do panel analyses in Table 4. That table provides strong statistical evidence that yields are increasing at a decreasing rate for both rich (Western) and poor (generally Central and Eastern) European countries alike. However, the table also shows that poorer countries can expect to realize large increases in yields as their levels of real GDP per person increase.

In the last two decades all growth rates except the world's 10 most productive wheat producers have been well below one-and-a-half percent and, in most cases, well below one percent. This trend is the most dramatic in the case of Europe's top wheat producing countries, which have seen yield growth rates of just $0.32 \%$ in the last decade, corresponding to a doubling of yields every 217 years. In addition, large differences in yield rates persist within Europe, with high yield countries producing four times the amount of wheat for a given area when compared to European countries with the lowest yields. Our study has found evidence of log tdivergence, meaning that there is no evidence of a common underlying growth rate for yields across Europe. However, there is strong evidence of absolute convergence which indicates that, on an average, countries with lower initial yields will grow faster than countries with higher initial yields. In short, although European countries have been growing at a variety of rates, those countries with lower initial rates will grow, on an average, at higher rates than countries with high initial growth rates. 
The short and erratic time series of many Central and Eastern European countries complicated the forecasting process. For instance, the sharp drop and then recovering of yields for many Central and Eastern European countries undergoing market rationalization increased yield variation, thereby reducing the effectiveness of standard time series techniques for those countries. To address the problem of short series, dynamic panel methods, which require short time series relative to the number of observations, were employed to estimate yield developments and included lagged yields and real GDP per person as exogenous variables. Results were consistent with observations based on the previous figures. Table 4 shows that there is a positive relationship for poorer countries between increases in real GDP per person and yield increases. While estimates for the variable changes in yields are all significantly negative, indicating that yields are increasing, but at a decreasing rate. Finally, Fig. 10 shows that countries are fairly consistent in either under or over performing in regard to estimated yields. However, forecasts using the panel model were rejected in favor of time series techniques because the diversity of countries within the data set raised concerns about the results. A final, perhaps surprising outcome, is the result that some European countries may experience decreases in yields in the coming years relative to their current levels. Although unlikely, the negative values are at the low end of the $80 \%$ confidence interval, a contraction in yields is possible.

The technique used to estimate yields resulted in a diverse range of forecast values (see Table 5) that were then used as input into the MAGNET model. The values give a rough indication of what might happen to yields in the future given historical developments in yields and real GDP per person. They indicate a diverse range of growth rates across Europe. In summary, there is evidence that Central and Eastern Europe have at least the potential for growth, although recent evidence indicates that their growth rates are slowing as well. As discussed in the text, forecasts are not perfect indicators given the small number of available years for some Central and Eastern European countries. With that qualification in mind, MAGNET used the calculated growth rates as input and has given us insight into the wider economic adjustments which occur when yields change.

MAGNET results, for the most part, followed what standard economic theory predicts would happen when yields either decrease or increase relative to the business as usual case, although there are a few interesting outcomes which require explanation. The effects of the case in which yields achieve the lower end of the $80 \%$ confidence interval are discussed first, followed by the case in which they achieve the highest values of the same interval.

When yields achieved the lower end of their forecasted values, land demand for wheat production increased across the vast majority of regions. The increase implies that the demand for wheat, in a sense, outweighs the higher cost of producing wheat. Recall that 
yields, which are output per land area, are a part of the cost of producing wheat, a decrease in wheat yields means that more land is required to produce the same amount of wheat. Since the demand for wheat is not perfectly elastic, in other words, demand for wheat does not fall as much as its price rises, more land was required to supply wheat demand. An increase in the demand for land to produce wheat means that, in general, there is less land to produce crops other than wheat. Land has become relatively scarce and therefore more expensive, leading to a decrease in land demand and an increase for other inputs into the production process. The net result is that land demand for agricultural sectors other than wheat fell. The total land demand and supply from all sectors including wheat increased slightly, meaning that the decrease in wheat yields caused additional land to become available for agricultural production.

It is perhaps surprising that the production of wheat decreased in regions in Western Europe, but increased in Central and Eastern Europe. However, this discrepancy is caused by the fact that it becomes relatively cheaper for Western European countries to import wheat from Central and Eastern Europe. Although the price of production increased in all European regions, increases in Western Europe were relatively higher. This difference between Western Europe and Central and Eastern Europe is clearly evident in the effects of a decrease in yields on land prices between the two regions. Land prices for wheat production in Western Europe saw a large increase compared to much smaller increases in Central and Eastern Europe.

When yields achieved the upper end of their forecasted values in Europe, land demand for wheat production fell across all countries, both in Europe and the rest of the world. This is essentially the story that is told in the models mentioned in the introduction of this paper. Higher yields mean more land available to grow wheat or some other bioenergy products. It is self-evident, less land is needed to grow the same amount of wheat. However, MAGNET, and standard economic theory, tell us that land demand from all other sectors, excluding wheat, rose for most regions as a result of the increase in wheat yields. The land freed from the production of wheat went to the production of other agricultural products, and not only the production of bio energy products. For instance, land used to raise livestock increased as well. Total land demand from all sectors including wheat decreased slightly for all regions of the world. In short, some of the land freed on account of wheat yield increases either went to the production of nonagricultural products or was idled.

Again, at first glance it may be surprising that wheat production increased by a large percent in Central and Eastern Europe, but fell in many regions in Western Europe. This shifting of production from Western Europe to Central and Eastern was a result of greater production price reductions in Central and East ern Europe when compared to Western Europe. The price of land used to grow wheat, generally a large percentage of the price of 
production, fell across all countries because land for wheat production, and the production of all other agricultural products, is now more plentiful.

The principle message, from either a decrease or increase in wheat yields, is that the economic effects of yield changes or any other significant change need to be analyzed with regard to their substitutes and complements, and the marketplace in which they operate. The analysis shows that land released by an increase in wheat yields will not necessarily go to produce bioenergy crops. Rather, it will go to the sector that values additional land the most. To complicate the matter still further, yield changes in wheat need to be analyzed with regard to yield changes in other crops as well, in our analysis we have assumed that the yields of other crops continue along their forecasted paths. Our analysis shows that wheat yields are likely, on an average, to increase, but at a decreasing rate. The effects of those wheat yield increases on the production of wheat is positive, but that increase is mitigated by the demand for other products for land which made relatively cheaper input. A more direct, but economically distorting, manner to increase wheat supply would be to make it more profitable to produce through, for instance, direct subsidies or subsidies to the bioenergy products that use it as an input. 


\section{References}

1. Anderson TW, Hsaio C. Estimation of dynamic models with error components. Journal of the American Statistical Association 1981;76:598-606.

2. Anderson TW, Hsaio C. Formulation and estimation of dynamic models using panel data. Journal of Econometrics 1982;59:87-97.

3. Arellano M, Bond S. Some tests of specification for panel data: Monte Carlo evidence and an application to employment equations. Review of Economic Studies 1991;58:277-97.

4. Balestr P, Nerlove M. Pooling cross sectional and time series data in the estimation of a dynamic model: the demand for natural gas. Econometrica 1966;34:585-612.

5. Baltagi Badi H. Econometric analysis of panel data. John Wiley and Sons Ltd; 2008.

6. Baltagi Badi H. Forecasting with panel data. Journal of Forecasting 2008;27:153-73.

7. Barro Robert J, Salai i Martin Xavier I. Economic growth. MIT Press; 2003.

8. Bond Stephen. Dynamic panel data models: a guide to micro data methods and practice. The Institute for Fiscal Studies Department of Economic, UCL CeMMAP working paper CWPO9/02, 2002.

9. CIA.The world factbook:GDP composition by sector, (https://www.cia.gov/library/publications/ theworldfactbook/fields/2012.html); July 2013.

10. Cleveland William S. Robust locally weighted regression and smoothing scatterplots. Journal of the American Statistical Association 1979;74 (368):829-36.

11. Cleveland William S. LOWESS: a program for smoothing scatterplots by robust locally weighted regression. American Statistician 1981;35(1):54.

12. Cleveland William S, Delvin Susan J. Locally weighted regression: an approach to regression analysis by local fitting. Journal of the American Statistical Association 1988;83(403):596-610.

13. Edwards R, Mulligan Declan, Marelli L. Comparison of models and results for marginal biofuels production from different feedstock. Publications Office of the European Union, Copyright European Union JRECIE, European Commission, EUR 24485 EN; 2010.

14. European Environment Agency. How much bioenergy can Europe produce without harming the environment? 2006.

15. European Parliament and Council. Directive 2009/28/EC of the European Parliament and of the Council of 23rd April 2009 on the promotion of the use of energy from renewable sources and amending and subsequently repealing Directives 2001/77/EC and 2003/30/EC. (http://eurlex. europa.eu/LexUriServ/LexUriServ.do?uri=CELEX:32009L0028:EN:NOT); April 2009.

16. Ewert F, Rounsevell MDA, Reginster I, Metzger MJ, Leemans R. Future

17. scenarios of European agricultural land use: 1. Estimating changes in crop productivity. Agriculture, Ecosystems \& Environment 2005;107(2-3):101-16.

18. FAO. World agriculture 2015/2030: an FAO perspective; 2010.

19. FAOSTAT. United Nations Food and Agricultural Organization (UNFAO) online statistics database. (http://faostat.fao.org/site/291/default.aspx). 
20. Fischer G, Prieler S, van Velthuizen H, Berndes G, Faaij A, Londo M. Biofuel production potentials in Europe: sustainable use of cultivated land and pastures. Part II: land use scenarios. Biomass and Bioenergy 2010;34 (2):173-87.

21. Francois JF, Reinert KA. Applied methods for trade policy analysis. Cambridge University Press; 1998.

22. GTAP. GTAP 8 database description. (https://www.gtap.agecon.purdue.edu/ databases/v8/ v8_doco.asp); September 2012.

23. Haas MJ, McAloon AJ, Yee WC, Foglia TA. A process model to estimate biodiesel production costs. Bioresource Technology 2006;97(4):671-8.

24. Sasha Hafner $S$. Trends in maize, rice, and wheat yields for 188 nations over the past 40 years: a prevalence of linear growth. Agriculture, Ecosystems \& Environment 2003;97:275-83.

25. Hansen LP. Large sample properties of generalized method of moment estimators. Econometrica 1982;50:1029-54.

26. Hellmann Fritz, Verburg Peter H. Impact assessment of the European biofuel directive on land use and biodiversity. Journal of Environmental Management 2010;91(6):1389-96.

27. Hertel T, TynerW, Birur D. The global impacts of biofuel mandates. Energy Journal 2010;31(1):75100.

28. Hertel Thomas W, editor. Global trade analysis: modeling and applications. Cambridge University Press; 1997.

29. Heston Alan, Summers Robert, Aten Bettina. Penn world trade version Center for International Comparisons of Production. Income and Prices at the University of Pennsylvania; 2011.

30. Huang $\mathrm{H}$, van Tongeren $\mathrm{F}$, Dewbre J, van Meijl $\mathrm{H}$. A new representation of agricultural production technology in GTAP. In: The seventh annual conference on global economic analysis; 2004.

31. Hodrick R, Prescott E. Post war business cycles: an empirical investigation. Journal of Money Credit and Banking 1997;29:1-16.

32. HoltzEakin D, Newey W, Rosen HS. Estimating vector autoregressions with panel data. Econometrica 1988;56:1371-96.

33. IFPRI. Climate change: impact on agriculture and costs of adaptation. Food policy report. Technical Report, IFPRI; 2009.

34. Laborde D, Valin H. Modeling land-use changes in a global CGE: assessing the EU biofuel mandates with the MIRAGEBioF model. Climate Change Economics 2012;3(3).

35. Lin M, Huybers P. Reckoning wheat yield trends. Environmental Research Letters 2012;7.

36. Lucas Jr. Robert $E$. The industrial revolution: past and future. Lectures on economic growth. Harvard University Press; 2002.

37. Macours Karen, Swinnen Johan FM. Causes of output decline in economic transition: the case of Central and Eastern European agriculture. Journal of Comparative Economics 2000;28:172206.

38. Neeft John. Biograce: harmonized calculations of biofuel greenhouse gas emissions in Europe. (http://www.biograce.net/); 2012. 
39. Peter Phillips $C B$, Sul Donggyu. Transition modeling and econometric convergence tests. Econometrica 2007;75(6):1771-855.

40. Peter Phillips CB, Sul Donggyu. Economic transition and growth. Journal of Applied Economics 2009;24:1153-85.

41. Pindyck Robert S, Rubinfeld Daniel L. Econometric models and economic forecasts. Irwin McGrawHill; 1998.

42. Plevin RJ, $\mathrm{O}^{\prime}$ Hare M, Jones AD, Torn MS, Gibbs HK. Greenhouse gas emissions for biofuels'indirect land use change are uncertain but may be greater than previously estimated. Environmental Science and Technology 2010;44 (21):8015-21.

43. Ramsey Frank. A mathematical theory of savings. Economic Journal 1928;38:543-59.

44. Goldberger AS. Best linear unbiased prediction in the generalized linear regression model. Journal of the American Statistical Association 1962;57:369-75.

45. Searchinger T, Heimlich R, Houghton RA, Dong F, Elobeid A, Fabiosa J, Tokgoz S, Hayes D, Tung Hsiang Yr. Use of U.S. croplands for biofuels increases greenhouse gases through emissions from land-use change. Science 2008;319(5867):1238-40.

46. Sims R, Taylor M, Saddler J, Mabee W. "From 1st to 2ndGeneration Biofuel Technologies Full Report An Overview of Current Industry and R\&D Activities." International Energy Agency. 2008.

47. Solow Robert M. A contribution to the theory of economic growth. Quarterly Journal of Economics 1956;70(1):65-94.

48. Tabeau Andrejz, Woltjer Geert. Modelling the agricultural employment development within the CGE framework: the consequences for policy responses. Trade for Sustainable and Inclusive Growth and Development (Bangkok, Thailand), Thirteenth Annual Conference on Global Economic Analysis; June 2010.

49. University of Wisconsin Madison, Nelson Institute, SAGE (Center for Sustain ability and the Global Environment; University of Wisconsin Madison. (http:// www.sage.wisc.edu/); October 2012.

50. van Meijl Hans, van Dijk Michiel, Powell Jeff, Smeets Edward, Tabeau Andrzej. Macroeconomic impact study for biobased Malaysia. Technical Report, LEl, Part of WageningenUR; 2012.

51. van Meijl Hans, van Rheenen T, Tabeau Andrezj, Eickhout B. The impact of different policy environments on land use in Europe. Agriculture, Ecosystems \& Environment 2006;114(1):21-38.

52. Verburg PH, Eickhout $B$, van Meijl Hans. A multiscale, multi-modal approach for analyzing the future dynamics of European land use. Annals of Regional Science 2008;42(1):57-77.

53. Wageningen UR.Wageningen UR site. (http://www.wageningenur.nl/en/AboutWageningenUR. html; October 2012.

54. Wicke Birka, Faaij A, van Vuuren D, van Meijl H. Indirect land use change: current status, possible improvements of existing models and strategies for mitigation, unpublished.

55. Windmeijer F. A finite sample correction for the variance of linear efficient two-step GMM estimators. Journal of Econometrics 2005(126):25-51. 
56. de Wit Mark, Londo Marc, Faaij Andre. Productivity developments in European agriculture: relations to and opportunities for biomass production. Renewable and Sustainable Energy Reviews 2011;15:2397-412.

57. Wooldridge Jeffrey M. Econometric analysis of cross section and panel data. MIT Press; 2010. 
CHAPTER 4 


\section{Effects of changing weather patterns on the trade of major food crops}

J.P. Powell', K. Shutes ${ }^{2}$ and A. Tabeau'

' LEl, Wageningen University and Research Center

${ }^{2}$ Coventry University 
The paper examines the economic effects of expected changes in temperatures and precipitation on the trade of ten major food crops. The relative effects for developing versus developed countries are emphasized. A series of econometric models using panel data and autoregressive integrated moving average models are used to estimate and forecast relationships between yields and weather data, the results of which are used as input into MAGNET, a global computerized general equilibrium modeling framework. Econometric results show that average temperatures have increased across all areas growing major food crops. Results for precipitation are ambiguous, however, there is statistical evidence of two distinct periods, a first in which, on average, precipitation fell, followed by a second in which it increased. Results for crops with statistically significant estimates show that increasing temperatures have negatively affected yields. These results hold for both poor and rich countries, however, the degree to which yields are reduced is crop specific and sensitive to a country's level of wealth. Results show that changes in weather will have significant effects on the production, trade, and, in some cases, the consumption of major food crops. 


\section{Introduction}

\subsection{The problem}

The effects of climate change on trade have been identified as an important, neglected, research topic (Josling et al., 2010; Tamiotti et al., 2009). This paper addresses the subject by examining the global consequences for trade of expected changes in temperatures and precipitation. In particular, it asks what will be the effects of changes in those variables on the trade of major food crops. Long-term changes in those important weather variables are expected to affect yields, and thereby the ability and willingness of countries to trade agricultural products and, ultimately, worldwide consumption patterns.

It has been argued that the economic effects of changing weather patterns on food consumption will depend as much on its role in trade as on it does on crop production directly (Reilly et al., 1994; Sonka, 1991). Trade of agricultural products is particularly important for the well-being of developing countries, and is widely considered to be a major potential contributor to their prospects for growth, food security, and efforts to reduce poverty (Moïsé et al., 2013). Although agricultural trade has fallen as a percentage of the value of total world trade of goods and services, it has been increasing at a faster rate than world agricultural production and remains an important component of the economies of both developing and developed countries (Josling et al., 2010). In particular, FAOSTAT data can be used to show that the share of developing countries in total world exports and imports of agricultural products has been steadily increasing since 1990, and that they have become net agricultural product importers (FAOSTAT, 2013). For these reasons, it is important that the potential impacts of changes in weather patterns on trade are assessed. Trade, in turn, directly affects domestic prices, quantities produced, and ultimately consumption.

Arvis et al. (2013) show that the relative costs of trading are higher for developing countries, placing them at a competitive disadvantage when compared to developed countries. There are many reasons cited for this disadvantage, including traditional and non-tariff trade barriers and regional integration agreements. Changing weather patterns represent a potentially significant additional cost for developing countries in that they may be less able than wealthier countries to adapt to changing weather patterns. We know, for instance, that farmers in developed countries are able to adapt to changes in weather patterns by changing when they plant, but also by changing in production inputs such as applications of fertilizers and pesticides and, in general, their use of inputs requiring energy (Powell, 2014). We hypothesize that developing countries are less able to substitute inputs, particularly high energy inputs, to meet changing climate conditions and are thereby at a competitive disadvantage when weather patterns change. This paper examines whether that hypothesis is supported by testing if there are significant 
differences between the effects of changing weather patterns on developing versus developed countries. Please note that the paper is concerned with the chronic hazards of changes in weather as opposed to what are known as sudden onset hazards or extreme weather events (Cutter et al., 2009).

\subsection{Methodology}

In order to determine the effects of precipitation and temperature changes on trade two methodologies are needed, namely, econometric methods are used to forecast changes in yields resulting from changes in the weather variables, thereafter, the forecasts are used to simulate the effects of the altered yields on the exports and imports of food crops. Our approach differs from previous studies by employing a combination of economic tools to address each point of this complex issue.

Pieces of the general topic of the effects of climate change on yields have been previously investigated (Greenstone and Deschenes, 2006; Licker et al., 2010; Lobell et al., 2011; Schlenker and Roberts, 2009) . For instance, statistically significant results on the effects of temperatures and precipitation on yields of major food crops have been reported, with Lobell and Field providing one of the first papers with results applicable at a global scale (Lobell and Field, 2007). In addition, a series of recent articles using prominent CGE models examined the effects of climate changes on global production and consumption, emphasizing the differences found among model results (Nelson et al., 2013a,b; Valin et al., 2014). Other studies have examined the effects of climate changes at lower levels of aggregation, for instance at regional and country levels of analysis (Erda et al., 2005; Powell, 2014; Prato et al., 2010). For instance, the literature on the adaptation of farms to climate changes is meant to address farm adaptation to changing weather patterns (Bradshaw et al., 2004; Gebrehiwot and Veen, 2013; Luers et al., 2002; Pandey et al., 2007; van Wijk et al., 2012).

Our approach combines country level data analysis with a global CGE model. It builds-on and refines previous econometric yield models by providing a more nuanced methodology for examining the effects of changes in weather on yields. In particular, it tests whether country specific heterogeneity is a statistically significant factor in the estimation of the relationship. Estimates are calculated using various panel data models including dynamic models (Baltagi, 2008; Frees, 2004; Hsiao, 2003). Panel models are the preferred method given the global scale of the issue under investigation. They provide, in a sense, insight into general econometric relationships across all countries, and are a means of disentangling the effects of general versus country specific data differences. In addition, the wide range of crops considered allows us to test whether there is variation in how crops react to changes in the weather. However, panel analyzes provide just one global relationship per crop. Although, country specific forecasts can be retrieved from such a global relationship 
(Frees and Miller, 2004), a more natural approach given the amount and completeness of the data available is to estimate country specific relationships directly from the data based on variables identified with the general model. Specifically, when data allows, country specific autoregressive, integrated, moving average (ARIMA) models are used to estimate and forecast the effects of weather variables on yields (Hamilton, 1994).

Those forecasts are then used as input to run a series of simulations using the computerized general equilibrium model (CGE) model MAGNET which is a significant extension of the Global Trade Analysis Project (GTAP) model (Hertel, 1997; Hertel et al., 2010). Two general types of simulations are implemented, one in which the calculated effects of weather are included in the model, and the other, a base case, in which the effects of weather are excluded from the model. Results for the separate models are then compared to determine the impacts of changing weather on trade. CGE models have been used extensively to simulate trade related issues (Dixon et al., 1977; Robinson, 1990; Robinson et al., 1990; Rutten et al., 2011). Indeed, as its name implies, analyzing trade was an important motivating factor behind the development of GTAP. The MAGNET modeling framework is an extension of the GTAP model in that it uses both the behavioral relationships and database of GTAP as a starting point for analyzes. By applying simple shocks to yields while retaining default GTAP relationships, MAGNET output will allow us to determine the effects of weather changes on trade at both country and global levels.

Together, the econometric techniques and CGE model provide a comprehensive analytical framework which allows the effects of weather events to be linked to a model with a global scope, the result is a unique perspective on the impacts of changing weather patterns on global trade. The proposed approach is admittedly complex in that it involves using descriptive, panel, time-series (ARIMA), and CGE techniques to address the research questions. The first section provides a description of the data and its primary characteristics. Thereafter follows a section describing the panel model and results. The ARIMA section then describes the procedure used to forecast changes in yields while emphasizing the uncertainty of those forecasts. The results of MAGNET simulations are then presented and, finally, general conclusions are drawn.

\section{Characteristics of the data}

This section examines the sources of the data used in the text and their important characteristics, in particular, weather trends are identifiable. Econometric techniques will give an indication of how confident we can be that observed trends will continue. The weather variables are presented first, thereafter, yield developments over the last 50 years for the crops in the study are examined. Results in the following sections 
provide fundamental information on the relationships between variables that need to be addressed in the econometric models.

\subsection{Temperatures and Precipitation}

Initially, three independent weather variables were used to estimate changes in yields, namely, precipitation, minimum, and maximum temperatures (Lobell and Field, 2007). In the data set developed, the globe is divided into $720 * 360$ grids according to an area's latitude and longitude. Temperatures and precipitation are reported for each grid on a monthly basis for each year in the analysis. Precipitation is the monthly average of precipitation in a grid measured in millimeters, while minimum and maximum temperatures are the monthly average low and high temperatures reported in Celsius. Temperature data were obtained from the East Anglia Climate Research Unit (CRUTS) 3.10 (Jones and Harris, 2008). Precipitation data were derived from a revised version of the 3.10 database upon recommendation of East Anglia. Spatially weighted averages of the CRU data were then computed for each crop, with weights defined by the spatial distribution of crop area based on the method by Leff et al. (Leff et al., 2004). The essence of the method used is that the greater the percentage that a grid provides to a country's total production of a crop, the greater the weight the weather variables in that grid receive in the calculation of a country's average yearly temperature and precipitation levels.

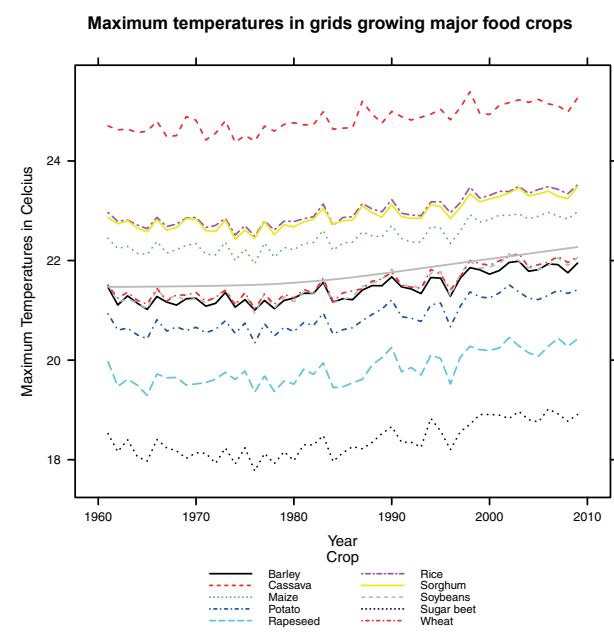

(a) Maximum temperatures.

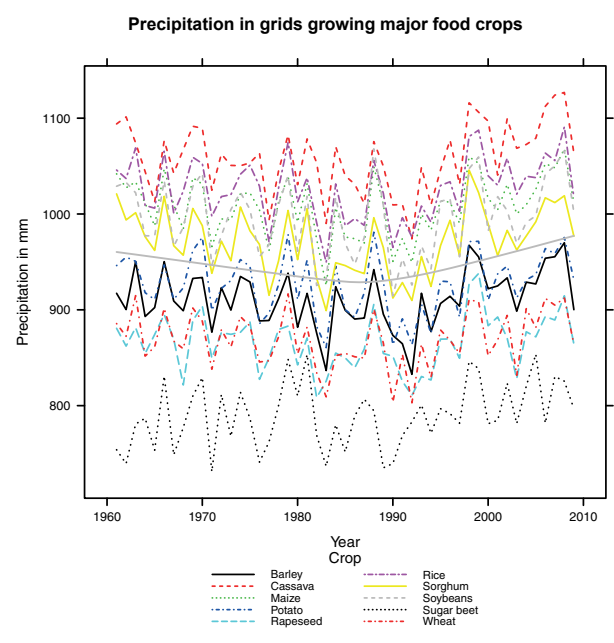

(b) Precipitation.

Figure 1. Average monthly high temperatures and precipitation during growing seasons for ten major food crops.

We initially follow the basic methodology as described in Lobell and Field of defining global growing seasons for each crop. The approach selects weather data only for the months important to the growth of a crop. However, in contrast to Lobell and Field, 
whenever the data allowed, we selected growing months per country rather than using a single growing period for all countries. For instance, say that the months from May to October are important months for the production of wheat in country ' $\mathrm{A}$ ', then only weather data from those months was selected and used in the analysis (Sacks et al., 2010). Data on months important for growing certain crops was not always available, in which case a yearly average of the weather variables was used. This use of country specific growing season data seems reasonable given that countries in Northern and Southern hemispheres are likely to grow the same crop during very different months. The resulting database contains crop-specific monthly time series data of selected global temperatures and precipitation for the years 1961-2009.

Figure 1a shows monthly average maximum temperatures during growing seasons in grids in which important food crops were grown from 1961 to 2009. An identical plot was made for minimum temperatures, however only the figure for maximum temperatures is included because of the high correlations between the two variables. The average trend line, the solid smooth gray line in the figure, is positive and statistically significant, as are the trends lines for each crop taken separately. Average results across all crops show that maximum average temperatures have increased by $0.017{ }^{\circ} \mathrm{C}$ per year in crop growing grids, while average minimum temperatures for all crops have increased by $0.020^{\circ} \mathrm{C}$ per year. The figure emphasizes the extent to which world wide temperatures are synchronized across grids despite the wide variety of crops grown, the range of growing seasons, and the various environments over which crops are grown.

Global temperatures, whether maximum or minimum, appear to react to the same shortterm temperature fluctuations and to be following the same long-term trends. At the individual crop level, cassavas appear to be grown in grids when they are relatively warm, while sugar beets are grown in grids when they have lower temperatures; wheat and barley are grown in grids with nearly the same temperatures. Because temperatures of grids were calculated based on the months in which a crop was grown, it is not possible to directly determine from the figures whether the extent to which the temperature of a grid is determined by its location or by the months in which it was grown. However, the figures do appear to conform to the common knowledge that cassavas, rice and sorghum are grown in warmer regions, sugar beets and rapeseed are grown in cooler climates, and the remaining crops are grown in milder regions.

The data in this subsection suggests that if underlying data generating processes behind the rise in temperatures persists, as it has throughout the period studied, then we can expect temperatures in the future to rise as well. Note that the intention of this section is not to predict changes in weather; other than time, no other explanatory variable is included in the model. In the current analysis it is only possible to deduce that if the 
effects of unidentified underlying variables continue to cause temperatures to increase and nothing of significance changes, then we can be fairly confident that temperatures will increase in the future. These are heavy qualifications, but they need to be explicitly stated in order to understand the limits of the analysis to follow and, at a minimum, they suggest that only short or medium term predictions should be attempted in order to mitigate the issue of potentially changing underlying data generating processes.

In contrast to temperatures, results for precipitation across all crops are, with the exception of sugar beets, insignificant, implying that there is no statistical evidence that precipitation in crop growing grids has significantly changed over the entire period under review. Precipitation in grids growing sugar beets has increased by around 0.075 millimeters per year. However, the trend line in figure 1b suggests two distinct periods, one from 1961 to around 1987, and the other continuing thereafter until 2010. Running separate regressions for the two periods leads to statistically significant results for crop averages in both periods with an estimate of -1.42 and t-value of -2.2 in the first period, and an estimate of 2.34 with a t-value of 3.0 in the second period. Chow tests confirm the observed structural break, and results from regressions are significant for each period reported.

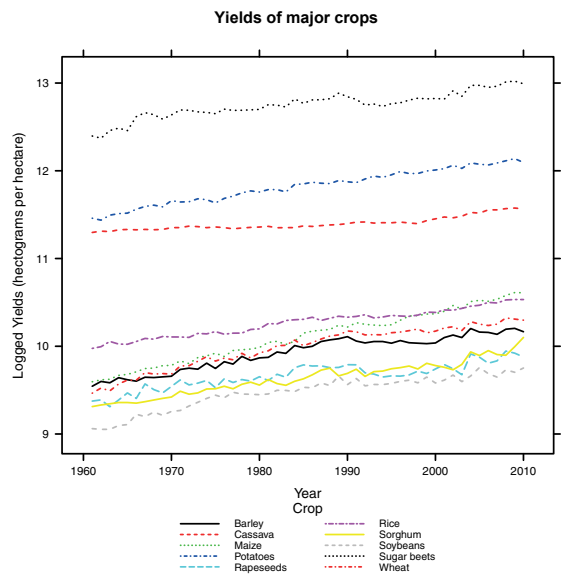

(a) Yields of ten crops over 50 years.

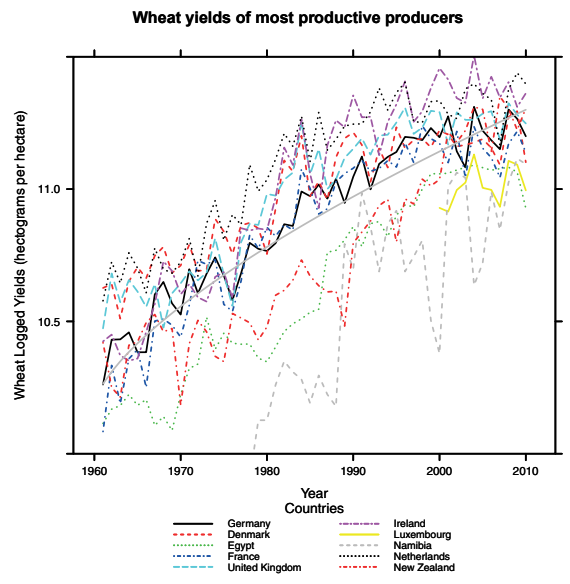

(b) Yields of countries with the highest wheat yields.

Figure 2. Yields of ten major crops.

In general, precipitation in crop growing areas has been increasing since 1988. The figure and tests suggest including a non-linear form of the precipitation variable in the model. They also suggest that, in contrast to temperatures, there has been a large amount of variation in the amount of precipitation falling in different crop growing grids. The ambiguous nature of the effects of precipitation reappear in the econometric results to follow. 


\subsection{Yields}

The FAO data used in the analysis spans a period from 1961 to 2010 and measures hectograms of a crop produced per hectare (FAOSTAT, 2013). However, only the years from 1961 to 2009 were used in the econometric analyses to follow because that is the range over which the CRU data extends. The intent of the analysis in this section is to present the general path that yields have followed over the last fifty years in order to identify possible trends which we would expect to reappear in the econometric analyses. Note that yields are rates in that they measure an amount of output per area and should not be confused with the amount of a crop produced. Yields are a measure of partial productivity in the sense that they inform us about one important aspect of the crop production process, other productivity measures, including labor and capital productivity, are not included in this study. We focus the analysis on yields because we expect that weather will have the greatest effect on that factor and because, frankly, that data are readily available in large quantities.

Figures $2 \mathrm{a}$ and $2 \mathrm{~b}$ show that, on average, crop yields have increased over the period under investigation, however they have in many cases, as has been previously noted, increasing at a decreasing rate (IFPRI, 2009; Sims et al., 2008). Figure 2a shows the general tendency of yield increases over the last 50 years. There have been noticeable differences in the growth rates of crops over the period. Yields of cassavas, at 31\%, have increased the least over the period, while percentage increases of sorghum (120\%), wheat (133\%) and maize (180\%) have been well over $100 \%$; while rapeseed $(65 \%)$, paddy rice $(75 \%)$, sugar beet (81\%), barley (86\%), potatoes (89\%) and soybeans (100\%) round out the field.

Figure $2 \mathrm{~b}$ provides a more detailed view of wheat yield developments. It shows the gradual decrease in the rate of yield increases which has occurred for ten countries with the highest wheat yields in 2009. The thick gray line near the middle of the figure was produced using a non-linear regression technique and shows the average path of yield increases. Please note that the $y$-axis in figure $2 b$ does not have a zero origin, this was done in order to direct focus to the marginal changes that have occurred over the period. Although the figure is only for wheat, the observed phenomenon extends to several crops in the study including barley, rapeseed, potatoes and rice, but less so for maize. A reduction in the rate of yield increases is less clear for soybeans and sugar beets, while yield growth appears flat for countries with the highest yields of cassava and sorghum. In any case, results from this section recommend adding a non-linear time trend to the model in order to try to capture potential effects of observed decreases in yield increases.

\subsection{MAGNET model}

The global economic simulation model used in the analysis is the Modular Applied General Equilibrium Toolbox (MAGNET) model, a CGE modeling framework developed 
at LEl, an institute which is a part of the Wageningen University and Research Centre in the Netherlands (WageningenUR, 2012). MAGNET has been used extensively to study the impact of policy changes on international trade, production, and consumption, and it took part in the comparison of CGE models mentioned above (Nelson et al., 2013a; Tabeau and Woltjer, 2010; van Meijl et al., 2006; Verburg et al., 2008). It is an extension and significant reorganization of the GTAP model, a widely used tool for global trade analyzes (Hertel, 1997). The following subsection provides a brief description of the model including the database, which forms the heart of the model, and the method of modeling actor behavior and markets.

The data used in the analysis is based primarily on version 8 of the database collected and processed by GTAP at Purdue University (Hertel, 1997). Version 8 uses 2007 as its base year and contains balanced economic data for 129 regions and 57 economic sectors (GTAP, 2012). For the purpose of this analysis, the 129 regions and 57 sectors have been aggregated in accordance with the research question. Aggregation allows less important data to be bundled together and the focus to be directed at the specific regions and sectors under investigation. The regional aggregation used in the current analysis consists of all primary crop producing countries and regions. The sectoral aggregation consists of the primary agricultural sectors available in MAGNET, namely, paddy rice, wheat, grains, and oils. The remaining sectors have been aggregated into a general manufacturing sector and a service sector. The model retains the standard MAGNET specification of five factors of production, including skilled and unskilled labor, capital, land, and natural resources.

MAGNET captures the behavior of three types of agents: households, firms and government, for each region of the model. Household behavior is captured via a representative regional household which is assumed to maximize its utility, collect all income that is generated in the economy, and allocate that income over private households, government expenditures, and savings for investment goods. Income is derived from payments by firms to the regional household for the use of endowments of skilled and unskilled labor, land, capital, and natural resources. The regional household also receives income from taxes paid by the private household, firms, and the government expenditures. Firms, profit maximizers, produce commodities by employing the aforementioned endowments and intermediate inputs from other firms based on constant returns to scale production technology and sell them to private households, the government, and other producers. Domestically produced goods can be either sold on the domestic market or exported. Similarly, intermediate, private household, and government demand for goods can be satisfied by domestic production or by imports.

Demand for and supply of commodities and endowments are traded in markets which are modeled as perfectly competitive and clear via price adjustments. Because all markets 
are in equilibrium, firms earn zero economic profits, households are on their budget constraints, and global savings must equal global investments. Since the CGE model can only determine relative prices, the GDP deflator is set as the numéraire of the model against which all other prices are benchmarked. Changes in prices resulting from the model simulations therefore constitute real price changes. For the current study we are using the model to carry out dynamic analyzes over time, specifically for 2007 (the base year) until 2020. Projections into the future are obtained by allowing the exogenous endowments of capital, land, natural resources, and labor, and the productivity of these factors, most notably yields, to grow according to standard forecast growth paths which are based on readily available economic data.

\subsubsection{Data used to shock MAGNET}

A shock in the current context means to change crop yield data in MAGNET from what it would be under the standard assumptions mentioned above, to what they are expected to be given forecasted changes in climate. The changes push the model from a starting equilibrium to an equilibrium which accounts for the changes in yields. Essentially, all countries are represented in the MAGNET model either as individual countries or as part of a region. Unfortunately for current purposes, many poorer countries, particularly in Africa, are not directly represented in the GTAP database. This is due primarily to data quality issues. Data for those countries are approximated at Purdue and then aggregated into regions. The aggregation of countries into regions in MAGNET means that our forecasted changes in yields need to be aggregated as well. The procedure used was to weight the ARIMA forecasts (explained below) according to the area that a country uses to grow a particular crop. For instance, if the total area of an aggregated region is 100 units, and the area of a particular country in that region is 20 units, then the forecasted yield change for that country is multiplied by $20 / 100$ and so forth for all countries in the region. Similarly, the number of agricultural sectors represented in MAGNET are aggregates, recall that standard GTAP has fifty- seven sectors to represent the entire global economy. Agricultural sectors, although well represented given their relatively small contribution to the world's economy, are few. For instance, grains is a sector in GTAP, and therefore MAGNET, which includes maize, but many other grains as well. We do not have data for all grains, consequently, we make the simplifying assumption that the sector grains follows our weighted estimates for maize, barley, and rye-the crops for which we do have data. Weighing the ARIMA forecasts was done according to the area used to grow each of the grain crops in MAGNET countries or regions; for instance, if a region primarily grows wheat, then wheat dominates the calculated shock. Similarly, the category oils in MAGNET was approximated based on the data we have for soybeans and rapeseed. Wheat and rice are separate sectors in MAGNET so no weighing was required. The resulting percentage change for each crop and each region and each of the five scenarios (see below) were used to shock MAGNET. 


\section{Models}

\subsection{Econometric Model}

\subsubsection{Introduction}

This section introduces the econometric models used to analyze relationships between yields and weather. It builds on the results of previous sections by incorporating observed relationships into the models and testing whether those relationships hold statistically. Econometric models are introduced according to their underlying assumptions, with particular attention paid to how the various models account for country heterogeneity. The purpose of this section is to develop a general model, applicable across all countries. The model is, by necessity, rough, and meant to give an overview of the relationship between yields and weather variables on a global scale. The model is then applied to the same data, but partitioned into poor and rich countries to determine whether there are statistical differences between the two groups. Finally, in the section thereafter, the data is further partitioned into country level data and run using the same model with the addition of autoregressive and moving average terms. This partitioning exercise allows us to examine differences between global and country level analyzes.

\subsubsection{Model descriptions}

Given the high level of correlation between maximum and minimum temperatures as observed in figures and confirmed statistically, minimum temperature was removed as an explanatory variable to avoid the problem of multicollinearity; although multicollinearity does not affect the consistency of estimates, it does adversely affect their efficiency. The choice to remove minimum rather than maximum temperature was somewhat arbitrary and, unsurprisingly given their high correlation, results were similar regardless of which temperature variable was included in the model. Model estimates for wheat, maize, rice, barley and soybeans are reported in table 1. The first three crops in the table were chosen, out of the ten crops in the study, because they are the world's top three food crops, while barley and soybeans were included because of the diversity they add in terms of model results. The range of significant outcomes runs the gamut, from cases in which both precipitation and maximum temperatures are statistically significant for a crop model, to cases in which neither variable is significant. Whenever results for the excluded five crops vary greatly from the five included in the table, those results are reported. Finally, this subsection concerns the specification or selection of a general model which is then to be applied to all crops, the results of which are reported in table 2 in subsection Model Estimates. 
Table 1. Estimates of yield data for 1990-2009

\begin{tabular}{l|cc|cc|cc|cc|cc} 
Model & \multicolumn{2}{|c|}{ Wheat } & \multicolumn{2}{c|}{ Maize } & \multicolumn{2}{c|}{ Rice } & \multicolumn{2}{c|}{ Barley } & \multicolumn{2}{c}{ Soybeans } \\
\hline Estimator & Precip. & Tmp. & Precip. & Tmp. & Precip. & Tmp. & Precip. & Tmp. & Precip. & Tmp. \\
\hline Aggregated & 13.77 & -35.74 & 4.41 & -131.39 & -0.10 & -44.44 & 2.99 & -109.92 & -10.55 & -709.05 \\
\hline & 2.29 & -0.38 & 0.61 & -0.90 & -0.03 & -0.55 & 0.60 & -1.45 & -2.11 & -5.36 \\
\hline First Diff. & 0.74 & -152.25 & 0.79 & -262.04 & 0.20 & 36.30 & -1.44 & -158.95 & -2.58 & -143.73 \\
\hline & 1.16 & -9.41 & 1.16 & -9.23 & 0.41 & 1.48 & -1.92 & -8.75 & -1.83 & -1.38 \\
\hline Pooled & -3.34 & -142.52 & -11.92 & -196.87 & -2.54 & -154.94 & -0.60 & -140.02 & 16.48 & -28.90 \\
\hline & -4.61 & -21.53 & -14.99 & -17.50 & -4.80 & -16.81 & -0.74 & -19.20 & 7.80 & -0.67 \\
\hline Within & 0.20 & -163.31 & 0.65 & -275.47 & 0.22 & 46.43 & -1.75 & -167.35 & -2.26 & 39.11 \\
\hline & 0.31 & -9.71 & 0.95 & -9.28 & 0.44 & 1.78 & -2.29 & -8.63 & -1.58 & 0.32 \\
\hline Between & -10.95 & -318.75 & 1.26 & 66.51 & -2.88 & 574.01 & -8.89 & -345.38 & -24.88 & -116.64 \\
\hline & -1.87 & -2.42 & 0.18 & 0.23 & -0.54 & 2.49 & -1.62 & -3.20 & -1.57 & -0.11 \\
\hline Random & 0.37 & -159.76 & 0.71 & -269.68 & 0.20 & 37.30 & -1.62 & -163.64 & -2.43 & -64.88 \\
\hline & 0.57 & -9.64 & 1.04 & -9.27 & 0.41 & 1.51 & -2.15 & -8.71 & -1.71 & -0.58 \\
\hline Random Sqr. & 2.94 & -149.30 & 5.09 & -250.40 & -1.70 & 29.59 & 2.96 & -148.00 & -1.14 & -61.05 \\
\hline & 2.12 & -8.62 & 2.92 & -8.43 & -1.13 & 1.16 & 1.77 & -7.61 & -0.25 & -0.54 \\
\hline Dynamic & 0.57 & -161.25 & 0.47 & -267.92 & 0.33 & 24.03 & -2.20 & -176.70 & 1.13 & -119.42 \\
\hline & 0.70 & -7.18 & 1.02 & -3.94 & 0.35 & 0.53 & -1.64 & -7.53 & 1.68 & -5.10 \\
\hline
\end{tabular}

Note: Estimators and estimates for wheat, maize, rice, barley and soybeans; t-values are reported underneath each estimate. An absolute value t-value of 1.96 or greater is generally considered to be statistically significant. Data for the pooled model are expressed in levels form, all other models use first-differenced data. Year dummies are included in all models, except the between models where it is not appropriate, in order to capture time effects. Tests for first and second-order serial correlation and Sargan tests provide no strong evidence that the dynamic AR(1) model is misspecified. The method by Swamy and Arora (Swamy and Arora, 1972) was used to calculate the variance components in the random effects model except when year correlations were negative, in which case the Nerlove method (Nerlove, 1971) was used. Asymptotic assumptions were not used when calculating standard errors because sample sizes do not justify the assumption of an $\mathrm{N}$ close to infinity for several of the crops examined. Asymptotic standard assumptions increase the $t$-value of a coefficient, not the value of the coefficient.

The number of countries used in the analyzes ranges from 145 for maize to 40 for sugar beets. A balance had to be struck between the number of countries included in a particular crop analysis and the number of years of available data. Although many countries have complete data sets for the entire period from 1961 to 2009, several important developing countries do not. Therefore, the decision was made to reduce the number of periods in the analysis from a potential of 50 to 20 years. This allowed more countries, and therefore more diversity, to be included in a particular crop analysis, and has the practical advantage of providing for data sets that meet the requirement of a large number of observations relative to the number of time periods (Bond, 2002).

$$
y_{\text {it }}=\mathbf{x}_{\text {it }}^{\prime} \beta+\mathbf{z}_{\mathrm{i}}^{\prime} \alpha+\varepsilon_{\text {it }}, \quad \text { where } i=1, \ldots, N ; \quad t=1, \ldots, T
$$


Equation 1 represents the basic panel framework (Greene, 2007). There are $K$ regressors in $\mathbf{x}_{\text {it }}$. The emphasis in panel models is on the second, individual effects, term $\mathbf{z}_{i}^{t}$, where $\mathbf{z}_{\mathrm{i}}$ contains a constant term and individual or group variables which may not be observable. Decisions regarding how $\mathbf{z}^{t}$ ia should be modeled are reflected in the assumptions made regarding heterogeneity.

The first model presented in table 1 is based on Lobell and Field's model as described in (Lobell and Field, 2007). Their model, identified here as the aggregated model, is included because of its influence and as a point of departure for discussing more standard panel models. Their methodology takes differences of the averages of each of the dependent and independent variables for each year in their analysis (41 years after first-differencing) and performs least squares on the aggregated differences. Their approach is labeled the aggregated model because it averages the hundreds and sometimes thousands of points of country level data available in the data set to one point for each year in the analysis without regard to heterogeneity.

A systematic, if not foolproof, means of interpreting the results for the aggregated model, and all of the other models in the table, is to find those variables in the table with absolute $\mathrm{t}$-values of around $\mathbf{1 . 9 6}$ or greater and determine how the variable in question changes yields. For instance, using the aggregated model and wheat, we can see that precipitation has an absolute t-value of 2.29 and so can be considered statistically significant. An estimator in a first-differenced model, including all models in the table with the exception of the pooled model, shows how a change in, for example, precipitation, affects changes in yields. Consider once again the precipitation aggregated model for wheat. The significant coefficient of 13.77 tells us that for every $1 \mathrm{~mm}$ increase in precipitation, we expect wheat yields to increase by 13.77 hectograms per hectare or 1.377 kilograms per hectare. Similarly, the value of -709.05 for soybeans and temperature tells us that for every increase of $0.1{ }^{\circ} \mathrm{C}$, the change in yields decreases by 709.05 hectograms per hectare or 70.91 kilograms per hectare. A negative estimate does not necessarily imply that yield levels are decreasing, only that yields are, on average, increasing at a decreasing rate (we know from figures above that soybean yields are increasing on average). Note that in the cases of wheat, maize, rice and barley, none of the temperature variables are significant, meaning that no statistical conclusions can be drawn in regards to relationships between yields and temperatures for those crops in the aggregated model. In regards to precipitation, the estimates for wheat and soybeans are significant. The high level of aggregation used in Lobell and Field's model comes at the cost of reducing the amount of information used to compute the estimates. More concretely, in this model and the two models to follow, no account is taken of individual country characteristics. These models assume, in short, that relations between yields and weather data are homogeneous across all countries. 
The second and third models in table 1 are the first-differenced and pooled (least squares) models. In terms of equation 3, these models, like the aggregated model, force all data to go through one common intercept term. As in the aggregate model, the first-difference model subtracts, per country, for all variables, the observation in period t from observation in $t+1$. Differences are then pooled together across all countries and run together using least squares. The result is a matrix with 19 (20 years minus the first observation) observations per country for each country per crop. This method has the advantage over the aggregated model of using much more of the available data. Comparing estimates from the first-differenced and aggregated models shows that maximum temperature is now significant for wheat, maize and barley. Precipitation is no longer significant for wheat, and just significant for barley and soybeans, and the effects of an increase in precipitation are negative for yields. In addition, the very high R-squared terms reported in Lobell and Field and replicated above for many of the crops, falls to nearly zero. By not averaging the data, the correlation between the dependent and independent variables decreases remarkably, implying that the act of aggregating imposes a structure on the data that disappears when the data is left in its disaggregated form.

Whereas the aggregated model averages all of the data by year, the other two models keep the data in their original, disaggregated, form and thereby retains the available variation in the data. In the pooled model, the 20 years of data for each country are stacked upon one another and run together using least squares. Panel data used in the pooled model was kept in levels form for statistical test purposes discussed below. Temperatures were significant for wheat, maize, rice and barley, and, all increases in temperatures had negative effects on yields. Precipitation is significant and negative for wheat, maize, rice and soybeans, but in the case of soybeans, an increase in precipitation has a positive effect on yields. Precipitation becomes significant for several crops and the variables for cassava, for the first time, become significant. Again, in this model, as in the previous two models, no account is made of individual country heterogeneity, thereby effectively circumventing an important advantage of panel data.

And the individual country effects are significant. A standard pooling test was performed using the sum of squared errors from the pooled and the within models. In the case of wheat, an F-ratio of 201 with a degree of freedom in the numerator of 2237 and a degree of freedom in the denominator equal to 2107 has an associated p-value of less than 0.0001 , providing strong evidence that country specific parameters should be included in models. Other crops showed similar results; in short, models that do not include country specific characteristics, such as those discussed above, should be avoided because they incorrectly assume that an important explanatory variable, namely country heterogeneity, has no influence on yields when it clearly does. 
The first model discussed to actually use information contained in the panel data format is the within model, a model which is numerically equivalent to the least-squares dummy variable model. The within model allows the unobserved country heterogeneity to be correlated with the observed variables. Essentially, country specific intercept terms are included in the model to capture time-invariant, country level effects. The within model is designed to capture and incorporate the individual country variation within the data. In this manner, those effects which are time invariant are removed from the data. For instance, a country's location does not, under normal circumstances, change significantly through time, the within methodology removes country location from the data and all other static information because subtracting the mean of a static variable from a static variable produces zero. In this manner, the effects of such variables, even those not explicitly in the model, drop out of the analysis. Results from the within model are similar to those from the first-difference model, a model which also removes time-invariant data. Temperature effects for both models for wheat, maize and barley are nearly identical; while the estimate for soybeans remains insignificant, the estimate for rice is nearly significant and positive. As for precipitation, only barley is significant and similar in magnitude to the first-difference estimate.

Whereas the intercept terms in the within model are assumed to be fixed and estimable, in the random effects model they are considered to be random drawings from a given probability distribution. In short, unobserved individual variables are assumed to be uncorrelated with the error term in the model (Baltagi, 2008; Greene, 2007, for discussion)). The estimator is calculated using generalized least squares, a method which transforms a least squares regression by a weighted average of the residuals of the within and between models. Standard errors for the between model are very small when compared to the within model which means, in short, the variation within a country dominates variation between countries. Finally, in order to capture the effects seen in 1b, a non-linear precipitation variable was added to the random effects model. This model is labeled as the random effects, squared, model. Estimates for the squared term are not included in the table, but were significant yet small for most crops. The random effects squared model is the most inclusive of the non-dynamic models examined in that it uses both within and between variations to estimate coefficients. Results indicate that temperatures for wheat, maize and barley are significant and, in all cases, lead to lower yields for higher temperatures, while increases in precipitation lead to increases in the yields of wheat, maize, and perhaps barley. Estimates for rice and soybeans remain insignificant. A BreuschPagan test rejects the null hypothesis that the intercepts are equal to zero, confirming that the pooled model should not be used. Finally, a Hausman test was run to test the null hypothesis that the coefficients estimated by the efficient random effects estimator are the same as those estimated by the consistent within effects estimator. In the model at 
hand, there is no evidence against the null that the GLS estimates are consistent, so a random effects estimator should be preferred to a fixed effects estimator.

The last model discussed is the dynamic panel AR(1) estimator. A dynamic estimator includes a lagged version of the endogenous variable as an explanatory variable. Lagged yields, although not of direct interest in the current study, are needed to calculate consistent estimates of the exogenous variables (Bond, 2002). Note that a squared precipitation term could not be included in the model because of the problem of near collinearity between that term and the time dummies. The time dummies were left in the model for reasons of comparison. Results for temperatures for wheat, maize, barley and now soybeans are all significant and negative. Precipitation is no longer significant for any of the crops in the table.

In general, results indicate that maximum temperatures and precipitation are statistically significant for several crops in several models. Ignoring standard errors for the moment, the results tell a fairly consistent story for models which incorporate individual effects, namely, increases in temperatures will reduce yields for all crops with the exception of rice. Results for precipitation are mixed, wheat, maize, and barley yields all increase, while rice and soybeans decrease. However, tests indicate that the random effects model is the preferred choice. An additional recommendation for that model is that its significant estimates fall between those of the levels pooled model and the within model, an indication that the model is well-specified (Bond, 2002). Other models considered and tested include a nonlinear time trend as suggested by figure $2 \mathrm{~b}$, and models with interaction terms, but they did not significantly alter the results of the random effects model. Finally, table 1 illustrates the consistency of the effects of weather on yields; higher temperatures almost certainly have negative effects on the yields of wheat, maize, and barley, and possibly soybeans.

\subsubsection{Model Estimates}

In the previous subsection we derived the general form of the model that will be applied in the analyzes to follow. This subsection addresses the hypothesis of whether there are statistical differences between how the yields of poor and rich countries have reacted to changing weather patterns.

$$
\begin{gathered}
\Delta \text { Yield }_{\mathrm{it}}=\text { constant }+\Delta \text { Maximum Temperature }_{\mathrm{it}}+\Delta \text { Precipitation }_{\mathrm{it}}+\Delta \text { Precipitation }_{\mathrm{it}}^{2}+u_{\mathrm{it}} \\
i=1, \ldots, N ; \quad t=1, \ldots, T ; \text { where } u_{\mathrm{it}}=\mu_{\mathrm{i}}+v_{\mathrm{it}}
\end{gathered}
$$


Table 2. Random effects model estimates of yield data for 1990-2009 for both poor and rich countries.

\begin{tabular}{l|ccc|ccc|} 
& \multicolumn{3}{|c}{ Poor Countries } & \multicolumn{3}{c|}{ Rich Countries } \\
\hline Crop & Temp. & Precip. & Precip. Sq. & Temp. & Precip. & Precip. Sq. \\
\hline Barley & -61.94 & 6.60 & 0.00 & -164.81 & 14.83 & -0.01 \\
\hline & -1.72 & 2.70 & -2.38 & -5.81 & 4.32 & -6.35 \\
\hline Cassava & 54.53 & 11.43 & 0.00 & -247.88 & -35.42 & 0.01 \\
\hline & 0.47 & 1.86 & -1.95 & -0.83 & -3.26 & 2.73 \\
\hline Maize & -164.82 & 3.14 & 0.00 & -276.98 & 6.97 & 0.00 \\
\hline & -3.97 & 1.59 & -1.46 & -5.84 & 2.12 & -1.97 \\
\hline Potatoes & 75.54 & 11.63 & 0.00 & -139.00 & -1.06 & 0.00 \\
\hline & 0.61 & 1.77 & -1.46 & -1.14 & -0.11 & -0.36 \\
\hline Rapeseeds & -33.66 & -7.72 & 0.00 & 4.86 & 2.55 & 0.00 \\
\hline & -1.37 & -4.13 & 3.86 & 0.19 & 1.22 & -1.79 \\
\hline Rice & -9.04 & -1.43 & 0.00 & 64.79 & -4.94 & 0.00 \\
\hline & -0.26 & -0.85 & 1.64 & 1.76 & -2.04 & 1.56 \\
\hline Sorghum & -16.24 & 1.70 & 0.00 & -182.62 & -1.50 & 0.00 \\
\hline & -0.96 & 2.23 & -1.54 & -2.67 & -0.28 & 0.16 \\
\hline Soybeans & -57.99 & 2.60 & 0.00 & -138.03 & 12.35 & -0.01 \\
\hline & -2.23 & 1.84 & -1.72 & -3.89 & 3.61 & -3.79 \\
\hline Sugar beets & -2258.91 & 160.51 & -0.06 & -899.97 & 223.41 & -0.11 \\
\hline & -3.17 & 3.03 & -2.55 & -2.40 & 4.83 & -4.40 \\
\hline Wheat & -106.36 & 3.40 & 0.00 & -153.57 & 10.20 & -0.01 \\
\hline & -3.85 & 1.78 & -1.40 & -6.42 & 3.64 & -4.76 \\
\hline
\end{tabular}

Note: All variables are first-differenced as in table 1. Year dummies are included in all models. As in table 1, either the Swamy and Arora or Nerlove methods were used to calculate the variance components of the model.

where the $\mu_{\mathrm{i}}$ denotes the unobservable individual specific effects and $v_{\mathrm{it}}$ denotes the remaining disturbance.

Table 2 reports regression results for all crops using the random effects model with maximum temperature, precipitation, and squared precipitation as exogenous terms. The method used to categorize countries was to split the data according to a country's average real GDP per person for available years in the Penn World Table database (Heston et al., 2011). For both poor and rich countries, F-statistics for barley, maize, sorghum, soybeans, sugar beets and wheat are significant at the $5 \%$ or better levels and rice nearly so at that same level. The regressions for potatoes are insignificant for both poor and rich countries, while the remainder are significant for one group or the other. Before turning to the results in the table, we note that equation 2 was used to run regressions for data combining both the poor and rich countries. A dummy variable to distinguish between poor and rich countries was included in the regressions in order to test whether there are significant differences between poor and rich countries. The dummy was positive 
and significant for maize, potatoes, rice and sugar beets. For those crops, poor and rich countries should be modeled separately in order to account for the higher initial yields of rich countries.

Maximum temperatures are significant for both poor and rich countries for barley, maize, sorghum, soybeans and wheat. Only in the case of sugar beets is the maximum temperature significant for poor but not rich countries. And in all cases, both for poor and rich countries, the effects of rising temperatures on yields are negative. Yields of rich countries appear to be more sensitive to temperature changes in the cases of barley, maize, sorghum, soybeans and wheat, although it is not possible to discuss the relative effects for sugar beets because the estimate for rich countries is insignificant. By sensitive we mean, for instance, that a 0.1 degree increase results in a greater decrease in yields for rich countries than the same temperature increase for poorer countries. However, yields in rich countries are generally higher than in poorer countries, in fact, there is a strong positive, non-linear, relationship between GDP per person and yield that can be observed by plotting yields against real GDP per person (Powell and Rutten, 2013). Yields in poorer countries are somewhere between a half and a third of those of richer countries in our sample for those crops for which estimates were significant.

Take the case of wheat, for which the average yields in poorer countries are 20,190 and 33,913 hectograms per hectare ( $\mathrm{hg} / \mathrm{ha}$ ) in richer countries. According to table 2, a 0.1 degree increase in temperature will reduce yields in poor countries by $106.36 \mathrm{hg} / \mathrm{ha}$, while for rich countries the reduction will be $153.57 \mathrm{hg} / \mathrm{ha}$, which convert to a reduction in wheat per ha of around $0.53 \%$ for poorer countries and $0.45 \%$ for richer countries, the relationship is similar for maize and sugar beets. For sugar beets, poorer countries do far worse than richer countries. However, for soybeans, it is the richer countries that are worse off. These are clearly rough estimates, for instance, standard deviations reported in the table show that there is a great deal of variation within the two broad GDP categories. The results indicate the importance of examining the effects of weather on a per crop basis.

For poorer countries, precipitation is significant for rapeseed, soybeans and sugar beets. An increase in precipitation leads to greater yields for those crops. Precipitation is significant for more crops grown in richer countries; in addition to rapeseed, soybeans and sugar beets, estimates for barley, cassava, maize and wheat are also significant for richer countries. Precipitation increases have a positive effect on yields of barley, maize, rapeseed, soybeans, sugar beets and wheat, but a negative effect on cassava yields. For the three crops which can be compared, namely rapeseed, soybeans and sugar beets, poor countries appear to be more susceptible in the case of rapeseed and sugar beets, but less so in the case of soybeans. In other words, a $1 \mathrm{~mm}$ increase in precipitation will reduce 
yields of rapeseed and sugar beets more for poor countries than for richer countries, but will have less of an impact for soybeans.

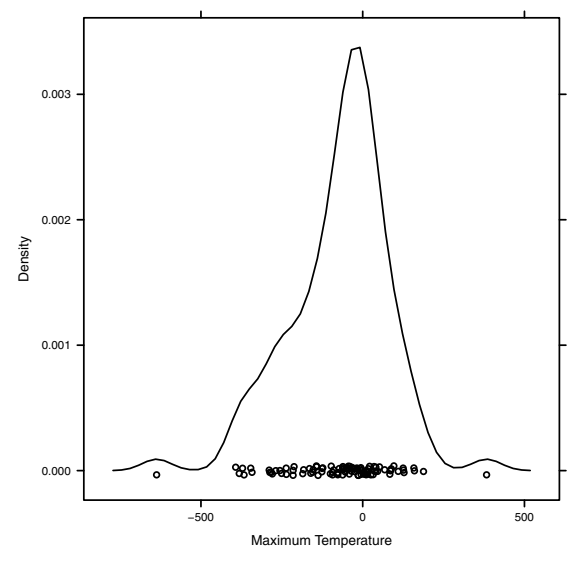

(a) Coefficients for wheat temperature estimates.

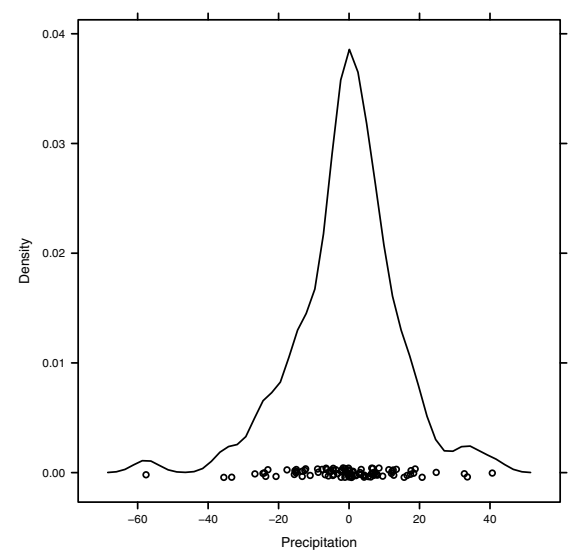

(b) Coefficients for wheat precipitation estimates.

Figure 3. Wheat coefficients for maximum temperatures and precipitation.

Conclusions to be drawn from this subsection are that the effects of weather variables on yields are both crop and country specific. Results from table 2 clearly indicate that for those crops with significant outcomes, higher temperatures will reduce yields, while increases in precipitation will have positive effects for all crops except cassava. In short, whether changes in weather will harm poorer or richer countries is crop dependent.

\subsection{ARIMA model}

Panel models give a general overview of relationships between yields and weather variables per crop at a global level. However, they produce just one global equation per crop characterizing the relationship between yields and weather variables, it that sense panel models are rough approximations. In this subsection, country level analyzes are calculated for use in MAGNET. In particular, ARIMA models are used to forecast yields for wheat, rice, barley, maize, rapeseed, sorghum and soy. These crops are then aggregated into the following four aggregate agricultural sectors included in MAGNET: wheat, rice, grains, and oils.

\subsubsection{ARIMA methodology}

ARIMA models are used to forecast time series variables using information contained in past realizations of the yields themselves and the weather variables. Estimates of the exogenous variables tell us the additional contribution to yields associated with the weather variables net of information contained in yields from previous periods. The ARIMA models estimated are not complete explanatory models, building that sort of 
model requires micro-economic, crop level data that is not generally available for a large number of countries.

The basic form of the model is:

$$
\begin{aligned}
y_{\mathrm{t}} & =\theta_{1} y_{\mathrm{t}-1}+\ldots+\theta_{\mathrm{p}} y_{\mathrm{t}-\mathrm{p}}+\varepsilon_{\mathrm{t}}+\alpha_{1} \varepsilon_{\mathrm{t}-1}+\ldots+\alpha_{\mathrm{q}} \varepsilon_{\mathrm{t}-\mathrm{q}}+ \\
& +\Delta \text { Maximum Temperature } \mathrm{t}+\Delta \text { Precipitation }_{\mathrm{t}}+\Delta \text { Precipitation }_{\mathrm{t}}^{2}
\end{aligned}
$$

For each country, the model was run across a spectrum of possible, meaningful, lags. The 'best' model was then chosen based on the Akaike Information Criterion (AIC). That model was then used to forecast yields ten years into the future using standard time series forecasting methods.

The figures in 3 show the density distributions of estimates for country level coefficients for wheat. For instance, figure 3a shows that a large majority of estimates for maximum temperatures for wheat range from -400 to 200 . The mean of the data is slightly negative, as expected given the generally negative effects of temperatures on wheat. A value of -100 implies that a $0.1{ }^{\circ} \mathrm{C}$ increase temperature reduces wheat yields by -10.0 hectograms.

The $t$-values presented in table 3 for each of the temperature and precipitation variables indicate that only a minority of the estimates are significant. That result is not surprising given that the autoregressive and moving average terms in the model are picking-up a lot of the variations and that there are many factors that influence yields which are not included in the model. What the ARIMA procedure employed does is select the best model given the parsimonious method used. The models, and resulting forecasts, should be seen as indicators of the direction that yields may take given changes in weather patterns, and not as precise predictions.

Table 3. Significance values of major crops at two levels.

\begin{tabular}{l|cc|cc|cc|c|} 
& \multicolumn{2}{|c}{ Temperature } & \multicolumn{2}{c}{ Precip. } & \multicolumn{2}{c|}{ Precip. Sq. } \\
\hline Crop & t-val. > 1.96 & t-val. > 1.50 & t-val. > 1.96 & t-val. > 1.50 & t-val. > 1.96 t-val. > 1.50 & $\begin{array}{l}\text { Num. } \\
\text { Countries }\end{array}$ \\
\hline Barley & 12 & 17 & 21 & 26 & 12 & 27 & 58 \\
\hline Maize & 19 & 29 & 19 & 38 & 21 & 32 & 132 \\
\hline Rapeseed & 3 & 7 & 8 & 8 & 5 & 9 & 26 \\
\hline Rice & 18 & 30 & 17 & 28 & 10 & 20 & 101 \\
\hline Sorghum & 11 & 15 & 9 & 18 & 13 & 19 & 73 \\
\hline Soybeans & 2 & 7 & 8 & 13 & 9 & 14 & 39 \\
\hline Wheat & 19 & 34 & 28 & 40 & 15 & 27 & 97 \\
\hline
\end{tabular}

Note: The $\mathrm{t}$-values are reported in absolute values. 


\subsubsection{MAGNET simulations}

This section discusses the economic implications of shocks calculated using ARIMA forecasts. It uses those results to run five simulations, one, the base scenario, in which neither temperatures nor precipitation change, and four scenarios in which yields are shocked assuming changes in temperatures and precipitation are realized. For instance, scenario $(0,1)$ shocks yields according to an assumed $0.0 \mathrm{~mm}$ increase in precipitation and a $0.1{ }^{\circ} \mathrm{C}$ increase in temperature for ten years; while scenario $(2,1)$ assumes that yields are affected by a $2.0 \mathrm{~mm}$ yearly increase in precipitation and a $0.1{ }^{\circ} \mathrm{C}$ increase in temperatures. The other two scenarios, $(0,2)$ and $(2,2)$, are calculated following the same methodology. The shock implemented assumes in the case of scenario $(2,1)$, that precipitation increases by $2 \mathrm{~mm}$ per year for ten years and $0.1^{\circ} \mathrm{C}$ per year for ten years. In short, in ten years precipitation is assumed to have increased by $20 \mathrm{~mm}$ and temperatures by $1.0^{\circ} \mathrm{C}$. This is a big simulated increase, but within the realm of possibility. For instance, earth's mean surface temperature has increased in the 20th Century by about $0.8^{\circ} \mathrm{C}$ with about two-thirds of that increase occurring since 1980 National Research Council (2011). However, the point of the MAGNET exercises is to establish direction rather than calculate precise estimates, relatively large shocks help to realize this aim without being so large as to destabilize the model. In addition, the results are reported using an average of the simulations so that the influence of extreme simulations are reduced.

The following two figures present, respectively, the expected changes in exports and imports resulting from changes in weather across four crop categories. As mentioned, each point in a figure is the average of the four simulated changes in weather less the base case in which weather remains constant for each of the 45 regions in the sample ${ }^{1}$ in the study. Together these regions encompass the world. Results should be interpreted as indicating the additional effects of changes in weather on the economy assuming everything else in an economy continues to develop as expected. Please note that MAGNET, like most CGE models, is a deterministic model, no stochastic assumptions are made. While the shocks were created using econometric techniques which allow measures of confidence to be associated forecasts, MAGNET produces unique, non-distributional, outcomes; therefore, terms such as estimates and forecasts do not have their associated technical connotations. The advantage of using MAGNET is that it provides a detailed, global, sectoral specific overview of economic results following a shock, something econometric models are not designed to do.

Figures 4a and import 5a show expected changes in exports and imports respectively. More precisely, they present the additional percentage changes in exports and imports expected in 2020 based on the average changes over the weather scenarios. It is important to keep in mind when reading the figures that the values reported are relative to a country's exports and imports and are percentage values. For instance, Korea is not a 
significant exporter of grains, so a nearly $10 \%$ increase in exports for that region is only a small amount in absolute terms.

Whereas production changes for the most part were found to be small, changes in trade vary considerably as can be seen by the range of values along the $x$-axes of the figures. The major exporters of grains are the United States, Argentina, Brazil, Ukraine, South Africa and the European Union. Exports from the United States increase slightly while the region Rest of South America, which includes Argentina, and the region of South Africa, will experience sharp falls in exports of between $4 \%$ and $5 \%$. Brazil, on the other hand, will experience a slight increase in exports. In what will become a familiar refrain, the situation for Europe is mixed, with some countries expected to experience increases in grain exports while others will experience decreases. The major European exporter, the Ukraine (ree), will see a decrease in exports of around $2 \%$, while exports from Russia will increase by around the same percentage.

Of the major palm oil exporters, Indonesia will experience a decrease in exports of oils of around 5\%, while exports from Malaysia (sea), will remain constant. A major soybean exporter Rest of South America, a region which includes Venezuela, can expect a large decrease in exports, while Brazil will see exports increase by around $5 \%$ and the United States by around $2 \%$. The large increases in rice exports for Japan and Korea have to be tempered by the fact that they export very little rice. All of the current major rice exporters, Thailand, Vietnam (both sea), and India, will experience slight decreases in exports.

\footnotetext{
${ }^{1}$ Regions: kor = Koreas; me = Middle East; indo = Indonesia; rus = Russia; fin = Finland; mex = Mexico; swe = Sweden; grc = Greece; mltcyp = Malta and Cyprus; prt = Portugal; rsas = Rest of South Asia; chi = China; tur = Turkey; usa = USA; aut = Austria; naf = North Africa; jap = Japan; can = Canada; deu = Germany; bra = Brazil; bulrom = Bulgaria and Romania; irl = Ireland; caf = Central Africa; rwe = Rest of Western Europe; nld = Netherlands; $d n k=$ Denmark; $g b r=$ United Kingdom; belu = Belgium and Luxembourg; ita = Italy; fra = France; india = India; svk = Slovakia; svn = Slovenia; pol = Poland; sea = Southeast Asia; esp = Spain; ree = Rest of Eastern Europe; $c z e=$ Czechoslovakia (and components thereof); hun = Hungary; oce = Australia and New Zealand; rsa $=$ Rest of South Asia; saf = South Africa (region); rca = Rest of Central America; euba = Eastern Europe and Baltic states; $r f s u=$ rest of former Soviet Union.
} 
Of the current major wheat exporters, the United States and Canada will see substantial increases in exports, Europe will experience mixed results with France showing a small decrease and Germany a small increase. Australia will see a slight decrease in exports, while Russia will see a remarkable increase nearing 30\%. In 2013 Russia exported around 12 million tons of wheat, so the increase of $30 \%$ amounts to around 3.6 million additional tons due to changes in temperatures and precipitation. The Ukraine (ree), which exported around 3.1 million tons in 2013 , is expected to experience a substantial decrease in production.

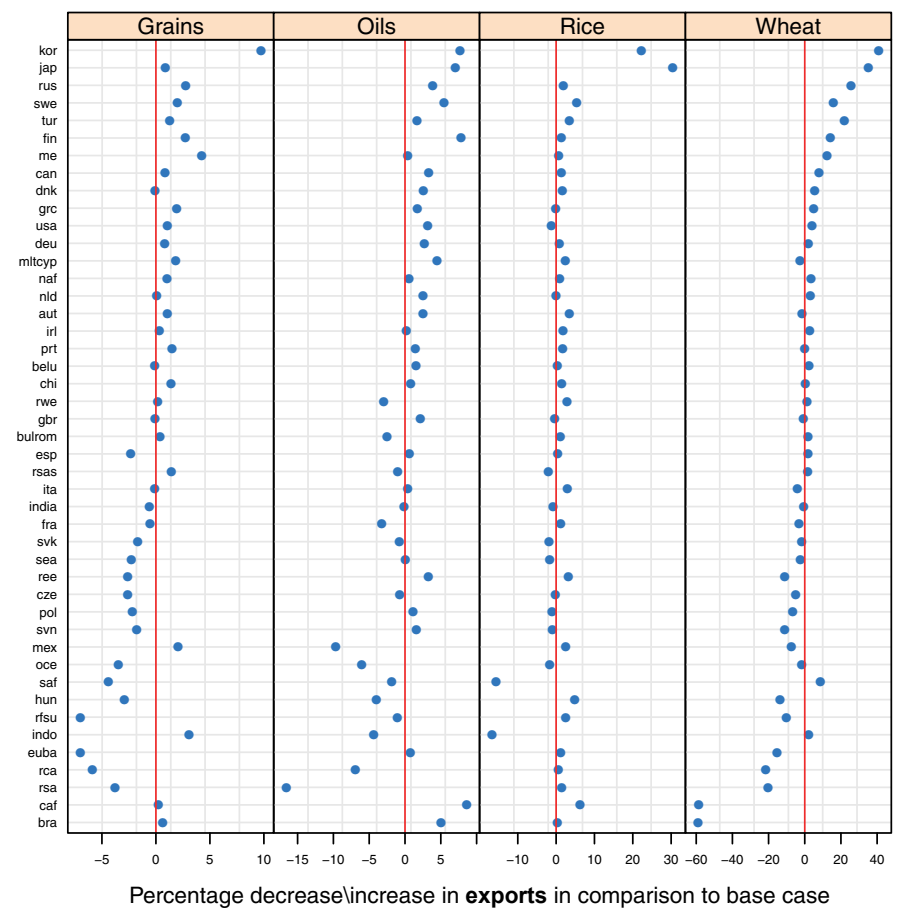

(a) Exports.

Figure 4. Exports.

Note: The values presented in this figure and the next are percentage differences.

Results reported in the import figure $5 \mathrm{a}$ are dominated by the region Rest of Former Soviet Union (rfsu), which includes countries such as Afghanistan, Kazakhstan, Kirghizstan, and Tajikistan. This region shows remarkable increases in the imports of grains, oils and wheat. However, these countries import very little of these products so their results should be interpreted with caution. The major importers of maize are Japan, Mexico, Korea, the Western Europe and China. Japan and Mexico will experience little change in amounts imported while Western Europe shows a slight decrease in imports. China will experience a slight decrease in oil imports, while India will experience a very large, over $20 \%$, increase 
in vegetable oil imports. Results for Western Europe show a slight increase in imports on average. India will import substantially more rice, 50\%, due to changes in weather, however, recall that it is a large net exporter of rice. Of the major importers of rice, the region of Central Africa (caf), which includes Nigeria, is stable, while imports to the region of North Africa (naf) fall, and imports into the region of South Africa increase. Imports into two other major importing regions, Bangladesh and the Middle East, also appear to be stable. Changes for wheat importers are generally small. Imports to Egypt (naf), the world's largest importer, will fall, as they will for Indonesia. Imports into Brazil will fall by $1 \%$ and $2 \%$, while Chinese imports will increase slightly.

Ultimately, policy makers are concerned with consumption, particularly in poorer countries. Changes to consumption were found to be small relative to changes in exports and imports. This is a reasonable outcome given the structure of the consumption of agricultural products in most countries. On the whole, countries or regions consume products produced within the country or region, while exports and imports absorb surpluses and deficits. Recall as well, that although the shocks implemented are large in terms of the weather changes simulated, weather effects on yields only explain a small part of the total production of crops.

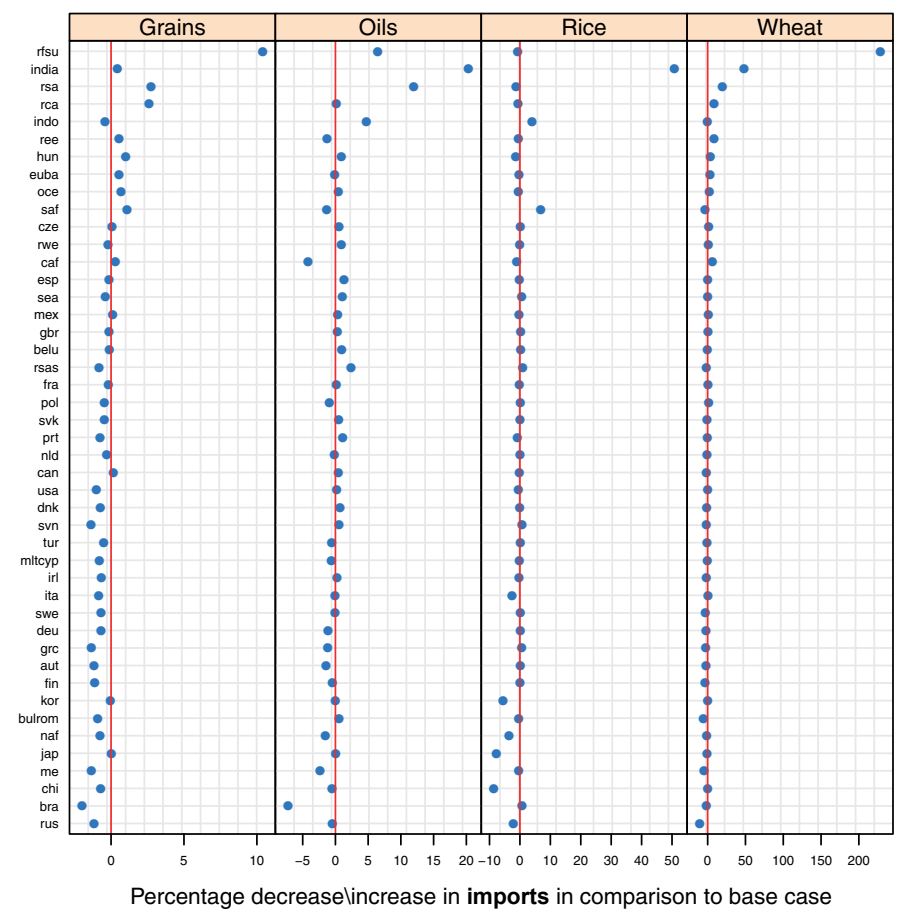

(a) Imports.

Figure 5. Imports. 
In terms of consumption, the biggest gainers and losers for grains are people from the region Rest of former Soviet Union ( $r f s u$ ), India, Central and South America, India, Central and North Africa, and some of the newer European countries. Korea, China, Turkey, and the Middle East region experience increases in consumption. Grain consumption in richer countries is not significantly affected by changes in weather. For oils, Indonesia and India consume less as do many other regions in Asia and the region Rest of Central America. All regions in Africa (naf, caf, saf), consume less oil. The only major increase in oil consumption occurs in Mexico. Consumption of rice in Indonesia, India, and other regions in Asia is also adversely affected. Africa escapes largely unscathed in terms of rice consumption. Finally, wheat consumption in the region of Central Africa falls, as it does in the region of the Rest of the Former Soviet Union. The countries that benefit are India, Rest of Central America and the Rest of South America. In general, rich countries are not significantly affected by weather changes; for instance, consumption in Germany, Canada, the United States and France change little. Japan consumes slightly less rice, and Ireland consumes less of everything.

\section{Conclusions}

Conclusions will be drawn from each of the above three sections with an emphasis placed on the unique contribution of each technique towards answering the research questions and the section's contribution to the paper's overall methodology and conclusions.

The first section described the basic characteristics of the data and found strong evidence of increasing temperatures in grids growing ten major food crops. Temperature fluctuations across crops follow similar short and long-term patterns and the increases were found to be statistically robust. Results for precipitation showed two distinct periods, a first in which precipitation fell, followed by a second in which it rose. They also suggest that, in contrast to temperatures, there has been a large variation in the amount of precipitation falling in different crop growing grids. The results suggest that if the underlying data generating processes behind the observed increases in temperatures persists, as it has throughout the period studied, then we can expect temperatures in the future to rise as well.

The yields subsection found that yields have been increasing but, in many cases, they have been increasing at a decreasing rate, results which suggest that a non-linear term should be included in regressions. Combining the weather and yield data stressed the degree to which relationships between those variables vary across the globe. While many countries have experienced increasing yields and temperatures, a sizable minority have experienced increasing yields and decreasing temperatures. 
Panel results indicated that temperatures for wheat, maize, and barley are significant and, in all cases, lead to lower yields given higher temperatures, while increases in precipitation lead to increases in the yields of wheat, maize, and perhaps barley. Estimates for rice and soybeans were insignificant. A Breusch-Pagan test rejected the null hypothesis that intercepts are equal to zero, confirming that pooled models should not be used. Finally, a Hausman test was used to test the null hypothesis that the coefficients estimated by the random effects estimator was the same as those estimated by the within effects estimator. There was no evidence against the null that the GLS estimates were consistent therefore a random effects estimator was found to be preferred to a fixed effects estimator. In short, individual country effects were found to be significant. Standard pooling tests were performed using the sum of squared errors from the pooled and within models. In all cases, an F-type test provided strong evidence that country specific parameters should be included in models. This outcome was expected given the previously observed diversity of relationships between yields and weather data. In short, models that do not include country specific characteristics should be avoided.

In general, results indicate that maximum temperatures and precipitation are statistically significant for several crops in several models. However, tests indicate that the random effects model is the preferred model choice. An additional recommendation for that model is that its significant estimates fall between the pooled model and the within model, an indication that the model is well-specified. Other models were considered, but they did not significantly alter the results of the random effects model. Ignoring standard errors, the results tell a consistent story for models with individual effects, namely, increases in temperatures will reduce yields for all crops with the exception of rice. Results for precipitation were mixed, wheat, maize, and barley yields all increased, while rice and soybeans decreased.

ARIMA models were then used to estimate ten year forecasts of the effects of changes in weather variables on yields. The 'best' models for each country and each crop in the analysis were chosen according to the AIC criterion; forecasts from the selected models were then used within MAGNET to simulate weather changes. For many countries, the weather variables were found to be statistically insignificant. However, the wide spectrum of countries and crops over which results were found to be significant gives some confidence that the basic ARIMA structure, including the weather terms and the AR and MA terms, is identifying important effects of the weather terms on yields.

The MAGNET model was then shocked using the ARIMA forecasts to determine the effects, ten years in the future, of changes in weather on the global production, trade, and consumption of four major crop groups, namely, grains, oils, wheat, and rice. Results for exports, imports, and consumption will be discussed immediately below in the order 
listed. Results for exports closely follow changes in production. Wheat exports from the United States and Argentina increase slightly, but many other countries in the region South America experience sharp decreases in exports. Exports from Indonesia, a major exporter of oils, will fall, as will oil exports from South America. However, oil exports from the United States and Brazil increase following their expected increases in production. All of the major rice exporters can expect slight decreases in exports, while the major wheat producers will all export more.

The major importers of grains are not substantially affected by the changes, although Chinese imports fall slightly. China will also experience a decrease in oil imports. Of the major importers of rice, the region of Central Africa (caf), which includes Nigeria, were stable, while imports to the region of North Africa (naf) fell, and imports into the region of South Africa increased. Changes for wheat importers were in general found to be small, while imports to Egypt (naf), the world's largest importer, will fall, as they will for Indonesia. Brazilian imports will fall by $1 \%$ and $2 \%$, while Chinese imports will increase slightly.

Ultimately, policy makers are concerned with consumption, particularly in poorer regions. For grains, the biggest losers are people from the region Rest of former Soviet Union (rfsu), India, Central and South America, Central and North Africa, and some of the newer European states. Those regions are Korea, China, Turkey, and the Middle East. Grain consumption in richer countries is not significantly affected by changes in weather. For oils, Indonesia and India will consume less as will many other regions in Asia and the region Rest of Central America. All regions in Africa (naf, caf, saf), will consume less oil. The only major increase in oil consumption occurs in Mexico. Consumption of rice in Indonesia, India, and other regions in Asia is also adversely affected, although Africa escapes largely unscathed in terms of rice consumption. Finally, wheat consumption in the region of Central Africa falls, as it does in the region of the Rest of the Former Soviet Union. The countries that benefit are India, the regions Rest of Central America and Rest of South America. In general, rich countries are not significantly affected by weather changes.

The analysis brought together several techniques, each with their own strengths and weaknesses. Analyzes which relied primarily on figures or simple regressions of variables through time, while fine for investigating general trends of individual variables, can be deceptive when examining interactions between variables. Using panel models it was possible to quantify the importance of country specific characteristics, but that methodology produces just one general model for all countries. The ARIMA methodology was used to forecast yields into the future, but, given the high aggregation level of the analysis and consequent lack of data, the methodology could not be used to analyze the underlying components determining yields. Furthermore, while the MAGNET model has a global scope, the results it produces are heavily dependent on the acceptance of 
underlying economic assumptions, and its deterministic nature means that it is impossible to attach statistical confidence to results. Finally, we asked a very limited set of data to do a lot of work. In our favor, we limited the forecast period to just ten years, a relatively small number of years in comparison to many CGE experiments, and our shocks were modest. We have attempted to play to the strengths of each method, while being forthright throughout the text concerning their respective limits.

Mindful of the above qualifications, in terms of the main research question, we conclude that changing weather patterns will have significant effects on the trade, and, in some cases, the consumption of major food crops. The effects will be both country and crop specific. As for the ancillary question concerning the relative effects of weather on richer versus poorer countries, results were mixed, but indicate that consumption in richer countries, with few exceptions, will be largely unaffected by changing weather patterns, while consumption in many poorer regions will decrease. 


\section{References}

Arvis, J., Duval, Y., Shepherd, B., and Utoktham, C. (2013). Trade Costs in the Developing World: 1995-2010. World Bank. Baltagi, B. H. (2008). Econometric Analysis of Panel Data. John Wiley and Sons, Ltd.

Bond, S. (2002). Dynamic panel data models: A guide to micro data methods and practice. The Institute for Fiscal Studies Department of Economic, UCL cemmap working paper CWPO9/02.

Bradshaw, B., Dolan, H., and Smit, B. (2004). Farm-level adaptation to climatic variability and change: Crop diversification in the Canadian prairies. Climatic Change, 67:119-141.

Cutter, S. L., Emrich, C. T., Webb, J. J., and Morath, D. (2009). Social vulnerability to climate variability hazards: A review of the literature. Staff report no. ages 9049, Hazards and Vulnerability Research Institute, Department of Geography, University of South Carolina, Columbia, SC 29208.

Dixon, P. B., Parmentar, B. R., Ryland, G. J., and Sutton, J. (1977). ORANI: A General Equilibrium Model of the Australian Economy. First progress report of the impact project, vol.2. Canberra, Australian Government Publishing Service.

Erda, L., Wei, X., Hui, J., Yinlong, X., Yue, L., Liping, B., and Luyong, X. (2005). Climate change impacts on crop yield and quality with co2 fertilization in china. Philosophical Transactions of The Royal Society, Biological Sciences, 360(1463):2149-54.

FAOSTAT (2013). United Nations Food and Agricultural Organization (UN-FAO) online statistics database. http:// faostat.fao.org/site/291/default.aspx.

Frees, E. W. (2004). Longitudinal and Panel Data: Analysis and Applications in the Social Sciences. Cambridge University Press.

Frees, E. W. and Miller, T. W. (2004). Sales forecasting using longitudinal data models. International Journal of Forecasting, 20:99-114.

Gebrehiwot, T. and Veen, A. v. (2013). Farm level adaptation to climate change: The case of farmer's in the Ethiopian Highlands. Environmental Management, 52:29-44.

Greene, W. H. (2007). Econometric Analysis. Prentice Hall, sixth edition.

Greenstone, M. and Deschenes, O. (2006). The economic impacts of climate change: Evidence from agricultural profits and random fluctuations in weather. FEEM Working Paper No. 6.

GTAP (2012). GTAP 8 database description. https://www.gtap.agecon.purdue.edu/databases/v8/ v8_doco.asp. Hamilton, J. D. (1994). Time Series Analysis. Princeton University Press.

Hertel, T.W., editor (1997). Global Trade Analysis: Modeling and Applications. Cambridge University Press.

Hertel, T. W., Martin, W. J., and Leister, A. M. (2010). Potential implications of a special safeguard mechanism in the WTO: the case of wheat. Policy research working paper series 5334, The World Bank.

Heston, A., Summers, R., and Aten, B. (2011). Penn world trade version 7.0. Center for International Comparisons of Production, Income and Prices at the University of Pennsylvania.

Hsiao, C. (2003). Analysis of Panel Data. Cambridge University Press, New York, second edition. 
FPRI (2009). Climate change: Impact on agriculture and costs of adaptation. food policy report. Technical report, IFPRI. Jones, P. and Harris, I. (2008). Cru time series (ts) high resolution gridded datasets. Technical report, University of East Anglia Climate Research Unit (CRU). NCAS British Atmospheric Data Centre.

Josling, T., Anderson, K., Schmitz, A., and Tangermann, S. (2010). Agricultural products: One hundred years of contributions by agricultural economists. American Journal of Agricultural Economics, 92(2):424-446.

Leff, B. N., Ramankutty, and Foley, J. A. (2004). Geographic distribution of major crops across the world. Global Biogeo- chemical cycles, 18.

Licker, R., Johnston, M., Foley, J. A., Barford, C., Kucharik, C. J., Monfreda, C., and Ramankutty, N. (2010). Mind the gap: how do climate and agricultural management explain the 'yield gap' of cropland around the world? Global Ecology and Biogeography, 19(6):769-782.

Lobell, D. B. and Field, C. B. (2007). Global scale climate-crop yield relationships and the impacts of recent warming. Environmental Research Letters, 2.

Lobell, D. B., Schlenker, W., and Costa-Roberts, J. (2011). Climate trends and global crop production since 1980. Science, 333(6042):616-620.

Luers, A. L., Lobell, D. B., Sklar, L. S., Addams, C. R., and Matson, P. A. (2002). A method for quantifying vulnerability, applied to the agricultural system of the Yaqui Valley, Mexico. Global Environmental Change, 13(4):255-267.

Moïsé, E., Delpeuch, C., Sorescu, S., Bottini, N., and Foch, A. (2013). Estimating the constraints to agricultural trade of developing countries. Trade policy papers no. 142, OECD.

National Research Council (2011). America's climate choices. Technical report, The National Academic Press.

Nelson, G. C., Valin, H., Sands, R. D., Havlik, P., Derying, D., Elliot, J., Fujimori, S., Hasegawa, T., Heyhoe, E., Kyle, P., von Lampe, M., Lotze-Campen, H., Mason d'Croz, D., van Meijl, H., van der Mensbrugghe, D., Müller, C., Popp, A., Robertson, R., Robinson, S., Schmid, E., Schmitz, C., Tabeau, A., and Willenbockel, D. (2013a). Climate change effects on agriculture: Economic responses to biophysical shocks. PNAS. Epub ahead of printing.

Nelson, G. C., van der Mensbrugghe, D., Blanc, E., Calvin, K., Hasegawa, T., Havlik, P., Kyle, P., LotzeCampen, H., von Lampe, M., Mason d'Croz, D., van Meijl, H., Müller, C., Reilly, J., Robertson, R., Sands, R. D., Schmitz, C., Tabeau, A., Takahashi, K., and Valin, H. (2013b). Agriculture and climate change in global scenarios: why don't the models agree. Agricultural Economics, 45(1):85-101.

Nerlove, M. (1971). Further evidence on the estimation of dynamic economic relations from a timeseries of cross-sections. Econometrica, 39:359-382.

Pandey, S., Bhandari, H., and Hardy, B. (2007). Economic costs of drought and rice farmers' coping mechanisms: a cross- country comparative analysis. Technical report, IRRI (International Rice Research Institute.

Powell, J. and Rutten, M. (2013). Convergence of European wheat yields. Renewable and Sustainable Energy Reviews, 28:53-70. 
Powell, J. P. (2014). Productivity implications of extreme precipitation events: the case of Dutch wheat farmers. Submitted February 2014.

Prato, T., Zeyuan, Q., Pederson, G., Fagre, D., Bengston, L. E., and Williams, J. R. (2010). Potential economic benefits of adapting agricultural production systems to future climate change. Environmental Management, 45(1):577-89.

Reilly, J., Hohmann, N., and Kane, S. (1994). Climate change and agricultural trade: Who benefits, who loses? Global Environmental Change, 4(1):24-36.

Robinson, S. (1990). Analysing agricultural trade with single-country computable general equilibrium models. In Goldin, I. and Knudsen, O., editors, Agricultural Trade Liberalization. Paris:OECD.

Robinson, S., Kilkenny, M., and Hanson, K. (1990). The USDA/ERS computable general equilibrium (CGE) model of the United States. Staff report no. ages 9049, Economic Research Service, U.S. Department of Agriculture.

Rutten, M. M., Chant, L. J., and Meijerink, G. W. (2011). Sit down at the ballgame: How trade barriers make the world less food secure. Available at SSRN: "http://ssrn.com/abstract=1769745" or "http://dx.doi.org/10.2139/ssrn. 1769745".

Sacks, W. J., Derying, D., Foley, J. A., and Ramankutty, N. (2010). Crop planting dates: an analysis of global patterns. Global Ecology and Biogeography, 19:607-620.

Schlenker, W. and Roberts, M. J. (2009). Nonlinear temperature effects indicate severe damages to U.S. crop yields under climate change. Proceedings of the National Academy of Sciences of the United States of America (PNAS), 106(37):15594- 15598.

Sims, R., Taylor, M., and Bioenergy, I. (2008). Biofuels technologies: An overview of current industry and $r$ \& d activities. Sonka, S. (1991). Methodological guidelines for assessing the socioeconomic impacts of climate change on agriculture. In Climate Change: Evaluating the SocioEconomic Impacts, pages 21-45. OECD, Paris.

Swamy, P. and Arora, S. (1972). The exact finite sample properties of the estimators of coefficients in the error components regression models. Econometrica, 40:261-275.

Tabeau, A. and Woltjer, G. (2010). Modelling the agricultural employment development within the CGE framework: the consequences for policy responses. In Trade for Sustainable and Inclusive Growth and Development, Bangkok, Thailand. Thirteenth Annual Conference on Global Economic Analysis.

Tamiotti, L., Teh, R., Kulaçg `lu, V., Olhoff, A., Simmons, B., and Abaza, H. (2009). Trade and climate change. A report by the United Nations environment programme and the world trade organization, World Trade Organization.

Valin, H., Sands, R. D., van der Mensbrugghe, D., Nelson, G. C., Ahammad, H., Blanc, E., Bodirsky, B., Fujimori, S., Hasegawa, T., Havlik, P., Heyhoe, E., and Kyle, K. (2014). The future of food demand: Understanding differences in global economic models. Agricultural Economics, 41(1):51-67. van Meijl, H., van Rheenen, T., Tabeau, A., and Eickhout, B. (2006). The impact of different policy environments on land use in Europe. Agriculture, Ecosystems and Environment, 114(1):21-38.

van Wijk, M. T., Rufino, M. C., Enahoro, D., Parsons, D., Silvestri, S., Valdivia, R. O., and Herrero, M. (2012). A review on farm household modelling with a focus on climate change adaptation 
and mitigation. Working Paper 20, CGIAR Research Program on Climate Change(CCAFS), Copenhagen, Denmark.

Verburg, P., Eickhout, B., and van Meijl, H. (2008). A multi-scale, multi-model approach for analyzing the future dynamics of European land use. Annals of Regional Science, 42(1):57-77.

WageningenUR (2012). WageningenURsite. http://www.wageningenur.nl/en/About-WageningenUR.htm. 
CHAPTER 5 


\section{Measuring the effects of extreme weather events on yields}

J.P. Powell, S. Reinhard 
Extreme weather events are expected to increase worldwide, therefore, anticipating and calculating their effects on crop yields is important for topics ranging from food security to the economic viability of biomass products. Given the local nature of weather, particularly precipitation, effects are best measured at a local level. This paper analyzes weather events at the level of the farm for a specific crop, winter wheat. Once it has been established that extreme events are expected to continue occurring at historically high levels for farming locations throughout the Netherlands, the effects of those events on wheat yields are estimated while controlling for the other major input factors affecting yields. Econometric techniques are applied to an unbalanced panel data set of 334 farms for a period of up to 12 years. Analyzes show that the number of days with extreme high temperatures in Dutch wheat growing regions has significantly increased since the early 1900 s, while the number of extreme low temperature events has fallen over that same period. The effects of weather events on wheat yields were found to be time specific in that the week in which an event occurred determined its effect on yields. High temperature events and precipitation events were found to significantly decrease yields. 


\section{Introduction}

\subsection{Introduction}

Weather, whether in terms of averages or events, is an important determinant of yields. Extreme weather events are expected to increase worldwide, therefore, anticipating and calculating their effects on crop yields is important for topics ranging from food security to the economic viability of biomass products. The latest IPCC report, confirming previous findings, attaches high confidence to the probability that extreme weather events will reduce food production (Field et al., 2012; Porter et al., 2014). Extreme events are expected to affect the volatility of yields and are seen as the principle immediate threat to global crop production (Meehl et al., 2000; Rosenzweig et al., 2001; Olesen et al., 2007; Urban et al., 2012; Min et al., 2011; Lobell et al., 2013). A natural question that arises is how to measure their effects on yields. We know from the above and other studies that variations in weather events are geographically specific, thereby implying that effects need to be examined at a correspondingly low level of analysis. An analysis of short-term weather events requires detailed time series data on weather variables at low spatial and temporal levels and corresponding data for all of the other primary factors influencing yields. The approach taken in this paper is to examine the effects of uncommon precipitation and temperatures events of short duration on winter wheat yields. By precisely analyzing the effects of observed events over a relatively short time span it becomes possible to anticipate the effects similar such events will have in the future when their occurrence is expected to increase.

The paper consists of two main threads: first, the increasing occurrence of extreme weather events, formally defined below, is established in order to motivate the relevance of the topic. Daily time series analyses using data from up to 100 years are used to establish and forecast the development of extreme precipitation and temperature events for over thirty regions in the Netherlands. Once the case has been made that the number of such events is either increasing and will continue to do so into the future, then the potential of extreme weather events to alter wheat yields is calculated using econometric techniques. In order to econometrically ascertain their specific, marginal, effects on yields, it is necessary to include all major inputs needed to produce winter wheat into the econometric model. In short, the specific effects of weather events on yields can only be correctly isolated once the effects of other production factors, including unobserved factors, have been filtered out or controlled for in a model. In this analysis, we combine production input data used of winter wheat, e.g., labor, capital and land, for over three hundred farms in the Netherlands from 2002 to 2013 with daily precipitation, temperature and evapotranspiration (ET) data measured at the local level. We test whether all of these various types of data are necessary in order to isolate the effects of extreme weather events on yields. 


\subsection{Literature review}

The impact of weather on yields has been analyzed in relation to several objectives. Traditionally, crop growth models attempt to simulate average crop growth while econometric approaches are used to link inter-annual variation in weather with yields. For example, inter-annual variation in yields has been estimated using experimental plots resulting from the weather conditions in a particular year (Oskam and Reinhard, 1992). That study included data on weather and nitrogen fertilizer over the period 1948-1964 and divided the Netherlands in five regions based on location and soil type. Other studies have estimated inter-annual variation in yields of winter wheat, sugar beets, and starch potatoes using farm level panel data including nitrogen fertilizer and the acreage planted (Leneman et al., 1999). In that study, weather effects, both direct and indirect, were captured by including year dummies (1975-1996) in the regressions.

The last decade has seen a variety of techniques applied at farm and regional levels which have begun to map the effects of climate change at a local level. A meta-analysis of crop yields for several crops under climate change conditions concluded that the interannual variability of mean yields is likely to increase and the consensus in the literature is that yield changes will be negative beginning in 2030 (Challinor et al., 2014). Recent studies of extreme events in Europe point to an increase in the number of warm days and nights, and a decrease of the number of cold days and nights (Porter et al., 2014). Several studies also indicate general increases in the intensity and frequency of extreme precipitation events particularly in winter months during the last four decades, however, inconsistencies between studies, regions and seasons are reported (Hirschi et al., 2011; Vautard et al., 2007; Seneviratne et al., 2010; Berrang-Ford et al., 2014; Yamamoto et al., 2014; Sugiyama et al., 2014; Moriondo et al., 2011; Calzadilla et al., 2013).

The diverse nature of prolonged drought and excess precipitation was found to affect specific aspects of the growth cycle of a given crop and associated field management. Extreme weather events can directly impact the physiological processes of a crop through physical damage, but can also affect the timing and conditions of field operations. Due to differences in growth patterns among crops the impact of warming temperatures and weather extremes is crop dependent (van der Velde et al., 2012). A study at the global level used various weather scenarios to measure the effects of extreme weather events on agricultural regions with diverse crops and found that higher temperatures and events may lead to significant reductions in crop yields (Rosenzweig et al., 2001). Insect, pest, and plant diseases may exacerbate those reductions. Another study used a model based on daily weather data to simulate yields under climate scenarios and concluded that the impact of climate changes on sunflower yields will be larger than that of winter wheat (Moriondo et al., 2011). Similarly, a wheat simulation model combined with local scale 
climate scenarios predicted that yield losses from drought will fall, but the yield losses due to heat stress will substantially increase (Semenov and Shewry, 2011).

Previous micro-level studies, including crop models, have shown that weather events affect yields. However, few of those models have included a complete set of the most important production factors affecting yields. That qualification aside, the net effects of extreme weather events have been shown to damage most crops, an observation that has most commonly been made in relation to rice yields (Wassmann et al., 2009; Welch et al., 2010).

In general, extremely high daytime temperatures are damaging and occasionally lethal to crops (Schlenker and Roberts, 2009; Porter and Gawith, 1999). However, there is debate within the climate change literature in regards to the point at which temperatures begin to negatively affect yields (Porter et al., 2014). For instance, some statistical studies find a positive effect of daytime warming on yields when extremes are infrequently realized (Welch et al., 2010). Rice yields in some regions of China have been found to be positively correlated with higher temperatures, while other regions show negative correlations (Zhang et al., 2010). Another study found that the availability of smaller spatial-scale yield data may allow for improvements in the empirical relation between hot days, precipitation and yields (Hawkins et al., 2013).

The exclusion of important variables affecting yields leads to omitted variable bias, an irrecoverable problem affecting all model estimates (Greene, 2012, e.g.). In addition, the local nature of weather, particularly precipitation, favors low level spatial studies, indeed, there appears to be a trend towards review studies in which conclusions from various micro-level studies are systematically extended to higher levels of aggregation (Porter et al., 2014, Chap. 7). For example, a recent study using a crop model to calculate the effect of multiple weather stress occurrences on wheat yields across fourteen European locations found that for all sites the overall adverse event frequency is much more likely to increase than to decrease (Trnka et al., 2014). Further points of comparison for the current study are briefly reviewed by country of analysis. Articles about the effects of climate change variables on Chinese agricultural production include articles by Tao et al. (2006), Wang et al. (2008) and Chen et al. (2010). The articles are principally phenological studies of the effects of climate change on agriculture production, including winter wheat, and use both panels and data analysis techniques Tao et al. $(2009,2014)$. In particular, Tao et al. (2014) regress weather variables to explain wheat growth in China; You et al. (2009) conduct a similar study for China as the one proposed in this paper but at a higher level of aggregation and not specifically focused on extreme weather events. For India, Pathak et al. (2003) used a simulation model to examine the effects of weather variables on rice and wheat yields, however, no other production variables were included in their model. A 
study by Auffhammer et al. (2012), which analyzes rice yields in India, takes a very similar approach to the current study except that it uses a much higher level of time and spatial aggregation. Kucharik and Serbin (2008) and Lobell et al. (2005) conduct statistical analyses for, respectively, the United States and Mexico, but do not include production variables in their analyzes. Brisson et al. (2010) provides a comprehensive analysis, including time series and simulation models, of the variables that have led to stagnating yields in France, yet at a higher level of aggregation then the one we propose. Licker et al. (2013) use times series weather variables to examine changes in wheat yields in Picardy, France and Rostov, Russia. Gregory and Marshall (2012) using a physiological based model, report potato yield increases for Scotland as a result of warming temperatures. Finally, Ludwig et al. (2009) used a model to show that despite decreasing rainfall in Western Australia, simulated yields based on actual weather data did not fall. This paper contributes to the literature by including a comprehensive set of microeconomic data and weather variables at a very low level of aggregation to examine the marginal effects of weather events on yields.

The remainder of this paper consists of two parts. The first presents the case that extreme weather events have steadily increased in the Netherlands for more than a century. If the argument is accepted that such events are real phenomena that will persist and perhaps increase in the future, then it is worthwhile to establish whether and to what extent they will affect yields. The second part of the paper does so by estimating the net effects of extreme events on winter wheat farmers in the Netherlands for the period 2002-2013.

\section{Dutch long-term weather trends}

The following section describes the data and methods used to identify long-term weather trends in the Netherlands and assess the likelihood that those trends will continue into the future.

\subsection{Weather trends data and methods}

The concept behind the approach used to identify events, whether for the long or short term, was to record the number of days for which measures exceeded a specific threshold. Two general methods were used to identify events, the first method is a relative method comparing, for example, the high daily temperature for a specific day in a year with the high temperature for that same day across all years in the sample. The second method used an absolute scale which identified, for instance, the number of days in a week equal to or above $32{ }^{\circ} \mathrm{C}$. Both the relative and absolute methods were used to identify event trends and included in panel regressions during the model selection phase, however, 
given their high correlation with one another only the relative results are presented in the trend section.

The relative method is an adaptation of the methodology presented in (Klein Tank et al. (2009). Data used to identify long-term trends has been collected for many years by the Royal Dutch Weather Institute (KNMI) at its primer weather station, station 260, which is located near the center of the country. Station 260 was chosen because it has the longest series of readily available data and the data has been homogenized. Four types of extremes were identified, daily high temperatures, daily low temperatures, precipitation, and the reference evapotranspiration (a measure of the potential water loss which is often used as a proxy for crop growth potential). The identical methodology was used to identify the extremes for each variable examined, however we describe the methodology only for the maximum temperature variable.

Daily maximum temperature data for each day in a given year was compared to data for that specific day across all years available. Temperature values above the $95 \%$ quantile were selected as extreme events. For instance, for a given day in a year there are 109 observations corresponding to the number of years in the data set; those days with temperatures above the $95 \%$ quantile were identified as extreme events. The $95 \%$ quantile is a somewhat arbitrary choice, the intention was to select very rare events, but still have enough of them to be able to draw statistically meaningful conclusions. Similarly, those days with temperatures below the $5 \%$ quantile for a given day across all years were selected as extreme minimum temperature events. Precipitation and evapotranspiration events were similarly identified. Evapotranspiration is calculated by the KNMI using the Makkink method (Hooghart, 1987).

Several alternative aggregation methods were tested in order to determine their effect on the number of events identified. The method described above takes a day as the unit of comparison, we also calculated events based on weeks and months. The methodology, for example high temperatures and months, sums the number of days with temperatures above the $95 \%$ quantile for a particular week or month in a year. The appropriate level of aggregation to use in the econometric analyses depends on the sensitivity of winter wheat across a time span for the event measured. For example, aggregating over months rather than a specific day produces more observations, but did not significantly affect the conclusions drawn. The choice of which aggregation level to use depends on the amount of data and the question at hand. An example might help to illustrate the issue. For winter wheat, the precise day a high temperature event occurs is probably not critical. For instance, whether an event occurs on July 24th or July 25th will make little difference to the overall yields realized on a farm and so those two events could be aggregated, stronger still, it is probably inappropriate to assume that events on the 24th are significantly different 
than events occurring on the 25th in terms of wheat production. However, the further apart two events are, the more likely they will be to have different effects on yields; events in early August will certainly affect yields more than events in late August because by late August the crop is harvested, therefore monthly aggregation is less appropriate. The testing several different aggregations and expert knowledge lead to the conclusion that a weekly aggregation is best.

\subsection{Weather trends results}

This section first presents the changes in weather patterns that have occurred in the Netherlands. Both extreme events and average weather events are plotted through time in order to identify trends. Unless otherwise noted, figures were made using weekly aggregated data. All of the weather data used in the paper were collected and disseminated by Royal Dutch Weather Institute (KNMI).

Fig. 1a shows that the number of yearly extreme low temperature events has decreased over the period from 1901 to 2013. The line near the center of the figure is a LOESS regression line showing, essentially, a locally weighted moving average trend line; its purpose is to help the reader to identify trends in the data. A Chow test was used to test where there was a structural break in the data in the 1970s, as the figures suggests but was rejected as was evidence of structural breaks in all other events analyzed. In short, there is no evidence that the number of events switched to another slope in the 1970s despite appearances in the figure. The slope across the entire data set is highly significant ( $t$-value 3.64), meaning that we can be confident that the trend is not a result of chance. An auto-regressive, integrated, moving average (ARIMA) model was used to fit and forecast weather event data. As necessary, the data have been differenced in order to transform non-stationary data to stationary data. The mean of the point forecasts of the fitted $\operatorname{ARIMA}(3,1,1)$ model over the period 2014-2023 was 12.6, indicating that the number of extreme low temperature events will remain low compared to the historical average of 18.8 over the entire sample. These point forecasts should be read with caution, Fig. 1a shows, and the ARIMA forecast confirms, that the amount of variation in the data is large; only the $\mathrm{AR}(2)$ and $M A(1)$ approach significance ( $z$ values $=1.77$ and 22 respectively). This holds true for all of the extreme ARIMA regressions. The regressions are meant to be an aid to identifying general trends visible in the figures.

Fig. 1b plots the number of yearly extreme high temperature events from 1901 to 2013. The slope is again highly significant $(t$-value $=5.56)$ and an $\operatorname{ARIMA}(0,1,1)$ model forecasts an average of 30.6 such events over the period 2014-2023, indicating that the relatively high number of extreme high temperature events are likely to continue compared to the historical number of yearly high temperature events of 18.8. The moving average term was found to be highly significant with a $z$ value of over 17 while the trend was nearly 
significant ( $z$ 1.72). The findings for low and high temperature events correspond to those found in the most recent IPCC report, specifically, the occurrence of more warm days and nights compared to the historical average. The findings reinforce the importance of measuring the effects of those events on yields in anticipation of more such events in the future.

Fig. 2a shows that the number of days with extremely high amounts of precipitation has increased, a similar figure, not included, for days with no precipitation shows a strong decreasing trend. Given the historical trend, the Netherlands can expect to experience more periods with heavy rains given that the regression slope is significant ( $t$-value 3.75). ARIMA results forecast an average of 23.4 events over the period 2014-2023. Fig. $2 \mathrm{~b}$ shows the number of evapotranspiration events since 1957, the first year for which data is available, has been steadily decreasing. The $t$-value is significant ( 2.45 ) and the $\operatorname{ARIMA}(2,1,1)$ model forecasts an average of 35 such events over the period 2014-2023, about the same as the historical average of 34.6 events. Nearly all of the AR ( $z$ values of $1.71,1.98)$ and MA (49) terms are significant as was the trend (4.14).

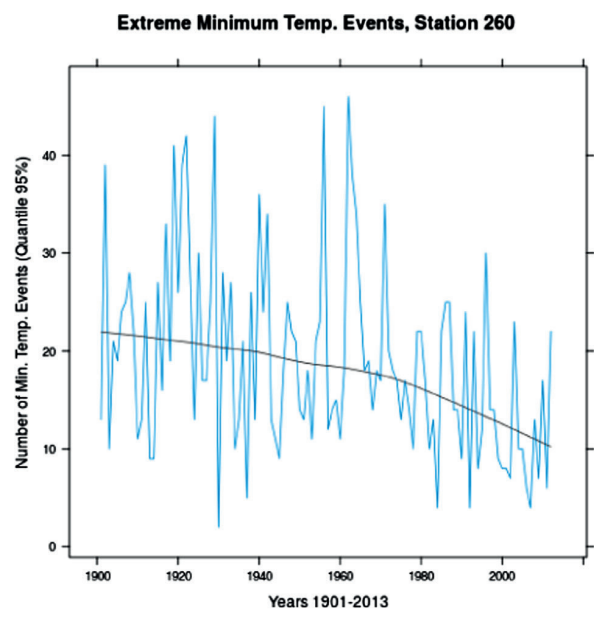

(a) Extreme minimum temp. events.

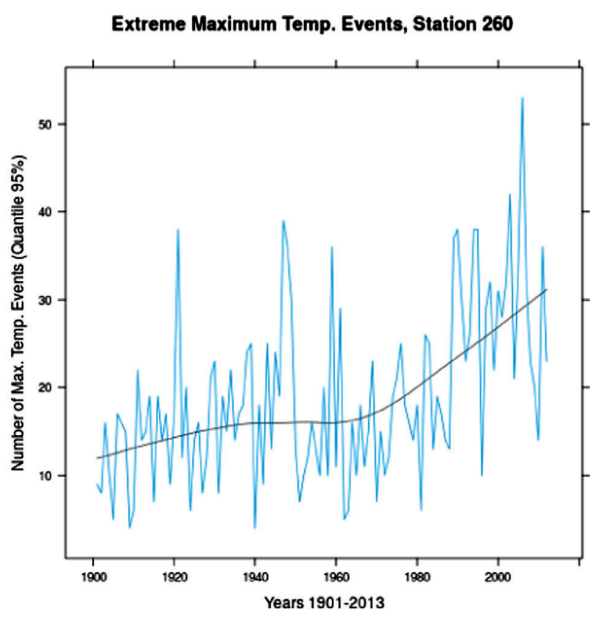

(b) Extreme maximum temp. events

Fig. 1. Extreme temperature events, source original data: (Koninklijk Nederlands Meteorologisch Instituut (KNMI): Royal Dutch Meteorological Institute, 2014). 


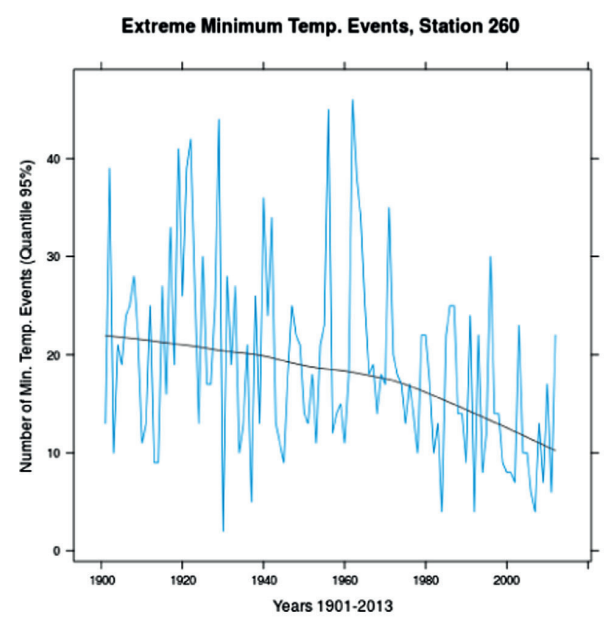

(a) Extreme precipitation events.

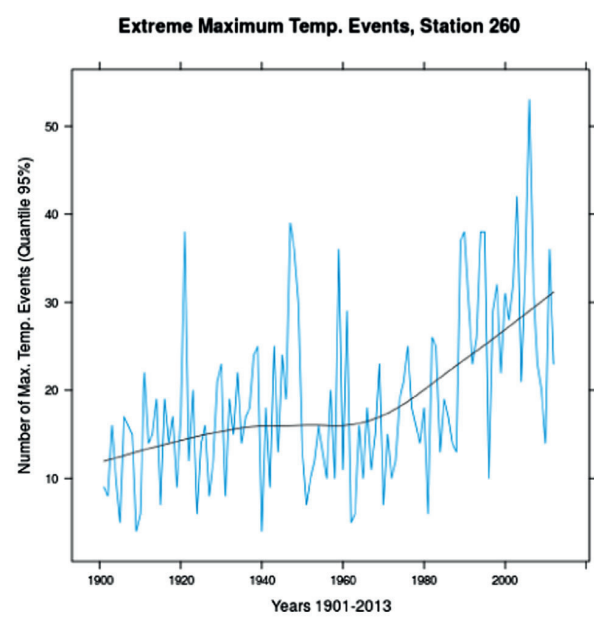

(b) Extreme evapotranspiration events.

Fig. 2. Precipitation and evapotranspiration events per month (Koninklijk Nederlands Meteorologisch Instituut (KNMI): Royal Dutch Meteorological Institute, 2014).

The data presented in Fig. $4 \mathrm{~b}$ is designed to show yearly changes in maximum temperatures, but with the data partitioned by month to keep the figure readable. The plotted lines are the LOESS regression lines of average high temperatures per month. The general trend across the entire period for all months is for a slight increase in maximum temperatures, particularly in the latter decades. Regressions against time show that April, July, August, October, November, and December have significant, positive, slope coefficients. A similar figure, not included, of minimum temperatures across all months shows a significant (t-value $=6.04)$, steadily increasing trend from 1902 to 2013. Temperatures, both the maximum highs and lows, appear to be increasing in the Netherlands although the changes vary by month.

The graphical and accompanying statistical evidence presented provide convincing evidence that high temperatures and precipitation events are occurring in historically high numbers; while low temperature and evapotranspiration events are occurring in decreasing numbers. The results are robust, with similar patterns appearing across different time aggregations and definitions of weather events. ARIMA forecasts suggest that the number of events will either stabilize or continue to increase thereby all of which motivates the following section which estimates the impacts of events on yields. 


\section{Estimating effects of weather events on yields}

Estimating the effects of weather events on yields requires specifying a suitable model. Given the number of potential variables in the data set, model selection involves a systematic removal of variables that are either redundant in terms of the information they convey or do not significantly add to the explanatory power of the model. The econometric method allows us to test the influence of extreme events and other inputs on yields. If an extreme event has no impact then that lack of influence should, ideally, be reflected in the econometric results, namely, the estimate for that variable should be insignificant. Ultimately, we are looking for measures that are highly correlated with and explain yearly changes in yields. Before turning to model specification, the primary potential model variables are described.

\subsection{Weather in regressions}

In addition to the relative event measures used to identify trends, absolute measures were defined for the same weather variables previously presented. In contrast to the relative measures which were identified using quantiles, absolute measures are a matter of choosing a threshold, for instance, daily measurements above or below a particular benchmark are identified as events. Choosing a good benchmark is crop, geographic, and time specific in the sense that crops in different regions are vulnerable to events at particular times during their development (van der Velde et al., 2012; Rosenzweig et al., 2001; Moriondo et al., 2011). In a sense, the term absolute is a misnomer in that farmers adapt their behavior to expected conditions where they are located and for the crops they farm. The term as used here primarily refers to events that are extraordinary for a given time in the Dutch winter wheat production cycle. Important months for the yields of winter wheat in the Netherlands are July and August when the kernel is forming, therefore weekly extremes were chosen with reference to those months (see Kennisakker (2014) and University of Kentucky (2014) for details). We are not claiming that only the weeks in those months are important for yields, for instance, during the winter months freezing temperatures are necessary for crop development. Rather, the focus of our study is on events that affect yields at one particularly vulnerable time in their development.

The thresholds of thirty-two degrees Celsius and above and ten degrees Celsius and below were identified as extremes for the weeks in our study. Thirty-two degrees was chosen because temperatures above thirty degrees are defined as tropical or extreme by the KNMI. Both benchmarks were chosen with reference to the data presented in Table 1 which shows that the benchmarks chosen are above and below their respective quantiles for given weeks of the year. Similarly, days with precipitation above $10 \mathrm{~mm}$ and evapotranspiration above $5 \mathrm{~mm}$ were flagged as events. Other measures include a measure of the number of consecutive days with precipitation above $10 \mathrm{~mm}$. 
Table 1. Data description.

\begin{tabular}{|c|c|c|c|c|}
\hline Variable & Mean & Standard deviation & $10 \%$ Quant. & 90\% Quant. \\
\hline Yield kg/ha & 8144.82 & 1988.54 & 5386.80 & 10392.44 \\
\hline Pesticides euros/ha & 177.91 & 84.85 & 62.87 & 274.23 \\
\hline Fertilizers euros/ha & 138.31 & 80.63 & 34.55 & 237.98 \\
\hline Farm size ha & 85.59 & 69.10 & 21.61 & 162.78 \\
\hline Land euros/ha & 221.80 & 838.00 & 17.55 & 377.55 \\
\hline Capital euros/ha & 268.41 & 1556.92 & 8.34 & 354.51 \\
\hline Labor euros/ha & 438.74 & 1926.75 & 18.79 & 638.05 \\
\hline Precip. Evt. Abs. Week 26 & 158.52 & 141.99 & 0.05 & 338.05 \\
\hline Precip. Evt. Abs. Week 32 & 192.27 & 148.75 & 27.05 & 398.61 \\
\hline Avg. Week Max Temp. Week 26 & 216.13 & 28.21 & 179.86 & 255.43 \\
\hline Avg. Week Max Temp. Week 32 & 222.01 & 29.90 & 197.57 & 258.57 \\
\hline Avg. Week Min Temp. Week 26 & 120.50 & 18.15 & 96.86 & 145.00 \\
\hline Avg. Week Min Temp. Week 32 & 133.83 & 20.07 & 108.57 & 163.14 \\
\hline Avg. Week Evap. Week 26 & 34.40 & 6.60 & 25.86 & 44.00 \\
\hline Avg. Week Evap. Week 32 & 27.00 & 4.65 & 21.57 & 32.34 \\
\hline Precip. Evt. Abs. Week 26 & 0.46 & 0.69 & 0.00 & 1.00 \\
\hline Precip. Evt. Abs. Week 32 & 0.54 & 0.65 & 0.00 & 1.00 \\
\hline Max Temp. Evt. Abs. Week 26 & 0.07 & 0.29 & 0.00 & 0.00 \\
\hline Max Temp. Evt. Abs. Week 32 & 0.22 & 0.85 & 0.00 & 0.00 \\
\hline Min Temp. Evt. Abs. Week 26 & 1.68 & 1.68 & 0.00 & 4.00 \\
\hline Min Temp. Evt. Abs. Week 32 & 0.90 & 1.17 & 0.00 & 3.00 \\
\hline Evap. Evt. Abs. Week 26 & 0.33 & 0.52 & 0.00 & 1.00 \\
\hline Evap. Evt. Abs. Week 32 & 0.32 & 0.55 & 0.00 & 1.00 \\
\hline Conseq. Days Precip. Week 26 & 0.46 & 0.69 & 0.00 & 1.00 \\
\hline Conseq. Days Precip. Week 32 & 0.54 & 0.65 & 0.00 & 1.00 \\
\hline Precip. Evt. Quantile Week 26 & 0.35 & 0.55 & 0.00 & 1.00 \\
\hline Precip. Evt. Quantile Week 32 & 0.37 & 0.54 & 0.00 & 1.00 \\
\hline Max. Temp. Evt. Quantile Week 26 & 0.41 & 0.74 & 0.00 & 2.00 \\
\hline Max. Temp. Evt. Quantile Week 32 & 0.34 & 1.05 & 0.00 & 1.00 \\
\hline Min. Temp. Evt. Quantile Week 26 & 0.24 & 0.52 & 0.00 & 1.00 \\
\hline Min. Temp. Evt. Quantile Week 32 & 0.29 & 0.59 & 0.00 & 1.00 \\
\hline Evap. Evnt. Quantile Week 26 & 0.43 & 0.58 & 0.00 & 1.00 \\
\hline Evap. Evnt. Quantile Week 32 & 0.42 & 0.59 & 0.00 & 1.00 \\
\hline
\end{tabular}

Note: data isfor all years across all farms. Original data: (LEl, 2014a, 2014b).

In addition to including extreme events in regressions, average weekly daily temperatures and precipitation amounts were considered for inclusion in the regressions. These variables, when falling within normal ranges, are expected inputs into the wheat production process and therefore should be included in the regressions along with other inputs. These weather data represent the general underlying trends, as opposed to disruptive events. Another reason for considering their inclusion is that doing so allows us to measure the effects of extreme events net of the effects of their expected, normal, values. 
As opposed to the weather data used in the trend analysis section, weather data used in the current section consists of data collected for 35 weather stations located throughout the Netherlands of which 29 or 30, depending on the weather variable measured, are used in the analyses. Weather data from 2002 to 2013 is used and matched with farm data which is only available over the same period.

Although the Netherlands is a small country $\left(41,543 \mathrm{~km}^{2}\right)$, there is a great deal of variation in weather across the country on any given day. This variation across space effectively multiplies the number daily observations. For example, instead of one temperature observation per day there are effectively 30 different, although correlated, observations, one for each weather station and associated farms in the data set. The weather data for a particular station was assigned to a farm based on its proximity, with the station closest determining the events for a particular farm.

Critical weeks for winter wheat yields in the Netherlands are in the last weeks before harvest when the wheat is ripening. In general, harvest begins somewhere in the second half of July in the southern provinces and gradually extends to the northern provinces. Both drought and dampness can affect winter wheat yields in these periods. In order to avoid the problems of damaged kernels and germination, an acute problem in wet circumstances, harvest has to begin at the right moment. Timing of the harvest is largely dependent on the dampness of the kernel with the ideal dampness at harvest at around $15-16 \%$ in the kernel. Too damp and the wheat cannot be stored for long, particularly if the temperature is above $15^{\circ} \mathrm{C}$. Dampness can also increase the likelihood of fungus infections. Kernels are also susceptible to damage if too dry. Tropical temperatures, defined as temperatures over $30^{\circ} \mathrm{C}$ as defined by the KNMI, can damage wheat in this period. However, enough rain and dampness in the ground can prevent high temperature damage.

\subsection{Farm data and method}

Farm level data used in the analysis is collected by LEI (LEI, 2014a). LEl, a part of the Wageningen University and Research Centre, the leading agricultural research institute in the country, is responsible for, among other activities, collecting, analyzing and disseminating agricultural data to national and international organizations.

The initial economic data set considered for inclusion in the analyzes to follow consists of the main inputs used to produce winter wheat on 334 farms over the period 20022013 throughout the Netherlands. Winter wheat is the most important grain grown in the Netherlands and the country enjoys one of the highest wheat yields in the world. The main inputs are: fertilizers, pesticides, energy, labor, capital, a catch-all account called other inputs, and four soil types. Data are converted to their per hectare equivalents. The 
econometric method prizes parsimony as one element of a model and it is the reason why it is common to report the adjusted R-squared instead of the R-squared. Adjusted R-squared, like other econometric measures of comparison such as the Akaike information criterion and Bayesian information criterion (Greene, 2012), penalize the addition of explanatory variables. In short, a model with fewer exogenous variables and the same explanatory power will be preferred to models with the same explanatory power and more variables. Variables that are highly correlated with one another are candidates for removal for reasons of parsimony, but also to avoid the problem of multicollinearity. This is not to say that the variables removed from the model are unimportant, only that their effects are already incorporated within the model by the included variables.

Dutch farms generally produce several different crops in a given year, therefore it is necessary to apportion the share of a farm's total productive resources to the share that is used to produce winter wheat. The method used here was based on the portion of profits derived from winter wheat in a farm's total yearly profits. For instance, if $50 \%$ of a farm's costs before tax profits came from winter wheat in a given year, then $50 \%$ of the total energy of a farm for that year were assigned to wheat. This is not a perfect methodology, for instance, some crops use more energy than others, but it is an economically sound approximation given that the costs that a farmer is willing to incur to produce a product are likely to reflect the relative profitability of that crop. Other apportionment methods were tried such as apportioning based on the area of a farm devoted to the production of winter wheat relative to the total size of a farm, but no appreciable differences were observed in the results. Similarly, the panel models were run using the quantities of variables used rather than their value in euros, again, no appreciable differences were noted in either the relative importance of estimates or their significance.

Indicators presented in Table 1 show the means, standard deviations, and $10 \%$ and $90 \%$ quantiles of the economic and weather variables used in the panel regressions. A feature of the data is the large standard deviations for the economic data, this implies a great deal of variation across Dutch farms in terms of the amounts of inputs they use per acre. This variation is important in the analysis; econometric methods depend upon such variation in order to calculate statistically meaningful results. It is this variation across time and across farms which makes the panel method employed effective. It allows us, essentially, to multiply the number of observations in the analysis and cover a wide range of differing input combinations and weather events.

Capital costs are based on yearly depreciation expenses. Labor costs are the total wages paid to all labor employed in the production process including an estimate of the value of the farmer's own labor. Energy includes both diesel and electricity costs. The costs of land are represented by the mortgage paid for farm land. In addition to the land costs, we 
also include the area of land to test for the returns of additional land. Fertilizers include costs for both nitrogen and phosphate, while pesticides include all inputs used to protect plants. Other variables were tested, in addition to using quantities, we tried: including nitrogen and phosphate as separate explanatory variables; using only the active pesticides rather than all inputs used to protect plants; including electricity and diesel as separate regressors, and; using only the wages of permanent farm employees by excluding the wages of temporary workers. However, none of these variations led to notable changes in the general conclusions which could be drawn from the final model.

The type of soil used to grow winter wheat greatly affects yields. There are ten relevant soil types in the Netherlands, these were consolidated into five major categories: sand, peat, loess, clay and mixed soil types. Peat is a spongy soil type that forms at the bottom of swamps and is found in the northern and western Netherlands; it tends to retain water. Loess is a rich soil primarily composed of sand and/or silt and to a lesser extent clay; it, like sand, has good drainage. Clay naturally tends to trap water which can damage wheat in periods of heavy rains, however, it is the most commonly taken to be the most productive soil type.

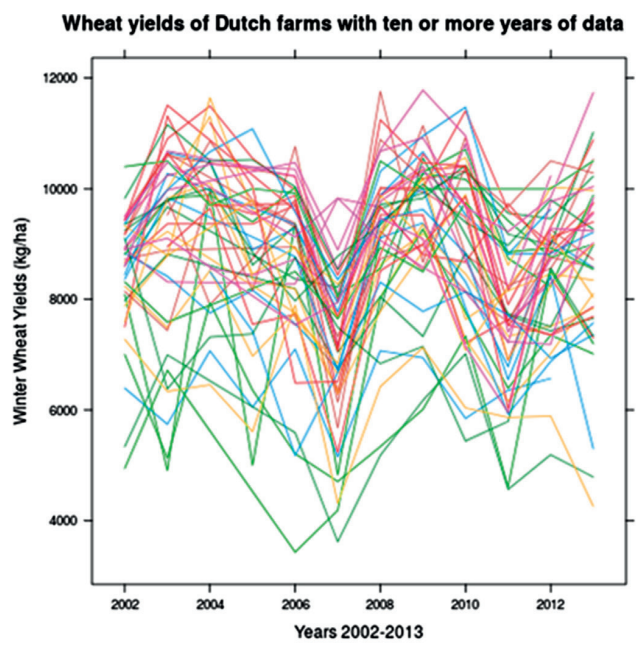

(a) Production for farms with data for all eleven years in the study.

Fig. 3. Yields and average precipitation amounts $(\mathrm{mm})$ across important wheat growing months (Koninklijk Nederlands Meteorologisch Instituut (KNMI): Royal Dutch Meteorological Institute, 2014).

Fig. 3a shows wheat yields for a representative subset of the farms in the data over the period 2002-2013. While there is a great deal of variation across farms, yields tend to move in the same direction and in response, presumably, to similar underlying disturbances. In short, there appears to be enough variation and yet enough similarity between farms in the Netherlands to make statistical analyses meaningful (Fig. 4). 


\subsection{Model specification}

Model specification concerns which variables to include in the model and in which form. There is a high degree of correlation between many of the weather variables and a few of the economic variables; the question is whether to remove one of the correlated variables and, if so, which one to remove. Using weekly weather data and absolute and relative measures of weather events results in hundreds of potential weather variables. That number was substantially reduced by concentrating the analyses on the weeks in July and August. The number of variables was further reduced by using a combination of statistical tools and expert knowledge. The first step was to run a basic linear regression model using all of the presumably relevant variables, and then use variance inflation factor (VIF) analysis to identify highly correlated variables. The VIF is a standard econometric technique used to quantify multicollinearity in an ordinary least squares regression analysis (Studenmund, 2006). The simple correlations of variables identified as problematic by VIF were then used to remove highly correlated variables from consideration in the regressions. For instance, high correlation was identified between the number of consecutive days with precipitation over $10 \mathrm{~mm}$, absolute precipitation events, and the total number amount of rain in a given week, indicating that perhaps any one of these indicators could be used as a proxy for the others and that only one of them should be included in the model. Similar high correlation was observed for weekly average low and high temperatures and their corresponding weekly events. Finally, high correlation between measures of absolute and relative events was identified as a potential problem.

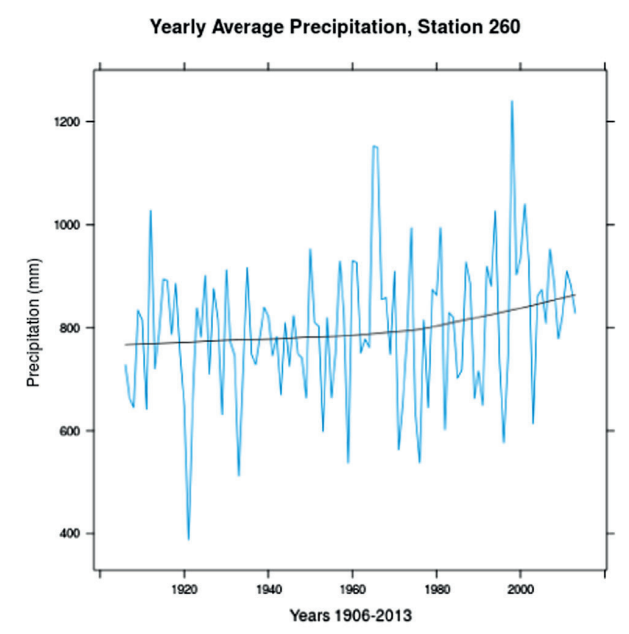

(a) Sum of monthly precipitation per year. per year.

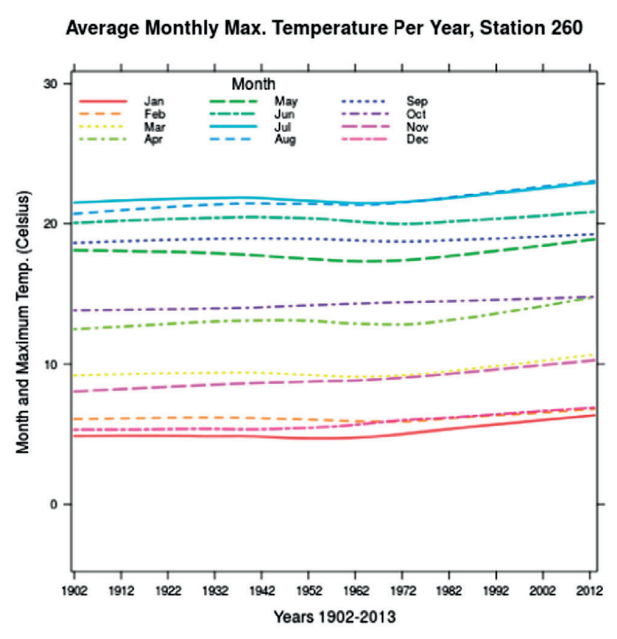

(b) Average monthly temperatures

Fig. 4. Time series Dutch of precipitation and temperatures. Source original data: (Koninklijk Nederlands Meteorologisch Instituut (KNMI): Royal Dutch Meteorological Institute, 2014). Station 260 is located in Utrecht, close to the center of the Netherlands. 
The degree of correlation between two or more variables is only an indicator of whether to remove a variable from a regression, if, with the exception of extremely high correlation which results in multicollinearity, there is a good economic or another reason to include a variable in a regression despite high correlation with other variables, then it should be included. That said, the decision was made to include only absolute measures rather than relative measures for consideration because some absolute measures have a recognized phenological effect on wheat whereas relative measures do not. In addition, high correlation between the absolute and relative measures indicate that these measures are identifying exceptional events.

Finally, the decision was made to include both high temperatures and evapotranspiration rates for consideration in the model. These two variables capture different processes, in particular, the evapotranspiration variable captures potential interactions between precipitation and high temperatures (Hiemstra and Sluiter, 2011). We follow convention by including typical inputs into the farm production function: fertilizers, pesticides, energy, labor, capital and other costs. In addition, farm size was included to capture the effects of scale on the production process. Only the costs of land per ha were removed because of its very high correlation with capital and labor costs.

Even after the problem of correlation was addressed, the potential number of variables was still large. While the decision to include only absolute measures of weather effectively halved the number of weather variables, each of these variables, precipitation, high and low temperatures and evapotranspiration, included seven weeks of data covering the period from the beginning of July to middle August. Given the exploratory nature of the study, a final selection of variables was made using measures of best fit. The procedure used was to include permutations of all of the remaining potential variables in regressions and choosing the best model based on the adjusted R-squared. The variables finally selected are those found in Table 1.

The data were then used to run a series of panel regressions with wheat yields as the endogenous variable and the other variables, including a measure of the effects of time, as explanatory or exogenous variables. It is common practice to include time effects in panel regressions to account for changes through time not otherwise identified (Baltagi, 2008). Results for three models are reported in Table 2. The Complete model, which includes both the economic and weather exogenous variables, and separate models for the economic and weather variables. By comparing results across models, we will be able to draw conclusions about the importance of each group of variables in determining yields. In particular, the comparison is important because it allows us to determine just how wrong we might be when only regressing yields against weather variables as is common in highly aggregated studies. 
Table 2. Panel results.

\begin{tabular}{|c|c|c|c|c|c|c|}
\hline \multirow[t]{2}{*}{ Coefficient } & \multicolumn{2}{|c|}{ Complete model } & \multicolumn{2}{|c|}{ Economic model } & \multicolumn{2}{|c|}{ Weather model } \\
\hline & Estimate & t-value & Estimate & t-value & Estimate & t-value \\
\hline Pesticides euros/ha & 12.854 & 8.608 & 12.766 & 8.445 & & \\
\hline Fertilizers euros/ha & 3.297 & 2.809 & 3.905 & 3.289 & & \\
\hline Farm Size ha & -6.154 & -1.761 & -5.728 & -1.617 & & \\
\hline Capital euros/ha & 0.324 & 4.897 & 0.329 & 4.918 & & \\
\hline Pesticides & -0.020 & -6.462 & -0.020 & -6.273 & & \\
\hline Fertilizer & -0.006 & -1.897 & -0.006 & -2.202 & & \\
\hline Farm size & 0.015 & 1.747 & 0.015 & 1.710 & & \\
\hline Capital & -0.000 & -4.273 & -0.000 & -4.376 & & \\
\hline Soil loess & -502.641 & -1.240 & -668.176 & -1.626 & & \\
\hline Soil mixed & -83.427 & -0.398 & -94.582 & -0.447 & & \\
\hline Soil peat & -208.77 & -0.549 & 75.084 & 0.201 & & \\
\hline Soil sand & 93.259 & 0.313 & 22.860 & 0.076 & & \\
\hline Precip. Evt. Week 26 & 31.650 & 0.596 & & & -15.622 & -0.286 \\
\hline Precip. Evt. Week 27 & -11.754 & -0.298 & & & -2.939 & -0.072 \\
\hline Precip. Evt. Week 28 & 58.236 & 1.291 & & & 51.591 & 1.106 \\
\hline Precip. Evt. Week 29 & -50.538 & -1.012 & & & -14.479 & -0.280 \\
\hline Precip. Evt. Week 30 & -25.549 & -0.475 & & & -26.496 & -0.475 \\
\hline Precip. Evt. Week 31 & -91.294 & -2.268 & & & -135.172 & -3.254 \\
\hline Max. Temp. Evt. Week 27 & -429.745 & -4.851 & & & -440.821 & -4.797 \\
\hline Max. Temp. Evt. Week 29 & -49.702 & -0.624 & & & -52.223 & -0.633 \\
\hline Max. Temp. Evt. Week 30 & -151.491 & -1.050 & & & -162.867 & -1.087 \\
\hline Max. Temp. Evt. Week 32 & 62.689 & 1.296 & & & 23.765 & 0.478 \\
\hline Min. Temp. Evt. Week 26 & 35.209 & 1.238 & & & 41.566 & 1.409 \\
\hline Min. Temp. Evt. Week 27 & -2.011 & -0.052 & & & 0.098 & 0.002 \\
\hline Min. Temp. Evt. Week 29 & -85.863 & -1.954 & & & -92.196 & -2.020 \\
\hline Min. Temp. Evt. Week 30 & -140.914 & -2.787 & & & -150.367 & -2.871 \\
\hline Min. Temp. Evt. Week 32 & 111.207 & 3.280 & & & 97.788 & 2.775 \\
\hline Evap. Evt. Week 27 & -200.450 & -1.706 & & & -209.200 & -1.733 \\
\hline Evap. Evt. Week 27 & -200.450 & -1.706 & & & -209.200 & -1.733 \\
\hline Evap. Evt. Week 28 & -148.745 & -1.490 & & & -111.177 & -1.075 \\
\hline Evap. Evt. Week 30 & 76.901 & 0.620 & & & -0.758 & -0.006 \\
\hline Year 2004 & 418.305 & 2.237 & 458.094 & 3.157 & 363.197 & 1.882 \\
\hline Year 2007 & -1675.280 & -10.198 & -1565.259 & -16.423 & -1778.394 & -10.461 \\
\hline Year 2011 & -1027.684 & -4.536 & -1101.385 & -11.564 & -995.056 & -4.266 \\
\hline Year 2012 & -573.073 & -4.197 & -460.655 & -4.585 & -376.207 & -2.711 \\
\hline Year 2013 & -508.192 & -3.359 & -199.596 & -1.891 & -320.623 & -2.063 \\
\hline
\end{tabular}

Note: the Complete model includes both the economic and weather variables, the Economic model includes only economic variables, while the Weather model consists of only the weather variables. The coefficients of all three models are for the fixed effects or 'within' model and include time effects as well as individual effects. Standard tests strongly reject a common group intercept ( $p=3.26 \mathrm{e}-87)$. The F-statistic $(374,1454)$ for the entire model is $11.89^{\circ}$ of freedom with a corresponding $p$-value of less than 6.3e-267. Adjusted R-squared=0.69. A F-test $(368,1460)=12.06$ indicates the overall regression is significant $(p$-value $=9.2 \mathrm{e}-269)$. A F-test $(333,1460)$ rejects an OLS model specification in favor of the within specification $(p$-value $=1.237 \mathrm{e}-88)$. A Wald test Chi-squared $(11)=156.25$ for joint significance of time dummies for all years is rejected ( $p$-value $=7.86 \mathrm{e}-28)$. $\mathrm{A}$ Hausman test favors the within over the random effects form of the model (ChiSq (35)=147.01, $p$-value $=1.12 \mathrm{e}-$ 15). Finally, Wald tests favor the Complete model over either the Economic or Weather models (ChiSq $=0.0012$ and $2.0 \mathrm{e}-11$ respectively). 
The within form of the panel model was chosen over the OLS and random effects models. The within model removes the effects of both unobserved and observed variables affecting yields (Baltagi, 2008). The statistics comparing these models are reported the end of Table 2. The essential messages of those statistics are that, on the whole, individual Dutch farms have distinguishing characteristics and should be analyzed as individuals rather than lumped together as a single set of data. In addition, a Hausman test indicates that the assumptions of the random effects model are not met, and so we use the within form (Greene, 2012). A test of the joint significance of the time variables is rejected, however, individual years were found to be significant as measured by their $t$-values. In particular, the years 2004, 2007, 2011, 2012 and 2013 were found to be significant, with yields in 2004 above average and those in 2007 and 2011 below average. The effects in 2007 and 2011 are clearly visible in Fig. 3a.

The first two columns in Table 2 present results for the Complete econometric model; the model which includes both economic and weather variables. Columns three and four show results for the Economic model; only the economic variables plus soil type and time are included in the model. Columns five and six present results for the Weather model which only includes time and the weather variables. A working assumption, later statically confirmed, is that the economic and weather models are wrong to the extent that they are misspecifications, i.e., they omit important determinants of yields out of the model. They were modeled precisely for that reason, to allow us to speculate on the effects of leaving out variables given that they are frequently not available or of poor quality in more aggregated studies. As reported in Table 2, Wald tests of comparing the Complete model with the Economic model and the Complete model with the Weather model reject the nulls, i.e., the Complete model is preferred to either of those two models.

The estimate column for each of the models shows the effect of a one-unit increase in a variable on the kilograms per hectare (yield) of winter wheat produced. The $t$-value reports the statistical confidence that can be placed in the variable, by convention, an absolute $t$-value of around 1.96 or greater is considered significant. Those t-values with absolute values less than 1.96 are considered to be insignificant in the sense that their contribution to the explanatory power of the model cannot be distinguished from zero, in short, they do not help to explain changes in yields given the other variables in a model.

Pesticides, fertilizers, and capital in the Complete model are all significant and have the expected sign, i.e., the more of these inputs added to the production of wheat, all else equal, the greater the yield. The negative, significant, sign for farm size indicates that increasing the size of a farm reduces yields. Quadratic terms for each of these variables were also included in order to assess whether diminishing returns are present. Although none of the coefficients is large, they are all significant or nearly so and have a negative 
sign indicating decreasing marginal productivity. The coefficients for three of the four soil types, although insignificant, are as expected in that they are all negative because they are calculated in relation to wheat grown on clay, generally regarded as the most productive of the soil types in the Netherlands. The coefficient for sand is positive; indicating that, all else equal, it is more productive than clay (which is absorbed in the intercept term). This result could be due to the drainage properties of sand, that is confirmed in previous studies (Oskam and Reinhard, 1992).

Turning to the effects of the weather variables in the Complete model, recall that variables are categorized according to whether they are events or averages. Given that we chose to use weekly rather than, e.g., monthly data, the effects of events and average values for the same variable in a given week are naturally highly correlated; accordingly, the decision was made to only include event variables. Although quadratic terms for each of these variables were included in the model, they were all insignificant and dropped from the final specification as were interaction terms.

The model indicates that events can have either positive, negative or no effect on yields. This is unsurprising given that we know that wheat kernels can be damaged by either too wet or too dry conditions. Results in the table can be read, loosely, as the average effects of these events on yields across all farms over the period 2002-2013. The only precipitation event that has a significant effect on yields is the precipitation event in week 31. This is near the end of the harvest season, and the effect is negative. Furthermore, the significance of the other precipitation terms remained low even when evapotranspiration events were removed from the model or when only weekly sums of precipitation and low and high temperature events were included in the model.

The coefficient for high maximum temperature events in week 27 (July 1st in 2013) is significant and negative, indicating that high temperature events near the beginning of the harvest season damage crops or, perhaps, force farmers to harvest before the yield has reached its maximum. They remained so in nearly every permutation of variables tried. The estimate for week 27 tells us that one additional high temperature event will lower yields by nearly $430 \mathrm{~kg}$ per hectare. Given the average yield in Table 1, this represents a loss of around $5 \%$. The effects of low temperature events were also significant and negative in the 29th and 30th week. Low temperature events in the middle and near the end of the harvest season, depending on the specific year, have negative effects on yields. The only positive effect of weather events observed is for cool days in the 32nd week near the end of the harvest season.

Cooler days in that week are associated with higher yields. 
The Wald-test favors the Complete model over the Economic and Weather models. Comparing the Complete model with the Economic model illustrates the importance of including weather variables. Although none of the variables that are significant in both models change signs, their magnitudes do change, in some cases substantially. A comparison of the Complete model with the Weather model indicates that a researcher would, in general, overestimate the negative effects of significant weather events, using the Weather model. Although the signs of the estimates that are significant in both models remain stable, their magnitudes are quite different, to the degree that they might convey the wrong impression.

\section{Discussion and conclusions}

\subsection{Discussion}

The added value of the current research is a narrowly focused analysis of the net effects of weather events on winter wheat yields at a local level after having controlled for the effects of differing production inputs and hidden fixed effects. There is a tension between precision of results and general applicability. The full value of the findings presented here will be realized when they are placed in a wider context along with other micro-level studies. We measure and report the combination of direct and indirect effects of weather events on Dutch winter wheat yields. Dutch farmers are some of the most productive in the world, they have access to the latest technologies and operate in an efficient, stable, economy, and have ready access to a large market. All of which allows them a degree of flexibility in how they produce, harvest, and distribute their products, thereby affording them a degree of insulation from environmental changes. Farmers in countries without these characteristics will presumably be more susceptible to extreme weather events. In short, the findings presented here need to be combined with other micro-level economic studies. Wheat production and consumption takes place within a global market which will adjust to prices and other economic indicators. Understanding how the production and consumption of wheat and other crops will react to climate changes will require placing micro-level studies into a wider context. The trick will be to retain the information contained in low aggregation studies while scaling-up the analyzes to levels at which global policies can be influenced.

Another characteristic of using micro-level data, particularly precise weather data, is the possibility of incorporating local knowledge. Our study required us to focus on a particularly susceptible period in the development of winter wheat in the Netherlands in order to retain adequate degrees of freedom in the regression models. Although this trade-off allows us to focus analyses on events that are most likely to affect yields when they are most vulnerable, we were required to limit the time frame of the study. 
That said, studies using data at higher levels of aggregation run the risk of incorporating weather events that do not significantly affect yields. In contrast to the low level analysis used here, highly aggregated econometric studies cannot disentangle changes in yields attributable to changes in weather variables versus changes attributable to other inputs simply because important yield determining variables cannot reasonably be included in such models (Lobell and Field, 2007; Lobell et al., 2011).

Our Complete model is comparable with that of (Oskam and Reinhard (1992). They aggregated weather over the entire growing season using monthly temperature and sum of evapotranspiration, but they did not include weather extremes. In their model, the time trend was significantly negative for three out of five regions and follows a similar pattern to the pattern observed in this paper. Both the temperature and evapotranspiration show decreasing marginal returns in their model, indicating that excess temperature and evapotranspiration reduce yields.

Another result, using meteorological information on temperature and precipitation during the growing season at a higher level of aggregation than our study, suggests that careful consideration of nonlinear technology trends and an interaction between temperature and precipitation is essential in any empirical mode (Hawkins et al., 2013). All of our quadratic and interaction terms were found to be insignificant, perhaps, as discussed, due to the short time scale used in our analysis. Finally, a study comparing observed and modeled yields of wheat and maize in France in two years with extreme conditions, found that both years adversely affected yields (van der Velde et al., 2012). Our results confirm that yields in 2007 were extremely, negatively, affected, however, 2003 does not appear to be either a significantly good or bad year for Dutch wheat yields. This discrepancy is due to differences in weather and harvesting patterns between the two countries.

\subsection{Conclusions}

Dutch weather data over the period 1901-2013 show that the number of extreme high temperatures and extreme precipitation events is increasing while the number of yearly low temperatures extremes is decreasing. Our findings confirm the IPCC findings and indicate that the number of precipitation events is increasing. Most importantly, the effects of those events on winter wheat yields in the Netherlands were found to be detrimental. Our findings support the conclusions of Trnka et al. (2014) who found, using site data, that adverse effects were likely to out-number the positive effects of weather events.

Furthermore, our results indicate that a model that includes both economic and weather variables is statistically preferred to one that includes only one of the two sets of data. Although the direction of the effects of a given subset of significant exogenous economic or weather variables in comparison to a model combining these variables remains the 
same; the magnitude of the variables changes, thereby leading to potentially erroneous conclusions. However, if only one set of data is available, either economic or weather data, then our results show that such a model would accurately identify the direction that the included variables would have yields, but not their magnitude.

This study contributes to the literature on climate change by assessing the impact of weather extremes on winter wheat yields of a panel of Dutch farms for twelve years. Yields are examined in relation to the actual regional weather data and observed productive inputs used to grow winter wheat on a farm. While the primary goal of this paper was to measure the effects of weather events on yields in the Netherlands, the relevance of that goal depends on the expected occurrences of weather events in the Netherlands. Based on an analysis of over a hundred years of daily data, the expected patterns of the occurrence of extreme events were estimated and forecasted ten years into the future. The number of extreme high temperature and precipitation events was shown to be significantly increasing over the period while the number of minimum temperature and evapotranspiration events was found to be significantly decreasing. These results provide convincing evidence that weather events have been steadily increasing and ARIMA model results indicate that they are likely to remain at historically high levels. In addition, average rainfall and both average maximum and minimum temperatures have been increasing steadily over the last 100 years.

Given that long-term trends indicate that the number of precipitation and high temperature events will increase or remain at historically high levels, we can conclude that their impacts will be detrimental for winter wheat yields. However, given that the number of minimum temperature events is decreasing and that a decrease in the number of minimum temperature events increases yields, all else equal, that process will increase yields. However, the number of extreme minimum temperatures is approaching zero. At the point that such events become rare, the negative effects of increasing precipitation and maximum temperature events will dominate Dutch wheat production.

Studies conducted at high levels of aggregation cannot adequately account for the effects of farm and crop level characteristics influencing yields. It was argued that a low level analysis is necessary in order to isolate the effects of weather events on yields. Therefore, in addition to weather variables, economic variables, including the main factors of production, were included in a within panel model to explain yields. Results indicate the importance of both weather events on yields and the need to specify the time period over which events are measured. Weather events can have either positive or negative effects on yields depending on the week in which they occur. However, the majority of events, either precipitation, or low or high temperature events reduce yields. 


\section{References}

Auffhammer, M., Ramanathan, V., Vincent, J., 2012. Climate change, the monsoon, and rice yield in India. Clim. Chang. 111 (2), 411-424.

Baltagi, B.H., 2008. Econometric Analysis of Panel Data. John Wiley and Sons, Ltd, West Sussex, UK. Berrang-Ford, L., Ford, J.D., Lesnikowski, A., Poutiainen, C., Berrera, M., 2014. What drives national adaptation? A global assessment. Clim. Chang. . http://dx.doi. org/10.1007/s10584-014-1078-3, http://dx.doi.org/10.1007/s10584-014-1078-3

Brisson, P.G.N., Gouache, D., Charmet, G., Oury, F., Huard, F., 2010. Why are wheat yields stagnating in Europe? A comprehensive data analysis for France. Field Crops Res. 119, 201-212.

Calzadilla, A., Rehdanz, K., Betts, R., Falloon, P., Wiltshire, A., Tol, R.S., 2013. Climate change impacts on global agriculture. Clim. Chang. 120, 357-374. http://dx.doi. org/10.1007/s10584-013-0822-4.

Challinor, A.J., Watson, J., Lobell, D.B., 2014. A meta-analysis of crop yield under climate change and adaption. Nat. Clim. Chang. 4, 637-643.

Chen, C., Wang, E., Yu, Q., Zhang, Y., 2010. Quantifying the effects of climate trends in the past 43 years (1961-2003) on crop growth and water demand in the north China plain. Clim. Chang., 559-578.

In: Field, C., Barros, V. et al. (Eds.), 2012. Managing the Risks of Extreme Events and Disasters to Advance Climate Change Adaptation. A Special Report of Working Groups I and II of the Intergovernmental Panel on Climate Change, Cambridge University Press, Cambridge, UK, and New York, USA.

Greene, W.H., 2012. Econometric Analysis, seventh ed. Pearson, Essex, England.

Gregory, P., Marshall, B., 2012. Attribution of climate change: a methodology to estimate the potential contribution to increases in potato yield in Scotland since 1960. Glob. Chang. Biol. 18, 1372-1388.

Hawkins, E., Fricker, T.E., Challinor, A.J., Ferro, C.A.T., Ho, C.K., Osborne, T.M., 2013. Increasing influence of heat stress on French maize yields from the 1960s to the 2030s. Glob. Chang. Biol. 19, 937-947.

Hiemstra, P., Sluiter, R., 2011. Interpolation of Makkink evaporation in the Netherlands. Royal Netherlands Meteorological Instituute (KNMI), De Bilt.

Hirschi, M., Seneviratne, S., V Alexandrov, F.B., Boroneant, C., Christensen, O., Formayer, H., Orlowsky, B., Stepanek, P., 2011. Observational evidence for soil- moisture impact on hot extremes in southeastern Europe. Nat. Geosci. 4, 17-21.

Hooghart, C., (ed), 1987. From Penman to Makkink, Vol 28, TNO committee on Hydrological Research, The Hague.

Kennisakker, 2014. Teelthandleiding Wintertarwe-groei en Ontwikkeling. Internet. Klein Tank, A., Zwiers, F., Zhang, X., 2009. Guidelines on analysis of extremes in a changing climate in support of informed decisions for adaptation, climate data and monitoring. Technical Report WCDMPNo. 72, WMO-TD No. 1500, World Meteorological Organization.

Koninklijk Nederlands Meteorologisch Instituut (KNMI): Royal Dutch Meteorological Institute, 2014. (https://data.knmi.nl/portal-webapp/knmi-datacen trum.html\#1). 
Kucharik, C., Serbin, S., 2008. Impacts of recent climate change on Wisconsin corn and soybean yield trends. Environ. Res. Lett. 3 (034), 003.

LEl, 2014a. (http://www.wageningenur.nl/en/Expertise-Services/Research-In stitutes/lei.htm).

LEl, 2014b. (http://www.wageningenur.nl/nl/project/EU-Farm-Accountancy-Data- Network.htm)(in Dutch).

Leneman, H., Reinhard, S., Hoogeveen, M.W., 1999. Weather and yield: impact of weather on yield in arable crops, Technical reports, LEl, The Agricultural Economic Institute, (in Dutch).

Licker, R., Kucharik, C., Doré, T., Lindeman, M., Makowski, D., 2013. Climatic impacts on winter wheat yields in Picardy, France and Rostov, Russia: 1973-2010. Agric. For. Meteorol. 176, 25-37. Lobell, D.B., Field, C.B., 2007. Global scale climate-crop yield relationships and the impacts of recent warming. Environ. Res. Lett. 2.

Lobell, D.B., Ortiz-Monasterio, J.I., Asner, G.P., Matson, P.A., Naylor, R.L., Falcon, W.P., 2005. Analysis of wheat yield and climatic trends in Mexico. Field Crop. Res. 94, 250-256.

Lobell, D.B., Hammer, G.L., McLean, G., Messina, C., Roberts, M.J., Schlenker, W., 2013. The critical role of extreme heat for maize production in the United States. Nat. Clim. Chang. 3, 497-501.

Lobell, D., Schlenker, W., Costa-Roberts, J., 2011. Climate trends and global crop production since 1980. Science 333 (6042), 616-620.

Ludwig, F., Milroy, S., Asseng, S., 2009. Impacts of recent climate change on wheat production systems in western Australia. Clim. Chang. 92, 495-517.

Meehl, G.A., Zwiers, F., Evans, J., Knutson, T., Mearns, L., Whetton, P., 2000. Trends in extreme weather and climate events: issues related to modeling extremes in projections of future climate change. Bull. Am. Meteorol. Soc. 81 (3).

Min, S., Zhang, X., Zwiers, F., Hegerl, G., 2011. Human contribution to more-intense precipitation extremes. Nature 470, 378-381.

Moriondo, M., Giannakopoulos, C., Bindi, M., 2011. Climate change impact assessment: the role of climate extremes in crop yield simulations. Clim. Chang. 104 (3-4), 679-701. http://dx.doi. org/10.1007/s10584-010-9871-0.

Olesen, J.E., Carter, T.R., et al., 2007. Uncertainties in projected impacts of climate change on European agriculture and terrestrial ecosystems based on scenarios from regional climate models. Clim. Chang. 81, 123-143.

Oskam, A.J., Reinhard, A.J., 1992. Weather indices of agricultural production in the Netherlands 1948-1989. Neth. J. Agric. Sci. 40, 187-205.

Pathak, H., Ladha, J., Aggarwal, P., Peng, S., Das, S., Singh, Y., Singh, B., Kamra, S., Mishra, B., Sastri, A., Aggarwal, H., Das, D., Gupta, R., 2003. Trends of climatic potential and on-farm yields of rice and wheat in the indo-gangetic plains. Field Crop. Res. 8, 223-234.

Porter, J., Gawith, M., 1999. Temperatures and the growth and development of wheat: a review. Eur. J. Agron. 10, 23-36.

Porter, J.R., Xie, L., et al. 2014. Climate change 2014: impacts, adaptation, and vulnerability. Working Group II contribution to the IPCC Fifth Assessment Report. IPCC, authors include: Coordinating lead authors, lead authors, contributing authors and review editors. 
Rosenzweig, C., Iglesias, A., Yang, X.B., Epstein, P.R., Chivian, E., 2001. Climate change and extreme weather events - implications for food production, plant diseases, and pests. Glob. Chang. Human Health 2 (2), 90-104.

Schlenker, W., Roberts, M.J., 2009. Nonlinear temperature effects indicate severe damages to U.S. crop yields under climate change. Proc. Natl. Acad. Sci. USA 106 (37), 15594-15598 (PNAS). http://refhub.elsevier.com/S2212-0947(16)30006-8/sbref33

Semenov, M.A., Shewry, P.R., 2011. Modelling predicts that heat stress, not drought, will increase vulnerability of wheat in Europe. Sci. Rep. 1.

Seneviratne, S., Corti, T., Davin, E., Hirschi, M., Jaeger, E., Lehner, I., Orlowsky, B., Teuling, A., 2010. Investigating soil moisture-climate interactions in a changing climate: a review. Earth-Sci. Rev. 99 (3-4), 125-161.

Studenmund, A.H., 2006. Using Econometrics: A Practical Guide, 5th ed. Pearson International, Prentice Hall, USA.

Sugiyama, M., Akashi, O., Wada, K., Kanudia, A., Li, J., Weyant, J., 2014. Energy efficiency potentials for global climate change mitigation. Clim. Chang. 123 (3-4), 397-411.

Tao, F., Yokozawa, M., Xu, Y., Zhang, Z., 2006. Climate changes and trends in phenology and yields of field crops in China, 1981-2000. Agric. For. Meteorol. 138, 82-92.

Tao, F., Zhang, Z., Liu, J., Yokozawa, M., 2009. Modelling the impacts of weather and climate variability on crop productivity over a large area: a new process-based model development, optimization, and uncertainties analysis. Agric. For. Meteorol. 149, 831-850.

Tao, F., Zhang, Z., Xiao, D., Zhang, S., Rötter, R.P., Shi, W., Liu, Y., Wang, M., Liua, F., Zhang, H., 2014. Responses of wheat growth and yield to climate change in different climate zones of China, 1981-2009. Agric. For. Meteorol. 189-190, 91-104.

Trnka, M., Rötter, R.P., Ruiz-Ramos, M., Kersebaum, K.C., Oleson, J.E., Žalund, Z., Semenov, M.A., 2014. Adverse weather conditions for European wheat production will become more frequent with climate change. Nat. Clim. Chang.

University of Kentucky, 2014. A Comprehensive Guide to Wheat Management in Kentucky. (http:// www2.ca.uky.edu/agc/pubs/id/id125/id125.pdfhttp://www2. ca.uky.edu/agc/pubs/id/id125/ id125.pdf) (accessed 18. 02.16).

Urban, D., Roberts, M.J., Schlenker, W., Lobell, D.B., 2012. Projected temperature changes indicate significant increase in inter-annual variability of U.S. maize yields. Clim. Chang. 112 (2), 525-533.

van der Velde, M., Tubiello, F.N., Vrieling, A.J., Bouraoui, F., 2012. Impacts of extreme weather on wheat and maize in France: evaluating regional climate simulations against observed data. Clim. Chang. 113 (3-4), 751-765.

Vautard, R., Yiou, P., D'Andrea, F., de Noblet, N., Viovy, N., Cassou, C., Polcher, J., Ciais, P., Kageyama, M., Fan, Y., 2007. Summertime European heat and drought waves induced by wintertime Mediterranean rainfall deficit. Geophys. Res. Lett. 34 (7).

Wang, H., Gan, Y., Wang, R., Niu, J., H Zhao, Q.Y., Li, G., 2008. Phenological trends in winter wheat and spring cotton in response to climate changes in northwest China. Agric. For. Meteorol. 148, 1242-1251. 
Wassmann, R., Jagadish, S., Heur, S., Ismail, A., Redona, E., Serraj, R., Singh, R., Howell, G., Pathak, H., Sumfleth, K., 2009. Climate change affecting rice production: the physiological and agronomic basis for possible adaptation strategies. Adv. Agron. 101, 59-122.

Welch, J., Vincent, J., Auffhammer, M., Moya, P., Dobermann, A., Dawe, D., 2010. Rice yields in tropical subtropical Asia exhibit large but opposing sensitivities to minimum and maximum temperatures. Proc. Natl. Acad. Sci. 107, 14562-14567.

Yamamoto, H., Sugiyama, M., Tsutsui, J., 2014. Role of end-use technologies in long term GHG reduction scenarios developed with the bet model. Clim. Chang. 123 (3-4), 583-596. http:// dx.doi.org/10.1007/s10584-013-0938-6.

You, L., Rosegrant, M., Wood, S., Sun, D., 2009. Impact of growing season temperature on wheat productivity in China. Agric. For. Meteorol. 149, 1009-1014.

Zhang, T., Zhu, J., Wassmann, R., 2010. Responses of rice yields to recent climate change in China: an empirical assessment based on long-term observations at different spatial scales (1981-2005). Agric. For. Meteorol. 150, 1128-1137. 
CHAPTER 6 
Forecasting Food Crop Yields and Assessing their Credibility

Jeffrey P. Powell 
An accurate forecast of crop yields is a critical piece of information used by policy makers to make informed decisions on topics ranging from the prospects for global food security to the economic viability of biomass products. An accessible and transparent framework is provided to allow policy makers to assess the trade offs involved when forecasting yields and measure the value of those forecasts. Yields of ten important global food crops are forecasted for ten years and their accuracy reported. A comparison is made between the results of the standard technique used to forecast yields, and auto-regressive, integrated, moving average (ARIMA) forecasts. ARIMA forecasts out-perform those of the standard methodology and provide a convenient means to assess their added value. While the mean forecasts of top producers for most crops are expected to increase, the amount of associated uncertainty is large, and forecasts beyond only a few years should be made with caution. 


\section{Introduction}

An informed understanding of yield forecasts and their limits is crucial for policy makers who must find a balance between the many competing demands for agricultural products and make the investment decisions today that will determine agricultural supplies in the future. This paper will present an easy to implement method for forecasting yields of major food crops. It compares the proposed, more general, technique to methods in common use and discusses the inherent, underlying, limits of forecasting. In particular, a distinction is made between the uncertainty associated with a specific forecasting method and a more fundamental uncertainty intrinsic to all of the forecasting methods discussed.

The demand for agricultural products that can be used as food is expected to increase due to population increases, policies designed to promote the use of biomass products, and a shift towards relatively more meat and dairy consumption [1, 15, 21, 22, 52, 60, 63]. Changes in climate, particularly increases in the number of extreme weather events, are expected to form an increasing threat to food supplies [19, 51].

Population growth will increase the direct demand for food. According to the United Nations Department of Economic and Social Affairs, the World's population will continue to increase for decades even under low growth scenarios [3]. An expected population of 8.1 billion in 2025 and 9.6 billion in 2050 will further strain the world's food supply. There is evidence that demands for biofuels have also increased the direct demand for certain crops such as maize, rapeseed, and sugarcane and, as a consequence, the supply and prices of crops which compete with them for land and other resources used in their production $[33,41]$. Although the issue of assessing the precise impact of biofuels on global land use and food supplies and prices is complex, there is circumstantial evidence of significant effects for specific countries and crops. For instance, of the total yearly supply of maize grown in the US in $2012,41.8 \%$ went to the production of ethanol, compared to $14.2 \%$ in 2005 , the year the Energy Policy Act was implemented $[63,64]$. In addition, rising income and increasing urbanization are adding to demand for more or different sources of animal products, principally meat and dairy products [67]. Large amounts of mainly maize and soybeans have gone to animal feeding facilities to satisfy demands for meat, production of which has risen from 50 million tons (Mt) in 1950 to about 110 Mt in 1975, thereafter more than doubling to around $275 \mathrm{Mt}$ in 2010 [59]. Changes in weather patterns too, although their effects will be crop and region specific, are predicted to reduce yields, with extreme weather events being the major threat to food supplies $[19,51]$.

Increasing the production of food crops will be a critical component in efforts to provide enough food to feed the world's growing population and ease tensions between the various demands for agricultural products. Estimates are that agricultural production 
may need to increase by between $60 \%$ and $110 \%$ to meet these demands $[17,46,60]$. Increasing yields, output per unit of area, is an attractive manner to increase production without having to bring more farmland into production and thereby avoiding further environmental degradation [6]. There appears to be a consensus that yield increases are the preferred alternative for increasing the amount of available food $[21,22,25,44,48,49$, 62].

Although desirable, is it possible to significantly increase yields in the future? Evidence from previous decades has shown that, among others, increases in the use of irrigation, synthetic fertilizers, machinery, genetic improvements and pesticides have led to steady increases in yields and prevented the mass starvations predicted by observers in the mid1960s [2]. The evidence would strongly suggest that we should expect yields to increase in the future. Indeed, the biophysical limits of crop yields have not yet been reached [9, $10,12,42,47,61]$. The introduction of biotechnology traits and the development of new breeding methodologies using DNA based markers are technologies expected to further improve yields [13]. For irrigated crops, that potential is defined as the yield of a crop cultivar when growth is limited only by solar radiation, temperature, and carbon dioxide from the atmosphere and additionally, for rain-fed cropping systems, the amount and distribution of precipitation $[16,42]$.

The range of potential yield measurements in the literature is large. It is reported that average yields in rain-fed systems are commonly fifty percent or less of potential yields, but the size of that gap is dependent on whether the comparison is based on experimental, model, or realized farmer potential yields [42]. A more optimistic forecast of potential yields is that the introduction of stress tolerant crops could mean that future yields might be three times current commercial maize yields [61]. Others warn that grain yields may have peaked in the mid-1990s, and further improvement in the genetic potential of grain yields awaits some new technologies or biological advance [24].

Realized yields are not only a matter of exploiting technologies, they are also influenced by a wide range of factors including social and economic policies, some of which are not intended to maximize yields. Dyson, 1999, claims that world cereal production has grown more slowly than population growth chiefly because of deliberate policies and political developments in North America, Oceania, Europe and the Former Soviet Union [11]. Farmers in well-functioning market economies are not motivated to increase or maximize yields per se, a better, if not perfect assumption is that they are motivated to maximize or satisfice their profits, while farmers in subsistence economies are motivated largely by survival considerations. 
Technical capabilities define yield potentials, and while social policies and economic considerations can influence those potentials, they also frequently result in yields that are well below those potentials. Yields are a product of a combination of breeding and management techniques [9]. The energetic response of maize farmers in the United States to increase yields in response to the higher prices afforded by the Energy Policy Act of 2005 and the Energy Independence and Security Act of 2007 is an example of how the profit motives of farmers can influence cropping decisions, see figure 1. The sub-figures show the large increases in both area used and yields achieved by maize farmers throughout the world; note that the United States is the world's largest producer of maize. Recent assessments show that the introduction of these sorts of crop yield response mechanisms into models were the most critical parameters in the models $[8,31]$.

Given the importance of increasing yields and the potential to increase those yields within genetic, technical, social and economic constraints, what can we expect from yields in the future? Global yield increases for most major cereal crops have been generally linear since the start of the green revolution $[20,27]$. Where linear, as will be discussed in greater detail below, refers to the linear trend model presented in equation 1. Many forecasters assume that these linearly increasing trends, with conditions, will continue into the distant future $[11,38,52,56]$. Others, including several using computational partial equilibrium models, assume compound annual rates of yield increases [30,53]. However, such optimism should be tempered by increasing evidence that while yields for many of the most important crops and producers are increasing, they are doing so at decreasing rates $[37,58]$. To account for this expected deceleration in crop yields, several recent projections of yields consider a declining compound rate of growth over time which aims to mimic the shape of an asymptotic trend [5].

Studies by Tilman et al. 2011, and Grassini et al. 2013 are two important recent contributions to efforts to forecast food demand and supply and so it is informative to take a closer look at how forecasts in those studies were modeled [23,60]. Tilman et al., as a part of their effort to forecast global food demand, include a time trend variable along with several other variables in their model. Specifically, they: '...used past yield relationships and trends to estimate yields that might be achievable by 2050 . They use aggregated yield data composed of nine time points. Mean yields for 1965, 1970, 1975, etc., combined with economic and biophysical data are used to forecast yields using a linear trend model. Grassini et al., claim that the mathematical form of the historical yield trend can be linear, exponential, parabolic, linear plateau or flat for the 36 countries and regions in their study. Further, they claim that linear models, with or without a discontinuous break point, adequately describe all yield trends in their study. 
To summarize, previous paragraphs have established that there is a need to increase the production of food crops to meet increasing demands and threats to supply, and that increasing yields is the preferred method to meet those demands. It was argued that while it is technologically possible to increase yields, increases are also a matter of social and economic policies. Finally, the prevalent current method to forecast food yields was presented. The remainder of the paper will present and argue for the implementation of a more general form of linear model to forecast yields, one that largely encompasses the models previously cited. It first outlines the standard, linear trend, forecasting methodology used to estimate future yields and then contrasts it with the ARIMA methodology. The paper outlines the decisions needed to develop an ARIMA model and compares the accuracy of resulting forecasts to those of the standard technique. In ends by asking whether it is meaningful to forecast decades into the future given two types of uncertainty.

Table 1. Data Description for 2012

\begin{tabular}{lcccccc}
\multicolumn{1}{c}{ Crop } & \multicolumn{1}{c}{$\begin{array}{c}\text { Yield } \\
\text { (kg/ha) }\end{array}$} & \multicolumn{2}{c}{ Area (ha) } & \multicolumn{2}{c}{ Production (tonnes) } \\
& $\begin{array}{l}\text { Nean } \\
\text { Obs. }\end{array}$ & SD & Mean & SD & Mean & SD \\
\hline Wheat & 105 & 22736 & 16418 & 1918205 & 4866328 & $\begin{array}{c}4289255 \\
12175793\end{array}$ \\
\hline Rice paddy & 108 & 29054 & 16832 & 1376402 & 5269790 & $\begin{array}{c}4440504 \\
19152729\end{array}$ \\
\hline Cassava & 95 & 91041 & 50443 & 148884 & 403969 & $\begin{array}{c}1496298 \\
4570902\end{array}$ \\
\hline Barley & 84 & 20963 & 14652 & 650451 & 1243809 & $\begin{array}{c}1439109 \\
2759161\end{array}$ \\
\hline Maize & 143 & 26267 & 27106 & 903854 & 3272465 & $\begin{array}{c}3348975 \\
19792846\end{array}$ \\
\hline Potatoes & 136 & 143691 & 87724 & 113953 & 408873 & $\begin{array}{c}1669972 \\
5869170\end{array}$ \\
\hline Rapeseed & 32 & 17579 & 8448 & 545203 & 1383631 & $\begin{array}{c}761464 \\
1957050\end{array}$ \\
\hline Sorghum & 79 & 15415 & 12868 & 561338 & 1880006 & $\begin{array}{c}738092 \\
2394001\end{array}$ \\
\hline Soybeans & 60 & 13724 & 7006 & 1031745 & 3964815 & $\begin{array}{c}2078006 \\
9302421\end{array}$ \\
\hline Sugar beet & 35 & 375482 & 171103 & 153597 & 209921 & $\begin{array}{c}5351388 \\
7632160\end{array}$ \\
\hline
\end{tabular}

Note: Data is from FAOSTAT, preliminary data 2012. Original data: [18] 


\section{Data and Method}

\subsection{Data}

The starting point for building an econometric forecasting model of any type is an examination of what happened in the past. Actualized, historical yields of the type used in this study are the yields that farmers realized given the entirety of constraints bounding their behavior and aims in a particular year. They are the result of the accumulated decisions, vagaries, and external influences affecting yields. Econometric methods do not ask, by way of contrast, what the maximum achievable yield was or will be; rather, they start with what is taken to be true, and move forward based on assumptions about the continuation of previously observed patterns in the data.

Data used in the analyses to follow are from the FAOSTAT database [18]. The database contains time-series information on yields, area used to grow a crop, and production. A time-series is simply a sequence of observations of an object over a number periods, i.e., yearly yields of wheat for France for the period 1961 to 2012. The ten crops in the study are representative of the most important global food staples. Note that yields are rates in that they measure an amount of output per area and should not be confused with the amount of a crop produced; for instance, several countries have very high yields for a crop but produce only a small amount. Yields are a measure of partial productivity in the sense that they inform us about one important aspect of the crop production process, other productivity measures, including labor and capital productivity, are not included in this study. All years for which data are available are included in the study, so 1961-2012 for countries with complete data sets.

Effort was made to include as many countries as possible in the analyses with the proviso that enough data exists to perform meaningful econometric regressions. Those countries with at least complete sets of yield data from 1983 to 2012 were included in the analyses. In short, to be included in the study, yield data for all years between 1983 and 2012 needed to be available; if, for instance, a country was missing data for one or more of those years it was removed. The thirty year cut-off time span (1983-2012) used is somewhat arbitrary, it is possible with just two years of data to calculate a time trend, but given that the aim is to forecast ten years into the future, thirty years provides a reasonable base from which to model historical relationships. Most countries in the analyses have data for the entire, 1961-2012, period. Other minimum time spans were tried including ten and twenty year spans, but these alternatives did not change the overall conclusions of the analysis. Effectively, the approach employed means that countries which were superseded by other countries, e.g., the Soviet Union, and newer countries such as Bosnia and Herzegovina, were dropped from the analysis. In total, 183 unique countries were included for one or more crops, only China had data for all ten crops. 
In contrast to many of the previously cited studies, the data used to forecast yields was not aggregated either across countries or time [23, 31,60]. Aggregating data is sometimes necessary, for instance when data for a country is missing or in order to reduce the number of explanatory variables in an analysis to a manageable number, but doing so results in a loss of information and should be avoided when data availability allows as in the current case. Aggregating countries into, e.g., regions, reduces the number of observations directly, while aggregating across time, such as averaging across five year time spans to create fewer time points, reduces the availability of variation, a necessary ingredient in forming robust econometric estimates.

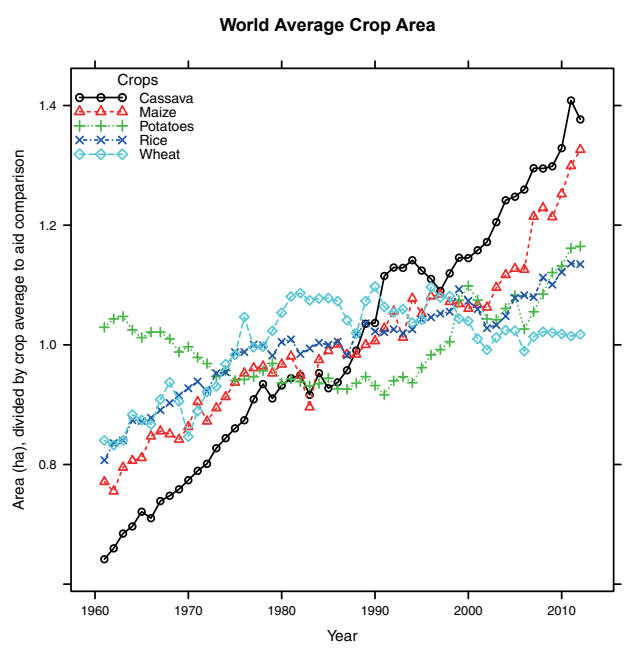

(a) Average Area

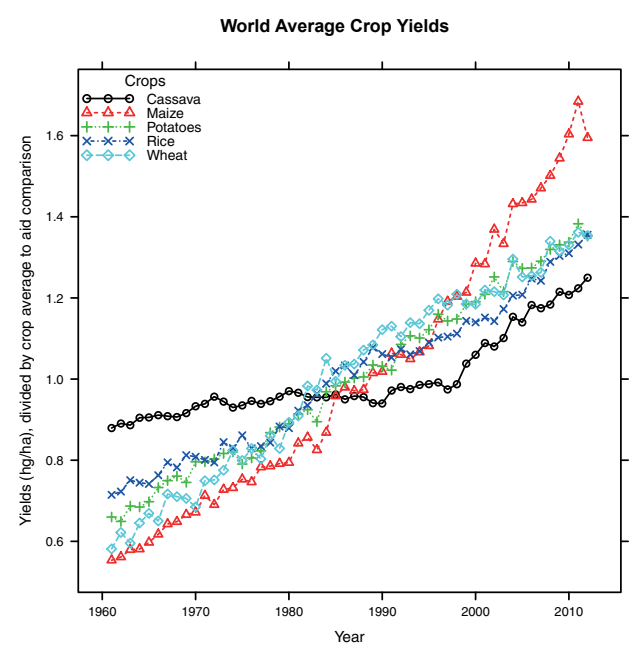

(b) Average Yield

Figure 1. Relative changes in average production, area and yields.

Figure 1 is a compact method to picture data with widely divergent units of measurement. Yearly averages of area and yield data for five of the ten major food crops were divided by their total respective averages over all years for all countries in the data set-it was not possible to include all ten crops in one figure and retain readability. Figure 1a shows how the relative area used to grow a crop has changed through time; where relative refers to the area used to grow that crop in a given year compared to the total average area used to grow crops across all time periods. For the sake of comparison, only countries with data for all fifty-two years were used to create the figures. To illustrate reading the figures, more land was used to grow cassavas in 2011 than any other year and the amount of land devoted to maize production grew at a very fast rate; however, the absolute amount of land used to grow cassavas in $2012(19,421,827)$ was much less than that used to grow wheat in the same year $(211,088,142)$. In contrast, the relative amount of land used to grow wheat and potatoes has stayed more or less the same for some decades. 
In contrast to area, relative yields, figure $1 \mathrm{~b}$, of all five crops have increased over the entire period. Yields (hg/ha) are not calculated from the area (ha) and production (tons) data, but taken directly from the FAO data set. Maize yields have, until 2012, been on a steeper trajectory than the other crops, due in part to the subsidies that have made biofuels profitable to produce, adding further support to claims that policies which affect prices are important mechanisms for increasing yields [8, 31, 32]. Another factor which may partially explain why the relative yields of maize have risen above those of rice and wheat is the difficulty of developing hybrids for those crops, both of which are self-pollinated [34]. The importance of the two figures is that they emphasize that steady yield increases have allowed production to expand without necessarily bringing new farmland into production.

There have been noticeable differences in the growth rates of crops over the period from 1961 to 2012 . The following are rough measures in that they do not weigh aggregate yields according to the amount a country produces. In short, the yields of a small country which produces little in a year, receive equal weight to the yields of countries that produce large amounts. However, the intent is to show how average yields per crop across all countries have changed between 1961 and 2012 and not how global averages have changed over that period. With that qualification in mind, yield percentage increases of countries with complete (1961-2012) sets of data were calculated. In decreasing order, growth rates were: maize $(188 \%)$, wheat $(133 \%)$, potatoes $(105 \%)$, barley $(104 \%)$, sugar beets $(104 \%)$, rapeseed $(91 \%)$, paddy rice $(90 \%)$, soybeans $(89 \%)$, sorghum $(68 \%)$ and cassavas $(42 \%)$. These highly aggregated growth rates are impressive, yields of many crops doubled or were close to doubling, although they hide the variation growth rates between countries. As will be discussed below, a linear trend model essentially projects these historical trend patterns into the future for as long as a researcher believes those rates will hold.

Finally, table 1 describes the basic characteristics of the data in 2012 across all countries. For instance, the number of countries used in the analysis of wheat yields was 105 , average wheat yields for all countries with wheat data in 2012 was $22,736 \mathrm{~kg} / \mathrm{ha}$, the average area used to grow wheat was $1,918,205$ ha, and production was $4,289,255$ tons. The standard deviations (SD) are large, reflecting the large amount of diversity in the data that individual country forecasts should identify.

\subsection{Method}

\subsubsection{Linear Trend Model}

The econometric models used in the time series studies cited above are forms of an extrapolation model, a standard technique that has been used for decades in economic and business forecasting [50]. The method should be used if the assumption can be made that yields will increase at a constant absolute rate in each time period into the future. If that assumption is accepted, then the following model can be used to fit the data with a trend line: 


$$
\text { yield } s_{\mathrm{t}}=\beta_{0}+\beta_{1} \times t+\varepsilon_{\mathrm{t}}
$$

where $t$ represents time, yields $s_{t}$ are yields at time $t, \beta_{0}$ is a constant (the intercept term), $\beta_{1}$ is a linear trend term estimator, and $\varepsilon_{\mathrm{t}}$ is the error term. The error or disturbance term is the deviation of the observed value from the unobserved true underlying value of the variable. The observed value may deviate from the real value for many reasons including measurement error. We know for instance, that the time variable used in equation 1 is an imperfect proxy for all of the factors affecting yields in a particular year for a particular country, so we should expect that there will be errors. Time $t$, is usually set equal 0 or 1 in the base period, 1961 for most of the countries in the FAO data set, and incremented by one for each year in the sample, so $t$ is a simply a variable of the form $1,2,3 \ldots, 52$. Yield data for each country and crop is then regressed against the time variable. Using the time trend model for U.S. wheat yields produces the following regression results:

$$
\text { yield } s_{\mathrm{t}}=17168.8+253.4 \times t+\varepsilon_{\mathrm{t}} ;
$$

which is interpreted to mean that wheat had an intercept term equal to 17,169 , while yields increased by a steady $253.4 \mathrm{~kg} / \mathrm{ha}$ per year over the period 1961-2012. The $\mathrm{t}$-values for both the intercept term and trend (slope) are highly significant (38.8 and 17.1 respectively). Significance can be understood as the probability that the estimates are different than zero, i.e., a significant term is a useful indicator of the relationship between yields and time. An absolute t-value of 1.96 or greater is, by convention, considered significant, so the observed values are highly significant.

A possible point of confusion when referring to trend models is the term linear. Linear, in the common linear regression model, refers to the linearity of the $\beta$ parameters, and not the linearity of the explanatory variables. The $\beta \mathrm{s}$ in equation 1 have a polynomial degree of one, while the ts may be squared, cubed, logged and so forth as long as the associated $\beta \mathrm{s}$ are of polynomial degree one and with a reasonable additional constraint that the resulting coefficients are economically or otherwise meaningful. The time data can be of a degree other than one, for instance, it is possible and common to add a $\beta_{2} t^{2}$ term to equation 1 to identify nonlinear effects in a time series. The $\beta_{2}$ would then be a measure of the change of the change (curvature) of yields through time, where a negative $\beta_{2}$ implies a decrease in the increase of yields through time. In any case, the model would still be a linear model because the degrees of all of the $\beta$ s are one.

Notice that the model represented in equation 1, and all models discussed in this paper, is not a structural model in that it does not attempt to explain the mechanisms causing yields to change. This model only says that if it can be assumed that those underlying mechanisms determining yields continue to determine yields in the future, we can assume that yields will 
continue to increase at the same constant, unwavering, rate. The principle advantages of the form of the model shown in equation 1 are that they are easy to implement, understand, and explain. And, most importantly, they have previously provided reasonably accurate forecasts. The model does well for most major producing countries that have avoided anything less than a disastrous disruption to their agricultural system; it does well for all countries represented in figure 2. For instance, the model for France, which has a trend coefficient of $933 \mathrm{~kg} / \mathrm{ha}$ (t-value $=17.3$ ), and Germany with a trend coefficient of $975 \mathrm{~kg} / \mathrm{ha}$ ( $\mathrm{t}$-value $=23.7$ ), two countries which have recently experienced diminishing yield increases, also perform well. Even Australia, which has been recovering from a decade of drought, has a significant t-value (4.55) for a calculated yearly increase of $133.9 \mathrm{~kg} / \mathrm{ha}$ [43]. These models do well in the sense that the trend term is highly significant and not, as reported in some of the studies reported above, in terms of the R-squared of the entire model.

\subsubsection{Linear Trend Limits}

So why if the linear trend model performs well use another model specification? The simple answer is the observation that recent yield increases, for some crops and countries, have not been following a linear trend path $[37,58]$, an observation that can be corroborated by examining figure $2 \mathrm{~b}$. The figure indicates that the yields for France and Germany, two of the world's top wheat producers, while increasing, are increasing at decreasing rates. Using a more systematic method, specifically, by comparing the corrected Akaike information criterion (AICC) indicators of several polynomial forms of models for all countries and crops, shows that the linear trend model is not always the preferred model [26]. The procedure indicates that the data for 129 countries across all crops are best described as linear trend, 234 are best described by a model with an additional term of degree two, 503 with a degree three term, and 11 with a degree four term. Please note that all models include lower degree terms as well, so a model of degree two includes a term of degree one as well. At first blush, using this basic comparative technique, the linear form of degree one seems inappropriate in many cases. For instance, adding a quadratic trend term $\left(\beta_{2} t^{2}\right.$ to equation 1 for the French and German wheat models results in significant negative values for that term (France: $-18.78 \mathrm{~kg} / \mathrm{ha}$, t-value $=3.04$; Germany: $-8.98 \mathrm{~kg} / \mathrm{ha}$, $\mathrm{t}$-value $=-3.29$ ); thereby confirming the visual evidence in figure $2 \mathrm{~b}$ that while wheat yields are increasing in those countries, they are doing so at a decreasing rate. In both the French and German models the linear trend term remains highly significant. However, adding a quadratic time term to the U.S. wheat model results in an insignificant, negative coefficient $(-1.42 \mathrm{~kg} / \mathrm{ha}$, $\mathrm{t}$-value $=-1.30$ ), while the linear time value remains significant. The insignificance of the quadratic term in the US case is predictable given the nearly constant trend in figure $2 \mathrm{~b}$; there is no observable tapering off of wheat yields for the US.

However, two potential issues arise when additional polynomial terms are added to a model, one is that interpretation can become difficult as the meaning of degree terms 
becomes more esoteric the higher they become and, although the resulting model most probably fits the observed data better, it may not forecast as well as a model with fewer terms. These two points are essential decisions facing forecasters when specifying any econometric forecasting model and are discussed below. There is no statistical test or rule book defining how many variables to include in a model or their form.

Interpreting a model with a quadratic term takes some getting used to, as discussed, it represents the change in the change in yields over time; attributing meaningful interpretations to higher degree estimates is problematic. Since the goal of the entire exercise is to develop a model that forecasts well, it could be argued that as long as it does that, then interpretation is an unnecessary luxury. This raises the second issue which is more subtle and perhaps counter-intuitive. An extreme example illustrates the issue. It is a simple matter to fit a line which goes through most or all points of the yield data for all sensible FAO data sets, perhaps by adding an increasing number of sequential polynomial terms to a model or by implementing a smoothing spline method. Such a line will then serpentine from observation to observation as the years pass. Although such a strategy will result in a better fit of the observed data, it does not necessarily lead to a better fit of the data one would like to forecast. This is a reason that the corrected AIC method mentioned above, and other model comparison techniques, penalize the addition of variables to a model; if two models explain the relationship between the dependent and independent variables equally well, then the model which uses the fewer number of variables is preferred. In short, parsimony is preferred, and not only for aesthetic reasons.

The process of adding too many variables to a model is called over-fitting; where how many is too many is a matter of experimentation and art. A model which accounts for every nuance in the yield data will, in a sense, be conflating random fluctuations in the data with more consistent underlying mechanisms which might help to forecast yields into the future $[29,39]$. We can be certain, for instance, that the FAO yield data contains measurement errors due, for instance, to aggregation. A model which fits a line to each point of a data set will likely perform worse than a model that ignores every twist and turn in data due to measurement error in favor of a more robust, uncomplicated, representation of the basic underlying data generating mechanisms. Both interpretation and forecasting suffer as a result of the over-fitting.

Part of the appeal of the linear trend model is that it avoids the problem of over-fitting because it uses just one explanatory variable. There is no pat formula to find the best model that fits both extant data and future data, although, as will be shown, it is possible to see how well a model would have done in forecasting existing data. Finally, a high $\mathrm{t}$-value alone or a lower corrected AIC statistic are not sufficient conditions for choosing a model. For instance, although the quadratic term in both the French and German models 
is significant, the corrected AIC statistic rejects its addition in both models because the curvatures is a relatively recent phenomenon. In short, the AIC prefers the linear trend model to the linear trend plus quadratic term model. However, if a researcher believes that the decrease will continue, then that term should be included in the model. In addition, the ARIMA model helps a researcher to determine which underlying data generating mechanisms are robust and therefore likely to continue into the future.

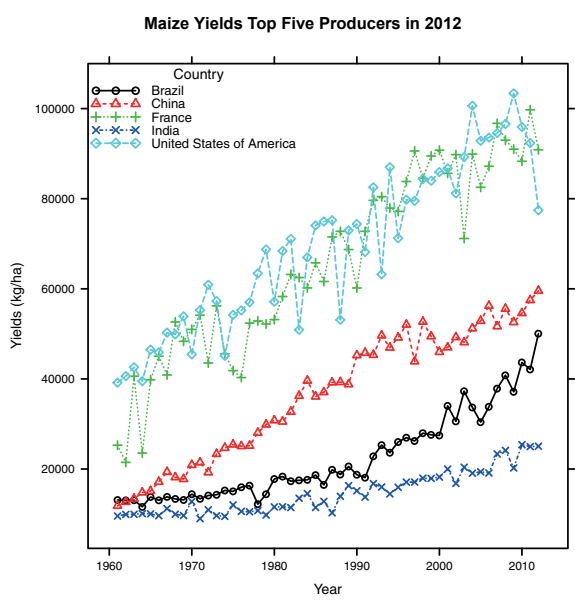

(a) Country Maize Yields

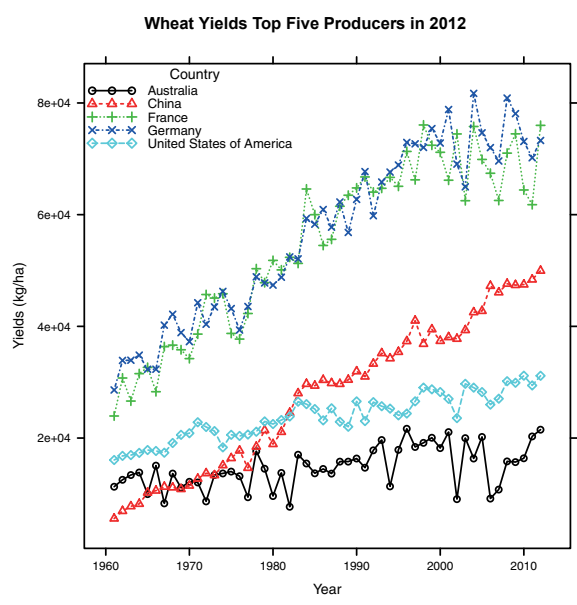

(b) Country Wheat Yields

Figure 2. Yields of largest producers of maize and wheat.

\subsubsection{ARIMA Model}

Rather than imposing a particular structure on a model ex ante, linear trend or otherwise, the auto-regressive, integrated, moving average (ARIMA) model uses historical data to formulate a model. The model was first described by Whittle in 1951 and made popular by Box and Jenkins in a series of papers and, eventually, a book published in 1970 [4, 45, 66]. ARIMA models were developed for forecasting and have been the standard forecasting tool for time series for decades. The basic principle underlying the methodology is that forecasts of a time series can be based solely on their past record. The form of the eventual forecast function is dictated, to a large extent, by the data-a principle known as "letting the data speak for itself" [45].

For the case at hand, the model assumes that yields in a particular year are linearly dependent on yields in previous years:

$$
\text { yield } s_{\mathrm{t}}=\theta_{1} \text { yield } s_{\mathrm{t}-1}+\varepsilon_{\mathrm{t}}+\alpha_{1} \varepsilon_{\mathrm{t}-1}
$$

$A R(1) M A(1)$ model form, where the 1 refers to the lag, for example, an $A R(2)$ model would contain a yields $t_{t-2}$ term in addition to the yields $s_{t-1}$ term. 
where the yields are yields at time $t, \theta_{1}$ yields $s_{t-1}$ are yields in the previous period, $\varepsilon_{\mathrm{t}}$ denotes a serially uncorrelated innovation term with mean zero and constant variance, and alpha $\varepsilon_{\mathrm{t}-1}$ are white-noise (error) terms from the previous period. Simply, the $\varepsilon_{\mathrm{t}}$ is no more than the error term of standard linear regression models (e.g., as in 1), while the alpha $\varepsilon_{1-1}$ term is the error term from the previous year. The model depicted represents a first order, autoregressive, first order, moving average process. Additional orders can be constructed by further lagging yields and white noise terms. ARIMA models are the obvious alternative to the models described above. They are, in theory, the most general class of model for forecasting time series which can be made to be stationary by differencing because they do not impose an ex ante structure on the data, but let the dynamics in the historical data define the model. A time series process is strictly stationary if its properties are unaffected by a change of time origin, but for our purposes it is enough to refer to weak stationarity, the idea that the means, variances, and covariances of a series are independent of time [65]. None of the series in figure 2 are stationary because their means are generally increasing through time, in short, the means are not independent of time.

Differencing is a manner to make a non-stationary series stationary. The effect of differencing is intuitive, in the case of yields, differencing-subtracting yields from the previous period from the current period-is simply the change in yields from one period to the next. The first data point in the series, in most cases 1961, is effectively removed from the analysis because data for 1960 is unavailable and therefore cannot be subtracted from the value for 1961. Given that some years' experience increases in yields and others decreases, a nonstationary process can be made stationary. There is no obvious reason to believe that the means, variances, and covariances of yearly changes in yields, and many economic variables, should be dependent on time. In a few cases it was necessary to difference the yield data twice-difference the already differenced data once again-in which case two data points were lost. The amount of differencing required is identified as integration, the 'I' term in the ARIMA model. It is possible to difference a series too often. Differencing tends to introduce negative correlation: if a series initially shows strong positive autocorrelation, then differencing will reduce the autocorrelation and perhaps even drive autocorrelation to a negative value $[14,28]$. The method of differencing only works if the original data changes through time. In several cases, FAO yield data are constant for a country over a number of years, in which case differencing was not an option and a linear trend model was the form assumed to represent the data.

The first step in fitting an ARIMA model was to determine the order of differencing needed to make the series stationary. Normally, the correct amount of differencing is the lowest order of differencing that produces a time series which fluctuates around a well-defined mean value and whose autocorrelation function (ACF) plot decays fairly rapidly to zero. The ACF and partial autocorrelation function plots (PACF) are convenient methods to 
visualize how yields in a year are correlated with yields in previous years, the stationarity condition requires that the correlation gradually falls to zero or fades to insignificance.

Although ACF and PACF figures are a good means to check for autocorrelation, it is not practical to analyze thousands of these figures. Therefore, Kwiatkowski-Phillips-SchmidtShin (KPSS) and augmented Dickey Fuller tests were used to initially test whether yields were stationary. If series were found to be non-stationary, they were differenced until they were made stationary $[40,54]$. Results of the two tests were then compared to an automated procedure developed by Hyndman and Khandakar, 2008 [36]. Only when there were discrepancies among the tests and procedures was the differencing decision based on a combination of the auto-correlation and partial auto-correlation plot functions and the difference order which received the most votes of the three methods [65]. Comparisons were made for each of the country crop combinations, the majority of which could be made stationary by differencing once (760), less than a hundred needed no differencing (75), while the remainder (42), needed to be differenced twice. There was generally agreement among the three methods used to identify differencing requirements.

The next step in the ARIMA procedure was to establish the order of the ARIMA model, i.e., the number of AR and MA terms to include in a model. All combinations of orders from zero to three for both the AR and MA terms were tested and compared-16 combinations in total. For example, an ARIMA model, using the differenced data, of the order $A R(0)$ and $M A(0)$ was run, then an $A R(0)$ and $M A(1)$ model was run and so forth until $A R(3)$ and $M A(3)$ terms were included in the model. I used the Akaike information criterion (AIC), the Bayesian information criterion (BIC), and the corrected AIC recommended in Burnham (AICC) to select the best model for a country and crop [7,57]. These are standard criteria to compare models which take not only model fit into account, but penalize the addition of variables. Another consideration in determining the order of differencing is the role played by the constant term in the model if one is included. The constant represents the mean of the series if no differencing is performed, the average trend in the series if one order of differencing is used, and the average trend-in-the-trend (curvature) if two orders of differencing are required. In a model with one or two orders of differencing, the constant or drift term may or may not be included depending on whether or not an average trend or an average trend-in-trend is meaningful. As previously argued, both measures are relevant for yields, and so a constant was included in all of the models.

The final step was to forecast yields based on the chosen model. Forecasting ARIMA models, like forecasting standard linear trend models, is essentially an iterative process in which the chosen model for each country and crops is used to forecast one year in advance, then that forecast is used to forecast the next year and so forth. 


\subsubsection{ARIMA Forecasts}

The model development procedures described above generated a parsimonious econometric model that was then used to forecast yields. Table 2 presents results for ARIMA ten year forecasts for the top three producers for each of the ten crops in the study. All results are available in the supplementary material section of the paper. The country column contains the ISO3 country code and the yield column yields in 2012, the last available year of data. The percent column contains the yearly percent increase (or decrease) required to move from a three year average of yields in years 2010, 2011, and 2012 , to the mean forecasted yield in 2022. For instance, taking wheat for China, China's average yield for the last three years of data would need to increase by $1.571 \%$ per year for ten years (2013-2022) to reach $58,379 \mathrm{~kg} / \mathrm{ha}$ in 2022 . A three year average was used in order to neutralize the effects of a particularly low or high yield in 2012. The required percentage increase is sensitive to the base yield used in its measurement, so using the average was an imperfect means to provide for a more neutral measure. In addition to mean forecasts, lower and upper forecast ranges for the $95 \%$ confidence interval are reported. The confidence intervals are set at their $95 \%$ values, showing, essentially, that in repeated sampling in $95 \%$ of the cases the intervals will contain the true value of the $\beta$ concerned. Ranges or some other indicator of uncertainty need to be reported along with the mean in order to be able to assess the accuracy attached to a forecast.

A strength of the econometric method in comparison to deterministic models, including most general and partial equilibrium models and simulation models, is that it is possible to quantify the uncertainty of results. The range of low and high values in the table is great, despite the consistency and general stability of the yields of the countries presented; countries which have experienced higher yield variances will generally have greater low and high confidence intervals in percentage terms. Taking a closer look at values in the percent column, values range from $-0.273 \%$ for barley in Australian, to $3.479 \%$ for maize in the US. A rate of 3.479 implies a doubling of yields in a little over twenty years; a value near the top of the potential current yield gap cited above. The negative value for barley yields in Australia is due to a series of droughts that led to erratic yields for several years.

The accuracy of a forecast is a measure of the confidence that can be placed in an outcome or range of outcomes. A forecast without an attached measure of accuracy is nearly meaningless; what use would a weather forecast of rain be without some indication of its likelihood? Figure 3 shows ten year forecasts for wheat in the Netherlands and maize in the United States. The Dutch have, depending on the year of measurement, the highest or one of the highest wheat yields in the world, while the USA is consistently one of the world's largest producers of maize. The figures are included because they show both the strengths and limits of forecasting with ARIMA models and forecasting in general. 
Figure $3 a$ of wheat yields in the Netherlands shows the ARIMA forecast at its best. Both ARIMA and linear-trend ten year forecasts (2013-2022) are presented in the figure. The wandering solid black line set against the light-gray colored background is the mean of ARIMA forecast, while the linear trend line forecast is the straight line intersecting the $\mathrm{y}$-axis at a point somewhat above $40,000 \mathrm{~kg} / \mathrm{ha}$. For a given year in the future, the distance between the gray boundaries represents the $95 \%$ confidence interval. The range of values is quite large, and should be disconcerting for a policy maker. For instance, in 2022, the high estimate for yields is around $118,000 \mathrm{~kg} / \mathrm{ha}$ while the low is around $78,000 \mathrm{~kg} / \mathrm{ha}$; a large spread given current yields of $85,870 \mathrm{~kg} / \mathrm{ha}$.

Table 2. Forecast and Ranges

\begin{tabular}{|c|c|c|c|c|c|c|}
\hline Crop & Country & $\begin{array}{c}\text { Yield (kg/ha) } \\
2012 \\
\end{array}$ & Percent & Lower & $\begin{array}{c}\text { Forecasts } 2022 \\
\text { Mean }\end{array}$ & Upper \\
\hline \multirow[t]{3}{*}{ Wheat } & $\mathrm{CHN}$ & 49952 & 1.571 & 51287 & 58379 & 65471 \\
\hline & IND & 31732 & 1.069 & 31630 & 35292 & 38954 \\
\hline & USA & 31148 & 0.543 & 29703 & 32880 & 36058 \\
\hline \multirow[t]{3}{*}{ Paddy Rice } & $\mathrm{CHN}$ & 67427 & 1.282 & 66553 & 76588 & 86624 \\
\hline & IND & 35906 & 1.282 & 35590 & 40785 & 45981 \\
\hline & IDN & 51360 & 1.257 & 50819 & 58196 & 65572 \\
\hline \multirow{3}{*}{ Cassava } & NGA & 140260 & 0.658 & 112135 & 149770 & 187405 \\
\hline & IDN & 213631 & 3.154 & 235422 & 291426 & 347430 \\
\hline & BRA & 136118 & 0.077 & 102126 & 137174 & 172222 \\
\hline \multirow[t]{3}{*}{ Barley } & FRA & 67381 & 1.131 & 62904 & 75403 & 87901 \\
\hline & DEU & 61925 & 1.081 & 61127 & 68956 & 76785 \\
\hline & AUS & 22109 & -0.273 & 15677 & 21514 & 27350 \\
\hline \multirow[t]{3}{*}{ Maize } & USA & 77442 & 3.479 & 95834 & 109016 & 122197 \\
\hline & $\mathrm{CHN}$ & 59552 & 1.305 & 59726 & 67796 & 75866 \\
\hline & BRA & 50057 & 1.730 & 52921 & 59421 & 65921 \\
\hline \multirow[t]{3}{*}{ Potatoes } & $\mathrm{CHN}$ & 158151 & 0.859 & 127740 & 172280 & 216821 \\
\hline & IND & 236842 & 0.184 & 217627 & 241226 & 264825 \\
\hline & USA & 418114 & 0.884 & 376116 & 456564 & 537012 \\
\hline \multirow[t]{3}{*}{ Rapeseed } & CAN & 18389 & 1.660 & 17956 & 21679 & 25402 \\
\hline & $\mathrm{CHN}$ & 19178 & 1.994 & 15523 & 23364 & 31206 \\
\hline & IND & 11446 & 1.554 & 11133 & 13355 & 15576 \\
\hline \multirow[t]{3}{*}{ Sorghum } & MEX & 38295 & 0.635 & 33439 & 40799 & 48159 \\
\hline & NGA & 12545 & 1.236 & 10214 & 14186 & 18157 \\
\hline & USA & 31280 & 2.996 & 32242 & 42019 & 51797 \\
\hline \multirow[t]{3}{*}{ Soybeans } & USA & 26642 & 1.676 & 28320 & 31461 & 34603 \\
\hline & BRA & 26366 & 1.958 & 28046 & 32008 & 35969 \\
\hline & ARG & 22814 & 2.402 & 21683 & 28926 & 36168 \\
\hline \multirow[t]{3}{*}{ Sugar beet } & FRA & 864785 & 1.649 & 839430 & 1018411 & 1197392 \\
\hline & USA & 655933 & 0.079 & 567037 & 661105 & 755174 \\
\hline & DEU & 693633 & 0.938 & 666661 & 761546 & 856430 \\
\hline
\end{tabular}


Note: Table of lower, mean, and upper forecasts for the top producers in 2012 of ten major food crops using ARIMA models with a trend or drift term. The percent column is the yearly percentage increase required to go from yields averaged across 2010, 2011 and 2012 to the mean forecast in 2022. The three year average was used to smooth the series and a void starting from either a yield peak or valley. IDN is Indonesia, IND is India, NGA is Nigeria, and ARG is Argentina. Original data: FAO preliminary data for 2012 [18]

Linear trend forecasts are always straight lines, while ARIMA forecasts, given enough information in the 'true' data upon which a model is estimated, will reproduce discerned patterns in forecasts. In the example, the estimated model is robust, and the forecast reproduces the consistent, undulating pattern observed for Dutch wheat yields from 1961-2012. In contrast, the linear trend line finds the best fit from previous years and extends that trend into the future, ignoring yearly variation in the data. In the Dutch case, the linear trend line appears to initially overestimate observed yields until the late 1970s at which point it underestimates them until the 1990s, thereafter it begins to alternate between underestimating and overestimating the data.

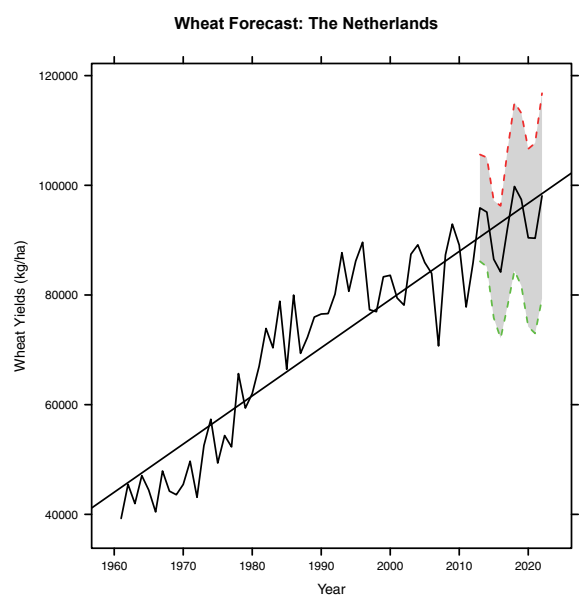

(a) Maize forecasts: The Netherlands

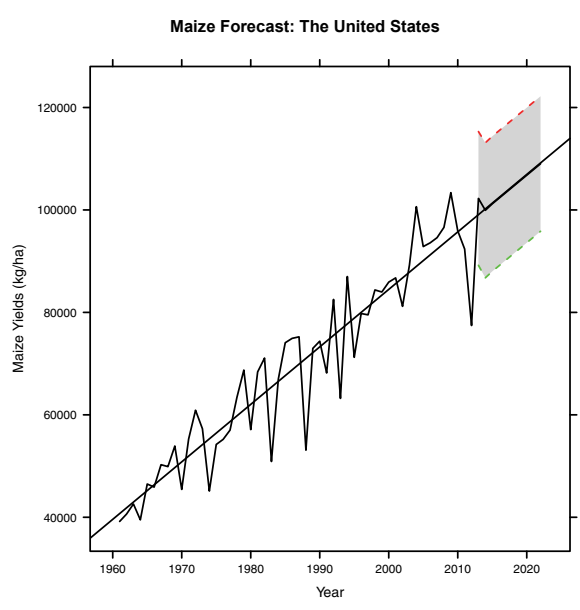

(b) Wheat forecasts: The United States

Figure 3. ARIMA forecasts for Dutch wheat and US maize.

Figure $3 \mathrm{~b}$ shows the limits of the approach, in particular, the ARIMA forecast 'reverts' to the linear trend model after the 2013 forecast. The reason for the reversion is that there is not enough information in the data upon which to base a forecast beyond the estimate that yields in future years will be the conditional mean of previous years. The erratic behavior is observable in the data from 1961-2012, periods of large fluctuations in US maize yields were followed by relatively flat periods and both correlated and uncorrelated consecutive yearly yield changes. The only reason that the forecast continues its assent is that a constant or drift term was added to the model. This allows the estimate to mimic the 
linear trend model once the additional information from the ARIMA procedure has been exhausted. It is in this sense that the ARIMA model is a general form of the linear trend line.

If the historical process is robust, then the ARIMA model will transcribe it into the future, if it is weak, the best ARIMA forecast for the future is simply the conditional mean of the yield or the yield in the last year for which it was able to forecast. Technically, there are insufficient temporal dynamics within the historical data to allow forecasts to vary from their means. This characteristic of ARIMA models allows researchers to characterize the robustness of a model. The procedure used in the analysis was to remove the constant from the model and then rerun the models. If a forecasted value does not change from its previous value for several years, then there is evidence that there is not enough information after that time to make a forecast other than the conditional mean. Following this procedure for each of the ten crops showed that data for around $40 \%$ of countries represented lacked the temporal dynamics necessary to forecast, in the first forecast year, anything other than the conditional mean; values range from $47 \%$ for rapeseed to $35 \%$ for soybeans. In addition, there is no readily discernible pattern in regards to which countries have enough dynamics to form forecasts other than the conditional mean, in fact, forecasts for 151 countries for one or more crops were the mean. The conclusion is that for many countries, the statistical information contained in the historical data does not justify making a forecast much beyond the statement that yields in the future will, on average, equal yields today.

Table 3. Data Performance

\begin{tabular}{|c|c|c|c|c|}
\hline \multirow[b]{2}{*}{ Crop } & \multicolumn{2}{|c|}{ One Year } & \multicolumn{2}{|c|}{ Ten Year } \\
\hline & ARIMA preferred & $\begin{array}{c}\text { Linear trend } \\
\text { preferred }\end{array}$ & ARIMA preferred & $\begin{array}{c}\text { Linear trend } \\
\text { preferred }\end{array}$ \\
\hline Wheat & 66 & 39 & 56 & 49 \\
\hline Rice paddy & 74 & 34 & 72 & 36 \\
\hline Cassava & 72 & 23 & 63 & 32 \\
\hline Barley & 52 & 32 & 55 & 29 \\
\hline Maize & 97 & 46 & 80 & 63 \\
\hline Potatoes & 96 & 40 & 88 & 48 \\
\hline Rapeseed & 21 & 11 & 17 & 15 \\
\hline Sorghum & 58 & 21 & 48 & 31 \\
\hline Soybeans & 31 & 29 & 30 & 30 \\
\hline Sugar beet & 23 & 12 & 22 & 13 \\
\hline
\end{tabular}

Note: ARIMA and Linear trend model forecasts for ten crops. Models are run for countries with complete data sets, i.e., 1961-2012. The ARIMA model includes a constant or drift term. Original data: [18] 


\section{Discussion and Conclusions}

\subsection{Linear Trend ARIMA Comparison}

Models are built using available data and used to predict future data. It is not possible to know how well a model will do in forecasting future events, but it is possible to assess how well a model would have done in forecasting a known entity. A procedure commonly used is to build a model based on a subset of the data, and then use the resulting model to forecast values taken to be true. Following this procedure, yield data for each country across all crops from 1961-2011 were used to construct ARIMA and time trend models and the resulting models were then used to forecast known 2012 values. Similarly, yield data from 1961-2002 were used to construct models that were then used to forecast the period 2003-2012.

Table 3 compares the forecasting accuracy of the selected ARIMA and the standard linear trend regression models for all crops using the mean absolute error (MAE) comparison method. The MAE indicator, like most accuracy indicators, penalizes the difference between a known outcome and the value predicted by the model [35]. Other comparison methods were used as well, but with no appreciable differences in outcomes.

Results for the one year forecast, as shown in table 3, indicate that the accuracy of the ARIMA model, with the exception of soybeans, is much better than the linear trend model; where better means that the MAE quantity indicates that the ARIMA model does a better job at forecasting the true 2012 value than the linear trend model. The values in the table refer to the number of countries per crop for which the ARIMA model performs better than the linear trend model. For instance, there are one hundred and five countries with wheat data used in the analysis, see the first row of table 1, in 66 of those cases the ARIMA model was preferred and in 39 cases the linear trend model was preferred. For the ten year (2003-2012) forecast, the ARIMA model, once again with the exception of soybeans, outperforms the linear model. The performance of the ARIMA falls off the longer the forecast period because, as shown, it reverts to the linear trend model. A plausible reason that the ARIMA model does not always outperform the linear trend model despite being a more general form is, as previously discussed, because a model that better fits historical or training data, does not necessarily fit future or test values better.

A natural question arises, namely, how far into the future should one forecast? It is not uncommon, particularly when general equilibrium models are employed [55], to forecast decades into the future, but is that reasonable given the results presented in this paper? There are two sources of uncertainty at play, the first regards the uncertainty of forecasts made assuming the historical data generating processes continues into the future, while 
the second concerns the more fundamental question of whether those generating processes are expected to continue into the future.

\subsection{Known and Unknown Uncertainties}

The discussion so far has focused largely on the first sort of uncertainty which is displayed in part in table 2 and figures 3. Evidence derived from table 2 shows that twenty-two of the thirty lower end forecasts reported are below the three year average of yields in 2010, 2011 and 2012. In short, it is possible that yields in 2022 could be below their current levels, unlikely, but possible. At the other extreme, achieving the high end forecasts will mean butting against the biophysical limits of yields. Given enough observations, 95\% of data will fall between the two extremes. In short, how far into the future to forecast is a decision that can be supported by the statistical confidence associated with a forecast. This is easiest to see in figures 3, which show, for a given year, the mean forecast and flanking confidence intervals.

A particular strength of the ARIMA model over the linear trend model is that it gives an indication of the robustness of past data patterns. Recall that around $40 \%$ ARIMA forecasts were unable to contribute anything more to the discussion other than the message that yields beyond 2012 will be the same as yields in 2012; nothing more can be defended statistically. The linear trend model has no equivalent means to indicate robustness, although it too is commonly presented with confidence intervals. Placed in a less flattering light, econometric forecasts in general are indicators of the ignorance contained in forecasts which policy makers should be aware of when formulating policies. In direct contrast to other, deterministic, modeling techniques, econometric models are explicit concerning what they cannot explain.

While the econometric models discussed can help assess forecast uncertainty, the forecasts themselves are made under the condition that historical data generating processes will continue into the future. If those processes significantly change, then forecasts will suffer accordingly. For instance, if a researcher believes, for whatever reason, that yield increases for high yield countries will continue to decrease, then linear trend forecasts will overestimate yields and a quadratic term should be added to the model. Projecting patterns into the future depends upon the belief that historically identified patterns will continue into the future. Forecasts by themselves, ARIMA or otherwise, provide no additional reason for expecting those patterns to continue. How yields will develop in the future is not primarily the prerogative of econometrists or other model builders. Rather, it is the place of agronomists, plant geneticists and others with the knowledge to comment on the technological likelihood of achieving the biophysical limits of crop yields, and political economists and other social scientists who are able to make meaningful 
statements on, not least, the economic capacity and willingness of actually realizing those higher potential yields.

ARIMA models are general models that encompass other linear models and do not require ex ante model specification; they let the data determine the model. In addition, they are easy to implement and while interpretation can be difficult if many lag AR and MA terms are included in a model, most data in the analyses above could be described with simple ARIMA model forms. In addition, in the majority of cases, ARIMA forecasts were more accurate than their linear trend equivalent. However they, as with all other models, will not help to clarify the uncertainty concerning the prolongation of underlying data generating mechanisms. Forecasts that purport to predict thirty or forty years into the future are only sensible if those underlying mechanisms can be expected to hold for as long into the future. 


\section{References}

1. AGENCY, U. S. E. P. Summary of the energy independence and security act. Internet, 2007. Accessed October, 2014: http://www2.epa.gov/laws-regulations/surrary-energyindependence-and-security-act.

2. ANDERSON, J. R., AND HAZELL, P. B. R., Eds. Implications for Agricultural Research and Policy in Developing Countries. The Johns Hopkins University Press, 1989.

3. ANDREEV, K., KANTOROVÁ, V., AND BONGAARTS, J. Demographic components of future population growth. Tech. Rep. 3, United Nations Department of Economic and Social Affairs: Population Division, New York, 2013.

4. BOX, G. E. P., AND JENKINS, G. M. Time Series Analysis, Forecasting and Control. Holden-Day, San Francisco, CA, 1970.

5. BRUINSMA, J. The Resource Outlook to 2050: By how much do land, water use and crop yields need to increase by 2050? FAO: Rome, 2011.

6. BURNEY, J., DAVIS, S. J., AND LOBELL, D. B. Greenhouse gas mitigation by agricultural intensification. Proceedings of the National Academy of Sciences of the United States of America 107 (2010), 12052-12057.

7. BURNHAM, K. P., AND ANDERSON, D. R. Model Selection and Multimodel Inference: A Practical Information- Theoretic Approach, 2 ed. Springer-Verlag, 2002.

8. DUMORTIER, J., HAYES, D., CARRIQUIRY, M., DONG, F., DU, X., ELOBEID, A., FABIOSA, J. F., AND TOKGOZ, S. Sensitivity of carbon emission estimates for indirect land-use change. Applied Economic Perspectives and Policy 33, 3 (2011), 428-448.

9. DUVICK, D. N. The contribution of breeding to yield advances in maize (zea mays I.). Advances in Agronomy, 86 (2005), 83-145.

10. DUVICK, D. N., AND CASSMAN, K. G. Post-green revolution trends in yield potential of temperate maize in the north-central United States. Crop Science 39 (1999), 1622-1630.

11. DYSON, T. World food trends and prospects to 2025. Proceedings National Academy of Sciences U.S.A. 96 (1999), 5929-5936.

12. E., S. J., HUME, D. J., AND KUMUDINI, S. V. Soybean yield potential-a genetic and physiological perspective. Crop Science 39 (1999), 1560-1570.

13. EDGERTON, M. D. Increasing crop productivity to meet global needs for feed, food and fibre. Plant Physiology 149 (2009), 7-13.

14. ENDERS, W. Applied Econometric Time Series, 3rd ed. Wiley, 2009.

15. EUROPEAN PARLIAMENT, COUNCIL OF THE EUROPEAN UNION. Directive 2009/28/ec of the European Parliament and the Council: on the promotion of the user of energy from renewable sources and amending and subsequently repealing directives 2001/77/ec and 2003/30/ec. Tech. rep., European Parliament, Council of the European Union, April 232007.

16. EVANS, L. T. Crop Evolution, Adaptation, and Yield. Cambridge University Press: Cambridge, 1993.

17. FAO. How to feed the world in 2050. Proceedings of the Expert Meeting on How to Feed the World in 2050 24-26 June 2009. Rome, 2009. 
18. FAOSTAT. United Nations Food and Agricultural Organization (UN-FAO) online statistics database, 2013. http://faostat.fao.org/site/291/default.aspx.

19. FIELD, C., BARROS, V., STOCKER, T., QIN, D., DOKKEN, D., EBI, K., MASTRANDREA, M., MACH, K., PLATTNER, G., ALLEN, S., TIGNOR, M., AND MIDGLEY, P., Eds. Managing the Risks of Extreme Events and Disasters to Advance Climate Change Adaptation. A Special Report of Working Groups I and II of the Intergovernmental Panel on Climate Change. Cambridge University Press, Cambridge, UK, and New York, USA, 2012.

20. FISCHER, R., AND EDMEADES, G. Breeding and cereal yield progress.Crop Science 50 (2010),85-98.

21. FOLEY, J. A., RAMANKUTTY, N., BRAUMAN, K. A., CASSIDY, E. S., MUELLER, J. S. G. M. J. N. D., O'CONNELL, C., RAY, D. K., WEST, P. C., C. BALZER, E. M. BENNETT, S. R. C., HILL, J., MONFREDA, C., POLASKY, S., ROCKSTROM, J., SHEEHAN, J., SIEBERT, S., TILMAN, D., AND ZAKS, D. P. M. Solutions for a cultivated planet. Nature 478 (2011), 337-342.

22. GODFRAY, H. C. J., CRUTE, I. R., HADDAD, L., LAWRENCE, D., MUIR, J. F., NISBETT, N., PRETTY, J., ROBINSON, S., TOULMIN, C., ANDWHITELEY, R. The future of the global food system. Philosophical Transactions of the Royal Society B: Biological Sciences 365, 1554 (September 2010), 2769-2777.

23. GRASSINI, P., ESKRIDGE, K. M., AND CASSMAN, K. G. Distinguishing between yield advances and yield plateaus in historical crop production trends. Nature Communications 4, 2918 (December 2013). doi:10.1038/ncomms3918.

24. GRAYBOSCH, R. A., AND PETERSON, C. J. Genetic improvement in winter wheat yields in the Great Plains of North America 1959:2008. Crop Science 50 (2010), 1882-1890.

25. GREEN, R. E., CORNELL, S. J., SCHARLEMANN, J. P. W., AND BRADFORD, A. Farming and the fate of wild nature. Science 307, 5709 (2005), 550-555.

26. GREENE, W. H. Econometric Analysis, seventh ed. Pearson, Essex, England, 2012.

27. HAFNER, S. Trends in maize, rice, and wheat yields for 188 nations over the past 40 years: a prevalence of linear growth. Agriculture, Ecosystems and Environment 97 (2003), 275-283.

28. HAMILTON, J. D. Time Series Analysis. Princeton University Press, 1994.

29. HASTIE, T., TIBSHIRANI, R., AND FRIEDMAN, J. The Elements of Statistical Learning: Data Mining, Inference and Prediction. Springer, 2001.

30. HEISEY, P.W. Amber wage. Tech. rep., USDA-RES Publication, 2009. Accessed online: http://www. ers.usda.gov/arber-waves/2009-decerber/science,-technology,-and-prospects-for-growth-inus-corn-yields.aspx\#.VC575a150PI.

31. HERTEL, T. W., GOLUB, A. A., JONES, A. D., O'HARE, M., PLEVIN, R. J., AND KAMMEN, D. M. Global land use and greenhouse gas emissions impacts of maize ethanol: the role of market-mediated responses. Bioscience 60 (2010), 223-231.

32. HILL, J., NELSON, E., TILMAN, D., POLASKY, S., AND TIFFANY, D. Environmental, economic, and energetic costs and benefits of biodiesel and ethanol biofuels. Proceedings of the National Academy of Sciences of the United States of America 103, 30 (2006).

33. HOCHMAN, G., RAJAGOPAL, D., TIMILSINA, G., AND ZILBERMAN, D. Quantifying the causes of the global food commodity price crisis. Biomass and Bioenergy 68 (September 2014), 106-114. 
34. HOISINGTON, D., KHAIRALLAH, M., REEVES, T., RIBAUT, J.-M., SKOVMAND, B., TABA, S., AND WARBURTON, M. Plant genetic resources: What can they contribute toward increased crop productivity. PNAS 96, 11 (1999), 5937-5943.

35. HYNDMAN, R., AND KOEHLER, A. Another look at measures of forecast accuracy. Online, 2005. Accessed online, Nov. 2, 2014: http://citeseerx.ist.psu.edu/viewdoc/ download?doi=10.1.1.154.9771\&rep= rep1\&type=pdf.

36. HYNDMAN, R. J., AND KHANDAKAR, Y. Automatic time series forecasting: The forecast package for $r$. Journal of Statistical Software 26, 3 (2008).

37. IFPRI. Climate change: Impact on agriculture and costs of adaptation. food policy report. Tech. rep., IFPRI, 2009.

38. JAGGARD, K. W., QI, A., AND OBER, E. S. Possible changes to arable crops yields by 2050. Philosophical Transactions of the Royal Society B 365 (2010), 2835-2851.

39. JAMES, G., WITTEN, D., HASTIE, T., AND TIBSHIRANI, R. An Introduction to Statistical Learning: with Applications in R. Springer, 2013.

40. KWIATKOWSKI, D., PHILLIPS, P. C. B., SCHMIDT, P., AND SHIN, Y. Testing the null hypothesis of stationarity against the alternative of a unit root. Journal of Econometrics 54, 1-3 (1992), 159-178.

41. LANGEVELD, J., DIXON, J., VAN KEULEN, H., AND QUIST-WESSEL, P. Analysing the effect of biofuel expansion on land use in major producing countries: Evidence of increased multiple cropping. Tech. Rep. 1301, Biomass Research, July 2013.

42. LOBELL, D. B., CASSMAN, K. G., AND FIELD, C. B. Crop yield gaps: their importance, magnitude, and causes. Annual Review of Environment and Resources 34 (2009), 1-26.

43. LUDWIG, F., MILROY, S., AND ASSENG, S. Impacts of Recent Climate Change on Wheat Production Systems in Western Australia. Climatic Change 92 (2009), 495-517.

44. MATSON, P. A., AND VITOUSEK, P. M. Agricultural intensification: Will land spared from farming be land spared for nature? Conservation Biology 20, 3 (2006), 709-710.

45. NEWBOLD, P. The principles of the Box-Jenkins approach. Operational Research Quarterly 26, 2 (July 1975), 397-412.

46. OECD/FAO. OECD-FAO agriculture outlook 2012-2021. Tech. rep., OECD and FAO, 2012. Accessed online: http://stats.oecd.org/Index.aspx?DataSetCode=HIGH_AGLINK_2012.

47. PENG, S., CASSMAN, K. G., VIRMANI, S., SHEEHY, J., AND KHUSH, G. S. Yield potential trends of tropical rice since the release of ir8 and the challenge of increasing rice yield potential. Crop Science 39 (1999), 1552-1559.

48. PHALAN, B., BLAMFORD, A., GREEN, R. E., AND SCHARLMANN, J. P. W. Minimizing the harm to biodiversity of producing more food globally. Food Policy 36 (2011), S62-S71.

49. PHALAN,B.,ONIA,M.,BLAMFORD,A.,ANDGREEN,R.E.Reconcilingfood productionand biodiversity conservation: Land sharing and land sparing compared. Science 333, 6047 (2011), 1289-1291.

50. PINDYCK, R. S., AND RUBINFELD, D. L. Econometric Models and Economic Forecasts. Irwin McGraw-Hill, 1998.

51. PORTER, J. R., XIE, L., CHALLINOR, A., COCHRANE, K., HOWDEN, M., IQBAL, M. M., LOBELL, D., TRAVASSO, M. I., CHHETRI, N., GARRETT, K., INGRAM, J., LIPPER, L., MCCARTHY, N., MCGRATH, 
J., SMITH, D., THORNTON, P., WATSON, J., ZISKA, L., AGGARWAL, P., AND HAKALA, K. Climate Change 2014: Impacts, Adaptation, and Vulnerability. Working Group II contribution to the IPCC Fifth Assessment Report. IPCC, 2014. Authors include: Coordinating lead authors, lead authors, contributing authors and review editors.

52. RAY, D. K., MUELLER, N. D., WEST, P. C., AND FOLEY, J. A. Yield trends are insufficient to double global crop production by 2050. PLOS ONE 8, e66428 (2013).

53. REILLY, J. M., AND FUGLIE, K. O. Future yield growth in field crops: what evidence exists? Soil Tillage Research 47 (1998), 275-290.

54. SAID, S. E., AND DICKEY, D. A. Testing for unit roots in autoregressive-moving average models of unknown order. Biometrika 71 (1984), 599-607.

55. SCHMITZ, C., VAN MEIJL, H., KYLE, P., NELSON, G. C., FUJIMORI, S., GURGEL, A., HAVLIK, P., HEYHOE, E., D'CROZ, D. M., POPP, A., SANDS, R., TABEAU, A., VAN DER MENSBRUGGHE, D., VON LAMPE, M., WISE, M., BLANC, E., HASEGAWA, T., KAVALLARI, A., AND VALIN, H. Land-use change trajectories up to 2050: insights from a global agro-economic model comparison. Agricultural Economics 45, 1 (January 2014), 69-84.

56. SEARCHINGER, T., HEIMLICH, R., HOUGHTON, R. A., DONG, F., ELOBEID, A., FABIOSA, J., TOKGOZ, S., HAYES, D., AND YR, T.-H. Use of U.S. croplands for biofuels increases greenhouse gases through emissions from land-use change. Science 319, 5867 (2008), 1238-1240.

57. SHUMWAY, R. H., AND STOFFER, D. S. Time Series Analysis and Its Applications, 3 ed. Springer, 2011.

58. SIMS, R., TAYLOR, M., AND BIOENERGY, I. Biofuels Technologies: An overview of current industry and R \& D activities, November 2008.

59. SMIL, V. Eating meat: Constants and changes. Global Food Security 3, 2 (July 2014), 67-71.

60. TILMAN, D., BALZER, C., HILL, J., AND BEFORT, B. L. Global food demand and the sustainable intensification of agriculture. PNAS 108, 50 (2011), 20260-20264.

61. TOLLENAAR, M., AND LEE, E. A. Yield potential, yield stability and stress tolerance in maize. Field Crops Research 75, 2-3 (May 2002), 161-169.

62. TSCHARNTKE, T., CLOUGH, Y., WANGER, T. C., JACKSON, L., MOTZKE, I., AND ET AL. Global food security, biodiversity conservation and the future of agricultural intensification. Biological Conservation 151, 1 (2012), 53- 59.

63. U.S. DEPARTMENT OF ENERGY: ENERGY EFFICIENCY \& RENEWABLE ENERGY. Alternative fuels data center. Internet, 2005. Accessed October, 2014: http://www.afdc.energy.gov/laws/ epact_2005.

64. USDA: UNITED STATES DEPARTMENT OF AGRICULTURE: ECONOMIC RESEARCH SERVICE. U.S. Bioenergy Statistics. Online, October 2014. Accessed online: http://www.ers.usda.gov/dataproducts/ us-bioenergy-statistics.aspx.

65. VERBEEK, M. A Guide to Modern Econometrics, fourth ed. John Wiley \& Sons Ltd., 2012.

66. WHITTLE, P. Hypothesis Testing in Time Series Analysis. Almquist and Wicksell, 1951.

67. WHO: WORLD HEALTH ORGANIZATION. Availability and changes in consumption of animal products (section 3.4). Online, October 2014. Accessed online: http://www.who.int/nutrition/ topics/3_foodconsurption/en/index4.html. 
Forecasting Food Crop Yields and Assessing their Credibility | 185 
CHAPTER 7

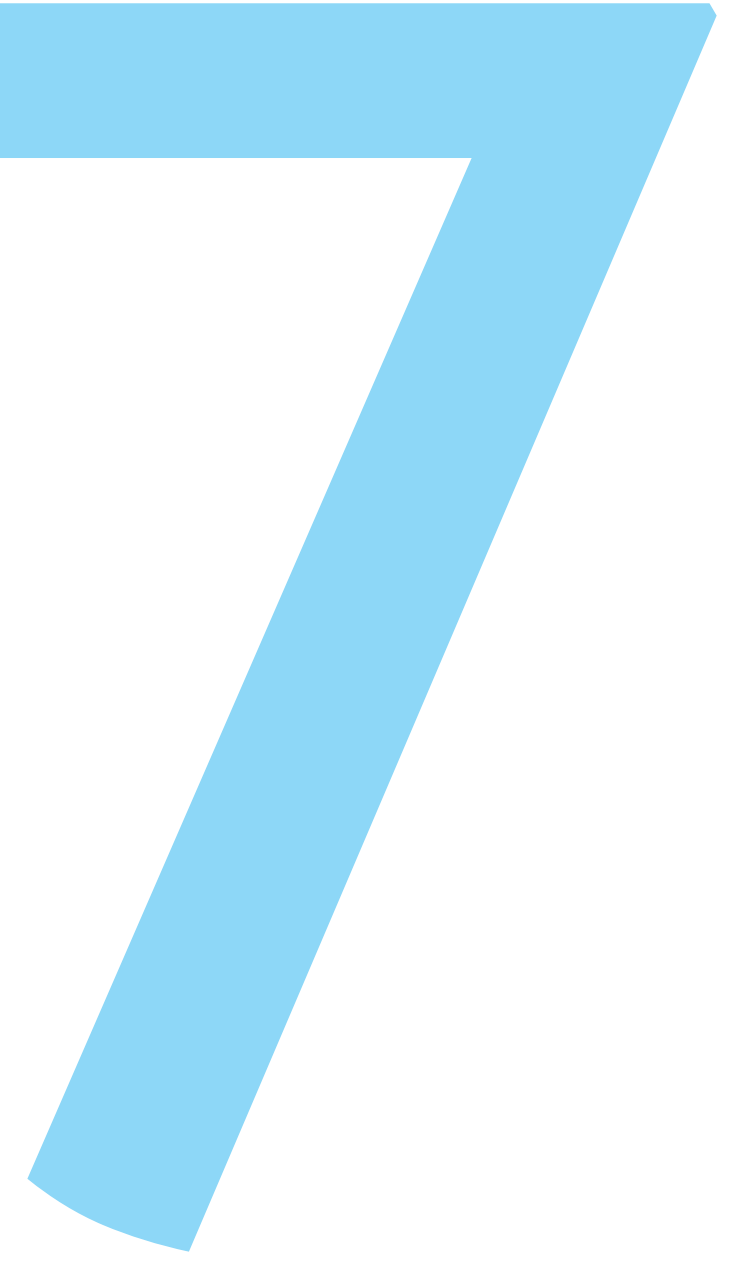


Conclusions and discussion 
Chapter 7 


\section{Conclusions and discussion}

This final chapter presents the main conclusions of each of the previous research chapters as well as more general conclusions and a discussion of the main policy implications of important findings. There is also a section that provides for critical reflection on the research, in particular, where there is room for improvement, and a final section which suggests possible avenues for future research.

\subsection{Research chapter conclusions}

In the following paragraphs, the conclusions of each of the research questions are presented. The research questions correspond to chapters in the manuscript. Research questions are briefly reiterated and the motivation behind each question are presented before they are answered.

Will climate change have significant country and crop specific effects on crop production? The overall objective of Chapter 2 was to estimate the effects of climate change on global agricultural production. In particular, it attempts to disaggregate the analysis found in Lobell and Field (2007) by using an econometric panel technique that controls for country level differences. Estimating the effects of climate change on agricultural production continues to be a critical topic for the viability of biomass products and issues such as food security (see also Hasegawa et al., 2018; Rozenzweig and Livermore, 2005; Edmonds and Rosenberg, 2005). In contrast to the highly aggregated econometric model used by Lobell and Field which leads to overly robust results, a panel model indexed across countries and years using the same base data as those authors was run. The basic objectives of the analysis were two fold, first, to estimate the effects of climate change on crop production while taking into account country specific differences and, second, to show that the technique employed allowed for a more nuanced analysis of the differing effects of weather changes across crops and countries. To allow for a comparison of the two techniques, I closely followed Lobell and Field's procedures for obtaining and preparing the data. The specific case examined was the effect of minimum and maximum temperatures and precipitation on the yields of six major global crops as reported by the FAO. In general, I confirmed Lobell and Field's claim that global temperatures have been increasing in the major crop growing regions over the forty-six years of available data. However, whereas Lobell and Field chose to use global yields, in other words, for each year in their study, one global yield data point was used to represent yields across all countries, I disaggregated the data to yields and weather data per country, per year. That choice turned out to have important implications for the conclusions which could be drawn from the data. In particular, the method used allowed me to attach statistical significance to estimated changes in yields per crop and country. 
Analyses for each of the six crops were run in a separate panel model. The analysis of wheat, for example, consisted of a database of 57 countries each with 45 years of data. I found that of those 57 countries, only 10 had statistically significant results for changes in yield against changes in precipitation, 9 countries had significant results for changes in yield against changes in minimum temperature, and 11 had significant changes in yield against changes in maximum temperature. Of the 10 wheat growing countries with significant results, 4 showed a positive relationship between changes in precipitation and changes in yields and 6 showed a negative relationship for the same regression. In other words, estimates showed that while some countries would experience decreases in yields, others would experience increases as a result of increases in precipitation. The high level of aggregation used by Lobell and Field leads them to report highly significant outcomes applicable across the globe, while a more disaggregated approach leads to the conclusion that for those countries for which significant results could be established, some countries will benefit from changing weather patterns while others will suffer. For many crop and country combinations, no statistically significant results could be reported, perhaps a less marketable conclusion, but one that more accurately represents the current state of knowledge. Some more general conclusions could be drawn, for instance, a majority of rice and maize growing countries will likely benefit from changes in precipitation. However, in general, across crops, a majority of countries with significant results were expected to suffer from increases in minimum and maximum temperatures, and to the degree that these crops are grown for local consumption, this will directly, adversely, affect consumption in those countries. The main finding related to the research is the conclusion that climate change may affect yields and that those effects will depend on the crop and the country in which the crop is grown. On balance however, climate changes will reduce yields for most crops and countries. A highly aggregated model, although parsimonious, cannot adequately account for the diversity of changes in yields that occur across different crops and countries.

Are crops yields in Europe converging and if so, what will be the effects on the supply of crops used in the production of biomass products?

Chapter 3 addresses the issue of whether crop yields in Europe are converging and the implications of any changes in yields on land used to produce major crops, with an emphasis on the effects of those crops used in the production of biomass products (see also Searchinger, 2008; Edwards et al., 2010; de Wit et al., 2011). The underlying issue addressed was whether increases in crop yields will lead to cheaper biomass products following the often unarticulated argument that as yields increase in eastern European countries biomass products will become cheaper. That position assumes that increases in yields will increase the production of biomass crops and that those crops will necessarily go to the production of biomass products. 
The first step in the analysis was to define and measure yield changes through time and measure whether they were converging. Thereafter, the greater effects of yield changes on the economy needed to be calculated. The transition rates of yields were estimated using a combination of convergence, time-series, and dynamic panel models. Scenarios are then run using estimated yields as input into a computable general equilibrium (CGE) model. As explained in the introductory chapter, a CGE model provides a narrative framework through which the total economic impact of changes in yields can be accessed (Hellman and Verburg, 2010; Hertel and Tyner, 2010). Although no evidence of a common rate of yield convergence across countries in Europe was found, evidence of absolute convergence in yield rates was estimated to be significant. Absolute convergence is the more obvious type of convergence, it tells us whether yields are converging towards a common level rather than a common rate of increase (Barro and Xavier, 2003). The working hypothesis of some biomass optimists seems to be that countries with lower initial yield rates will increase their yields at a faster rate than countries with higher initial rates. The higher yields will result in the production of more biomass products without adversely affecting the consumption in other sectors competing for these crops. The reasoning behind the argument for absolute convergence is that countries with lower initial yield rates will be readily able to adapt and implement extant technologies.

Analysis showed that lower initial yield rates were correlated with higher growth rates over the period 1961-2010. The importance of this finding for the current analysis is that we can expect, on average, that European countries with lower initial yields will increase their yields at higher rates than established European countries. In short, although there is not a common yield rate among countries, we expect, on an average, that countries with lower yields will catch-up to European averages. So while standard time series and panel forecasting methods indicated the potential for only very modest yearly yield increases across most of Europe; potential yearly increases in newer European states could, in some cases, be substantially higher.

The next step was to establish whether estimated yield increases will necessarily result in significantly higher production of the associated crop. The argument is that, all else equal, higher yields will release or free-up additional land for the production of additional crops and, in particular, biomass products. In order to address this question, I decided to concentrate the analysis on one product, in other words, I address the question, what are the economic effects across sectors when the yields of one crop increases? The wheat sector was chosen as the object of the CGE study because wheat is grown in countries across Europe and it is an important sector in the CGE model employed in the study. By focusing on one major crop, I was able to isolate and follow the impacts of a change in yields on the economy without the added complications of disentangling the effects of changes to yields of two or more crops. 
The overall question of whether significant wheat yield increases will necessarily lead to large increases in land available to produce bio-energy crops was rejected. Analysis found that land freed by wheat yield increases will go to the production of a wide range of agricultural products that value land as an input. The same reasoning which links yields and land use applies to all significant agricultural products when they are produced and distributed in well-functioning markets. In short, the total amount of land released as a result of potential yield increases in the wheat sector was found to be modest because of an increase in demand for land by sectors other than wheat.

The principle message of the chapter is that the economic effects of yield changes or any other significant change in production need to be analyzed with regard to their substitutes and complements and the marketplace in which they operate. The analysis showed that while wheat yields are likely to increase, the resulting land released will not necessarily go to produce biomass crops as argued by biomass proponents.

How will changing weather patterns due to climate changes affect the global trade of major food crops? What will be the effects on less developed countries?

The effects of climate change on trade have been identified as an important, neglected, research topic (Josling et al., 2010; Tamiotti et al., 2009). In chapter 4, I attempt to address this gap in the literature through a combination of techniques, namely, econometric models were used to forecast the effects of climate variables on crop yields the results of these models were then to "shock", as explained in Chapter 1, MAGNET, a CGE model, in order to assess their on global trade (Meijl, van et al., 2018; Wang, 2018). In particular, I compare and contrast the effects of changing trade patterns on developed versus less developed countries. The scope of the chapter is global and includes all major crops represented in MAGNET and all crop growing regions. The approach implemented differs from those found in previous studies by employing this combination of techniques to address the interactions of climate change and trade.

As in previous studies (Parry et al., 2004; Schlenker and Roberts, 2009; Lobell and Field, 2007; Zhao et al., 2017), I found strong evidence of increasing temperatures in grids growing ten major food crops. Temperature fluctuations across crops followed similar short and longterm patterns and the increases were found to be statistically robust. Average results across all crops showed that maximum average temperatures have increased by $0.017 C^{\circ}$ per year in crop growing grids, while average minimum temperatures for all crops have increased by $0.020 \mathrm{C}^{\circ}$ per year. Results for precipitation showed two distinct periods, a first in which precipitation fell, followed by a second in which it rose. The results also suggested that, in contrast to temperatures, there has been large variation in the amount of precipitation falling in different crop growing grids. The results suggested that if the underlying data generating processes behind the observed increases in temperatures persist as they have 
throughout the period studied, then we can expect temperatures in the future to rise as well. Running separate regressions for the two precipitation periods lead to statistically significant results for crop averages in both periods with an estimate of negative 1.42 and $\mathrm{t}$-value of negative 2.2 in the first period, and an estimate of positive 2.34 with a t-value of 3.0 in the second period. Chow tests confirmed the observed structural break, and results from regressions are significant for each period reported.

Results for time series analyses of crop yields show that, on average, yields have increased over the period under investigation, however our results confirm previous findings that they have been increasing at a decreasing rate (IFPRI, 2009; Powell and Rutten, 2013; Sims et al., 2008). There have been noticeable differences in the growth rates of crops over the 50 year period for which data were available. Yields of cassavas, at 31\%, increased the least over the period, while percentage increases of sorghum (120\%), wheat (133\%) and maize $(180 \%)$ have been well over $100 \%$; rapeseed $(65 \%)$, paddy rice $(75 \%)$, sugar beet $(81 \%)$, barley $(86 \%)$, potatoes $(89 \%)$ and soybeans $(100 \%)$ round out the field. Results indicate that for wheat, maize, and barley higher temperatures lead to lower yields, while increases in precipitation lead to increases in the yields of wheat, maize, and perhaps barley. Estimates for the effects of precipitation on rice and soybeans were insignificant. ARIMA models were then used to estimate ten year forecasts of the effects of changes in climate variables on yields. The best performing models for each country and each crop in the analysis were chosen according to the AIC criterion; forecasts from the selected models were then used within MAGNET to simulate weather changes.

The MAGNET model was then shocked using the yield forecasts to determine the effects, ten years in the future, of changes in weather on the global production, trade, and consumption of four major crop groups in MAGNET; namely, grains, oils, wheat, and rice. Results for exports closely followed changes in production. Wheat exports from the United States and Argentina increased slightly, but many other countries in the region South America experienced sharp decreases in exports. Exports from Indonesia, a major exporter of oils, are expected to fall, as were oil exports from South America. However, vegetable oil exports from the United States and Brazil are expected to increase following their increases in production. All of the major rice exporters can expect slight decreases in exports, while the major wheat producers can all expect to export more.

The major importers of grains were not substantially affected by the changes, although Chinese imports fell slightly. Of the major importers of rice, the region of Central Africa, which includes Nigeria, were stable, while imports to the region of North Africa fell, and imports into the region of South Africa increased. Changes for wheat importers were in general found to be small, while imports to Egypt, the world's largest importer, are 
expected to fall, as would those for Indonesia. Brazilian imports were expected to fall by $1 \%$ and $2 \%$, while Chinese imports are expected to increase slightly.

Ultimately, policy makers are concerned with consumption, particularly in poorer regions. For grains, the biggest losers in terms of consumption were people from the regions: Rest of former Soviet Union, India, Central and South America, Central and North Africa, and some of the newer European states. Grain consumption in richer countries was not significantly affected by changes in weather. For oils, Indonesia and India would consume less as would many other regions in Asia and the region Rest of Central America. All regions in Africa consumed less oil. The only major increase in oil consumption occurred in Mexico. Consumption of rice in Indonesia, India and other regions in Asia were also adversely affected, although Africa escaped largely unscathed in terms of rice consumption. Finally, wheat consumption in the region of Central Africa fell, as it did in the region of the Rest of the Former Soviet Union. The countries that benefited were India, the regions Rest of Central America and Rest of South America. In general, rich countries were not significantly affected by weather changes while many poorer regions will experience decreases in consumption.

What will be the implications of extreme weather events on yields?

In contrast to the other chapters in this manuscript, chapter 5 analyzes the effects of extreme weather events at the level of the farm for a specific crop, winter wheat, in the Netherlands. This level of analysis, as opposed to the higher geographical aggregations used in previous chapters, allows more precise measurement of the effects of climate change on a specific crop across time. The major contribution of the chapter to the literature is that it combines weather data with factors of production over time into one model, thereby allowing an estimation of the effects of extreme weather events after having controlled for the effects of changes in other important input factors (Rosenzweig et al., 2001; Porter and Gawith, 1999; Vogel, 2018, Komen and Peerlings, 2001).

The first goal of this chapter was to establish whether extreme weather events have been increasing in the Netherlands, which required a working definition of what constitutes an extreme event. The concept used to identify events, whether for the long or short term, was to record the number of days for which measures exceeded a specific threshold. Two general methods were used to identify events, the first method was a relative method comparing, for example, the high daily temperature for a specific day in a year with the high temperature for that same day across all years in the sample. The relative method is an adaptation of the methodology presented in Klein Tank (Klein Tank et al., 2009). The second method used an absolute scale which identifies, for instance, the number of days in a week equal to or above $32^{\circ} \mathrm{C}$. The two methods were found to be highly correlated. Data used to identify long-term trends has been collected for many years by the Royal 
Dutch Weather Institute (KNMI) at its primer weather station, station 260, which is located near the center of the country.

Studies conducted at high levels of aggregation cannot adequately account for the effects of farm and crop level characteristics influencing yields. Therefore, in addition to weather variables, economic variables, including the main factors of production, were included in a'within' panel model to explain yields. Results indicated the importance of both weather events on yields and the need to specify the time period over which events were measured. Weather events could have either positive or negative effects on yields depending on the week in which they occur; however, the majority of events, either precipitation or low or high temperature events were found to reduce yields.

Analysis showed that the number of yearly extreme low temperature events decreased significantly over the period from 1901-2013. An autoregressive, integrated, moving average (ARIMA) model forecasted that there would be 14 low temperature events in 2023 which, on average, is a lower number than has occurred over the last decade. In short, there will be fewer extreme cold events in the future. In contrast, the outcomes of the analysis showed a significant increase in the expected number of yearly extreme high temperature events. ARIMA models forecast 30 such events in 2023, a number which is significantly higher than the average number of such events that have occurred in the past decade. The findings for low and high temperature events correspond to those found in the most recent IPCC report, specifically, the occurrence of more warm days and nights compared to the historical average. For the case of precipitation events, the Netherlands can expect to experience more periods with heavy rains; the slope for that variable is significant ( $t$-value=3.75) and ARIMA results forecast 23 such events in 2023 . Finally, the number of evapotranspiration events since 1957, the first year for which data is available, has been steadily decreasing and the t-value is significant (-2.45). An ARIMA model forecasts 18 such events in 2023.

The general trend in temperatures, so not events, across the entire period for all months showed a slight increase in maximum temperatures, particularly in the latter decades. Regressions against time showed that April, July, August, October, November, and December had significant positive slope coefficients; while minimum temperatures across all months were positive and significant ( $\mathrm{t}$-value=6.04). A steadily increasing trend was identified for the period 1902-2013. In short, temperatures, both the maximum highs and lows, were increasing in the Netherlands although the changes vary by month.

Once the expected number of weather events and temperature trends were determined, the remainder of the chapter attempted to determine the effects of those variables on Dutch winter wheat yields. The approach used was to combine production input data 
used to produce winter wheat, i.e., fertilizers, pesticides, energy, labor, capital, a catch-all account called other inputs, and four soil types labor, capital and land, for 334 farms in the Netherlands from 2002 to 2013 with precipitation, temperature and evapotranspiration data measured at the local level. All of these various types of data were necessary in order to isolate the effects of extreme weather events on yields.

Model results show that pesticides, fertilizers, and capital are all significant and have the expected sign, i.e., the more of these inputs added to the production of wheat, all else equal, the greater the yield. The negative, significant, sign for farm size indicates that increasing the size of a farm reduces yields. Of the weather variables in the model, only the precipitation event in week 31, near the end of the harvest season, had a significant, negative, effect on yields. Furthermore, the significance of the other precipitation terms remained low. The effect for high maximum temperature events in week 27 (July 1st in 2013) is significant and negative, indicating that high temperature events near the beginning of the harvest season damage crops or, perhaps, force farmers to harvest before yields have reached their maximum. The estimate for week 27 tells us that one additional high temperature event lowers yields by nearly -430 kilograms per hectare. The effects of low temperature events, periods of cold, were also significant and negative in the 29th and 30th week. Cooler periods in the middle and near the end of the harvest season, depending on the specific year, have negative effects on yields.

The findings confirmed IPCC findings which indicate that the number of precipitation events has been increasing (Field et al., 2012; Porter et al., 2014). Most importantly, the effects of those events on winter wheat yields in the Netherlands was found to be detrimental. The findings also supported the conclusions of researchers who found, using site data, that adverse effects were likely to out-number the positive effects of weather events. Furthermore, results indicate that a model that includes both economic and weather variables was statistically preferred to one that included only one of those two sets of data. However, if only one set of data is available, either economic or weather data, then results showed that either model would accurately identify the direction that the included variables would have on yields, but not their magnitude.

How do the various econometric techniques used to forecast yields affect predictions of country level yields? How far into the future should you trust forecasts?

The purpose of chapter 6 was to provide an argument for estimating yields for the crops found in CGE models using ARIMA models rather than standard linear trend models. ARIMA models can better account for the complex trends observable in yields across crops and countries (Chao, 2015; Alam, 2018). 
The approach used was to compare simple time-trend models and ARIMA yield forecasts for each country in the FAO data set across all crops from 1961-2011 and compare forecast results to known 2012 values. Other combinations were tried, for instance comparing forecasts made using training data from 1961-2002 to forecast 2003-2012 values, but the various permutations tried did not significantly affect the results of the analysis. Forecast accuracy of ARIMA and the standard linear trend regression models for all crops were measured using the mean absolute error (MAE) comparison method. The MAE indicator, like most accuracy indicators, penalizes the difference between a known outcome and the value predicted by the model. Other comparison methods were tried as well (RMSE, MSE), but there were no appreciable differences in outcomes.

Results for the one year forecast indicated that the accuracy of the ARIMA model, with the exception of soybeans, was much better than the linear trend model; where better means that the MAE statistic indicates that the ARIMA model did a better job at forecasting the true 2012 value than the linear trend model. For instance, there were one hundred and five countries with wheat data used in the analysis, in 66 of those cases the ARIMA model out-performed the linear trend model while in 39 cases the linear trend model was preferred. For the ten year (2003-2012) forecast, the ARIMA model, with the exception of soybeans, outperformed the linear model. The performance of the ARIMA model fell-off the longer the forecast period because, as argued in the chapter, it reverted to the linear trend model.

In addition to providing evidence that the ARIMA model should generally be preferred to the linear trend model, I addressed the question of how far into the future one should reasonably hope to forecast yields. It is not uncommon, particularly when general equilibrium models are employed, to forecast yields decades into the future. Is this reasonable given uncertainty in ARIMA models? A particular strength of the ARIMA model is that it gives an indication of the robustness of past data patterns. Remarkably, models indicated that that in close to $40 \%$ of the ARIMA forecasts, the analyses were unable to contribute anything more to the forecast other than the message that yields beyond 2012 would be the same as yields in 2012; in short, no more informative conclusion could be defended statistically despite the large amount of historical data.

Placed in a less flattering light, while ARIMA models generally out-perform simple time trend models, they will often be of little assistance to policy makers when deciding the direction and magnitude of yields in the long term. However, in contrast to other, deterministic, modeling techniques, econometric models are explicit concerning what they are unable to explain. 


\subsection{General conclusions}

This manuscript examines relationships between crops yields, climate change, prices, and the bioeconomy. It brings together a diverse set of techniques including general equilibrium models, time series and panel analysis, and applies a multi-level approach. A primary objective of this research was to answer the question of whether an economy based on first generation biomass products will be economically viable. It is argued that this question turns, in large part, on the expected yield increases of crops used in their production. An important determinant of future yields, in turn, will be the effects of climate change.

Research presented in previous chapters examined the significant economic and environmental factors influencing yields across several levels of aggregation. The use of several layers of geographic aggregation including global, European and farm level aggregation, allowed me to estimate effects of climate change on the yields of various crops directly and estimate the repercussions of those changes on production, trade and consumption. The lower the level of aggregation, the more detail that can be brought to bear to examine and disentangle the effects of climate change on yields.

In general, it might be argued that lower levels of aggregation are more desirable because it might still be meaningful to aggregate results to higher levels of aggregation. However, lower levels of aggregation call for vastly more data and, as shown in this manuscript, not all questions can be answered at low levels of aggregation. For instance, with enough crop and farm level data it might be possible to draw conclusions for countries, regions and the world. However, such a database would be extensive and would ideally include data similar to that used in the chapter on the effects of extreme events on Dutch wheat farmers found in this manuscript. For instance, in addition to factor inputs for a specific crop over time, weather data would also ideally be included at the farm or county level in order to account for its effects on yields. Such data is not yet generally available, and therefore higher levels of aggregation are necessary in order to address the questions posed in this manuscript. In addition, the implications of climate change on trade can only be analyzed at the level at which crops are traded. Therefore, while each of the chapters in this manuscript contributes to the topic of forecasting changes in the yields of one or more major crops, crops that will either directly or indirectly affect the production of biomass products, they do so at different levels of aggregation. The methodologies used range from purely econometric to a combination of econometric and global, general equilibrium models. The next few sections the main findings and implications of each chapter will be presented with an emphasis on the level of aggregation at which the analysis was conducted. 
The highest possible level of aggregation is the global level across all crops. However, the second chapter argues that effects of climate changes on crop yields are better understood at a country rather than a global level. The chapter provides strong evidence that the effects of climate change will depend in part on country specific characteristics, for instance, the location of a country on the globe, and the type of crop grown. Country is still a high level of aggregation, it conflates important characteristics affecting yields, for instance, a country's economic and technical development, into one explanatory feature. The implications of this level of analysis is that countries and crops will be affected differently and should therefore be analyzed separately. However, in general, yields of some important crops will be adversely affected by forecasted changes in weather patterns. Global yields of important crops are generally expected to fall, so agricultural policies should therefore reflect those differences as well as the general trend. In addition, several chapters argued and demonstrated that the rate of yield of high yield countries is falling. In other words, the yields of high yield countries for some crops have plateaued, perhaps for biological, economic or some other reason. Determining why yields have stagnated will have important policy implications, for instance, if the cause is economic, then economic incentive could be used to increase yields, while if it is determined that yields have approached their biological limit, then yields will continue to stagnate unless the underlying biology changes.

The third chapter examined the effects of climate change and economic development on yields at the European level and it demonstrates that crops should not be aggregated. Results from that chapter showed that although there is no evidence that the yields of European countries are converging to a common yield rate, there is statistical evidence that yields from less economically developed countries are increasing. The chapter argues that crop yields should not be studied in isolation from the yields of other crops, in short, because crop yields influence one another through the market.

More generally, it showed that the effects of changing crop yields of a particular crop on production and consumption need to be examined in relationship to the complements and substitutes of that crop and the entire economic web in which the crop is produced and consumed. The chapter demonstrated that CGE models are uniquely designed to address these issues by including the key economic sectors of the real economy in one modelling framework. The policy implications are that the effects of yield changes of important biomass products produced in Europe need to be understood at least at a regional level and, more importantly, the effects of yield changes of biomass crops can only be understood with reference to other affected crops.

Chapter four demonstrated that the effects of climate changes on trade need to be examined with reference to the entire, global, economy because the crops in question are 
traded globally. The effects of changes in weather on trade and ultimately consumption were found to have greater negative effects on poorer countries implying that trade policies might need to be adjusted to mitigate these effects. For instance, by lowering trade barriers or stimulating more local production. A downside of using models that include all of the key elements of a real economy is that there is little room for subtlety in terms of the particular effects of changes in weather on yields. For these types of questions, less aggregated models are necessary such as used to examine the effects of extreme weather events on yields.

Consequently, in chapter five I defined several definitions of extreme weather events and showed that, regardless of the common definitions used, extreme events are expected to increase in the Netherlands. The chapter uses the most disaggregated level of data. It includes a wide range of inputs into the analyses including fertilizers and pesticides used to produce winter wheat. Using farm and crop level data I showed that extreme weather events, after controlling for other factor inputs, will have a negative effect on wheat yields. This level of aggregation allows analysts to measure the effects of climate change relative to other crop inputs. In principle, this level of analysis might be the most relevant for policy makers because, given enough data, and particularly diversity within the data, it might be to experiment and identify those inputs that mitigate the negative effects of climate change. However, the level of expert knowledge necessary to understand these models is high. An analyst must understand how different factor inputs, including weather, affect yields at different stages of crop development over at least several years.

The sixth chapter argues that there are more accurate forecasting techniques available, including ARIMA models, than the standard time series with trend methods used in some CGE modelling frameworks. Furthermore, it demonstrates that models that claim to forecast decades into the future should be viewed with skepticism.

\subsection{Discussion}

By bringing together a combination of techniques to address the issue of the effects of changes in weather on yields at several levels of aggregation I was able to gain a more complete understanding of the range of effects that can be expected from climate change. The aggregation level of the data largely determined the type of the model which could be employed which in turn determined the types of questions that could be addressed. The earlier chapters used data that was aggregated at the country level, making panel models indexed by country and year the obvious econometric technique of choice. Panel models were chosen because they take into account correlations between countries and across time. From the panel models I was able to estimate and forecast changes in temperatures and precipitation, but also expected changes in yields over time. These forecasts were then used in MAGNET, a CGE model. In short, the different levels of 
geographic aggregation recommended research questions and techniques appropriate to that given level of aggregation. The result is that while all of the chapters address changing yields in one form or another, together they do not sum to unified whole, rather, they come at the issue of yields from various angles. Unfortunately, for instance, a farm level database containing factors of production for farms around the world does not yet exist. Instead, I used country indexed panel models and a CGE model at the highest level of aggregations, and a farm indexed panel model with factors of production at the lowest level of aggregation.

CGE models are ambitious in their scope, but are required to make severe assumptions in terms of behavior and economic relationships such as elasticities in order to model the flow of goods globally. The GTAP database, and as a consequence the MAGNET model, consists of just 57 sectors and 113 regions to represent all products produced and traded globally. The sectors directly relevant to the thesis are remarkably well represented in the database given their relatively small economic importance, they include the sectors wheat, paddy rice, cereals and grains, oil seeds, sugar cane and sugar beets, and the category other crops. These agricultural sectors are the interfaces through which to affect the MAGNET model and assess the implications of changes to yields on these sectors and consequences for other sectors. Furthermore, biomass products represent just a small subset of the value of those products. The various elasticities of the 57 products in the GTAP database are critical in determining how the demand and supply of products react in relationship to one another. However, elasticity values are difficult to determine particularly for new products (Horridge, 2018, Sato, 2017). CGE models also assume that technological change remains constant over time, a particularly vulnerable assumption given rapid increase in technology directly relevant to crop production. In short, GTAP can be a rather blunt instrument with which to measure the influence of relatively small valued products such as biomass products. The approach used in this thesis was to use only the agricultural products represented in the GTAP database rather than defining new biomass sub-products and attempting to calculate their inputs and outputs and elasticities, although this would have been a valid approach.

Econometric techniques were used to estimate changes in agricultural sectors due to changes in weather and other significant variables. Estimated models were then used to calculate forecasts which were used to shock the MAGNET model in order to determine how various GTAP products would react to the changing weather patterns. The greatest single weakness of using these techniques was the limited amount of data. For instance, we were heavily dependent on FAO yield data, a very good data source, but one consisting of largely aggregated data. For example, there is only one type of wheat and only two types of maize. In response to this lack of detail, I decided to look at one specific crop in the Netherlands and the inputs used to produce it over a number of years, this level of 
detail is not possible to reproduce across crops and countries, the data simply doesn't yet exist. Such databases are starting to be developed and will provide a means to make detailed studies of the effects of changes in weather at regional or global levels while accounting for changes in other inputs.

While the econometric models discussed in the thesis can help to assess forecast uncertainty, forecasts themselves were made under the condition that historical data generating processes would continue into the future. If those processes significantly changed, then forecasts would suffer accordingly. We argued that forecast models, ARIMA or otherwise, provide no additional reason for expecting underlying patterns to continue into the long run. How yields develop in the future is not primarily the prerogative of econometricians or other economic model builders. Rather, it is the place of agronomists, plant geneticists and others with the knowledge to comment on the technological likelihood of achieving the biophysical limits of crop yields, and political economists and other social scientists who are able to make meaningful statements on, not least, the economic capacity and willingness of actually realizing those higher potential yields.

\subsection{Future research}

The range of the themes discussed in this manuscript, yields, climate change, and the bioeconomy and other economic sectors, is large, and the techniques used are correspondingly blunt. This breadth of topics and approaches was driven by research questions which attempt to address the economic consequences of climatic changes affecting agriculture production. Each of the themes is an academic discipline so combining them in order to understand their interactions required a general purpose tool such as MAGNET. Econometric tools were primarily used to incorporate the effects of climate change on variables used as input to MAGNET. However there may be some interesting alternatives to these admittedly heavy-handed approach.

There is no getting away from the fact that the chapters in this manuscript were written some time ago and that I have left academia. This, however, does not mean that I have lost my interest in some of the topics addressed in this manuscript. My current assignment is with a large commodity trading company which needs to make crop forecasts in order to take trading positions. I have been quite busy comparing modeling techniques for crop yields for states and counties in the USA, provinces and departments in Argentina, and Brazilian states, to name a few. The linear approach with weather features such as temperatures, precipitation, and various measures of drought measures work well for most analyses and can explain around $80 \%$ of the variance in yields through time, particularly when the trend term is strong (NASS, 2020; NOAA, 2020). 
Data can be obtained via an API, FTP or scraping if necessary and stored inexpensively. Big data techniques, in regards to the current context, allow the rapid testing of many feature permutations to the point that preventing over-fitting becomes the main challenge. However, the small number of observations, even USDA data only goes back to 1924 , means that many of these high powered techniques are wasted because of the limited degrees of freedom available. For many USA states, a simple regression of weather features and a time trend against yield does very well with the time trend picking up technical change; sometimes a squared time trend term can help to pick-up increasing or decreasing rates of technological change. In short, standard linear regression techniques, and panel models, remain appropriate techniques when there are few years of data, and there is enough variation in the data.

However, linear techniques may be just the starting point, for instance, they cannot account for conditions that have never occurred before, for instance, a lack of rainfall for the first three months of the planting season in Brazil this year which will likely have severe effects on soybeans (Reis, et al., 2020). If history doesn't include at least one example of the effects of three months without rain, other techniques, including expert knowledge, are required to estimate yields.

As mentioned in the introductory chapter, several other methods have been applied to assess the impact of temperatures and other weather features on crops (Zhao, 2017). Two approaches mentioned are processed-based crop models and simulation models (Rosenzweig et al., 1994, Rosenzweig, 2014; Archontoulis, 2020). The approach to estimating yields applied in this manuscript is based on historical data which was used to build models which are then used to estimate future yields. As mentioned, as long as estimated historical patterns can be estimated, and to the degree that they continue into the future, this approach can be accurate given enough data. This approach depends on recurring patterns, if, for whatever reason, those patterns are broken, then the accuracy of forecasts will fall until a pattern reemerges. It is an obvious point, but one worth mentioning, that a major advantage of using historical yield data is that the yield data in any given year or period represents all of the factors affecting yields. In short, it includes the historical circumstances of a crop growing area, as well as the economic, technical, political, logistical, and all of the determinants which went into production per area in a given period in a given location. For instance, it might be possible for a farmer to increase yields given no constraints, but the farmer does face historical, technical and logistical constraints which act as very real limits to their ability and willingness to produce crops. Accurately reported yields reflect these constraints. In this sense, it is a purely empirical approach and takes no stance on what yields should or could be. 
The yield gap literature attempts to determine what yields might be if constraints were removed or reduced and can potentially give policy makers a guide from which to improve yields (Ittersum, et al., 2013a; Ittersum and Cassman, 2013b; van Oort, et al., 2017). The approach has been criticized for concentrating on technical solutions while ignoring the wider social, economic and political contexts that shaps farmer decision-making about agricultural production (Snyder et al., 2017). Successful adoption of newer techniques will require deeper understanding of the wider historical and societal contexts in which they are to be placed (Clapp and Ruder, 2020).

The yield gap literature continues to identify more precisely the elements of these gaps more generally and in specific countries (Zeist, et al. 2020; van Dijk, 2017; van Dijk, 2020). A recent paper from Zeist, et al. (2020), concludes that many countries are well below their attainable yield based on linear and plateau trends taken from 1990 to 2010 and extends the forecasts to the 2040-2050 period. More recent yield data from the FAO (2020) and USDA (2020) sources show increasing yields, shifting the trend line up to a higher intercept or plane. However, forecasting decades into the future is of questionable value, statistical models cannot help there (Chapter 6). Recent developments have led to better understanding of the relationships between yields and technology and via R\&D (SmeetsKristkova, et al., 2017a; Smeets-Kristkova, et al., 2017b; Smeets-Kristkova, et al., 2016). These developments, particularly in regards to better estimates of R\&D elasticities, will help CGE models to better estimate the effects of technological change on yields and resulting implications for the wider economy. Another developing line of research which will improve the performance of CGE models such as MAGNET, are on-going experiments to reduce the short-run flexibility of many features of those models, for example, land allocation is not allowed to adjust immediately and thereby becomes fixed in the short term (van Meijl, personal correspondence). Finally, new sectors such as biobased chemicals and pharmaceuticals have been added to some of these models and will make the relationship between these sectors and the economy more explicit. An alternative or supplement to MAGNET might be a CGE model specifically developed to model relationships between agricultural and energy markets and the rest of the economy. Specifically models that account for the introduction of new technologies and are focused on the medium term rather than the long term. However, CGE models will always be limited by their scope; by design they encompass such a wide spectrum of the global economy that they cannot be expected to adequately model specific sectors, particularly those undergoing rapid change.

A more promising approach will use massive amounts of microeconomic data. For example, farm level panel databases which contain factors of production at the crop level across many years are becoming available in certain regions, see for instance the Living Standards Measurement Study (LSMS) program at the World Bank Group. These 
panels of data, combined with weather data and other features, will allow researchers to better understand the factors affecting yields and yield forecasts. Ideally, global farm level panel datasets would allow researchers to discern ever greater patterns including trade patterns. The increasing use of robots, sensors, aerial images and GPS technologies will only increase the amount of data available, while distributed computing power largely removes the computing power constraints. An emerging constraint, as I found out, is the engineering and coding expertise necessary to combine such diverse sources of data. $A$ successful project will have to combine the expertise of economists, agronomists, and data scientists. 


\section{References}

Alam, W., Ray, M., Kumar, R.R., Sinha, K.K., Rathod, S. and Singh, K.N. (2018). Improved ARIMAX modal based on ANN and SVM approaches for forecasting rice yield using weather variables. Indian Journal of Agricultural Sciences 88 (8): 1909-2013.

Archontoulis, SV, Castellano, MJ, Licht, MA, et al. Predicting crop yields and soil-plant nitrogen dynamics in the US Corn Belt. Crop Science. 2020; 60: 721- 738.

Böhringer, C. (1998). The synthesis of bottom-up and top-down in energy policy modelling. Energy Economics, 20(3), 233-248.

Chao, F., Pei-Ge, C., Tie-Jun Y,. and Hong-Liang, F. (2015). Research on the prediction model of grain yield based on the ARIMA method. Proceedings of the 2015 4th International Conference on Sensors, Measurement and Intelligent Material.

Clapp, J. and Ruder, S-L, (2020), Precision Technologies for Agriculture: Digital Farming, Gene-Edited Crops, and the Politics of Sustainability, Global Environmental Politics 2020 20:3, 49-69.

Dijk, M. van, Morley, T., Jongeneel, R., van Ittersum, M., Reidsma, P., \& Ruben, R. (2017). Disentangling agronomic and economic yield gaps: An integrated framework and application. Agricultural Systems, 154, 90-99.

Dijk, M. van, Morley, T., Loon, M. van, Reidsma, P., Tesfaye, K., Ittersum, M.K. van, (2020). Reducing the maize yield gap in Ethiopia: Decomposition and policy simulation, Agricultural Systems, Vol $183,102828$.

Edmonds, J. A. and Rosenberg, N. J. (2005). Climate change impacts for the Conterminous USA: an integrated assessment summary Climate Change 69: 151-62.

Hasegawa, T., Shinichiro, F., Havlík, P., Valin, H., Bodirsky, B.L., Doelman, J.C., Fellmann, T., Kyle, P., Koopman, J.F.L., Lotze-Campen, H., Mason-D'Croz, D., Ochi Y., Domínguez, I.P., Stehfest, E., Sulser, T.B., Tabeau, A., Takahashi, K., Takakura, J., Meijl, van H., Zeist, W., Wiebe, K., and Witzke, P., (2018). Risk of increased food insecurity under stringent global climate change mitigation policy, Nature Climate Change 8: 699-703.

Ittersum, M.K. van and Cassman, K.G., (2013a). Yield gap analysis - rationale, methods and applications, introduction to the special issue. Field crops research: 143: 1-3.

Ittersum, M.K. van, Cassman , Kenneth G., Grassini , Patricio, Wolf, Joost, Tittonell , Pablo, Hochman, Zvi, (2013b). Yield gap analysis with local to global relevance-A review, Field Crops Research, Vol 143, Pages 4-17.

Komen, M. and Peerlings, J. (2001). Endogenous technology switches in Dutch dairy farming under environmental restrictions. European Review of Agricultural Economics, 28(2): 117-142

Meijl, van H., Havlik, P., Lotze-Campen, H., Stehfest, E., Witzke, P., Domíngue, I.P., Bodirsky, B.L., Dijk, van M., Doelman, J., Fellmann, T. (2018). Comparing impacts of climate change and mitigation on global agriculture by 2050, Letter, Environmental Research Letters vol. 13(6).

National Agricultural Statistics Service (NASS). https://www.nass.usda.gov/Statistics_by_Subject/, accessed 2020. 
Oort, P.A.J. van, Saito, K., Dieng, I., Grassini, P., Cassman, K.G., Ittersum, M.K. van (2017). Can Yield Gap Analysis be used to Inform R\&D Prioritisation?, Global Food Security, Vol 12,2017,Pages 109-118,

Parry, M.L., Rosenzweig, C., Iglaesias, A.,Livermore, M. and Fischer, G. (2004). Effects of climate change on global food production under SRES emissions and socio-economic scenarios. Global Environmental Change, Vol. 14(1), April: 53-67.

Porter, J., and Gawith, M. (1999). Temperatures and the growth and development of wheat: a review. European Journal of Agronomy 10: 23-36.

Reis, L., Santos e Silva, C.M., Bezerra, B., Mutti, P., Spyrides, M.H., Silva, P., Magalhães, T., Ferreira, R., Rodrigues, D., Andrade, L., (2020). Influence of Climate Variability on Soybean Yield in MATOPIBA, Brazil. Atmosphere, 11, 1130.

Rosenzweig, C., Elliott, Joshua, Deryng, Delphine, Ruane, C. Alex, Müller, Christoph, Arneth, Almut, Boote, J. Kenneth, Folberth, Christian, Glotter, Michael, Khabarov, Nikolay, Neumann, Kathleen, Piontek, Franziska, Pugh, A. M. Thomas, Schmid, Erwin, Stehfest, Elke, Yang, Hong, Jones , W. James (2014). Global multi-model crop-climate impact assessment. Proceedings of the National Academy of Sciences, 111 (9): 3268-3273.

Rosenzweig, C., Iglesias, A., Yang, X.B., Epstein, P.R., Chivian, E. (2001). Climate Change and Extreme Weather Events; Implications for Food Production, Plant Diseases, and Pests. Global change \& Human Health 2(2):90-104.

Rosenzweig, C., and Parry, M.L. (1994). Potential Impact of Climate-Change on World Food-Supply, Nature 367: 133-8.

Schlenker, W., Roberts M.J. (2009). Nonlinear temperature effects indicate severe damages to U.S. crop yields under climate change. PNAS September 15, 106 (37).

Smeets-Kriskova , Z., Dijk, M. van, Gardebroek, K., Meijl, H. van, (2017). The impact of R\&D on factor augmenting technical change - an empirical assessment at the sector level, Economic Systems Research, Vol. 29 , Iss. 3, Pages 385-417.

Smeets-Kristkova, Z., Dijk, M. van, Meijl, H. van (2017). Assessing the impact of agricultural R\&D investments on long-term projections of food security, Frontiers of Economics and Globalization 17. - p. $1-17$.

Smeets-Kriskova, Z., Dijk, M. van, Meijl, H. van, (2016). Projections of long-term food security with R\&D driven technical change - a CGE analysis, NJAS-Wageningen Journal of Life Sciences, 77, 39-51.

Smeets-Kristkova, Z., Gardebroek, C., Dijk, Michiel van, Meijl, H. van (2017). The impact of R\&D on factor-augmenting technical change - an empirical assessment at the sector level, Economic Systems Research, 29:3, 385-417.

Snyder, K., Miththapala, S., Sommer, R., Braslow, J. (2017). The Yield Gap: Closing the Gap by Widening the Approach. Experimental Agriculture, 53(3), 445-459

Vogel, E., Donat, M.G., Alexander, L.V., Meinshausen, M., Ray, D.K., Karoly, D., Meinshausen, N., Frieler, K. (2019). The effects of climate extremes on global agricultural yields. Environmental Research Letters, May 3, Vol. 14(5). 
Wang, X., Dietrich, J.P., Lotze-Campen, H., Biewald, A., Munson, T.S. and Muller, C. (2018). Trading More Food in the Context of High-end Climate Change: Implications for Land Displacement through Agricultural Trade, Conference Paper/Presentation, International Association of Agricultural Economics.

Zeist, W.J., Stehfest, Elke, Doelman, Jonathan, Valin, Hugo, Calvin, Katherine, Fujimori, Shinichiro, Hasegawa, Tomoko, Havlik, Petr, Humpenöder, Florian, Kyle, Page, Lotze-Campen, Hermann, Mason-D'Croz, Daniel, Meijl van, Hans, Popp, Alexander, Sulser B., Timothy, Tabeau, Andrzej, Verhagen, Willem, Wiebe, Keith, (2020), Are scenario projections overly optimistic about future yield progress? Global Environmental Change, Volume 64, September 2020, 102120.

Zhao, C., Liu, B., Piao, S., Wang, X., Lobell, D.B., Huang, Y., Huang, M., Yao, Y., Bassu, S., Ciais, P., Durand, J., Elliott, J., Ewert. F., Janssens, I.A., Li, T., Lin, E., Liu, Q., Martre, P., Müller, Shushi Peng, C., Peñuelas, J., Ruane, A.C., Wallach, D., Wang, T., Wu, D., Liu, Z., Zhu, Y., Zhu, Z, and Asseng, S. (2017). Temperature Increase Reduces Global Yields of Major Crops in Four Independent Estimates. PNAS August, 114 (35): 9326-9331. 

The research described in this thesis was carried out within the BE-Basic R\&D Program, which was granted a FES subsidy from the Dutch Ministry of Economic affairs, agriculture and innovation (EL\&l)

Cover design by Proefschriftmaken.nl

Printed by Proefschriftmaken.nl 